\title{
Estudio del comportamiento susceptor de microondas de nanotubos de carbono y grafeno multicapa para su aplicación en el calentamiento de polímeros
}

Begoña Galindo Galiana

Directores:

Enrique Gimenez Torres

Adolfo Benedito Borrás

Departamento de Ingeniería Mecánica y de Materiales

\section{AIMPLAS}

INSTITUTO TECNOLÓGICO

DEL PLÁSTICO

Valencia, Abril 2016 
El objetivo de la presente Tesis Doctoral consiste en el desarrollo de nanocompuestos de polipropileno (PP) capaces de ser calentados y procesados de manera efectiva mediante radiación microondas. Los polímeros apolares como el polipropileno son transparentes a la radiación microondas. Con el fin de aumentar la capacidad del polipropileno para absorber radiación microondas se emplearon dos tipos de nanopartículas carbonosas: nanotubos de carbono (NTC) y grafeno multicapa (GMC). Las nanopartículas se incorporaron en la matriz de polipropileno por mezclado en fundido en extrusora co-rotativa de doble husillo.

La primera fase del experimental consistió en evaluar la influencia de las condiciones de procesado en la dispersión de las nanopartículas susceptoras en la matriz de polipropileno (PP). La dispersión fue evaluada en base a la morfología y propiedades reológicas de los nanocompuestos con un contenido del $1 \%$ en peso de NTC y GMC. De esta primera fase se seleccionaron las condiciones de procesado más adecuadas para los sistemas PP/GMC y PP/NTC, y que para ambos sistemas coincidieron en la incorporación de las nanopartículas mediante dilución de un masterbatch, el empleo de una configuración de husillo de alta cizalla y la aplicación de velocidades de extrusión altas (800 rpm).

Los estudios llevados a cabo en los sistemas nanocompuestos PP/NTC y PP/GMC preparados en las condiciones seleccionadas mostraron un aumento de la rigidez mecánica y de la estabilidad térmica con el incremento del contenido de nanocarga. Se obtuvo un aumento del módulo de almacenamiento del $125 \%$ para ambos sistemas con un porcentaje de aditivación en peso del $1 \%$.

El GMC mostró un efecto lubricante semejante al grafito cuando se incorporó en bajos porcentajes. Las curvas reológicas mostraron una disminución de la viscosidad de los nanocompuestos con respecto al PP virgen.

Del análisis de las propiedades eléctricas y dieléctricas se determinó que el límite de percolación eléctrica para los nanocompuestos de PP/NTC se encuentra alrededor del $1 \%$ de NTC, mientras que para los nanocompuestos PP/GMC este límite está alrededor del 10\% de GMC (obteniendo un valor de 
$\left.10^{-6} \mathrm{~S} / \mathrm{cm}\right)$. Todos los nanocompuestos de NTC mostraron un comportamiento semiconductor, con valores de conductividad volumétrica situados en un rango de $\left[10^{-1}-10^{-6}\right] \mathrm{S} / \mathrm{cm}$ según el contenido de NTC.

Los nanocompuestos de NTC mostraron un aumento de la constante dieléctrica y del factor de pérdidas con el contenido de NTC. Por lo tanto, los nanocompuestos basados en NTC son capaces de absorber radiación microondas y transformar esta energía en calor. Sin embargo, las propiedades dieléctricas del GMC fueron muy bajas y apenas aumentaron con el contenido de GMC.

Se estudió la influencia del grado de dispersión en la efectividad de calentamiento por microondas de los diferentes sistemas nanocompuestos desarrollados con $1 \%$ de GMC y NTC. Los nanocompuestos PP/GMC no reflejaron ningún comportamiento susceptor de radiación microondas con contenidos de GMC del $1 \%$ en peso. Sin embargo, los nanocompuestos con $1 \%$ de NTC (alrededor del umbral de percolación) aumentaron la temperatura al someterse a radiación microondas. El grado de dispersión de los NTC en la matriz de PP mostró ser un factor de gran influencia, pudiendo aumentar la temperatura de calentamiento en un $230 \%$ al variar las condiciones de procesado del nanocompuesto.

Los valores de temperatura registrados durante el calentamiento por microondas de nanocompuestos PP/NTC con altos porcentajes de carga mostraron una gran disparidad, debido a la presencia de un mayor número de aglomerados que actúan como "hot spots" o puntos calientes. Sin embargo, los nanocompuestos con $1 \%$ de NTC mostraron un calentamiento mucho más homogéneo

Por ello, en la fase última de este trabajo se seleccionó el nanocompuesto PP/NTC con $1 \%$ carga para el desarrollo de un prototipo fabricado mediante calentamiento por microondas, con el fin de validar tanto el nanocompuesto susceptor, como la técnica de calentamiento. Se fabricó de forma exitosa una espinillera para protección deportiva a partir de polímeros autoreforzados (PP reforzado con fibras de $\mathrm{PP}+1 \% \mathrm{NTC}$ ) en la que el nanocompuesto susceptor actuaba también de refuerzo mecánico. 
The objective of the present Doctoral Thesis consist of developing polypropylene (PP) nanocomposites able to be effectively heated and processed by microwave heating. Unpolar polymers like polypropylene are transparent to microwave radiation. Two types of carbonous nanoparticles were studied aiming to increase the capacity of polypropylene to absorb microwave radiation: Carbon nanotubes (CNT) and multilayer graphene (MLG). Nanoparticles were incorporated into polypropylene matrix by melt compounding in co-rotative twin screw extruder.

The first phase of the experimental work consisted of evaluating the influence of the processing conditions on the dispersion of susceptor nanoparticles into the polypropylene matrix (PP). The dispersion was evaluated based on the morphology studies and the rheological properties of the nanocomposites with a CNT and MLG content of $1 \% \mathrm{w} / \mathrm{w}$. The optimum processing conditions were selected for PP/MLG and PP/CNT systems. These conditions were based on the nanoparticles incorporation by means of masterbatch dilution, employment of high shear screw configuration and high extrusion speed (800 rpm).

Nanocomposites with different content of MLG and CNT were prepared with the optimum processing conditions. These nanocomposites showed an increase in the mechanical rigidity and higher thermal stability compared to virgin PP. Storage modulus increase in a $125 \%$ with respect to the PP with a nanoparticle content of $1 \% \mathrm{w} / \mathrm{w}$ for both nanocomposite systems.

MLG showed a lubricant effect similar to graphite when it was incorporated at low percentages. Rheological curves showed a decrease on the nanocomposites viscosity with respect to virgin PP.

Electrical and dielectric properties analysis determined that the electrical percolation limit for PP/CNT nanocomposite was set around 1\% w/w of CNT, while $10 \% \mathrm{w} / \mathrm{w}$ was the percolation limit for PP/MLG systems (obtaining a value of $10^{-6} \mathrm{~S} / \mathrm{cm}$ ). All the nanocomposites based on CNTs were semiconductors with conductivity values in the range of $\left[10^{-1}-10^{-6}\right] \mathrm{S} / \mathrm{cm}$ depending on the CNT content. 
Nanocomposites based on CNT showed an increase on the dielectric constant and the loss factor with the CNT content. Therefore, CNT nanocomposites are able to absorb microwave radiation and transform this energy into heat. Nevertheless, dielectric properties of MLG nanocomposites were very low and barely increase with MLG content.

The influence of the dispersion degree on the microwave heating effectiveness was analyzed for the nanocomposites with $1 \% \mathrm{w} / \mathrm{w}$ of MLG and CNT. PP/MLG nanocomposites did not show microwave susceptor behaviour with MLG content of $1 \% \mathrm{w} / \mathrm{w}$. Nonetheless, nanocomposites with $1 \% \mathrm{w} / \mathrm{w}$ of CNT increased the temperature when exposed to microwave radiation. The dispersion grade of CNT in the PP matrix was a very influencing factor. The maximum reached temperature was increased in $230 \%$ by varying the processing conditions.

Nanocomposites with high content of CNT showed very different values of the mean reached temperature in the microwave due to the higher presence of agglomerates which act as hot spots. Nanocomposites with $1 \% \mathrm{w} / \mathrm{w}$ of CNT showed a very homogeneous heating.

For that reason, the nanocomposite of PP with $1 \% \mathrm{w} / \mathrm{w}$ of CNT was selected to develop a prototype produced with microwave heating. The aim of producing a prototype was to validate the heating technique and the performance of the nanocomposite selected as microwave susceptor. A shinguard was produced with self-reinforced polymers (PP reinforced with $\mathrm{PP} / \mathrm{CNT}$ fibre) in which the susceptor nanocomposite also acts as mechanical reinforcement. 
L'objecte d'aquesta tesi doctoral consisteix en el desenvolupament de nanocompostos de polipropilè (PP) capaços d'ésser escalfats i processats de forma efectiva mitjançant radiació microones. Els polímers apolars como el polipropilè són transparents a la radiació microones. Amb la finalitat d'augmentar la capacitat del polipropilè per absorbir radiació microones s'han utilitzat dos tipus de nanopartícules carbonoses: nanotubs de carboni (NTC) i grafè multicapa (GMC). Les nanopartícules s'han incorporat a la matriu de polipropilé mitjançant mesclat en fos amb extrusora co-rotativa de doble cargol.

La primera fase de l'experimental va consistir en avaluar la influència de les condicions de processat en la dispersió de les nanopartícules susceptores dins de la matriu de polipropilé (PP). La dispersió va ser avaluada en base a la morfologia i propietats reològiques dels nanocompostos amb un contingut del $1 \%$ en pes de NTC y GMC. D'aquesta primera fase es van seleccionar les condicions de processat més adequades per als sistemes PP/GMC i PP/NTC, i que als dos casos es van basar en la incorporació de les nanopartícules mitjançant dilució d'un masterbatch, l'ús d'una configuració d'un cargol d'alta cisalla i l'aplicació de velocitats d'extrusió elevades (800 rpm).

Els estudis realitzats als sistemes nanocompostos PP/NTC y PP/GMC preparats en les condicions seleccionades van mostrar un augment de la rigidesa mecànica i de l'estabilitat tèrmica amb l'increment del contingut de nanocàrrega. S'ha obtingut un augment del mòdul d'emmagatzematge del $125 \%$ per als dos sistemes amb un percentatge d'additivació en pes de l'1\%.

EI GMC va mostrar un efecte lubricant semblant al grafit quan en va incorporar en baixos percentatges. Les corbes reològiques van mostrar una disminució de la viscositat dels nano compostos respecte al PP verge.

De l'anàlisi de les propietats elèctriques i dielèctriques es va determinar que el límit de percolació elèctrica per als nanocompostos de PP/NTC es troba al voltant de l'1\% de NTC, mentre que per als nanocompostos PP/GMC eixe límit està al voltant del $10 \%$ de GMC (s' obté un valor de $10 \mathrm{E}-06 \mathrm{~S} / \mathrm{cm}$ ). Tots els nanocompostos de NTC van mostrar un comportament semiconductor, 
amb valors de conductivitat volumètrica situats en un rang de [10E-01 - 10E06] S/cm segons el contingut de NTC.

Els nanocompostos de NTC van mostrar un augment de la constant elèctrica i del factor de pèrdues amb el contingut de NTC. En conseqüència, els nanocompostos basats en NTC són capaços d'absorbir radiació microones i transformar aquesta energia en calor. No obstant això, les propietats dielèctriques del GMC van ser molt baixes i quasi no van augmentar amb el contingut de GMC.

Es va estudiar la influència del grau de dispersió en l'efectivitat de l'escalfament per microones dels diferents sistemes nanocompostos desenvolupats amb 1\% de GMC y NTC. Els nanocompostos PP/ GMC no van reflectir cap comportament susceptor de radiació microones amb continguts de GMC del $1 \%$ en pes. No obstant això, els nanocompostos amb $1 \%$ de NTC (al voltant del llindar de percolació) van augmentar la temperatura al sotmetre's a radiació microones. El grau de dispersió dels NTC a la matriu de PP va mostrar ésser un factor de gran influència i va poder augmentar la temperatura d'escalfament en un $230 \%$ al variar les condicions de processat del nanocompost.

Els valors de temperatura registrats al llarg de l'escalfament per microones de nanocompostos PP/NTC amb elevats percentatges de càrrega van mostrar una gran disparitat, a causa de la presència d'un major nombre d'aglomerats que actuen com "hot spots" o punts calents. No obstant això, els nanocompostos amb $1 \%$ de NTC van mostrar un escalfament molt més homogeni.

Com a conseqüència de tot això, a l'última fase d'aquest treball es va escollir el nanocompost PP/NTC amb $1 \%$ de càrrega per al desenvolupament d'un prototipus fabricat mitjançant escalfament per microones, amb l'objectiu de validar tant el nanocompost susceptor, como la tècnica d'escalfament. Es va fabricar de forma exitosa una canyellera de protecció esportiva utilitzant polímers autoreforçats (PP reforçat amb fibres de PP+1\%NTC) en la qual el nanocompost susceptor actuava també de reforç mecànic. 


\section{ÍNDICE}

CAPÍTULO 1: INTRODUCCIÓN 15

1.1 MOTIVACIÓN 15

1.2. OBj EIVOS 17

1.3. METODOLOGÍA DE TRABAJO 18

CAPÍTULO 2: ESTADO DEL ARTE 25

2.1. TECNOLOGÍA DE CALENTAMIENTO POR MICROONDAS ........25

2.1.1. Introducc ción 25

2.1.2. Fundamentos del calentamiento de polímeros por mic roondas................................................................................... 28

2.1.3. Interac ción materiales - microondas................................. 29

2.1.4. Ventajas del proc esado por mic roondas.............................. 35

2.1.5. Fuentes de radiación de microondas .................................. 36

2.1.6. Tec nologías de calentamiento por mic roondas existentes en el mercado. .................................................................................. 38

2.2. SUSCEPIORES DE MICROONDAS ..........................................41

2.2.1. Introduc ción ...................................................................... 41

2.2.2. Grupos funcionales más susceptibles de la absorción de radiación microondas..................................................................... 43

2.2.3. Influencia de las cargas susceptoras de microondas ........ 45 
2.2.4. Tipos de cargas susc eptoras ...................................................46

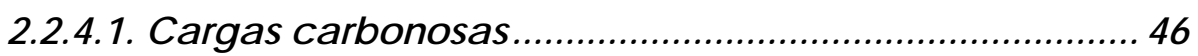

2.2.4.2. Cargas fenoeléc tricas ..................................................... 49

2.2.4.3. Cargas femomagnéticas.............................................. 50

2.3. NANOCOMPUESTOS DE NANOTUBOS DE CARBONO (NTC) ..51 2.4. NANOCOMPUESTOS DE GRAFENO MULTICAPA (GMC).........59

CAPÍTULO 3: MATERIALES Y MÉTODOS ..................... 67

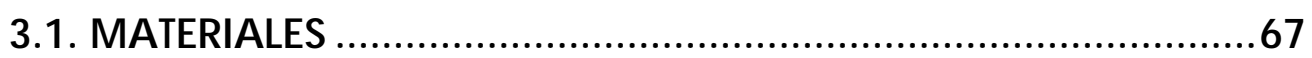

3.1.1. Nanotubos de carbono ...............................................................67

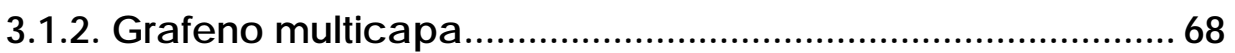

3.1.3. Polipropileno ……............................................................................. 70

3.2. MÉTODOS Y TÉCNICAS INSTRUMENTALES..............................72

3.2.1. Procesado de Nanoc ompuestos .......................................... 72

3.2.1.1. Equipamiento ...................................................................... 72

3.2.1.2. Diseño de experimentos................................................ 74

3.2.1.3. Muestras obtenidas - Codificación .............................. 76

3.2.2. Técnicas de caracterización ............................................... 79

3.2.2.1. Microscopía óptica .......................................................... 79

3.2.2.2. Mic rosc opio electrónico de banido (SEM).................... 81

3.2.2.3. Microscopio electrónico de transmisión (TEM) ............. 82 


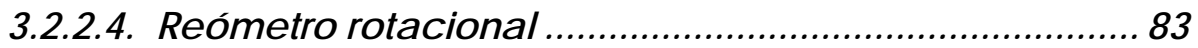

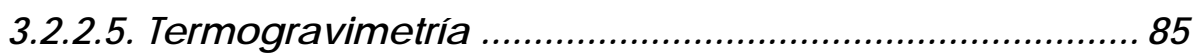

3.2.2.6. Espectrosc opia de impedancia electroquímica........... 86

3.2.2.7. Medida de las propiedades eléctricas ........................ 87

3.2.2.8. Ensayos dinámico-mecánic os (DMA) ........................... 88

3.2.2.9. Espectroscopía inframoja con transformada de Fourier

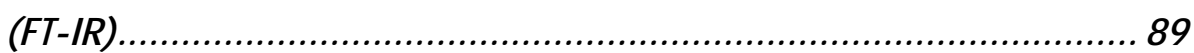

3.2.2.10. Espectroscopia RAMAN...................................................90

3.2.3. Calentamiento por microondas............................................. 93

3.2.3.1. Equipamiento ................................................................ 93

3.2.3.2. Medida de la temperatura ........................................... 94

\section{CAPÍTULO 4: ESTUDIO DE LA DISPERSIÓN DE LOS NANOCOMPUESTOS...................................................... 95}

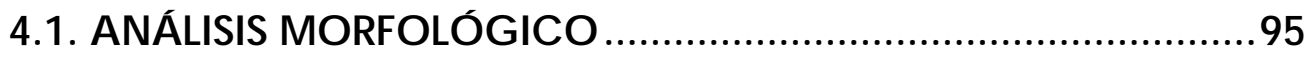

4.1.1. Estudio micrográfico ….....................................................95

4.1.1.1. Mic roscopía óptica ...................................................... 95

4.1.1.2. Microscopía electrónica de bamido (SEM) ................. 100

4.1.1.3. Mic rosc opía electrónica de transmisión (TEM) ............ 109

4.1.2. Densidad de aglomerados.................................................... 113

4.1.3. Tamaño medio de partícula ............................................ 121 


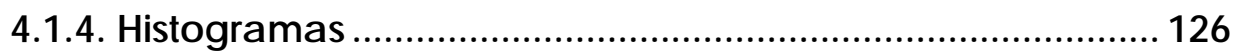

4.1.5. Índice de dispersión ................................................................ 129

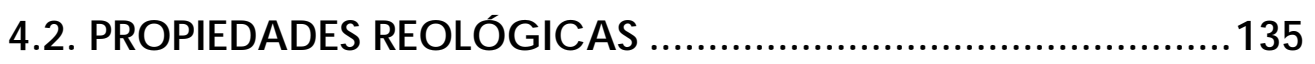

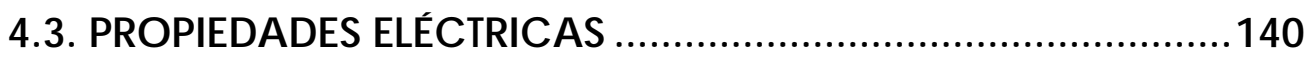

4.4. ESTUDIO DE LA DEGRADACIÓN ........................................144

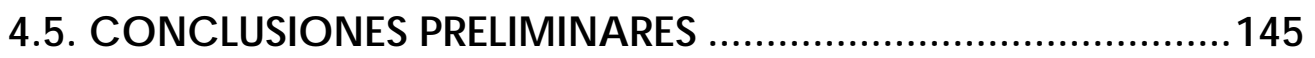

CAPÍTULO 5: INFLUENCIA DEL PORCENTAJE DE CARGA EN LAS PROPIEDADES DE LOS NANOCOMPUESTOS .............................................. 147

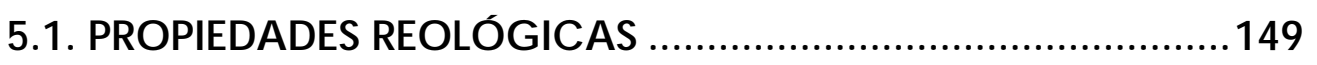

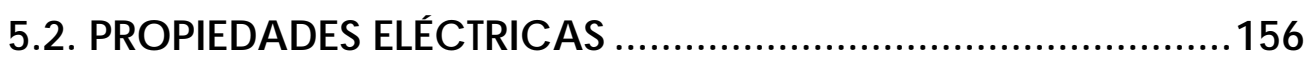

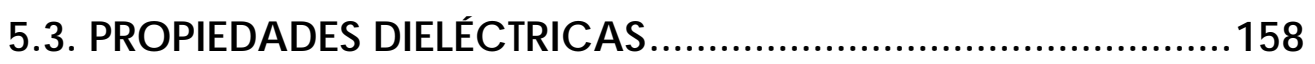

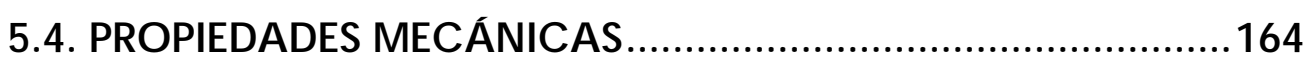

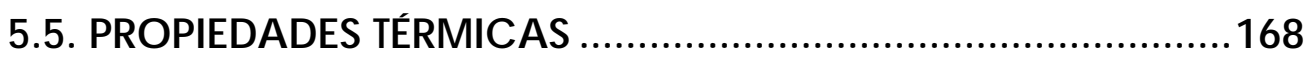

5.6. CONC WSIONES PREUMINARES..............................................171

CAPÍTULO 6: CALENTAMIENTO POR MICROONDAS DE LOS NANOCOMPUESTOS .......................................... 173

6.1. INRUENCIA DE LA DISPERSIÓN EN LA ERCACIA DE CALENTAMIENTO. .173 
6.2. ERCIENCIA DE CALENTAMIENTO

6.3. HOMOGENEIDAD DE CALENTAMIENTO

6.4. CONCLUSIONESY SELECCIÓN DELME OR SSTEMA SUSCEPIOR

194

CAPÍTULO 7: DESARROLLO DE PROTOTIPO

CAPÍTULO 8: CONCLUSIONES

199

REFERENCIAS

205 


\section{CAPÍTULO 1: INTRODUCCIÓN}

\subsection{MOTIVACIÓN}

El procesado de materiales plásticos implica un coste energético muy elevado. La producción global de plástico se cifró en 299 millones de toneladas en 2013 1 .Teniendo en cuenta que el sector consume entre $1.5-4$ $\mathrm{kWh} / \mathrm{kg}$, dependiendo del proceso de transformación, esto implica un consumo global de energía muy alto. Con el fin de optimizar los recursos energéticos se están investigando nuevas técnicas de calentamiento en polímeros. Una de estas técnicas es el calentamiento por microondas. Este nuevo método de calentamiento ofrece diferentes ventajas desde el punto de vista del procesado industrial, entre las que destacan el ahorro de un $70 \%$ de energía respecto a los métodos tradicionales de calentamiento y aumento de la producción por el rápido calentamiento del material ${ }^{2}$. Así pues, la industria se beneficia tanto en aspectos medioambientales como económicos. Aplicaciones industriales relacionadas con esta técnica de calentamiento por microondas incluyen el procesado de polímeros, el curado de cauchos y resinas termoestables, reciclado químico de residuos poliméricos, calentamiento selectivo de matrices poliméricas y refuerzos sensibles a la temperatura, soldadura, etc.

El calentamiento mediante microondas implica la excitación de moléculas con un claro momento dipolar. Sin embargo, gran cantidad de materiales poliméricos, como las poliolefinas, son no-polares. Esto significa que el efecto de la radiación microondas es mínimo sobre este tipo de polímeros. Es en estos casos donde cobra especial relevancia el uso de unos aditivos llamados susceptores. Los susceptores dispersos en una matriz polimérica son aditivos muy sensibles a la excitación por microondas, calentando el material por fenómenos alternativos de conducción térmica. Hay muchos tipos de susceptores con diferentes comportamientos frente a la radiación microondas dependiendo de su estructura, concentración, y dispersión en la matriz polimérica.

Sin embargo, la mayoría de los materiales poliméricos no son susceptibles a la radiación por microondas debido al bajo momento dipolar de sus moléculas. En este trabajo se plantea como novedad la incorporación en una matriz poliolefínica de polipropileno (PP) de aditivos llamados 
susceptores, y en particular, el uso de nanoestructuras carbonosas tales como los nanotubos de carbono (NTC) y el grafeno multicapa (GMC). La eficacia de calentamiento de estos aditivos depende de la concentración necesaria para calentar la matriz y de la correcta dispersión de los mismos, lo cual resultará en el calentamiento homogéneo del polímero. Hasta el momento las estructuras alotrópicas del carbono más estudiadas son las de tamaño micrométrico, teniendo como inconvenientes la baja efectividad y homogeneidad de calentamiento.

El desarrollo de nanoaditivos funcionales en matrices poliméricas es uno de los pilares básicos de la investigación actual en el campo de materiales poliméricos. Es conocido que el efecto de aditivos a escala nanométrica proporciona una efectividad muy acusada del aditivo por la específica interacción con la fase polimérica e incluso la aparición de nuevos efectos asociados en las propiedades finales del material. En el caso de los nanoaditivos, tiene una importancia crítica, no sólo el efecto de la geometría del aditivo, sino también la dispersión de las mismas durante el proceso de mezclado de ambas fases. Las estructuras carbonosas han demostrado una gran efectividad como aditivos susceptores a las microondas.

El presente proyecto nace de la inquietud de estudiar el efecto de los nanotubos de carbono y el grafeno multicapa en la efectividad del calentamiento por microondas en matrices poliméricas de diferente naturaleza apolar como el polipropileno (PP). 


\subsection{OBJETIVOS}

El objetivo general consiste en desarrollar sistemas poliméricos capaces de ser calentados y procesados de manera totalmente efectiva mediante radiación por microondas. Se plantea como un método de calentamiento alternativo a los sistemas convencionales de calentamiento por conducción de menor eficiencia energética.

El objetivo general puede desglosarse en los siguientes objetivos parciales:

- Evaluar la influencia de las condiciones de procesado en la morfología y dispersión de nanotubos de carbono (NTC) y grafeno multicapa (GMC) en la matriz de polipropileno.

- Caracterización extensa de las propiedades eléctricas, dieléctricas, térmicas, mecánicas y reológicas de los nanocompuestos basados en NTC y GMC

- Determinar los porcentajes de nanocarga que permiten alcanzar propiedades de conductividad eléctrica y dieléctrica óptimas para el calentamiento por radiación microondas.

- Analizar la relación entre la dispersión alcanzada de los nanotubos de carbono y del grafeno multicapa en la matriz polimérica y la optimización de sus propiedades.

- Estudiar la eficacia de los nanotubos de carbono y del grafeno multicapa como susceptores de microondas, y determinación del porcentaje óptimo de susceptor necesario para obtener un calentamiento homogéneo de la matriz polimérica.

- Evaluar la aplicabilidad industrial del calentamiento con microondas frente al calentamiento tradicional: desarrollo de prototipo. 


\subsection{METODOLOGÍA DE TRABAJO}

El presente trabajo de tesis se divide en tres fases diferenciadas.

\section{- FASE 1}

La Fase 1 consiste en la elaboración del Estado del Arte recopilado en el capítulo 2 de la presente memoria. Como fase previa a los trabajos experimentales se llevará a cabo una revisión bibliográfica a través de la cual se recopilarán las conclusiones más importantes reportadas en diferentes trabajos científicos. La búsqueda incluye artículos científicos, revisión de patentes, publicaciones a congresos, etc. Esta fase se extiende durante la duración de la Tesis Doctoral con el fin de conocer la información más actualizada en referencia al tema tratado en el presente trabajo.

\section{- FASE 2}

En la Fase 2, capítulo 3, 4 y 5 de la memoria, se obtendrán diferentes sistemas nanocompuestos con distinto tipo de nanocarga carbonosa (nanotubos de carbono y grafeno multicapa). Los compuestos se obtendrán mediante compounding, a través del mezclado en fundido en extrusora corotativa de doble husillo, ajustando los parámetros principales de proceso, tales como velocidad de giro, perfil de temperaturas, método de adición de las nanocargas, etc. En este experimental se incluye:

\section{a) Estudio y optimización de la dispersión de las nanocargas}

En esta tarea se estudiará la influencia de las condiciones de procesado en la dispersión de las nanocargas (nanotubos de carbono y grafeno multicapa) en la matriz polimérica. Se desarrollará un diseño de experimentos a partir de los principales parámetros de procesado como: diseño de la configuración de husillo y velocidad de máquina, ya que son los parámetros que mayor influencia ejercen sobre la energía mecánica implicada en los procesos de mezclado y dispersión. Como resultado del diseño de experimentos se analizará el tamaño medio de las partículas y la densidad de aglomerados en los nanocompuestos obtenidos. Ambas respuestas se estudiarán mediante análisis de la morfología resultante, utilizando para ello microscopía óptica y electrónica de barrido. 
b) Obtención de compuestos con diferentes porcentajes de nanocargas

A partir de las condiciones optimizadas en la etapa anterior, se obtendrán diferentes concentraciones de carga en un rango entre $0 \%-15 \%$ en peso para cada uno de los sistemas nanocompuestos con nanotubos de carbono y grafeno multicapa. Para cada sistema se definirá, la curva de percolación, mediante medidas de conductividad eléctrica y propiedades dieléctricas, que permitirá identificar el contenido mínimo de carga en el que el material puede actuar como susceptor.

c) Caracterización extensa de los sistemas nanocompuestos

Se realizará una caracterización completa de los nanocompuestos seleccionados basada en un estudio morfológico, y de propiedades reológicas, térmicas, mecánicas, eléctricas y dieléctricas. En la Tabla 1 se detallan los diferentes ensayos que se llevarán a cabo. 
Tabla 1: Caracterización de los nanocompuestos desarrollados

\begin{tabular}{|c|c|c|}
\hline Propiedad & Técnicas analíticas & Objetivo \\
\hline \multirow{3}{*}{ Morfología } & Microscopía óptica (MO) & \multirow{3}{*}{$\begin{array}{c}\text { Estudio de la dispersión de las } \\
\text { nanocargas en la matriz } \\
\text { polimérica }\end{array}$} \\
\hline & $\begin{array}{l}\text { Microscopía electrónica } \\
\text { (SEM) }\end{array}$ & \\
\hline & $\begin{array}{l}\text { Microscopía electrónica de } \\
\text { transmisión (TEM) }\end{array}$ & \\
\hline Reología & Reómetro rotacional & $\begin{array}{c}\text { Medida indirecta de la } \\
\text { dispersión de las nanocargas }\end{array}$ \\
\hline \multirow{2}{*}{ Térmica } & Termogravimetría (TGA) & Estabilidad térmica \\
\hline & $\begin{array}{l}\text { Análisis dinámico- } \\
\text { mecánico (DMA) }\end{array}$ & $\begin{array}{l}\text { Análisis de la relajaciones } \\
\text { moleculares en un rango } \\
\text { amplio de temperaturas }\end{array}$ \\
\hline Dieléctrica & $\begin{array}{c}\text { Análisis de la permitividad } \\
\text { a la frecuencia microondas } \\
\text { empleada }\end{array}$ & \multirow{2}{*}{$\begin{array}{l}\text { Efecto de las nanocargas en la } \\
\text { capacidad de absorción de } \\
\text { radiación electromagnética }\end{array}$} \\
\hline Eléctrica & $\begin{array}{l}\text { Conductividad volumétrica } \\
\qquad(\mathrm{S} / \mathrm{cm})\end{array}$ & \\
\hline
\end{tabular}




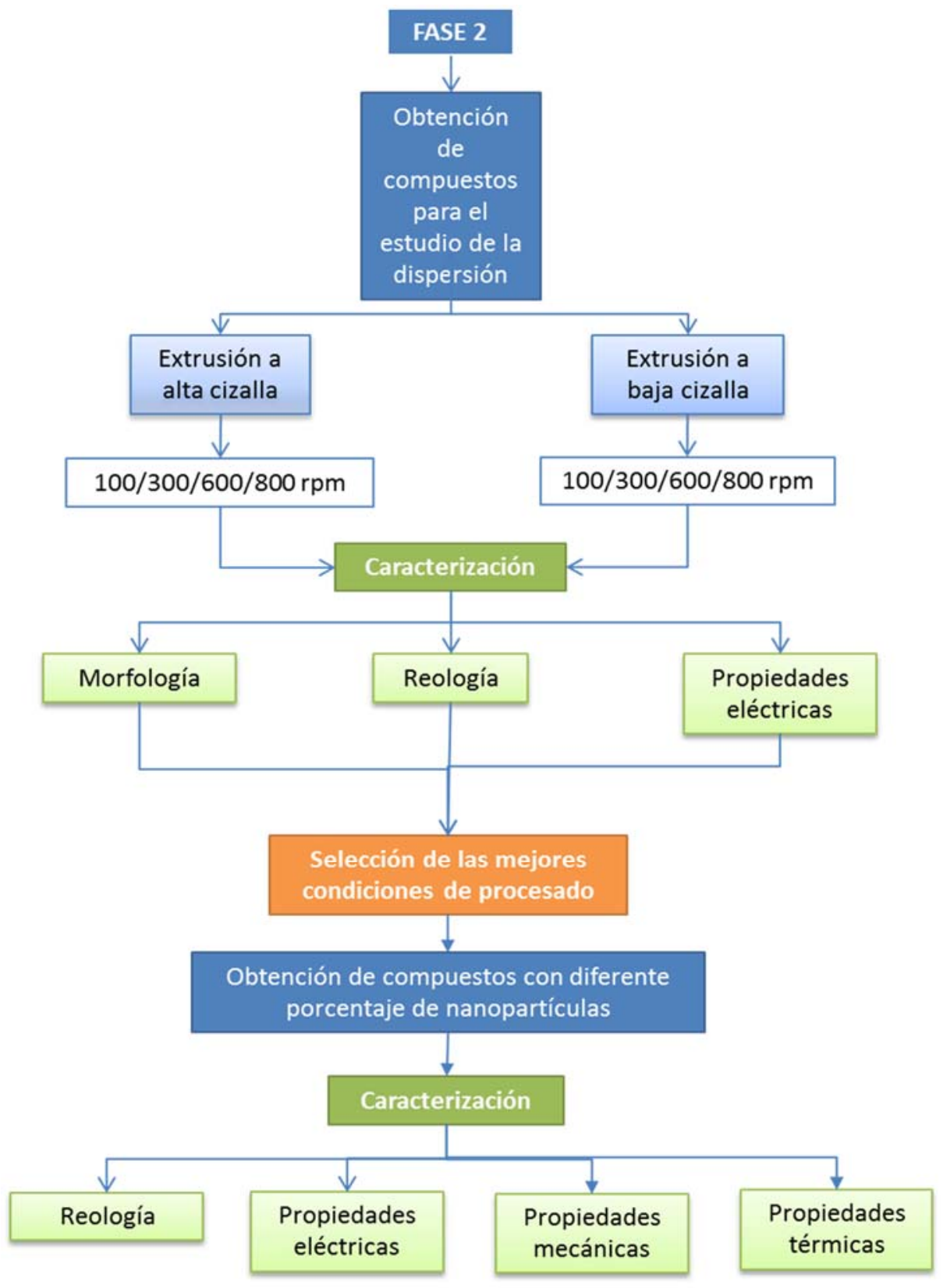

Figura 1. Organigrama de la Fase 2 


\section{- FASE 3}

La Fase 3, capítulo 6 y 7 , hace referencia al estudio de la interacción de los nanocompuestos con la radiación microondas.

Se dividirá en las siguientes tareas:

a) Estudio de la influencia de la dispersión de la nanocarga en la matriz polimérica

Con el fin de estudiar cómo influye la dispersión de las nanocargas en la eficiencia del calentamiento, se realizarán ensayos fijando la potencia de calentamiento y se medirá la temperatura alcanzada por el polímero, transcurrido un tiempo determinado. A partir de estos resultados, se podrá analizar qué grado de dispersión de las nanocargas es el más óptimo para el calentamiento por microondas.

b) Estudio de la influencia del porcentaje de carga

En este experimental se someterán los nanocompuestos con diferentes porcentajes de nanocarga al calentamiento por microondas a una potencia fija durante un mismo tiempo de exposición, analizándose la temperatura alcanzada por el polímero. A partir de los resultados obtenidos se determinará la eficacia de calentamiento para cada tipo de susceptor $\left({ }^{\circ} \mathrm{C} / \%\right)$.

c) Comparativa entre nanocargas: Nanotubos de Carbono versus Grafeno Multicapa

Se comparará el comportamiento frente a la radiación microondas de los nanotubos de carbono frente al grafeno multicapa. Se estudiará cuál es más eficaz, es decir, cuál permite aumentar en mayor grado la temperatura de la matriz polimérica empleando la menor adición en peso de susceptor.

d) Desarrollo y validación de un prototipo a partir del sistema nanocompuesto seleccionado

En esta tarea final se desarrollará un prototipo empleando el sistema nanocompuesto con mejor absorción de microondas. El prototipo con la 
geometría de un producto comercial se realizará mediante la tecnología de moldeo por compresión. El objetivo de esta tarea será demostrar la viabilidad de este sistema de calentamiento a nivel semi-industrial o de planta piloto.

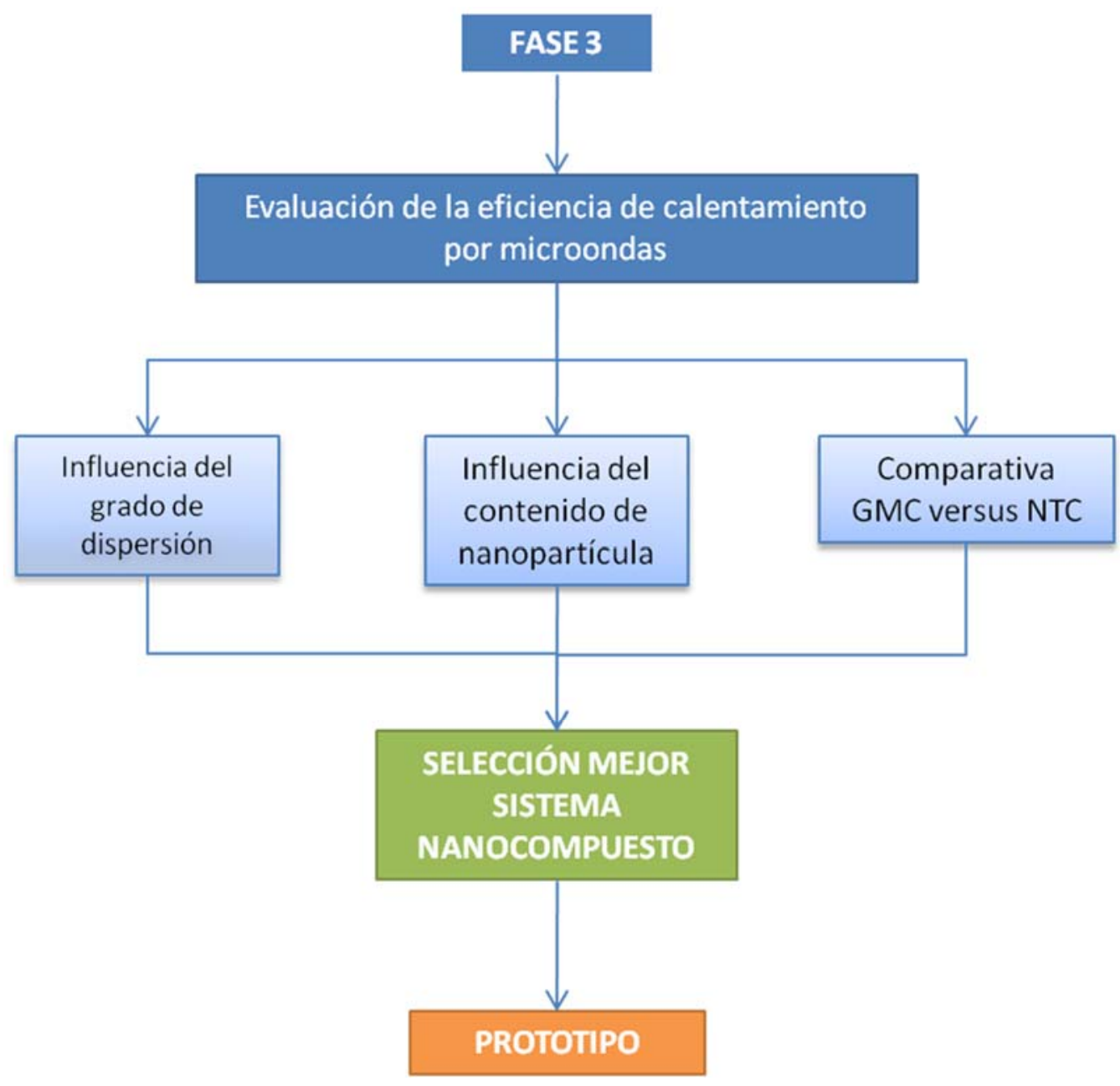

Figura 2: Organigrama de la Fase 3 


\section{CAPÍTULO 2: ESTADO DEL ARTE}

\subsection{TECNOLOGÍA DE CALENTAMIENTO POR MICROONDAS}

\subsubsection{Introducción}

La radiación electromagnética cuya longitud de onda se encuentra entre 300 $\mathrm{MHz}$ y $300 \mathrm{GHz}(1 \mathrm{~m}-1 \mathrm{~mm})$ recibe el nombre de radiación microondas ${ }^{3}$. Estas radiaciones se propagan a través del espacio a la velocidad de la luz. En la Figura 3 se observa la posición de las microondas en el espectro electromagnético. La radiación microondas son ondas electromagnéticas con una frecuencia y una longitud de onda intermedia entre las de una onda de radio y las infrarrojas.

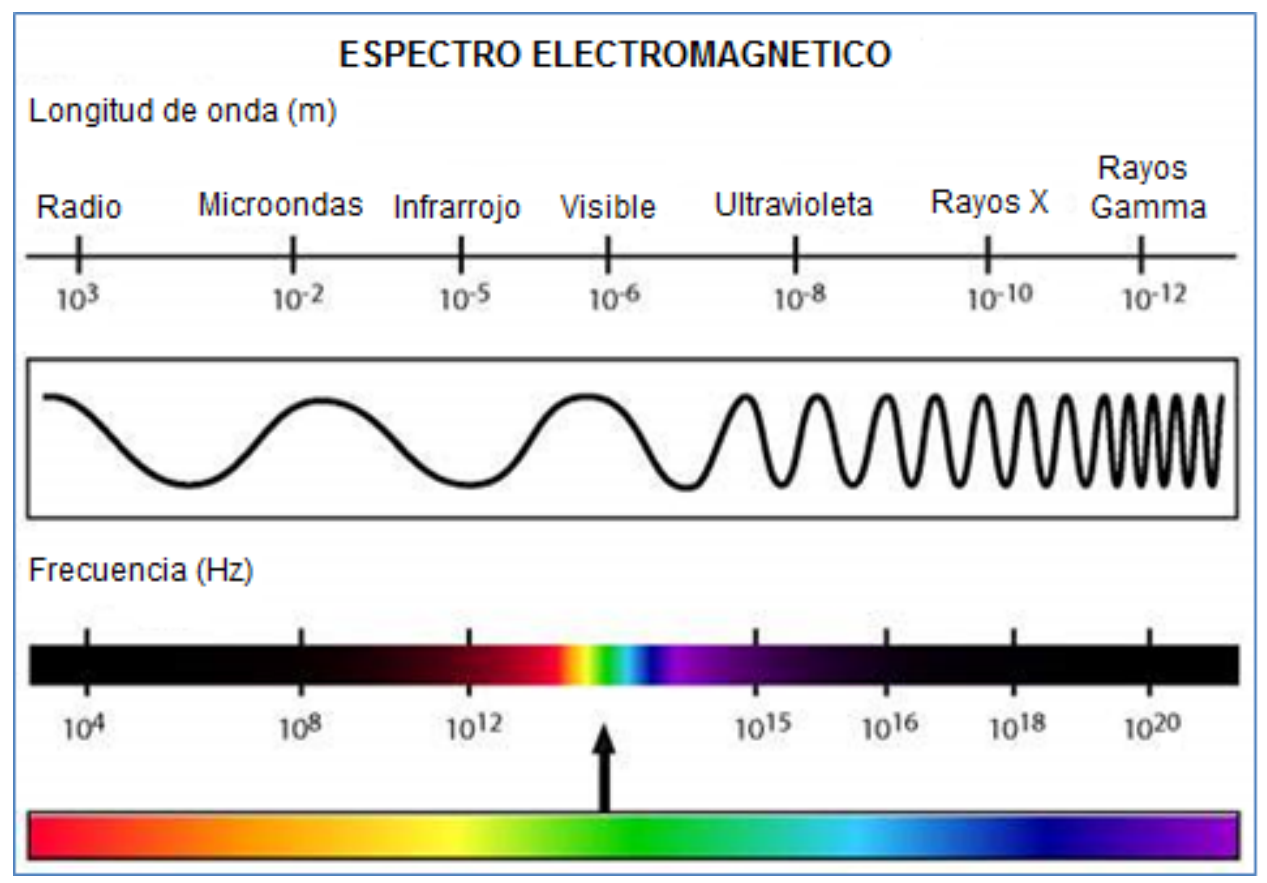

Figura 3. Espectro de frecuencias electromagnéticas ${ }^{4}$

Según el Comité Consultivo Internacional de Radiocomunicaciones (CCIR) la región referente a las microondas puede dividirse en tres bandas: 
- UHF: Ultra alta frecuencia

- SHF: Súper alta frecuencia

- EHF: Extrema alta frecuencia

La Tabla 2 muestra la designación de bandas por el CCIR 5 .

Tabla 2: CCIR designación de bandas

\begin{tabular}{|c|l|}
\hline Frecuencia & \multicolumn{1}{|c|}{ Designación de banda } \\
\hline $3 \mathrm{~Hz}-30 \mathrm{~Hz}$ & Ultra Low Frequency (ULF) \\
\hline $30 \mathrm{~Hz}-300 \mathrm{~Hz}$ & Extra Low Frequency (ELF) \\
\hline $300 \mathrm{~Hz}-3 \mathrm{kHz}$ & Voice Frequency (VF) \\
\hline $3 \mathrm{kHz}-30 \mathrm{kHz}$ & Very Low Frequency (VLF) \\
\hline $30 \mathrm{kHz}-300 \mathrm{kHz}$ & Low Frequency (LF) \\
\hline $300 \mathrm{kHz}-3 \mathrm{MHz}$ & Medium Frequency (MF) \\
\hline $3 \mathrm{MHz}-30 \mathrm{MHz}$ & High Frequency (HF) \\
\hline $30 \mathrm{MHz}-300 \mathrm{MHz}$ & Very High Frequency (VHF) \\
\hline $300 \mathrm{MHz}-3 \mathrm{GHz}$ & Ultra High Frequency (UHF) \\
\hline $3 \mathrm{GHz}-30 \mathrm{GHz}$ & Super High Frequency (SHF) \\
\hline $30 \mathrm{GHz}-300 \mathrm{GHz}$ & Extreme High Frequency (EHF) \\
\hline $300 \mathrm{GHz}-3 \mathrm{THz}$ & Infrared light \\
\hline $3 \mathrm{THz}-30 \mathrm{THz}$ & Infrared light \\
\hline $30 \mathrm{THz}-300 \mathrm{THz}$ & Infrared light \\
\hline $300 \mathrm{THz}-3 \mathrm{PHz}$ & Visible light \\
\hline $3 \mathrm{PHz}-30 \mathrm{PHz}$ & Ultra Violet light \\
\hline $30 \mathrm{PHz}-300 \mathrm{PHz}$ & X-rays \\
\hline $300 \mathrm{PHz}-3 \mathrm{EHz}$ & Gamma rays \\
\hline $3 \mathrm{EHz}-30 \mathrm{EHz}$ & Cosmic rays \\
\hline
\end{tabular}

La tecnología de radiación microondas fue desarrollada durante la Segunda Guerra Mundial para su uso en navegación y detección de radares. Desde entonces la tecnología ha evolucionado, incrementando su uso en aplicaciones tanto industriales como domésticas. Las frecuencias empleadas a nivel industrial suelen ser $915 \mathrm{MHz}, 2.45 \mathrm{GHz}, 5.8 \mathrm{GHz}$ y $24.124 \mathrm{GHz}$, siendo las frecuencias en los equipos domésticos de $2.45 \mathrm{GHz}$. Una onda electromagnética lleva asociada un campo eléctrico y un campo magnético (ver Figura 4). Estos dos campos viajan juntos en el espacio propagándose a la velocidad de la luz. 


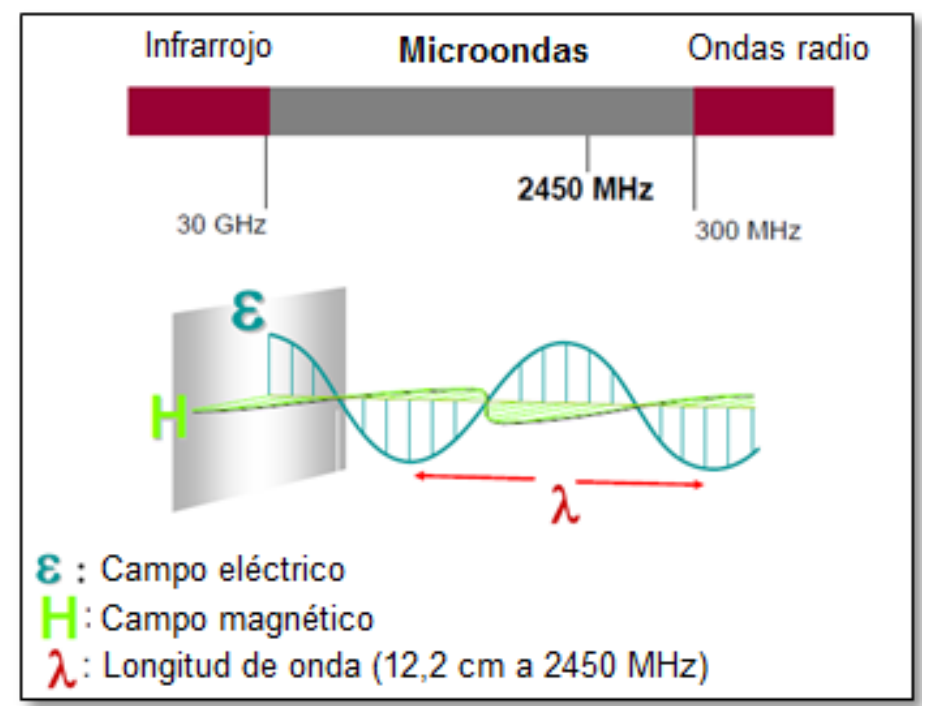

Figura 4. Campos eléctrico y magnético asociado a las microondas ${ }^{5}$

Las microondas son una alternativa a los métodos de calentamiento convencionales y ha encontrado su espacio en la industria alimentaria, química y textil6. A continuación se detallan algunas de las aplicaciones reportadas en la bibliografía:

- Secado de materiales: la radiación microondas consigue eliminar de forma muy efectiva el contenido de agua de secciones de gran volumen gracias al calentamiento volumétrico de proporciona. Se ha aplicado en materiales como la madera ${ }^{7}$, en la deshidratación de carbonato sódico monohidrato y cuero en la industria textil ${ }^{8}$.

- Sinterizado de cerámicas: La radiación microondas se emplea para el sinterizado de diferentes cerámicas funcionales como la alúmina ${ }^{9}$, el óxido de zinc $^{10}$, carburo de silicio ${ }^{11}$, hidroxiapatita ${ }^{10}$ y otras muchas aleaciones. Se obtienen piezas sinterizadas de muy alta densidad con tiempos de producción cortos.

- Curado de resinas termoestable: La radiación microondas permite reducir el tiempo de curado de las resinas termoestables, lo cual acorta en gran medida los ciclos de producción de piezas voluminosas beneficiando a la industria naval, eólica y aeronáutica entre otras. 


\subsubsection{Fundamentos del calentamiento de polímeros por microondas}

Los procesos de transformación de polímeros se llevan a cabo a altas temperaturas, siendo el método de calentamiento más convencional el calentamiento por conducción empleando resistencias eléctricas. Durante el proceso de calentamiento por conducción el polímero es calentado desde la superficie hasta el interior de la granza. Los polímeros se caracterizan por su baja conductividad térmica, por lo que el calentamiento total de la masa de polímero requiere largos tiempos de calentamiento.

La temperatura máxima en la superficie también está limitada por la temperatura de degradación del polímero de modo que aumentar la temperatura no siempre es posible y la única metodología aplicable es el aumento del tiempo de calentamiento. Sin embargo, el calentamiento de polímeros por radiación microondas sigue un mecanismo totalmente diferente ${ }^{12,13}$. Las ondas microondas penetran en el interior de la granza de polímero calentando la masa desde el interior al exterior.

El calentamiento volumétrico del polímero es relativamente independiente de la conductividad térmica del polímero, acelerando el proceso de calentamiento. La Figura 5 muestra de forma gráfica el flujo de calor en un polímero calentado por conducción, donde el calor se dirige del exterior al interior, y por radiación microondas, en el que el calor comienza en el interior de la masa de polímero siendo, por tanto, más efectivo.

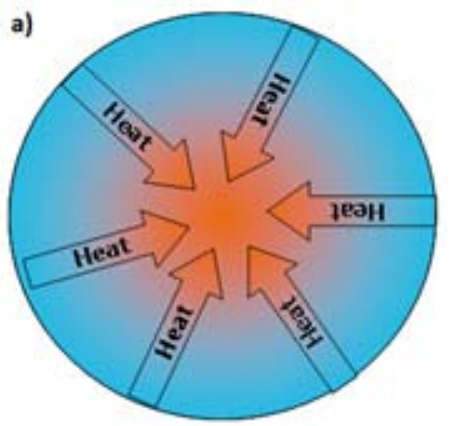

Calentamiento conducción

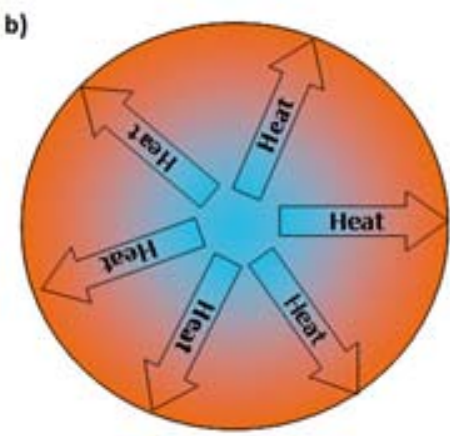

Calentamiento microondas

Figura 5. Comparativa del flujo de calor en el calentamiento por conducción (a) y calentamiento por radiación microondas (b) ${ }^{14}$ 


\subsubsection{Interacción materiales - microondas}

Los materiales se pueden clasificar en tres categorías según la forma en que interaccionan con la radiación microondas ${ }^{15}$, ver Figura 6 :

- TRANSPARENTES: son aquellos materiales con baja constante dieléctrica. La radiación microondas traspasa este tipo de materiales sin sufrir ninguna atenuación.

- OPACOS: son materiales conductores. La radiación microondas es reflejada y no penetra en este tipo de materiales.

- SUSCEPTORES: son materiales con alta constante dieléctrica. Absorben la radiación microondas, siendo la cantidad de energía absorbida mayor a medida que aumenta su constante dieléctrica.

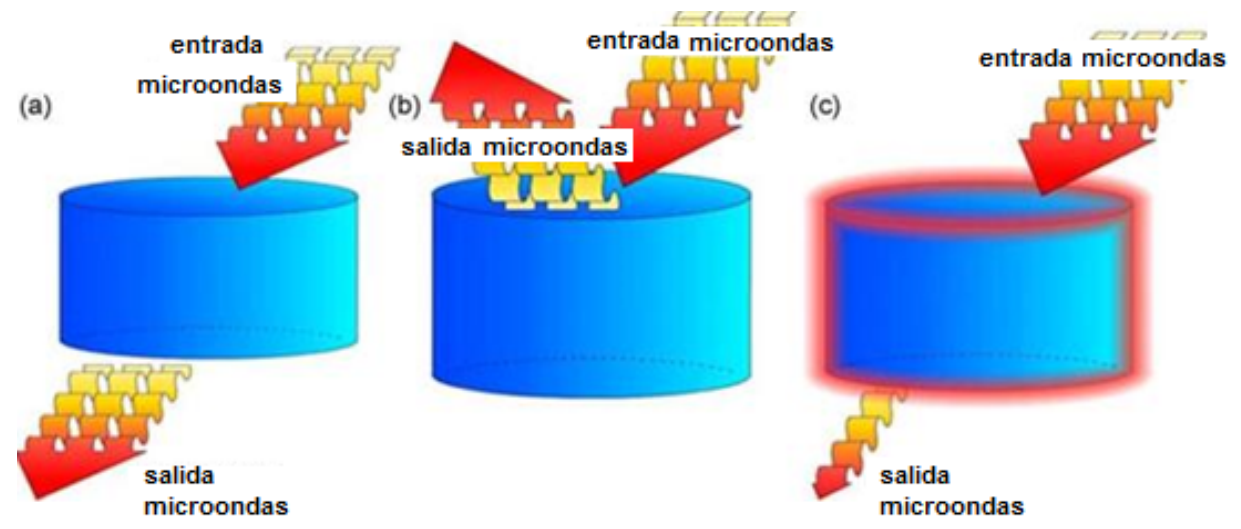

a) transparente; b) opaco; c) susceptor

Figura 6. Interacción entre las microondas y diferentes materiales ${ }^{16}$

Los principales parámetros que se deben tener en cuenta a la hora de procesar materiales por microondas ${ }^{17}$ :

- Energía Absorbida (P)

- Profundidad de penetración de las microondas (D)

El calentamiento por microondas es el resultado de la absorción de la energía generada por un material cuando éste es expuesto a un campo electromagnético distribuido en una cavidad reflectora. Esto se puede expresar como la energía absorbida por unidad de volumen: 


$$
P=\sigma|E|^{2}=2 \pi f \varepsilon_{0} \varepsilon_{e f f}^{\prime \prime}|E|^{2}=2 \pi f \varepsilon_{0} \varepsilon_{r}^{\prime} \tan \delta|E|^{2}
$$

Donde:

$$
\begin{aligned}
& \mathrm{E}=\text { campo eléctrico } \\
& \varepsilon_{e f f}^{\prime \prime}=\text { constante dieléctrica efectiva } \\
& \varepsilon_{0}=\text { permitividad eléctrica del espacio } \\
& f=\text { frecuencia del microondas } \\
& \sigma=\text { conductividad eléctrica } \\
& \varepsilon_{r}^{\prime}=\text { constante dieléctrica relativa } \\
& \tan \delta=\text { pérdida de energía requerida para almacenar }
\end{aligned}
$$

Como se observa en la Ecuación2, la energía absorbida por un material sometido a las microondas es directamente proporcional a sus propiedades dieléctricas. Esta energía absorbida se convierte en calor según la siguiente ecuación:

$$
\frac{\Delta T}{\Delta t}=\frac{2 \pi f \varepsilon_{0} \varepsilon_{e f f}^{\prime \prime}|E|^{2}}{\rho C_{p}}
$$

Donde:

$$
\begin{aligned}
& C_{p}=\text { capacidad calorífica del material } \\
& \rho=\text { densidad del material }
\end{aligned}
$$

Las propiedades dieléctricas también están relacionadas con la profundidad de penetración de las microondas en el material, siguiendo la siguiente ecuación: 


$$
D=\frac{3 \lambda_{0}}{8.686 \pi \tan \delta\left(\frac{\varepsilon_{r}^{\prime}}{\varepsilon_{0}}\right)^{\frac{1}{2}}}
$$

(Ecuación 3)

Donde:

$$
\begin{aligned}
& \mathrm{D}=\text { profundidad de penetración de las } \\
& \text { microondas } \\
& \lambda_{0}=\text { longitud de la onda incidente }
\end{aligned}
$$

La profundidad de penetración es importante ya que marcará la uniformidad de calentamiento a lo largo de todo el material. Se puede afirmar que altas frecuencias de trabajo (a mayor frecuencia menor longitud de onda: $1 \mathrm{GHz}-$ $1 \mathrm{~m} ; 300 \mathrm{GHz}-1 \mathrm{~mm}^{16}$ ) y altas constantes dieléctricas darán lugar a un calentamiento de la superficie del material. Sin embargo, bajas frecuencias y bajas constantes dieléctricas darán lugar a un calentamiento más uniforme en todo el volumen del material ${ }^{8}$.

Como conclusión se puede afirmar que las propiedades dieléctricas de los materiales son de gran importancia en el calentamiento por microondas. Las propiedades dieléctricas críticas de un material para ser procesado por microondas son ${ }^{18}$ :

- Permitividad $\quad \varepsilon=\varepsilon^{\prime}-\mathrm{j} \varepsilon^{\prime \prime}$

- Tangente de pérdidas (o pérdida dieléctrica) $\tan \delta=\varepsilon^{\prime \prime} / \varepsilon^{\prime}$

La parte real de la permitividad, $\varepsilon^{\prime}$, llamada constante dieléctrica, determina qué cantidad de la energía incidente penetra en el material. La parte imaginaria de la permitividad compleja, $\varepsilon$ " 0 factor de pérdidas, hace referencia a la capacidad del material de almacenar energía.

La propiedad más importante es la tangente de pérdidas, ya que predice la habilidad de un material para convertir la energía incidente en calor.

Es importante tener en cuenta que $\varepsilon^{\prime}$ y $\varepsilon^{\prime \prime}$ dependen de la temperatura y de la frecuencia. A bajas frecuencias toda la energía es absorbida por el movimiento rotatorio de los dipolos, la $\varepsilon$ ' es máxima pero no hay colisiones 
porque el desplazamiento es muy lento. A muy altas frecuencias el material no tiene tiempo para responder al campo eléctrico, siendo \&' mínima. La pérdida de energía causada por las colisiones se representa por $\varepsilon$ ". Por ello, un factor clave sería encontrar la frecuencia para cada material en la que tanto la absorción de energía $\left(\varepsilon\right.$ ') como la pérdida de la misma ( $\left.\varepsilon^{\prime \prime}\right)$ sean altas, ver Figura 7.

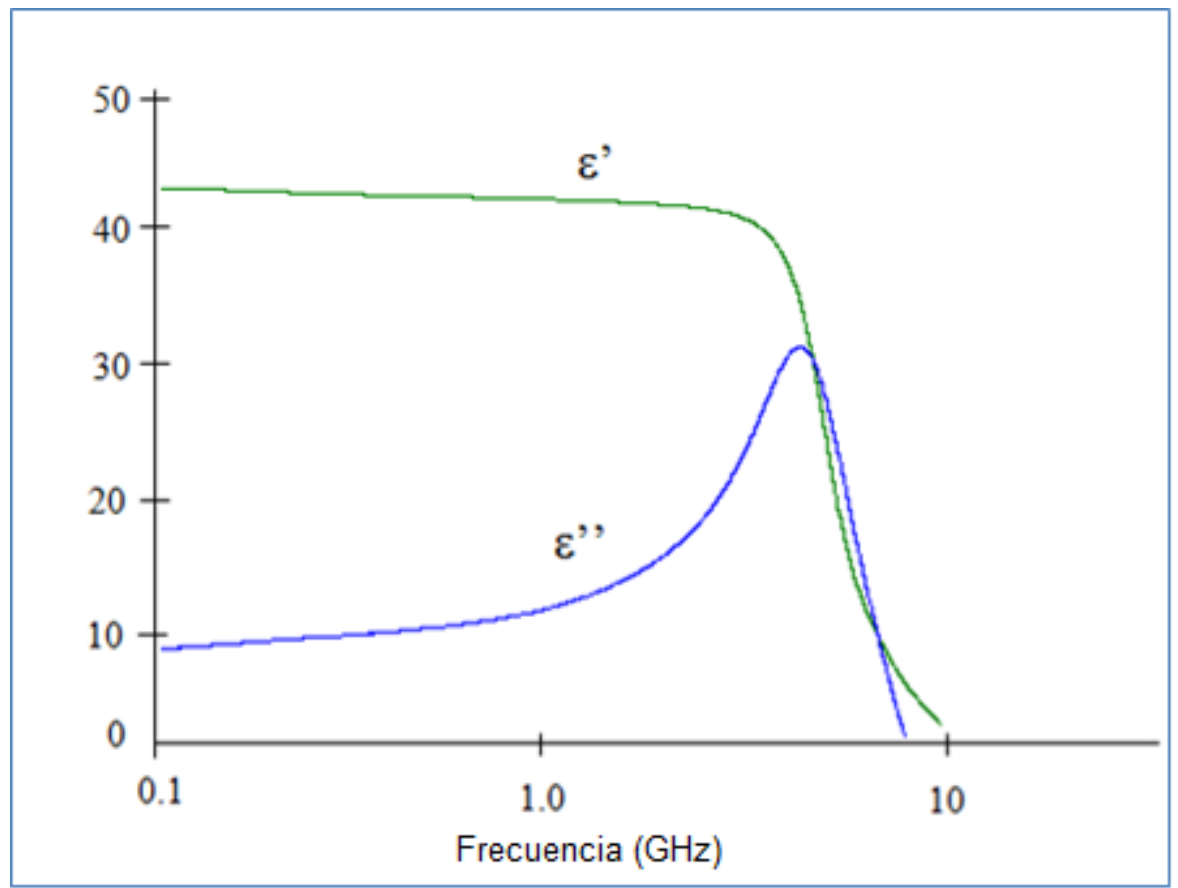

Figura 7. Variación de las propiedades dieléctricas con la frecuencia ${ }^{18}$

Este punto de equilibrio viene determinado por la pérdida dieléctrica ( $\tan \delta$ ), la cual predice la habilidad de un material para convertir la energía absorbida en calor ${ }^{19}$. Por ejemplo, para el agua, la mayor pérdida dieléctrica tiene lugar a $2.0 \mathrm{GHz}$, frecuencia que se encuentra en el rango de los microondas domésticos.

Dos fenómenos son responsables del calentamiento de los materiales cuando se someten a radiación microondas ${ }^{20,21}$ (ver Figura 8): 
1. Polarización iónica: los iones se mueven como respuesta a un campo eléctrico. Los iones están eléctricamente cargados y reciben energía cinética suministrada por el campo eléctrico. Los iones chocan entre sí, convirtiendo la energía cinética en calor. El número de colisiones aumenta a medida que aumenta la frecuencia, incrementando la temperatura del material. Este fenómeno tiene lugar en los sólidos iónicos como: $\mathrm{NaCl}, \mathrm{MgO}$, etc.

2. Rotación de dipolos: este fenómeno depende de la existencia de moléculas polares. Normalmente, las moléculas polares tienen una orientación aleatoria, pero en presencia de un campo eléctrico estas moléculas se alinean con dicho campo eléctrico. La polaridad del campo eléctrico varía con la frecuencia. Las moléculas siguen los cambios del campo eléctrico produciéndose la fricción entre las mismas y, por lo tanto, produciendo calor. La Figura 9 muestra las moléculas polares antes y después de ser sometidas a un campo eléctrico. Este fenómeno tiene lugar en materiales como el agua, polímeros y aceites.

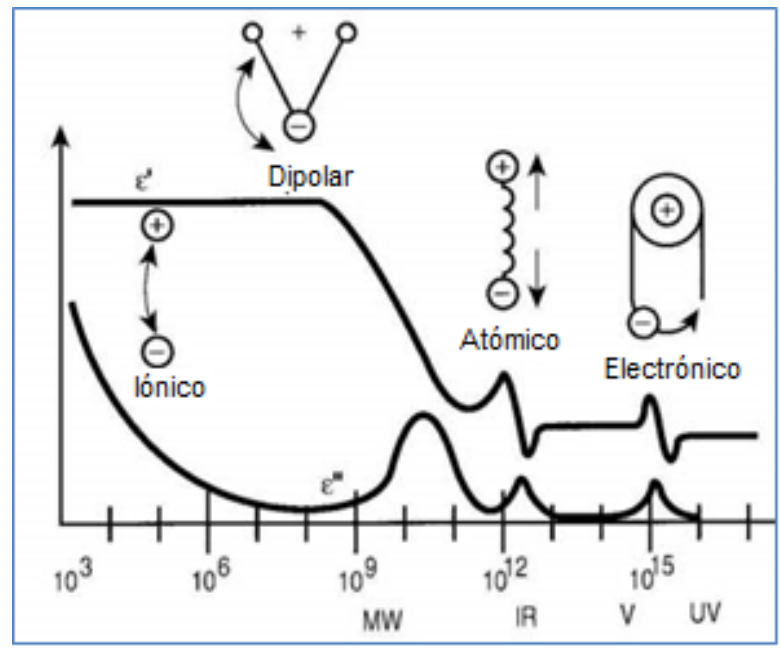

Figura 8. Fenómenos responsables del calentamiento de los materiales cuando son sometidos a las microondas ${ }^{22}$ 


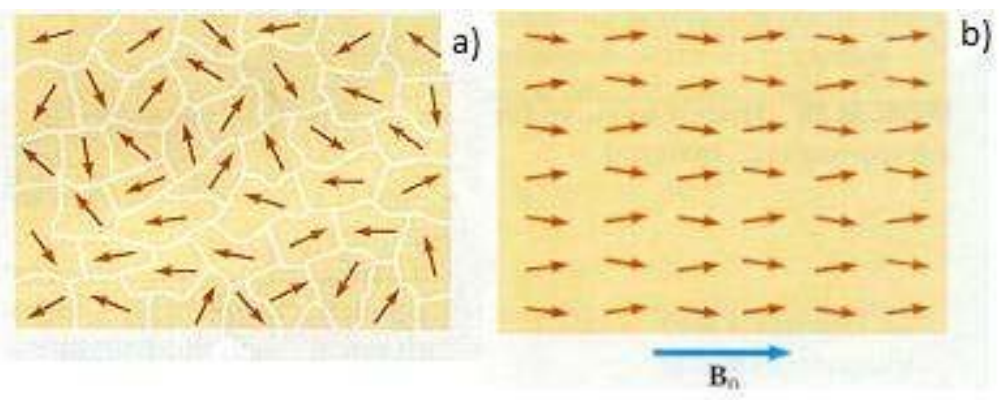

Figura 9. Moléculas polares con orientación aleatoria (a) y tras ser sometidas a un campo eléctrico $(b)^{18}$ 


\subsubsection{Ventajas del procesado por microondas}

En relación con el objeto de este trabajo, las principales ventajas del calentamiento por microondas pueden resumirse en tres: reducción de tiempos de producción, reducción de costes de producción y beneficios medioambientales.

A continuación se recoge un listado de las ventajas de este tipo de procesado comparando con los métodos convencionales de calentamiento ${ }^{23}$ :

- Emplea un $70 \%$ menos de energía que los métodos de calentamiento convencionales, debido a las altas densidades de energía aplicadas y a la absorción directa de la misma por los materiales.

- Mejora la calidad del producto final, ya que los materiales son calentados rápidamente $\mathrm{y}$, normalmente, pueden ser procesados a menores temperaturas.

- Permite el calentamiento selectivo. Dependerá de la constante dieléctrica del material.

- Aumento de la producción debido a que el calentamiento se produce rápidamente.

- Reducción de la contaminación medioambiental, ya que se incrementa la eficiencia energética. 


\subsubsection{Fuentes de radiación de microondas}

La radiación electromagnética se produce al acelerar cargas eléctricas. Para alcanzar altas frecuencias y potencias se emplean tubos de vacío, siendo los más empleados:

- Magnetrones

- Tubos de onda viajera (Travelling wave tubes - TWTs)

\section{a) Magnetrones}

Los magnetrones transforman la energía potencial de los electrones en energía electromagnética. Son las fuentes de microondas más empleadas debido a su alta eficiencia ${ }^{24}$. Su producción en masa permite que su precio final sea bajo, por lo que son empleados en los hornos microondas domésticos.

El funcionamiento del magnetrón se basa en el movimiento de los electrones bajo la influencia combinada de los campos eléctricos y magnéticos. Para que el magnetrón funcione los electrones deben fluir desde el cátodo al ánodo. Los magnetrones emplean estructuras resonantes para generar campos electromagnéticos ${ }^{25}$. Por ello, sólo pueden generar campos electromagnéticos a una frecuencia fija.

En los tubos de vacío el ánodo tiene una alta energía potencial si es comparada con el cátodo. Esta diferencia de potencial da lugar a campos eléctricos elevados que producen el calentamiento del cátodo, como consecuencia de la aceleración de los electrones que son liberados hacia el ánodo.

Los magnetrones emplean un campo magnético ortogonal al campo eléctrico creando una fuerza circunferencial sobre los electrones que se dirigen al ánodo. Esta fuerza hace que la trayectoria de estos electrones sea en forma de espiral, creando un remolino de electrones. Cuando esta nube de electrones pasa a través de las cavidades resonantes se producen oscilaciones o perturbaciones de esta nube de electrones. La frecuencia de estas oscilaciones depende del tamaño de las cavidades. La potencia de los magnetrones puede regularse mediante la corriente eléctrica que incide sobre el cátodo o ajustando la fuerza del campo magnético exterior ${ }^{26}$. 


\section{b) Tubos de Onda Viajera (TWTs)}

En los hornos de frecuencia variable se emplean tubos de onda viajera (wave travelling tubes - TWTs) para generar el campo electromagnético. Este tipo de sistema permite trabajar a mayores frecuencias ya que actúa como un amplificador. El voltaje de entrada controla la frecuencia del oscilador y esta señal es enviada al tubo de onda viajera (TWT) para ser amplificada. Este tipo de sistemas permiten variar rápidamente la frecuencia de salida ${ }^{27}$.

Los elementos que componen el tubo de onda viajera son 28 :

- Tubo de vacío: El tubo de onda viajera está contenido en un tubo de vidrio al vacío.

- Emisor de electrones. Está formado por un cátodo a alta temperatura el cual produce electrones que son acelerados hacia el ánodo y emitidos a lo largo del tubo.

- Imán situado a lo largo del tubo el cual asegura que el haz de electrones recorre la longitud del tubo.

- Hélice: Reduce la velocidad de las microondas hasta igualarla con la velocidad del haz de electrones ${ }^{29}$. Cuando la radiación microondas se propaga a lo largo de la hélice, la componente axial del campo electromagnético interacciona con el haz de electrones. Esto resulta en una aceleración o deceleración del haz lo que permite la amplificación de la señal. 


\subsubsection{Tecnologías de calentamiento por microondas existentes en el mercado.}

Actualmente, en el mercado existen diferentes tecnologías de calentamiento por microondas con diferentes características y funciones:

- Sistemas multimodo:

o Frecuencia fija (fixed frequency)

o Frecuencia variable (Variable frequency - VFM)

o Antena abierta

- Sistemas monomodo

\section{A) SISTEMAS MULTIMODO}

Los hornos microondas multimodo están diseñados para que múltiples ondas electromagnéticas se reflejen en la cavidad del horno microondas. El objetivo de estos hornos consiste en conseguir un sistema lo más caótico posible de aplicación de radiación microondas. Para ello las cavidades son de acero inoxidable buscando una doble funcionalidad: evitar que las ondas se escapen fuera del horno y reflejar repetidamente las ondas sobre la muestra. Para conseguir el sistema multimodo la cavidad es muy grande en relación a la muestra y a la longitud de onda de la radiación microondas.

\section{Frecuencia Fija}

Las frecuencias más comunes a las que trabajan este tipo de hornos son las siguientes: $915 \mathrm{MHz}, 2.45 \mathrm{GHz}, 5.8 \mathrm{GHz}$, ó $24.124 \mathrm{GHz}$. La geometría de la cavidad debe ser optimizada según la aplicación. Dado que es un sistema cerrado, el aislamiento de la cavidad será un punto muy importante para evitar escapes de radiación. Así pues, las principales desventajas de los hornos de frecuencia fija multimodo son la presencia de puntos calientes ${ }^{30} \mathrm{o}$ "hot spots". Los hornos convencionales de frecuencia fija experimentan fluctuaciones locales del campo electromagnético, las cuales causan una distribución no uniforme de la energía en la cavidad del horno. Esto provoca que todo el volumen del material no se caliente por igual, originando puntos calientes $\mathrm{y}$, consecuentemente, baja calidad del producto final ${ }^{31}$. 
Se han desarrollado diferentes soluciones para minimizar este problema como:

- Empleo de platos rotatorios: la pieza a calentar descansa sobre un plato que rota mientras inciden las microondas sobre la pieza. El objetivo es reducir los puntos calientes cambiando las zonas del material sometidas a altos campos eléctricos.

- Empleo de ventiladores en el interior de la cavidad. Las palas metálicas del ventilador reflejan la radiación redistribuyendo la energía en el interior de la cavidad. Esta medida es menos empleada.

Otras rutas posibles para minimizar el problema de los puntos calientes es el empleo de hornos de frecuencia variable o de frecuencia fija monomodo.

\section{Frecuencia Variable}

En hornos de frecuencia variable la frecuencia oscila alrededor de un rango (determinado por la frecuencia media y el tamaño de la cavidad). La distribución de energía es más uniforme debido a la superposición de cientos o miles de microondas en pocos milisegundos ${ }^{32}$. Miles de frecuencias son lanzadas a la cavidad del microondas de forma secuencial. Cada frecuencia incidente equivale a un campo eléctrico individual que pasa a través del material. El resultado es la aparición de puntos calientes en diferentes zonas del material. Estos puntos calientes van cambiando y no se concentran en los mismos sitios como ocurre en los hornos de frecuencia fija. Aplicando el correcto rango de frecuencias se puede obtener un calentamiento uniforme ${ }^{33}$.

Los ciclos de variación de la frecuencia tienen una duración entre 0.2 s y 0.5 $\mathrm{s}$, estando el material sometido a un campo eléctrico alternado en el rango de $2.4-18 \mathrm{GHz}$.

Esta tecnología se emplea en aplicaciones en las que se necesita un control exahustivo de proceso. Entre ellas destacan: síntesis química, curado de polímeros y adhesivos, etc. 


\section{Antena Abierta}

Los sistemas de antena abierta están pensados para aplicar radiación microondas sobre grandes piezas, donde no es posible o es muy caro el empleo de hornos cerrados. Es una tecnología muy empleada en la industria aeronáutica. El equipo puede variar según la geometría de la pieza. Uno de los sistemas de antena abierta más empleados está basado en el microondas tipo tunel, donde la pieza se coloca en una cinta transportadora y se hace pasar a través de un tunel dotados de magnetrones que irradian radiación microondas ${ }^{34}$. La cantidad de radiación a la cual está sometida la pieza variará según la velocidad de la cinta transportadora. En este caso, los magnetrones están fijos y es la pieza la que se mueve.

Otro tipo de microondas de antena abierta se basa en mantener la pieza fija y son los magnetrones los que se mueven alrededor de la misma. Los magnetrones son acoplados a un robot mientras que la pieza permanece fija sobre un banco. Este sistema permite llegar a toda la geometría de la pieza. Se emplea principalmente con piezas de geometria compleja.

\section{B) SISTEMAS MONOMODO}

Los hornos monomodo acoplan las microondas antes de que éstas incidan en el material generando una sola onda. De este modo se maximiza la eficiencia del campo eléctrico evitando las pérdidas por resonancia. Comparativamente con los sistemas multimodo, los hornos monomodo son mucho más eficientes. La desventaja es que la cavidad tiene un tamaño menor que los hornos multimodo ${ }^{35}$. Los hornos multimodo son los más empleados, tanto a nivel industrial como doméstico, por su mayor versatilidad y precio más competitivo. 


\subsection{SUSCEPTORES DE MICROONDAS}

\subsubsection{Introducción}

Los materiales dieléctricos son aquellos que al aplicar un campo eléctrico orientan sus dipolos en la dirección del campo aplicado. Estos materiales almacenan la energía eléctrica que será transformada en calor por efecto Joule $^{36}$. Los materiales dieléctricos se caracterizan por tener una baja permitividad o constante dieléctrica $\left(\varepsilon^{\prime}\right)$ y un alto factor de pérdidas $\left(\varepsilon^{\prime \prime}\right)^{37}$.

El agua, que es el susceptor de microondas más simple, puede ser empleada en materiales porosos o higroscópicos como elemento susceptor de microondas ${ }^{38}$.

El principal mecanismo de absorción de microondas de los materiales dieléctricos es la polarización de los dipolos debido a la aplicación de un campo eléctrico. Aquellos materiales que exhiben mayor movilidad de los dipolos presentan un comportamiento susceptor de microondas más eficiente.

La polarización está íntimamente relacionada con el tipo de material y afecta directamente a la movilidad 39 :

- Polímeros amorfos; existe una alta movilidad, suficiente para que se produzca la polarización.

- Polímeros semicristalinos; su estructura es más rígida, tienen menor movilidad y, debido a ello, poseen constantes y resistencias menores que los amorfos. La excepción se produce cuando tienen cadenas asimétricas que aumenta su constante dieléctrica.

Así pues, los materiales poliméricos formados por grupos funcionales dotados de fuertes dipolos absorben microondas sin la necesidad de incorporar partículas susceptoras. Los grupos epoxi, amino, hidroxilo y cianatos son algunos ejemplos de los grupos funcionales con fuertes dipolos.

La permitividad y el factor de pérdidas dieléctricas de los polímeros termoestables aumentan con la temperatura y disminuyen con el aumento del grado de reticulación ${ }^{40}$. Es decir, los termoestables absorben gran cantidad de radiación microondas antes de comenzar el curado, ya que aumenta la 
permitividad con la temperatura. El problema se presenta cuando comienza el curado. Al ser una reacción exotérmica introduce un exceso de calor en el sistema dificultando el control de la temperatura. Este exceso de calor incontrolado provoca puntos calientes en la pieza, "hot spots", dando lugar a un calentamiento o curado no uniforme.

Respecto a los polímeros termoplásticos hay un factor muy importante a tener en cuenta. A partir de una cierta temperatura se produce un incremento en la permitividad del material, produciendo un rápido aumento de la temperatura ${ }^{41}$. Esta temperatura crítica está relacionada con el aumento de la movilidad de las moléculas que hace que aumente la temperatura localmente, pudiendo provocar puntos calientes o hot spots. Otro factor importante es la cristalinidad de los polímeros termoplásticos, siendo los polímeros amorfos más eficientes en cuanto a la absorción de microondas en comparación con los polímeros semicristalinos ${ }^{42}$.

El reto más importante en referencia al procesado de polímeros mediante microondas es el control de la temperatura durante el procesado. La aparición de puntos calientes no permite un calentamiento homogéneo de las piezas. Si la temperatura en estos puntos calientes es muy elevada se puede producir la degradación del material. Por este motivo en los últimos años los polímeros han sido aditivados con partículas susceptoras de microondas con el fin de conseguir un calentamiento homogéneo y controlado 43 . 


\subsubsection{Grupos funcionales más susceptibles de la absorción de radiación microondas}

Tal como se comentó en el apartado anterior sólo algunos grupos funcionales son susceptibles de absorber la radiación microondas. En concreto aquellos que poseen momentos dipolares significativos. El momento dipolar de una molécula representa la distorsión de la nube electrónica entre dos átomos con distinta electronegatividad. Así, si una molécula está compuesta únicamente por dos átomos, a mayor diferencia de electronegatividad entre ambos, mayor será su momento dipolar.

Dentro de los grupos funcionales con fuertes o medios dipolos destacan los hidroxilos, epóxidos, aminos, cianos, imidas, derivados clorados, etc.

En el presente apartado se describen más detalladamente algunos de estos grupos:

\section{a) Grupo hidroxilo}

El grupo hidroxilo está formado por un átomo de hidrógeno y otro de oxígeno, cuyas electronegatividades son bastante diferentes lo que conduce a un momento dipolar significativo. Cuantos más grupos hidroxilo posea una molécula, más susceptible será de absorber la radiación microondas.

\section{b) Grupo epóxido}

El grupo epóxido está formado por dos átomos de carbono y uno de oxígeno. A su vez los átomos de carbono estarán unidos a otros átomos de carbono e hidrógeno, según se trate de un epóxido terminal o no.

Los átomos de oxígeno son bastante electronegativos pero los átomos de carbono poseen una polaridad media. Por esta razón la diferencia de electronegatividades en este caso no es tan evidente como en el caso del grupo hidroxilo (un átomo de hidrógeno presenta una electronegatividad menor que un átomo de carbono), siendo ésta la causa de que este grupo sea menos adecuado que el grupo hidroxilo para acoplar con la radiación microondas. A pesar de ello presenta cierta tendencia al acoplamiento, lo que no ocurre con cadenas hidrocarbonadas. 
Tal como ocurre en el caso de los grupos hidroxilo, la absorción de radiación microondas será mayor a medida que se incremente la cantidad de grupos epóxido.

c) Grupo amino

El grupo amino está formado por un átomo de nitrógeno y hasta tres hidrógenos. La electronegatividad de un átomo de nitrógeno es ligeramente inferior a la de un átomo de oxígeno. Por esta razón se comportará de un modo similar a un grupo hidroxilo frente a la radiación microondas, siendo menos susceptor de la misma que éste último.

d) Grupo ciano

El grupo ciano está compuesto por un átomo de nitrógeno y otro de carbono a través de un enlace triple. La diferencia de electronegatividades entre los dos átomos implicados no es demasiado importante, y por ello este grupo, a pesar de acoplar con la radiación en estudio, no destaca como uno de los más adecuados para trabajar con microondas.

e) Grupo imida

El grupo imida está formado básicamente por un átomo de nitrógeno unido a dos carbonilos $(\mathrm{C}=\mathrm{O})$. Tal como se ha comentado en este apartado la mayor diferencia de electronegatividad entre un átomo de carbono y uno de oxígeno generará dipolos que acoplarán con la radiación microondas. 


\subsubsection{Influencia de las cargas susceptoras de microondas}

Es muy común adicionar a los polímeros, partículas y fibras que facilitan el procesado o que mejoran las propiedades mecánicas, físicas u ópticas de la matriz. Por ello, la adición de cargas susceptoras de microondas varía el modo en el que la matriz polimérica interactúa con la radiación electromagnética generada por las microondas. En este sentido, se modificará el patrón del campo eléctrico, tanto en el interior como en el entorno del compuesto, obteniéndose perfiles de calentamiento muy distintos a los conseguidos con el polímero sin aditivar. Así, al introducir una carga conductora, aunque el compuesto final no adquiera un carácter conductor, la superficie de la partícula incorporada sí interaccionará fuertemente con la radiación microondas.

El efecto de los aditivos conductores sobre el calentamiento por microondas depende del tamaño, forma, concentración y resistividad eléctrica de las partículas, así como de su distribución en la matriz. Por otro lado, la presencia de partículas conductoras podría inhibir el calentamiento por microondas mediante reducción de la profundidad de penetración. Sin embargo, mediante el control de la naturaleza, orientación, y concentración de las cargas, la respuesta a la radiación microondas del material puede ser ajustada ${ }^{44}$. Por ejemplo, las fibras de carbono tienen una resistividad relativamente alta y sin embargo calientan la matriz que las rodea muy eficazmente, presentando un perfil térmico con un máximo en la superficie de las fibras. Este calentamiento preferencial se ha demostrado que mejora la adhesión interfacial entre las fibras y la matriz de resina, lo que conduce a una mayor resistencia a la fractura de los materiales compuestos procesados mediante microondas ${ }^{45}$.

Aditivos no conductores tales como fibras de vidrio y algunos pigmentos, pueden también influir en las propiedades del compuesto a través de mecanismos de calentamiento preferencial, dependiendo de sus propiedades dieléctricas. 


\subsubsection{Tipos de cargas susceptoras}

En los últimos años se han desarrollado números estudios para mejorar la susceptibilidad de los polímeros a la radiación microondas. La finalidad es desarrollar un material compuesto de matriz polimérica cargado con partículas o fibras conductoras. Combinando los porcentajes adecuados de éstas partículas, se puede conseguir valores óptimos de la permitividad $\left(\varepsilon^{\prime}\right)$ y del factor de pérdidas ( $\left.\varepsilon^{\prime \prime}\right)$ para la frecuencia de trabajo deseada.

Los aditivos susceptores pueden ser catalogados en tres grandes grupos:

- Partículas carbonosas

- Partículas ferroeléctricas

- Partículas ferromagnéticas

\subsubsection{Cargas carbonosas}

Las partículas carbonosas son excelentes susceptores de microondas, convirtiendo con facilidad la energía generada por microondas en energía térmica. Estos materiales muestran altos valores de $\varepsilon$ " $y$, por lo tanto, también altos valores de tanס. La Tabla 3 muestra los valores de la tangente de pérdidas dieléctrica para varias partículas carbonosas.

Tabla 3: Tangente de pérdidas dieléctricas de varias partículas carbonosas

\begin{tabular}{|c|c|c|}
\hline Partícula carbonosa & Tan $\boldsymbol{\delta}=\boldsymbol{\varepsilon} ' / \boldsymbol{\varepsilon}$ & Referencia \\
\hline Carbón & $0.02-0.08$ & 46,47 \\
\hline Carbón vegetal & $0.11-0.29$ & 48,49 \\
\hline Negro de humo & $0.35-0.83$ & 50,51 \\
\hline Carbón activo & $0.57-0.80$ & 52 \\
\hline Nanotubos de carbono & $0.25-1.14$ & 53,54 \\
\hline
\end{tabular}


Las partículas carbonosas absorben la radiación electromagnética debido a la presencia de electrones $\pi$ deslocalizados, los cuales pueden moverse libremente. La energía cinética de los electrones aumenta hasta tal punto que pueden saltar del material, provocando la ionización de la atmósfera cercana. A nivel macroscópico se observa la formación de arcos eléctricos y, a nivel microscópico, se pueden formar puntos calientes o "hot spots" 55 .

\section{a) Negro de humo}

El negro de humo actúa como susceptor de microondas al ser empleado como carga en polímeros. Diferentes autores han estudiado su comportamiento susceptor de microondas. J. Harper et al. ${ }^{56}$ concluyeron que el área superficial de la partícula de negro de humo influye en su capacidad de absorber radiación. Cuando mayor es el área superficial, mayor resulta la eficiencia de calentamiento del polímero. En el estudio emplearon un negro de humo con una suerficie específica alta $\left(137 \mathrm{~m}^{2} / \mathrm{g}\right)$ obteniendo una eficiencia de calentamiento de $7.5^{\circ} \mathrm{C} / \%$ ( $800 \mathrm{~W}, 20 \%$ de negro de humo). F.Liu et al. 57 estudiaron el porcentaje óptimo de negro de humo como susceptor de microondas, siendo este un 20\% (superficie específica 39 $\mathrm{m}^{2} / \mathrm{g}$ ). Obtuvieron un aumento de la temperatura del polímero de $139^{\circ} \mathrm{C}$ cuando fue expuesto a una radiación microondas de $800 \mathrm{~W}$ durante $150 \mathrm{~s}$. X. Liu et al. ${ }^{58}$ demostraron que la eficacia de calentamiento del negro de humo se incrementaba añadiendo carburo de silicio a una matriz epoxi. Los porcentajes empleados fueron de $5 \%$ de negro de humo y $50 \%$ de carburo de silicio. C. Brosseau at al. ${ }^{59}$ centró su investigación en la morfología de las partículas de negro de humo. Concluyó que la geometría de los aglomerados de negro de humo tenía una gran influencia sobre la capacidad susceptora del composite. Cuanto mayores eran los aglomerados, menor resultó ser su eficiencia de calentamiento. K.H. Wu et al ${ }^{60}$ reportaron que el negro de humo mejoraba la absorción de microondas de la polianilina cuando era cargado en porcentajes del 10 al $30 \%$.

\section{b) Grafito}

No se han encontrado referencias bibliográficas en las que se emplee el grafito como carga susceptora para el procesado de polímeros por 
microondas. Sin embargo, hay autores que han analizado su idoneidad como elemento de apantallamiento ${ }^{61,62}$. Se ha observado que el grafito tiene buenas propiedades de apantallamiento electromagnético en el rango de frecuencias de las microondas. En el apantallamiento de ondas electromagnéticas intervienen fenómenos de reflexión y de absorción ${ }^{63}$.

En el rango de frecuencias de un microondas doméstico el apantallamiento viene dado principalmente por el fenómeno de absorción ${ }^{64}$. Por este motivo, el grafito podría ser empleado como susceptor de microondas. Las referencias estudiadas combinan el grafito con otras cargas para mejorar su absorción de radiación electromagnética. Al- Ghamdi et al65 emplea combinaciones de grafito y cobre como susceptor, mientras que $\mathrm{M}$. Koledintseva et al66 centró sus estudios en la combinación de grafito con diferentes ferritas.

\section{c) Nanotubos y nanofibras de carbono}

En la bibliografía hay pocas referencias que estudien las nanocargas carbonosas como susceptor de microondas si se compara con el número de estudios realizados con el negro de humo. Debido a su gran superficie específica las nanocargas deberían ser mucho más eficaces que las microcargas. En particular, se han hallado algunos estudios con nanofibras de carbono y nanotubos de carbono en diferentes matrices poliméricas.

F. Nanni at al ${ }^{67}$. estudiaron la incorporación de nanofibras de carbono en una matriz epoxi. Concluyeron que la buena dispersión de las nanofibras en la matriz incrementaba la capacidad de absorción de microondas. La constante dieléctrica aumentó considerablemente con un $4 \%$ de nanofibras trabajando a frecuencias de entre 8 a $12 \mathrm{GHz}$. R. Benitez et al ${ }^{68}$ incorporó las nanofibras al polietileno de alta densidad destacando su baja efectividad como susceptor de microondas ya que sólo con altos porcentajes de nanofibras se observaba un aumento de la temperatura del polímero, siendo el incremento de $34^{\circ} \mathrm{C}$ para un contenido de nanofibras del $15 \%$.

En referencia al empleo de nanotubos de carbono se han encontrado estudios en los que se evalúan las propiedades dieléctricas de los nanocompuestos pero no se ha abordado su procesado por microondas. P. Zhinhua et al ${ }^{69}$ 
incorporaron nanotubos de carbono multicapa en matriz de poliestireno. Se observó que la constante dieléctrica del poliestireno aumentaba considerablemente al añadir $2.5 \%$ de nanotubos de carbono en un rango de frecuencias de $50 \mathrm{MHz}-3 \mathrm{GHz}$. Z. Fan et $\mathrm{al}^{70}$ estudiaron las propiedades dieléctricas de los nanotubos de carbono multicapa en polietileno, polipropileno y polietilentereftalato. Se observó que al aumentar el porcentaje de NTC se incrementaba la tangente de pérdidas, siendo este aumento muy acusado para porcentajes de nanotubos superiores al 4\%. La absorción de radiación electromagnética del $\mathrm{PET}$ fue superior a la del polietileno (PE) y polipropileno (PP) a $6 \mathrm{GHz}, 10 \mathrm{GHz}$ y $13 \mathrm{GHz}$ debido a su polaridad.

\subsubsection{Cargas ferroeléctricas}

Un material ferroeléctrico se caracteriza por alinear sus dipolos en la dirección del campo eléctrico aplicado. Cuando se elimina el campo eléctrico estos dipolos siguen apuntando en la dirección del campo que se había aplicado en vez de volver a su estado de mínima energía. Por lo tanto, estos materiales presentan una polarización neta o remanente sin necesidad de aplicar un campo eléctrico. Los materiales ferroeléctricos se caracterizan por poseer constantes dieléctricas muy altas, ya que la contante dieléctrica indica la tendencia de un material a polarizarse. Estos dipolos interactúan con los campos electromagnéticos provocados por la radiación microondas. Esta característica ha propiciado que muchos investigadores estudien su comportamiento como susceptores de microondas para el calentamiento o curado de polímeros.

En la bibliografía destaca el titanato de bario $\left(\mathrm{BaTiO}_{3}\right)$ como susceptor de microondas en compuestos poliméricos. $\mathrm{X}$. Chen at $\mathrm{al}^{71}$ incorporaron un $8 \%$ de $\mathrm{BaTiO}_{3}$ en una matriz epoxi, observando un aumento de la absorción de microondas en rangos de frecuencia de 8 a $18 \mathrm{GHz}$. Dubkova et al72 también observaron que el $\mathrm{BaTiO}_{3}$ aceleraba el curado trabajando a frecuencias de $2.45 \mathrm{GHz}$ y una potencia de $650 \mathrm{~W}$.

J. Robertson at al ${ }^{73}$ desarrollaron compuestos con diferentes porcentajes de titanato de bario en polietilentereftalato (PET), concluyendo que la constante 
dieléctrica y el factor de pérdidas aumentaban de forma lineal con la amplitud del campo eléctrico aplicado. H.C.Pant et al74 observaron que la adición de titanato de bario a la polianilina aumenta la contante dieléctrica y la tangente de pérdidas, incrementando la absorción de radiación por microondas.

Otros compuestos que han sido estudiados en menor medida son: el titanatocirconato de plomo (PZT) ${ }^{75}$, el $\mathrm{Pb}\left(\mathrm{Mg}_{1 / 3} \mathrm{Nb}_{2 / 3}\right) \mathrm{O}_{3} \quad(P M N){ }^{76}$ y el $0.67 \mathrm{~Pb}\left(\mathrm{Mg}_{1 / 3} \mathrm{Nb}_{2 / 3}\right) \mathrm{O}_{3}-0.33 \mathrm{PbTiO}_{3}(\mathrm{PMNT})^{76}$.

\subsubsection{Cargas ferromagnéticas}

Los materiales ferromagnéticos son aquellos que presentan un momento dipolar magnético espontaneo en ausencia de un campo magnético, observándose este fenómeno solo por debajo de una temperatura dada. Entre estos materiales se encuentran las ferritas, $\mathrm{Fe}_{3} \mathrm{O}_{4}$, caracterizadas por su elevada permitividad dieléctrica, exhibiendo tanto pérdidas dieléctricas como magnéticas, lo cual hace que sea un material excelente para absorber ondas electromagnéticas de alta frecuencia.

Usualmente, este tipo de materiales se emplea no con la finalidad de fundir el polímero en el que están dispersas las partículas sino más bien en aplicaciones donde se requiere apantallamiento electromagnético ${ }^{77}$. C-H Peng et al78. consiguieron un apantallamiento electromagnético a $9 \mathrm{GHz}$ de $25 \mathrm{~dB}$ en poliuretano termoplástico aditivado con ferritas y partículas de plata. S. M. Abbas et al ${ }^{79}$ incorporaron $80 \%$ en peso de hexaferrita tipo $\mathrm{M}\left(\mathrm{BaCo}^{+2} 0.9\right.$ $\left.\mathrm{Fe}^{+2}{ }_{0.05} \quad \mathrm{Si}^{+4} 0.95 \quad \mathrm{Fe}^{+3}{ }_{10.1} \mathrm{O}_{19}\right)$ en poliuretano termoestable obteniendo un apantallamiento electromagnético de $24.5 \mathrm{~dB}$ a $12 \mathrm{GHz}$. A Verma et al ${ }^{80}$ estudiaron el apantallamiento de epoxi aditivado con ferrita, obteniendo resultados variables en función de la pieza de compuesto. 


\subsection{NANOCOMPUESTOS DE NANOTUBOS DE CARBONO (NTC)}

\section{A) Definición y tipos de nanotubos de carbono (NTC)}

Los nanotubos de carbono son una forma alotrópica del carbono, como el diamante, el grafito o los fullerenos. Su estructura puede considerarse procedente de una lámina de grafeno enrollada sobre sí misma. Dependiendo del grado de enrollamiento y la manera como se conforma la lámina original, el resultado puede llevar a nanotubos de distinto diámetro y geometría interna ${ }^{81}$.

Los nanotubos de carbono pueden clasificarse según su estructura en nanotubos de pared simple o nanotubos de pared múltiple.

- Nanotubos de carbono de pared simple:

Hay diferentes tipos de nanotubos de pared simple según la quiralidad. La quiralidad hace referencia a la orientación de las caras hexagonales, véase la Figura 10 , y determina la estabilidad del nanotubo y sus propiedades electrónicas. La lámina de grafeno, de naturaleza semiconductora, enrollada como un nanotubo puede tener propiedades dieléctricas e incluso metálicas.

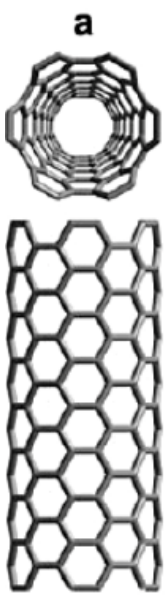

armchair

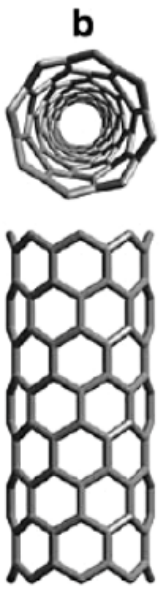

zigzag
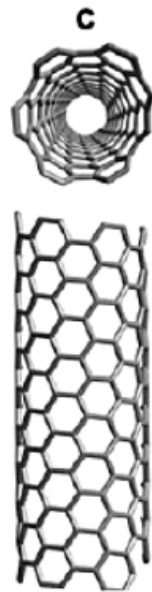

chiral

Figura 10. Diferentes tipos de configuración de SWCNT. a) Tipo "Arm-chair"; b) Tipo "Zig-zag"; c) Tipo Quiral. ${ }^{82}$ 
- Nanotubos de carbono de pared múltiple:

Los nanotubos de pared múltiple pueden encontrarse con dos modelos estructurales distintos: Modelo "Muñeca Rusa" y el modelo "Pergamino"83. El primero consiste en un nanotubo con otro de menor tamaño en su interior. En modelo pergamino una lámina de grafeno se enrolla sobre sí misma múltiples veces.

\section{B) Influencia de la dispersión de los NTC en la matriz polimérica}

Las propiedades de los NTC se dan a nivel microscópico. Para poder aprovechar estas propiedades a nivel macroscópico hay que optimizar el procesado de los materiales compuestos con NTC, asegurando la correcta dispersión de los mismos en la matriz polimérica, para que sus propiedades se transfieran al compuesto. Por lo tanto, el mayor reto es conseguir una óptima dispersión de los NTC.

La utilización efectiva de los nanotubos de carbono en la preparación de nanocompuestos depende en gran medida de la dispersión de los NTC en la matriz termoplástica, sin dañar ésta ni reducir la relación L/D de los nanotubos, o buscando un compromiso entre ambas. Todos los métodos de obtención de nanocompuestos de NTC intentan afrontar de forma directa los siguientes aspectos: ruptura de aglomerados, dispersión homogénea de los NTC en la matriz plástica, alineamiento de la carga e interacción interfacial.

La dispersión de los nanotubos de carbono en las matrices termoplásticas consiste en una secuencia simultánea de fases. En primer lugar se produce el mojado de los NTC por el polímero fundido. Durante este proceso se forman grandes aglomerados de NTC. El siguiente proceso asociado es la infiltración del polímero entre los NTC, haciendo que el aglomerado se expanda y se separen los nanotubos. El proceso de dispersión lleva asociado dos mecanismos diferenciados: la erosión de los aglomerados obteniendo nanotubos individuales y la ruptura de aglomerados por esfuerzos de cizalla. Por último, los nanotubos son distribuidos uniformemente en la matriz. La Figura 11 describe el proceso de dispersión de NTC de manera gráfica. 


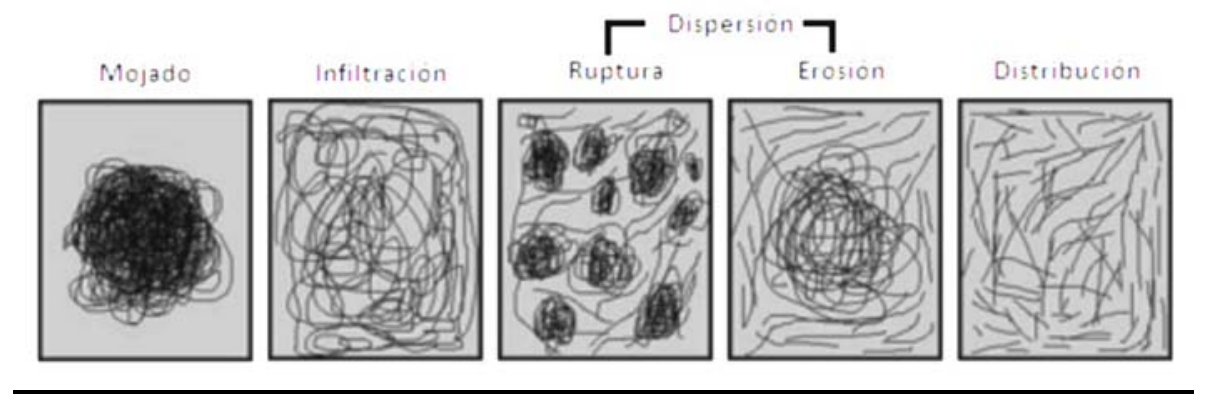

Figura 11. Mecanismo de dispersión de los $\mathrm{NTC}^{84}$

\section{C) Métodos de dispersión}

- Mezclado en fundido:

Consiste en el procesado de NTC con materiales termoplásticos en extrusor co-rotativa de doble husillo. El empleo de este tipo de extrusoras es fundamental para obtener una óptima dispersión de los NTC en la matriz polimérica. La principal ventaja de las extrusoras co-rotativas de doble husillo frente a las extrusoras monohusillo es el alto grado de cizalla que ejercen sobre el material. El grado de cizalla impartido por las extrusoras co-rotativas puede adaptarse a cada tipo de material cambiando los elementos que conforman los husillos. Esta versatilidad sólo puede conseguirse con este tipo de extrusoras.

Así pues, el mezclado en fundido consiste en la fusión del polímero y, una vez se tiene el polímero en forma de líquido viscoso en el interior de la extrusora, se añaden los NTC y se mezclan por medio de altas cizallas en equipos de compounding dando lugar a un producto intermedio en forma granular. Posteriormente, se obtiene la muestra final mediante moldeo por inyección, moldeo por compresión, o extrusión de perfilería, entre otros métodos. Es importante que las condiciones de procesado se optimicen para cada combinación de tipo de nanotubos y matriz plástica. Esto es debido a que la adición de los nanotubos modifica las propiedades del fundido como la viscosidad pudiendo darse efectos inesperados como la degradación del material. 
La principal ventaja de estos métodos frente al resto reside en su escalabilidad a procesos industriales existentes y la ausencia de contaminantes como disolventes o surfactantes, presentes en otras técnicas como el procesado en disolución o la polimerización in-situ.

\section{- Polimerización in-situ:}

Un método alternativo al procesado en fundido para la preparación de nanocompuestos con nanotubos de carbono consiste en el empleo de monómeros en vez de polímeros como material de partida.

La principal ventaja de este método radica en que permite el injerto de macromoléculas poliméricas en las paredes de los nanotubos de carbono. Esto proporciona una mayor facilidad de dispersión de los nanotubos así como una mejor interacción interfacial entre los nanotubos y la matriz polimérica. Además, esta técnica permite la adición de una gran cantidad de nanotubos de carbono ofreciendo buena miscibilidad casi con cualquier matriz polimérica. Esta técnica se emplea en aquellos polímeros insolubles o térmicamente inestables que no pueden ser procesados en disolución o fundido.

\section{- Procesado en Disolución:}

Este método consiste en mezclar ambos componentes en un disolvente adecuado para después evaporar el mismo y dar lugar a un film del material compuesto.

Uno de los principales beneficios de este método es que la agitación de los nanotubos disueltos facilita su dispersión y la ruptura de agregados. Normalmente, la agitación tiene lugar mediante uno o varios de los siguientes métodos: ultrasonidos (el más común), agitación magnética, mezcla por cizalla o reflujo. La agitación por ultrasonidos se lleva a cabo en un baño (media intensidad) o mediante una punta o sonotrodo introducido en la mezcla (alta intensidad). Un problema asociado a la mezcla vía ultrasonidos es la supuesta ruptura de los nanotubos reduciendo su relación de aspecto ${ }^{85}$.

Prácticamente todas las referencias bibliográficas acerca de este método de mezcla son variaciones del siguiente esquema de trabajo: dispersión de los nanotubos en un disolvente o en una disolución del polímero mediante 
agitación; mezcla de los nanotubos y el polímero en disolución por agitación; por último, evaporación controlada del disolvente dejando un film de material compuesto.

\section{D) Propiedades de los nanocompuestos de NTC obtenidos por mezclado en fundido}

El desarrollo de nanocompuestos ha supuesto un área de gran interés para los investigadores durante las dos últimas décadas. La búsqueda de compuestos con multifuncionalidades y bajo peso ha encaminado las investigaciones hacia la mejora de propiedades y optimización de los compuestos tradicionales. Tras la revisión bibliográfica se puede destacar como principales propiedades de los nanocompuestos de NTC las siguientes: propiedades eléctricas ${ }^{86,87,88,89}$, térmicas ${ }^{90,91,92}$ y mecánicas ${ }^{93,94,95,96}$.

La reducción del precio de los nanotubos de carbono, sobre todo los de pared múltiple, ha propiciado el desarrollo de aplicaciones a nivel industrial. Se ha estudiado la viabilidad de los nanocompuestos basados en NTC en aplicaciones tales como: apantallamiento electromagnético ${ }^{97}$, sensores ${ }^{98}$, disipación de carga electrostática ${ }^{99}$, retardante a la llama ${ }^{100}$ y cables conductores ${ }^{101}$.

\section{- Propiedades mecánicas de los nanocompuestos de NTC:}

Los nanotubos de carbono poseen unas propiedades mecánicas excepcionales, por lo que a priori deberían ser un buen refuerzo para matrices termoplásticas. Sin embargo, sus óptimas propiedades mecánicas no siempre se trasladan al compuesto termoplástico. Diferentes factores tienen una gran influencia en las propiedades mecánicas finales del nanocompuesto: la dispersión y distribución de los nanotubos en la matriz polimérica, la relación de aspecto de los NTC, la alineación y orientación de los NTC en la matriz y la naturaleza química de la interfase polímero-NTC.

La dispersión de los NTC juega un papel crucial a la hora de asegurar la transmisión de esfuerzos del nanotubo a la matriz. La presencia de aglomerados disminuye en gran medida la eficacia de los nanotubos como refuerzo. La facilidad de dispersión de los nanotubos en la matriz depende en gran medida de la naturaleza química del polímero. Algunos polímeros como 
el policarbonato $(\mathrm{PC})^{102}$, el polivinil alcohol $(\mathrm{PVOH})^{103}$ y la poliamida $(\mathrm{PA})^{104}$ han demostrado su mayor facilidad para obtener una buena dispersión de los NTC. Por el contrario, las poliolefinas son consideradas las matrices menos afines a los NTC debido a su carácter apolar, y por lo tanto, la obtención de una buena dispersión es mucho más complicada. Aun así, optimizando el procesado se han obtenido propiedades mecánicas mejoradas. Prashantha et al. ${ }^{105}$ consiguieron un aumento del módulo elástico y de la resistencia a tracción del polipropileno con un $1 \%$ de NTC, siendo la mejora de 1.27 y 1.18 veces, respectivamente. Castillo et al. ${ }^{106}$ no observaron ninguna mejora en las propiedades mecánicas de los sistemas policarbonato-nanotubos de carbono (PC-NTC) a pesar de conseguir una dispersión de alta calidad.

La interfase entre los nanotubos de carbono y el polímero es fundamental ya que a través de ella se transfieren los esfuerzos desde la nanopartícula a la matriz polimérica. Coleman et al. ${ }^{107}$ consiguieron un aumento significativo de las propiedades mecánicas del polipropileno añadiendo un $1 \%$ de nanotubos de carbono. En este experimental los nanotubos se anclaron químicamente al polipropileno clorado. Como resultado se obtuvo una módulo elástico 3.1 veces superior al polipropileno, una resistencia a la tracción 3.9 veces superior y un alargamiento a rotura mejorado en 4.4 veces. Yuan et al. ${ }^{108}$ también consiguió una mejora significativa de las propiedades del poliestireno (PS) mediante la funcionalización de los nanotubos de carbono, aumentando la resistencia al impacto en un $250 \%$ con un $0.32 \%$ de NTC.

La relación de aspecto de los nanotubos también es un factor determinante en la mejora de las propiedades mecánicas. Schafer et al. ${ }^{109}$ demostraron que la incorporación de nanotubos de poca longitud tiene poca influencia en el polímero de partida.

La orientación de los nanotubos durante el procesado mejora las propiedades mecánicas pero tiene un efecto negativo en las propiedades eléctricas ${ }^{110}$. En este experimental Villmov et al. estudiaron diferentes condiciones de procesado por moldeo por inyección, correlacionando la orientación de los nanotubos con las propiedades obtenidas.

Tras la revisión del estado del arte queda patente que las propiedades mecánicas teóricas que prometían los nanotubos de carbono están siendo difícilmente alcanzables. La obtención de nanotubos individuales 
perfectamente dispersados en la matriz polimérica es de gran dificultad con las técnicas de transformación de polímeros actuales. La presencia de aglomerados disminuye la efectividad de los nanotubos de carbono. Si se aplican altos niveles de cizalla durante la fabricación de los nanocompuestos se puede mejorar la dispersión, pero también puede ocurrir la rotura de los nanotubos, disminuyendo su relación de aspecto y su poder de refuerzo.

\section{- Propiedades eléctricas de los nanocompuestos de NTC:}

La propiedad más interesante de los nanocompuestos de NTC es la conductividad eléctrica. La principal ventaja de los NTC con respecto al negro de humo convencional es la obtención de buenas propiedades eléctricas con bajos porcentajes de carga. Así pues, se consigue buen comportamiento eléctrico sin comprometer las propiedades mecánicas y la densidad del compuesto.

El límite de percolación hace referencia al porcentaje de nanotubos de carbono a partir del cual el nanocompuesto pasa de ser aislante a ser conductor. Muchos autores han evaluado el límite de percolación de los NTC en diferentes matrices termoplásticas así como los factores con mayor influencia sobre la disminución del límite de percolación. Munson-McGee et al. ${ }^{111}$ concluyeron en sus estudios que la percolación podía pasar del $1 \%$ al $20 \%$ dependiendo de las condiciones de procesado, en relación a la dispersión y orientación alcanzada de los nanotubos. En la literatura se han encontrado límites de percolación muy diferentes, desde $0.0025 \%$ hasta el $15 \%$ de NTC. Esta variación tan grande se debe a que la percolación depende de:

- Naturaleza de la matriz polimérica ${ }^{112,113}$

- Tipo de nanotubos de carbono ${ }^{114}$

- Relación de aspecto ${ }^{115}$

- Procesado ${ }^{113}$

- Orientación, alineamiento y dispersión ${ }^{116,117}$ 


\section{- Propiedades térmicas de los nanocompuestos de NTC:}

La alta conductividad térmica de los nanotubos de carbono se debe a la vibración de los átomos o fonones, mientras que el aumento en la estabilidad térmica de los nanocompuestos se debe a que los electrones actúan como captadores de radicales ${ }^{118}$. Las mejoras esperadas con respecto a las propiedades térmicas no han sido alcanzadas según la revisión bibliográfica llevada a cabo. El transporte de fonones ocurre con mayor facilidad a través de la matriz polimérica por lo que no se alcanzan los valores deseados de conductividad térmica. La interfase entre polímero-NTC actúa como aislante de forma que dificulta la transmisión del calor. Los factores que más influyen en las propiedades térmicas de los nanocompuestos son la dispersión, la relación de aspecto y la funcionalización de los NTC ${ }^{119}$.

Sin embargo, los NTC sí que han demostrado su eficacia aumentando la estabilidad térmica de diferentes compuestos, ya que frena la producción de radicales libres durante la oxidación del polímero. Sathyanarayana et al. ${ }^{113}$ demostraron que un contenido de NTC del $2 \%$ incrementaba la resistencia térmica del poliestireno y polipropileno a la vez que aumentaba la temperatura de degradación de $300^{\circ} \mathrm{C}$ a $337^{\circ} \mathrm{C}$. El aumento del porcentaje de NTC no tuvo mayor efecto en la resistencia a la degradación térmica. Este efecto fue también estudiado de forma positiva en polipropileno por el mismo autor.

Los NTC actúan como nucleante en polímeros semicristalinos. El aumento de la temperatura de transición vítrea con bajos porcentajes de NTC ha sido también demostrado por autores como Sathyanarayana et al. ${ }^{113}$.

Otra de las propiedades destacables de los nanotubos de carbono es su capacidad de mejora de la resistencia al fuego cuando son mezclados con polímeros. Diversos artículos tratan de la incorporación de NTC a bajos niveles ( $<3 \%$ en peso) en diferentes resinas termoplásticas y observándose mejores propiedades de resistencia al fuego: $\mathrm{EVA}^{120}, \mathrm{PS}^{121}, \mathrm{PMMA}^{122}, \mathrm{PA}$ 6 ${ }^{123}$, LDPE $^{124}$, PE $^{125}$. 


\subsection{NANOCOMPUESTOS DE GRAFENO MULTICAPA (GMC)}

\section{A) Definición de grafeno}

El grafeno es una estructura alotrópica del carbono (hibridación $\mathrm{sp}^{2}$ ) formada por una lámina de un átomo de carbono de espesor en la que los átomos de carbono están unidos conformando una estructura de panal de abeja ${ }^{126,127}$. Esta disposición espacial bidimensional del grafeno hace que sea considerado como el constituyente básico de los materiales de carbono grafíticos. Fue descubierto en 2004 por los investigadores A.Geim y K. Novoselov de la Universidad de Manchester, los cuales fueron premiados en 2010 con el Premio Nobel de Física por su descubrimiento.

Una de las aplicaciones potenciales del grafeno es su incorporación en matrices poliméricas para la fabricación de nanocompuestos de grafeno con propiedades mecánicas, térmicas y eléctricas mejoradas.

\section{B) Nomenclatura}

Al realizar la búsqueda bibliográfica sobre nanocompuestos basados en grafeno se observó una gran variedad e inconsistencia en la nomenclatura utilizada para definir diferentes estados de la nanopartícula de grafeno. Con el objetivo de estandarizar la terminología empleada. A. Bianco et al. publicaron un artículo en la revista Carbon recogiendo las definiciones de las diferentes afecciones del grafeno ${ }^{128}$ :

1. Grafeno: El grafeno es un alótropo del carbono (hibridación $\mathrm{sp}^{2}$ ), cuya estructura está formada por una lámina de un átomo de carbono de espesor en la que los átomos de carbono están unidos conformando una estructura de panal de abeja

2. Grafeno multicapa-GMC (Multilayer graphene-MLG): material de 2 dimensiones conformado por un número de capas de grafeno que varía entre 2 - 10 capas.

3. Grafeno de pocas capas (Few Layer Graphene - FLG): es una subclasificación del grafeno multicapa con un número más reducido de capas de grafeno, entre $2-5$ capas.

4. Nanoláminas de grafito (Graphite nanoplates - GnPs, graphite nanoflakes or graphite nanosheets): grafitos de 2 dimensiones con un espesor $<100 \mathrm{~nm}$. 
5. Grafito exfoliado: es un grafito de 3 dimensiones. Esta definición se solapa o superpone con otras definiciones ya que ésta hace referencia al método de fabricación más que a la estructura de la partícula.

6. Nanolámina de grafeno (Graphene nanosheet): es un grafeno adherido a otra superficie y cuyas dimensiones del plano $x-y$ es inferior a $100 \mathrm{~nm}$.

7. Microlámina de grafeno (Graphene microsheet): es un grafeno adherido a otra superficie y cuyas dimensiones del plano $x-y$ tiene unas dimensiones entre $100 \mathrm{~nm}-100 \mu \mathrm{m}$.

8. Óxido de grafeno (Graphene oxide - GO): grafeno químicamente modificado preparado por oxidación y exfoliación, resultando en un alto contenido de oxígeno. C/O ratios entre 3 y 2.

9. Óxido de grafito (Graphite oxide - GO): grafito oxidado mediante procesos que funcionalizan los planos basales e incrementan la distancia entre láminas. Este óxido de grafito puede ser exfoliado para obtener óxido de grafeno.

10. Óxido de grafeno reducido (rGO): óxido de grafeno que ha sido reducido por métodos químicos, térmicos, fotoquímicos, fototérmicos o métodos microbiológicos para reducir el contenido en oxígeno.

\section{C) Producción de grafeno}

El grafeno puede producirse empleando diferentes metodologías. El método de producción marcará la calidad de grafeno a obtener, la cantidad y, por lo tanto, su precio. Las metodologías se clasifican en dos grandes grupos:

- Método "Top-down" o de producción descendente en el que se obtienen estructuras pequeñas a partir de otras más grandes.

- Método "Botton-up" o de producción ascendente en el que la lámina de grafeno se obtiene a partir de pequeñas moléculas en estado gaseoso.

\section{- Método "Top-down":}

Los métodos Top-down hacen referencia a procesos de exfoliación del grafito: exfoliación mecánica, fase líquida y fotoexfoliación. 
El primer método empleado por Novoselov y Geim consistía en la exfoliación mecánica de gratito pirolítico mediante una cinta adhesiva para obtener láminas de grafeno. Con este método se pueden obtienen láminas de grafeno de alta calidad pero no puede ser reproducido a nivel industrial, quedando su empleo limitado al laboratorio.

La exfoliación en fase líquida es una alternativa a la exfoliación mecánica. Este método se basa en aumentar la distancia entre las capas del grafito, produciendo un grafito expandido y así poder separar las capas de grafeno con mayor facilidad. Se suelen emplear ultrasonidos para conseguir la separación de las capas. Se intercalan surfactantes o polímeros de bajo peso molecular entre las capas de grafito para favorecer la expansión de las capas. El inconveniente es que se requieren altos tiempos de ultrasonidos y las láminas de grafeno obtenidas son de pequeño tamaño. Sin embargo, si se parte de grafito oxidado, el tiempo de ultrasonidos se reduce, obteniendo un proceso de gran rendimiento y escalable a nivel industrial. El óxido de grafito tiene una distancia interlaminar mayor y se disuelve en agua con mayor facilidad, lo que mejora la exfoliación del mismo. Posteriormente, se puede emplear el óxido de grafeno o reducirlo para aplicaciones electrónicas. La reducción se lleva a cabo por métodos químicos o térmicos. Este método es el más empleado en la actualidad a nivel industrial y más adecuado para la elaboración de nanocompuestos poliméricos.

Existe un nuevo método en desarrollo que consiste en la exfoliación directa del grafito sin expansión previa mediante el empleo de disolventes y ultrasonidos $^{129}$. Este método fue inicialmente desarrollado por el Profesor Coleman del Trinity College de Dublin empleando una batidora. Con este método se obtienen grafenos en grandes cantidades a una calidad y precio razonables.

El siguiente método a destacar es el de unión anódica. Este método consiste en unir el grafito a un vidrio y aplicar un alto voltaje. Se obtiene un campo eléctrico muy intenso en la interfase de ambos materiales, consiguiendo que las láminas de grafeno se peguen al vidrio por interacción electrostática.

La fotoexfoliación consiste en aplicar un pulso láser sobre un grafito causando su exfoliación. Es clave llevar a cabo el proceso en vacío para 
evitar la oxidación del grafeno y controlar la potencia láser para no dañar las láminas.

Existen varios métodos para obtener grafeno a partir de nanotubos de carbono ${ }^{130,131}$. La calidad obtenida por esta metodología es mucho peor que la obtenida con los métodos basados en la exfoliación del grafito. Esto se debe al gran número de defectos que aparecen en los bordes de la lámina que ha sido atacada químicamente para romper los enlaces $C$-C. También es muy difícil controlar el tamaño del grafeno obtenido.

\section{- Método "Botton-up":}

Los métodos Botton-up engloban cuatro técnicas diferentes: descomposición térmica del carburo de silicio, crecimiento molecular o síntesis química, deposición química en fase vapor o método CVD (chemical vapour deposition) y método de crecimiento epitaxial ${ }^{132}$.

La descomposición térmica de carburo de silicio consiste en el tratamiento térmico de los cristales de silicio de forma que se produzca la eliminación por evaporación de los átomos de silicio. De esta forma los átomos de carbono se reorganizan obteniendo láminas de grafeno. El principal inconveniente es la separación de las láminas y su transferencia a otros sustratos. Por este motivo este método no se produce a nivel industrial.

Los métodos de crecimiento molecular consisten en el control de la síntesis de grafeno a partir de pequeñas moléculas orgánicas como el benceno. El método de deposición química en fase vapor se basa en la descomposición química de hidrocarburos sobre un sustrato metálico, como el cobre o el níquel, a alta temperatura. Los átomos de carbono que se obtienen durante la descomposición se reorganizan sobre el sustrato formando una lámina de grafeno. Este método se emplea a nivel industrial porque, aunque la deposición sea lenta, se obtienen láminas de gran tamaño y excelente calidad.

El método epitaxial consiste en el crecimiento de átomos de carbono por haces moleculares sobre un sustrato aislante de carburo de silicio o alúmina. 


\section{D) Propiedades clave del grafeno}

Se pueden definir tres propiedades clave de las nanopartículas de grafeno que tendrán un gran impacto en las propiedades finales del compuesto polimérico. Estas propiedades son ${ }^{133}$ :

1. Diámetro medio (tamaño del plano $x-y$, ver Figura 12 )

2. Espesor medio (número de capas o z, ver Figura 12 )

3. Número de defectos

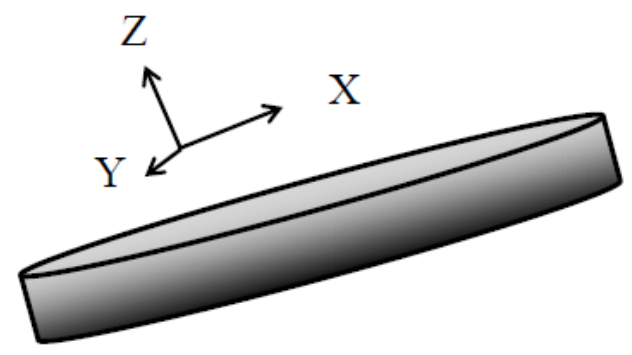

Figura 12. Representación esquemática de las láminas de grafeno

\section{1.- Diámetro medio}

El diámetro medio de una partícula de grafeno se define como la media estadística del tamaño del plano XY proyectado y medido con técnicas de microscopía, tales como microscopía óptica, microscopía electrónica de barrido y microscopía de fuerza atómica.

El diámetro medio juega un papel muy importante en las propiedades del nanocompuesto. Tras la revisión bibliográfica se observan las siguientes tendencias:

- Diámetros pequeños de lámina aumentarán el límite de percolación eléctrica, según los modelos teóricos ${ }^{126}$, aunque algunos autores como Sanjib Biswas et al. obtuvieron resultados contradictorios ${ }^{134}$.

- Diámetros pequeños producirán un efecto positivo en la mejora de las propiedades mecánicas.

- El límite de tamaño para considerar un diámetro de partícula pequeño se encuentra entre $100 \mathrm{~nm}$ y $0.1 \mu \mathrm{m}$.

- Los diámetros intermedios muestran un comportamiento balanceado entre buenas propiedades eléctricas y mecánicas. 


\section{2.- Número de capas o espesor}

Se ha demostrado que las propiedades eléctricas del grafeno multicapa se ven influenciadas en gran medida por el número de capas ${ }^{135}$, mejorando las propiedades eléctricas de los nanocompuestos cuanto menor es el número de capas. Teóricamente una lámina de grafeno tiene un espesor de $0.34 \mathrm{~nm}$. Tomando este valor como referencia, se podría averiguar el número de capas de grafeno midiendo el espesor con técnicas de microscopía.

\section{3.- Número de defectos (ruta química)}

Resulta muy difícil sintetizar una estructura hexagonal perfecta por el proceso de síntesis en sí mismo. Estos defectos se pueden clasificar en:

- Defectos en la estructura del átomo de carbono: Se produce cuando el grafeno se obtiene por la oxidación y reducción química del grafito. La introducción de oxígeno hace que el carbono participe en enlaces sencillos (hibridación $\mathrm{sp}^{3}$ ), reduciendo sus propiedades eléctricas.

- Formación de arrugas: Se producen cuando se aplican tratamientos térmicos a temperaturas por debajo de $2000^{\circ} \mathrm{C}$ en el proceso de reducción. Este defecto se puede solucionar si se aplica una temperatura superior a $2000^{\circ} \mathrm{C}$.

\section{E) Propiedades de los nanocompuestos de GMC}

El grafeno fue seleccionado como refuerzo de matrices poliméricas debido a sus extraordinarias propiedades eléctricas, térmicas y mecánicas. El número de publicaciones referentes al desarrollo de nanocompuestos basados en grafeno no deja de crecer con los años siendo numerosos los investigadores que estudian cómo optimizar las propiedades de los nanocompuestos. Se busca como objetivo obtener nanocomposites multifuncionales de baja densidad. Como se comentó en puntos anteriores se observó una inconsistencia en la nomenclatura del grafeno entre la bibliografía revisada. A continuación se revisarán las principales propiedades de los nanocompuestos atendiendo a todo tipo de nomenclatura del grafeno. 


\section{- Propiedades mecánicas de los nanocompuestos de GMC:}

Se ha observado una mejora de las propiedades de los nanocompuestos de grafeno respecto otras cargas como los nanotubos de carbono ${ }^{136}$, siendo este efecto mucho más acusado en polímeros elastoméricos. Se ha demostrado la eficacia del grafeno en la mejora del módulo elástico en polímeros amorfos, tales como el $\mathrm{PMMA}^{137}$ y PC ${ }^{138}$. Se obtuvo una mejora del módulo elástico del $33 \%$ ( $0.01 \%$ de contenido de grafeno) y $50 \%$ (3\% de contenido de grafeno), respectivamente. Kim et al. ${ }^{139}$ demostró la influencia del procesado en las propiedades finales del nanocompuesto, consiguiendo mejores propiedades mecánicas con aquellos nanocompuestos procesados por disolución en comparación con los obtenidos por mezclado en fundido. Este se atribuyó a la reaglomeración del grafeno durante el procesado por mezcla en fundido debido al flujo elongacional asociado al proceso de extrusión.

Cabe destacar que el aumento de la rigidez de los nanocompuestos basados en grafeno no supone un deterioro de la resistencia a impacto tan acusadas como con otros refuerzos. Das et al. ${ }^{140}$ demostraron estas propiedades tanto en PVA como en PMMA.

\section{- Propiedades térmicas de los nanocompuestos de GMC:}

La conductividad térmica del grafeno puede que sea en la actualidad su propiedad más destacada. Su utilidad en diferentes aplicaciones ha sido demostrada por varios autores: nanocomponentes electrónicos ${ }^{141}$, pastas térmicas ${ }^{142}$ y polímeros con memoria de forma ${ }^{143}$. Se ha demostrado la mayor eficacia de las partículas de grafeno comparando con los nanotubos de carbono. Aun así, los valores obtenidos son mucho menores a los calculados teóricamente. Como se ha expuesto anteriormente, la energía térmica se transfiere por vibraciones atómicas o fonones. La interfase entre polímerografeno vuelve ser la clave para la baja transmisión de calor entre ambos materiales $^{144}$.

Diferentes estudios demuestran la efectividad del grafeno aumentando la conductividad térmica de varios polímeros: $\mathrm{PP}^{145}, \mathrm{PE}^{146}, \mathrm{PA}^{146}$ y cera parafínica $^{147}$. 


\section{- Propiedades eléctricas de los nanocompuestos de GMC:}

La conductividad eléctrica es una de las propiedades más destacables de los nanocompuestos de GMC pudiendo obtener compuestos con propiedades semiconductoras con bajos porcentajes de adición ${ }^{148}$. Sin embargo, la teoría no siempre es fácil trasladarla a la morfología real del nanocompuestos, siendo la relación de aspecto y la orientación de las nanopartículas de GMC clave para la obtención de una conductividad eléctrica óptima.

Tras la revisión bibliográfica se encontraron muchos estudios en referencia a la conductividad eléctrica de nanocompuestos de GMC obtenidos en mezclado en fundido. Centrando la atención en los nanocompuestos basados en polipropileno, los mejores resultados de conductividad eléctrica fueron obtenidos por Kalaitzidoy et al ${ }^{149}$, alcanzando los $10^{-3} \mathrm{~S} / \mathrm{cm}$ con la adición de un $25 \%$ en peso de GMC. Un orden de magnitud inferior consiguió Wakabayashi et al. ${ }^{150}$ con menor porcentaje de GMC (4\%). La diferencia entre ambos estudios es que Wakabayashi et al. premezcló el grafeno con polipropileno en polvo y alimentó la mezcla de polvos previamente predispersada. 


\section{CAPÍTULO 3: MATERIALES Y MÉTODOS}

\subsection{MATERIALES}

\subsubsection{Nanotubos de carbono}

Como susceptor microondas se emplearon nanotubos de carbon (NTC) de la empresa belga Nanocyl. Estos nanotubos multicapa se producen por el deposición química de carbono (chemical vapour deposition-CVD). La Tabla 4 recoge las principales propiedades de los nanotubos NANOCYL NC 7000.

Tabla 4: Propiedades de los nanotubos multicapa Nanocyl NC7000 (valores suministrados por Nanocyl)

\begin{tabular}{|l|c|}
\hline \multicolumn{1}{|c|}{ Propiedad } & Valor \\
\hline Diámetro medio & $9.5 \mathrm{~nm}$ \\
\hline Longitud media & $1.5 \mu \mathrm{m}$ \\
\hline Pureza & $90 \%$ \\
\hline Relación de aspecto & 158 \\
\hline BET (Superficie específica) & $250-300 \mathrm{~m}^{2} / \mathrm{g}$ \\
\hline Densidad aparente & $0.07 \mathrm{~g} / \mathrm{l}$ \\
\hline
\end{tabular}

En la Figura 13 se muestra es espectro Raman de los NTC empleados en el experimental. El ensayo se realizó según el procedimiento descrito en el apartado 3.2.2.9. En el espectro se observan las bandas típicas de los NTC según la revisión bibliográfica ${ }^{151}$. La posición e intensidad de las bandas confirman que se trata de nanotubos de carbono de múltiple pared (MWCNT) mostrando su carácter grafítico en los picos:

- Banda G - $1580 \mathrm{~cm}^{-1}$ : hace referencia a la vibración del enlace C-C en el plano 
- Banda D - $1342 \mathrm{~cm}^{-1}$ : hace referencia a los defectos en sistemas de carbon.

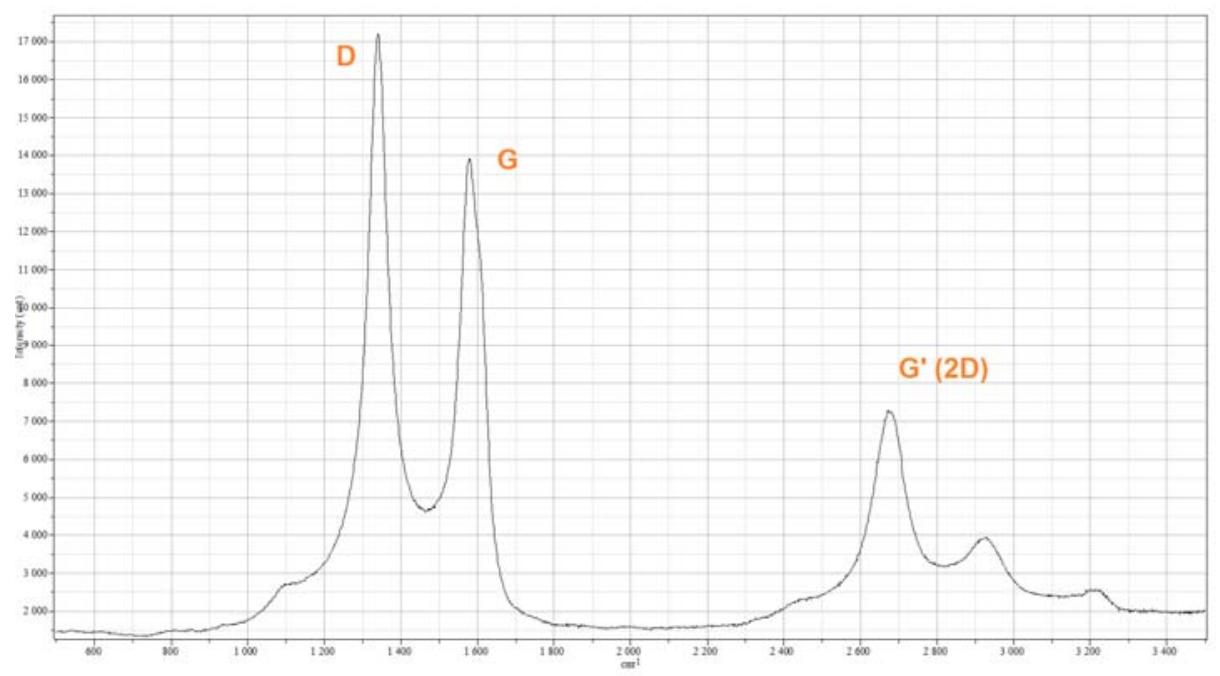

Figura 13. Espectro Raman de los NTC Nanocyl NC7000

\subsubsection{Grafeno multicapa}

El grafeno multicapa fue adquirido a través de la empresa americana XGScience pionera en la producción de grafeno a nivel industrial. El grado empleado en este estudio ha sido el $x G n P$-grade $5 \mathrm{M}$, con un diámetro medio de $5 \mu \mathrm{m}$, el cual según datos del fabricante representa el mejor grado comercial para propiedades eléctricas y térmicas. La Tabla 5 recopila las propiedades suministradas por XGScience. La empresa comercializa dicho grado de grafeno en polvo como nanoláminas de grafeno formadas por un número bajo de capas con un espesor de 6-8 nm. El espectro Raman aportado en la ficha técnica no es similar al obtenido en la presente Tesis doctoral. Tal y como se muestra en la Figura 14. 
Tabla 5: Propiedades del grafeno multicapa XGScience (xGnP-grade 5M)

\begin{tabular}{|l|c|}
\hline \multicolumn{1}{|c|}{ Propiedad } & Valor \\
\hline Contenido en carbono & $>99.5 \%$ \\
\hline Contenido en oxígeno & $<1 \%$ \\
\hline Densidad aparente & $0.1 \mathrm{~g} / \mathrm{l}$ \\
\hline Diámetro medio (plano $x-y)$ & $5 \mu \mathrm{m}$ \\
\hline BET (Superficie específica) & $120-150 \mathrm{~m}^{2} / \mathrm{g}$ \\
\hline
\end{tabular}

La Figura 14 muestra el espectro Raman del GMC cGnP-5M de XGScience. La intensidad de la banda $G$ del espectro muestra el carácter grafítico del GMC empleado. La banda 2D hace referencia al número de capas. A mayor intensidad del mico $G$ y $2 D$, mayor número de capas tiene el grafeno. Además, la anchura del pico 2D indica que el número de capas es muy elevado. Por lo tanto se corrobora que el grafeno empleado en el estudio es un grafeno conformado por varias capas. Se observa que el grafo de GMC empleado tiene defectos en su estructura que pueden afectar a sus propiedades finales (Banda D).

En la misma Figura 14 se muestra en la esquina superior el espectro Raman suministrado por XGScience en su ficha técnica. Se puede afirmar que la muestra de grafeno recibida como XGScience Grade M5 no cumple con las características especificadas en la ficha técnica comercial. 


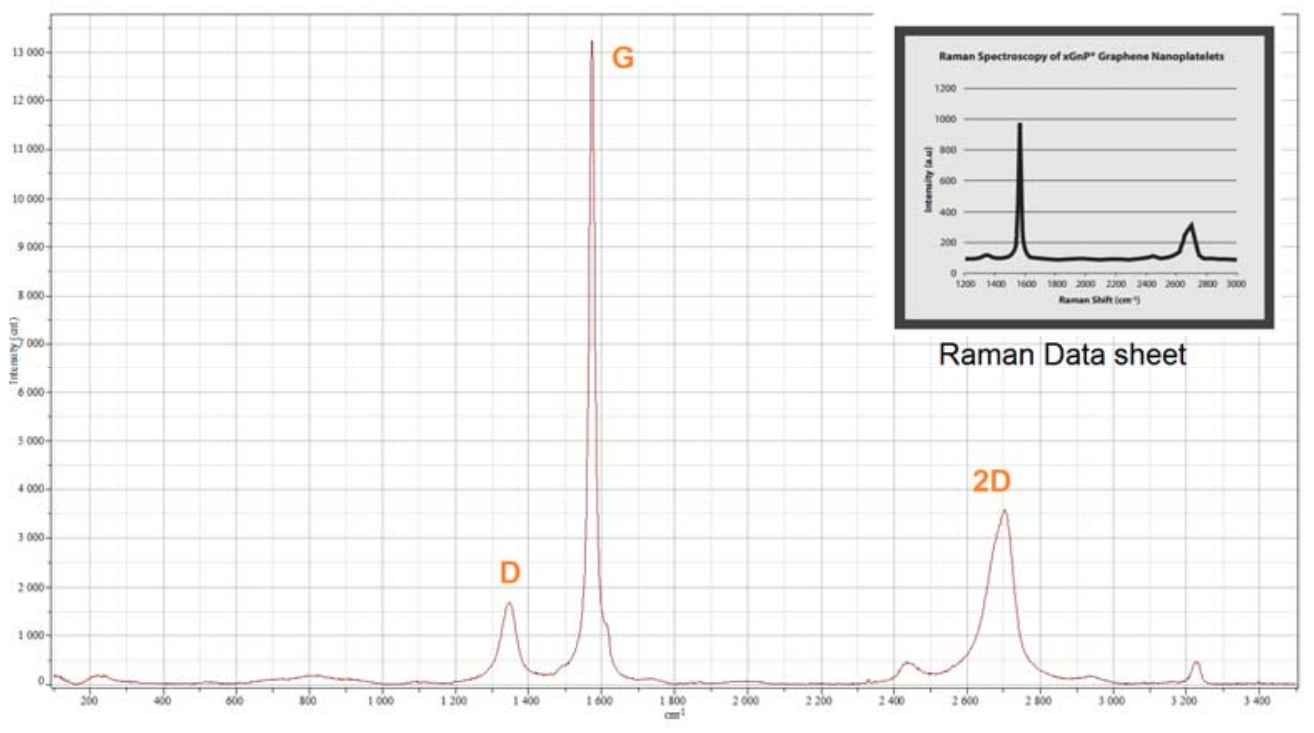

Figura 14. Espectro Raman del GMC xGnP-grade 5M

\subsubsection{Polipropileno}

El polímero utilizado en este trabajo ha sido un polipropileno homopolímero (PP) de la empresa DUCOR Petrochemicals. Se seleccionó el grado PP DUCOR $1101 \mathrm{~S}$ con un índice de fluidez de $25 \mathrm{~g} / 10 \mathrm{~min}\left(230^{\circ} \mathrm{C} / 2.16 \mathrm{~kg}\right)$, un módulo elástico de $1500 \mathrm{MPa}$ y una temperatura de fundido de $163^{\circ} \mathrm{C}$. La Tabla 6 muestra sus principales propiedades. El polipropileno se seleccionó por ser apolar y tener una baja interacción con la radiación microondas. Además, su carácter apolar reduce su afinidad química con las nanocargas carbonosas, haciendo mucho más complicada la correcta dispersión de las mismas en la matriz polimérica. De esta forma buscaríamos la mejora de la situación más desfavorable posible en lo que se refiere a dispersión y a interacción con la radiación microondas. Por último, hay que mencionar que el polipropileno es uno de los polímeros de mayor empleo en la industria plástica. 
Tabla 6: Propiedades del polipropileno PP DUCOR $1101 \mathrm{~S}$

\begin{tabular}{|l|c|}
\hline \multicolumn{1}{|c|}{ Propiedad } & Valor \\
\hline Índice de fluidez & $25 \mathrm{~g} / 10 \mathrm{~min}\left(230^{\circ} \mathrm{C} / 2.16 \mathrm{~kg}\right)$ \\
\hline Temperatura de fusión & $163^{\circ} \mathrm{C}$ \\
\hline Módulo elástico $(\mathrm{v}=1 \mathrm{~mm} / \mathrm{min})$ & $1500 \mathrm{MPa}$ \\
\hline Resistencia a la tracción $(\mathrm{v}=50 \mathrm{~mm} / \mathrm{min})$ & $35 \mathrm{MPa}$ \\
\hline Alargamiento a rotura $(\mathrm{v}=50 \mathrm{~mm} / \mathrm{min})$ & $>50 \%$ \\
\hline $\begin{array}{l}\text { Resistencia al impacto Charpy (con } \\
\left.\text { entalla, } 23^{\circ} \mathrm{C}\right)\end{array}$ & $2.5 \mathrm{~kJ} / \mathrm{m}^{2}$ \\
\hline Densidad & $0.91\left(\mathrm{~g} / \mathrm{cm}^{3}\right)$ \\
\hline
\end{tabular}




\subsection{MÉTODOS Y TÉCNICAS INSTRUMENTALES}

\subsubsection{Procesado de Nanocompuestos}

\subsubsection{Equipamiento}

A) LINEA DE COMPOUNDING: OBTENCIÓN DE NANOCOMPUESTOS

Se empleó una extrusora de doble husillo co-rotativa Werner \& Pfleiderer, modelo ZSK25 del grupo Coperion, con alimentador lateral ZSB25. Esta extrusora se caracteriza por tener un diámetro de husillo de $25 \mathrm{~mm}$, una relación longitud-diámetro de $40 \quad(\mathrm{~L} / \mathrm{D}=40)$ y una relación diámetro externo/diámetro interno de 1.55 . El procesado requirió del siguiente equipamiento periférico para completar la línea de extrusión:

- Dosificadores:

o Dosificador gravimétrico Brabender para la dosificación de la granza.

o Dosificador gravimétrico KTron KT20 para la dosificación de la nanocarga

- Baño de enfriamiento IPS con recirculación de agua

- Granceadora IPS-SG-E 60

Se diseñaron dos tipos de configuración de husillo:

- Alta cizalla: compuesto por un elevado número de elementos de amasado dispersivos caracterizados por tener un filete ancho y un ángulo entre filetes de $90^{\circ}$ (ver Figura 15).

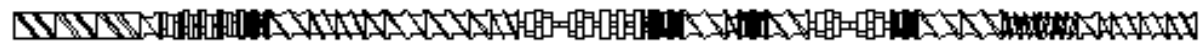

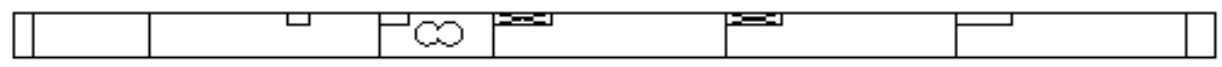

Figura 15. Configuración de husillo de alta cizalla 
- Baja cizalla: a diferencia del husillo anterior se caracteriza por estar compuesto por elementos de amasado distributivos con filete estrecho y ángulos de $30^{\circ}$ (ver Figura 16).

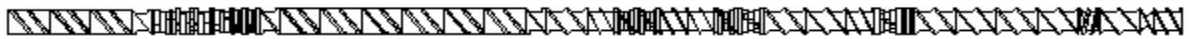

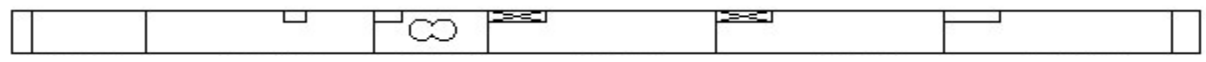

Figura 16. Configuración de husillo de baja cizalla

\section{B) MOLDEO POR COMPRESIÓN: OBTENCIÓN DE PROBETAS}

Se prepararon probetas por moldeo por compresión empleando una prensa de platos calientes del fabricante Collin (modelo P 200 E). Se obtuvieron probetas de diferentes geometrías dependiendo del ensayo a realizar. En particular, las probetas obtenidas fueron empleadas para el análisis morfológico, medida de las propiedades dieléctricas y eléctricas, y análisis de las propiedades mecánicas. La Tabla 7 recoge las condiciones de presión, tiempo y temperatura aplicadas en la producción de todas las muestras o probetas.

Tabla 7: Condiciones de procesado para la obtención de probetas

\begin{tabular}{|c|c|c|c|c|c|}
\hline & ciclo1 & ciclo2 & ciclo3 & ciclo4 & ciclo5 \\
\hline Tiempo (min) & 4 & 1 & 1 & 2 & 12 \\
\hline Presión (bar) & 4 & 75 & 30 & 150 & 70 \\
\cline { 1 - 3 } & Plato superior & Plato inferior & \multicolumn{1}{|l}{} \\
\cline { 1 - 3 } Temperatura $\left({ }^{\circ} \mathrm{C}\right)$ & 200 & 200 &
\end{tabular}




\subsubsection{Diseño de experimentos}

Se propone un diseño de experimentos aplicado al proceso de obtención de los diferentes nanocompuestos con la finalidad de analizar la influencia de los principales parámetros de procesado en la distribución y dispersión de las nanocargas - nanotubos de carbono y del grafeno multicapa — en la matriz polimérica. Como ya se ha expuesto en el Capítulo 2, cuanto más homogénea sea la dispersión de la carga en el seno de la matriz polimérica, mejores serán las propiedades que dicha carga confiera al compuesto. Esto se debe a que la buena dispersión permite disponer de las nanopartículas aisladas en la matriz polimérica, sin presencia de aglomerados, y de ese modo se evitaría que las nanopartículas se comportasen como cargas micrométricas disminuyendo su efectividad.

Se planteó un diseño de experimentos multifactorial categórico con el software análisis estadístico Statgraphics@ $\bigcirc$. El objetivo de este diseño de experimentos consiste en estudiar cómo influyen las condiciones de procesado en la dispersión de las nanopartículas, ya que será clave para obtener un calentamiento homogéneo bajo radiación microondas. Los factores definidos en el diseño de experimentos, sus diferentes niveles y las variables respuesta se recogen en la Tabla 8.

Tabla 8: Diseño de experimentos

\begin{tabular}{|c|c|c|}
\hline Factores & Niveles & Respuestas \\
\hline \multirow{2}{*}{ Metodología } & Masterbatch (MB) & \multirow{5}{*}{ Densidad de aglomerados (\%) } \\
\hline & Compuesto directo (CD) & \\
\hline \multirow{2}{*}{$\begin{array}{l}\text { Configuración de } \\
\text { husillo }\end{array}$} & Baja cizalla (BC) & \\
\hline & Alta cizalla (AC) & \\
\hline \multirow{4}{*}{$\begin{array}{l}\text { Velocidad de la } \\
\text { extrusora }\end{array}$} & $100 \mathrm{rpm}$ & \\
\hline & 300 rpm & \multirow{3}{*}{$\begin{array}{l}\text { Tamaño medio de las partículas } \\
\qquad(\mu \mathrm{m})\end{array}$} \\
\hline & 800 rpm & \\
\hline & 1200 rpm & \\
\hline
\end{tabular}


La selección de estos factores se realizó con el fin de evaluar dos parámetros: la energía mecánica i cizalla impartida al material durante la extrusión y el tiempo de residencia de las nanopartículas en la extrusora, es decir, el tiempo que el material está sometido a esos diferentes grados de cizalla. La cizalla está englobada por el tipo de configuración de husillo y la velocidad de extrusión. El tiempo de residencia vendrá determinado por el la forma en la que se incorporan las nanopartículas. En la incorporación en polvo, o compuesto directo, las nanopartículas están sometidas a un solo proceso de extrusión. En el caso de la introducción en forma de masterbatch, las nanoparticulas soportan dos procesos de mezcla. La Figura 17 es un esquema de los factores a analizar en el diseño de experimentos.

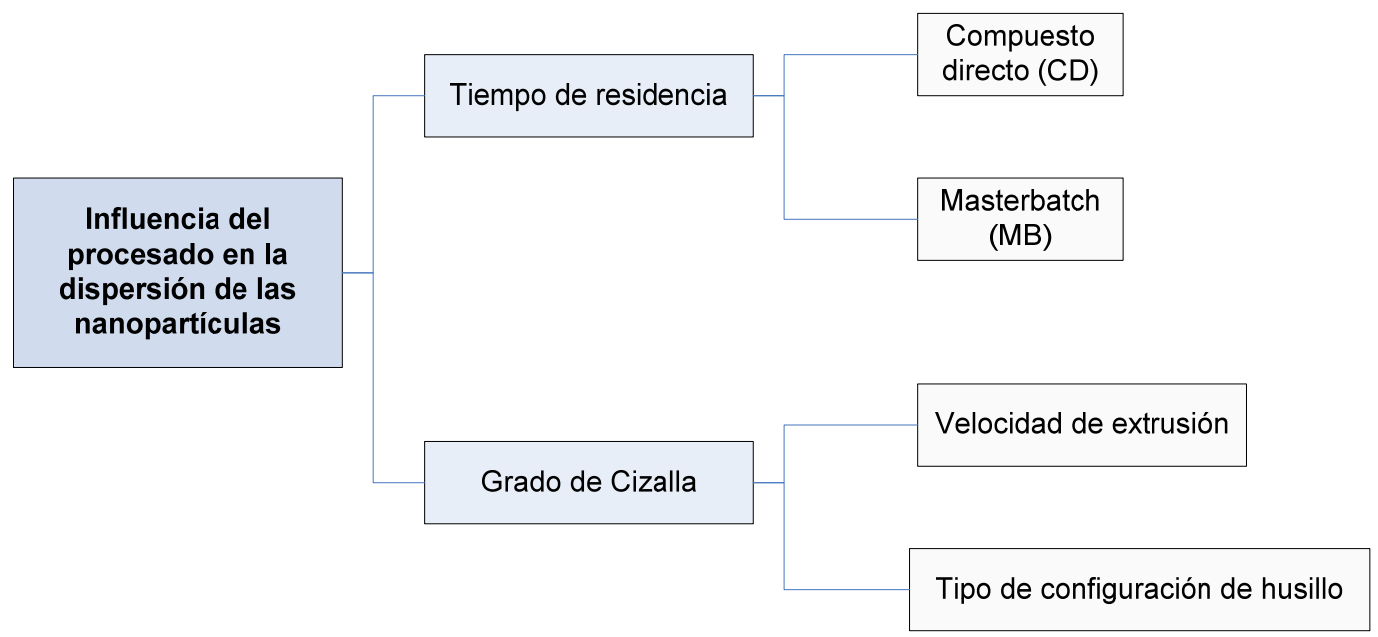

Figura 17. Descripción de las condiciones de procesado objeto de estudio

En todo el experimental se mantuvieron constantes los siguientes parámetros de procesado:

- Perfil de temperaturas: $230^{\circ} \mathrm{C} / 220^{\circ} \mathrm{C} / 220^{\circ} \mathrm{C} / 210^{\circ} \mathrm{C} / 200^{\circ} \mathrm{C} / 190^{\circ} \mathrm{C}$

- Producción: 6 kg/h

El porcentaje de nanotubos de carbono y del grafeno multicapa se mantuvo en un $1 \%$ en todos los compuestos obtenidos con el fin de poder estudiar la dispersión por técnicas de microscopía óptica y electrónica. Se escogió un porcentaje bajo de nanopartícula, ya que en nanocompuestos con 
elevados porcentajes se observan aglomerados independientemente de las condiciones de extrusión debido a la densidad aparente de las mismas.

\subsubsection{Muestras obtenidas - Codificación}

\section{A) Estudio de la influencia del procesado}

Con el diseño de experimentos detallado en el apartado anterior se obtuvieron las muestras descritas en la Tabla 9 y Tabla 10. La Figura 18 describe la codificación empleada para nombrar las muestras. En la codificación $B$ hace referencia al número de muestra obtenido en Statgraphics, $A C / B C$ describe la configuración de husillo (alta o baja cizalla), a continuación se detalla la velocidad de extrusión y la metodología (incorporación en polvo (CD) e incorporación en masterbatch (MB). Por último se hace referencia a si el nanocompuesto contiene grafeno multicapa (G) o nanotubos de carbono (NT).

Se emplearon dos metodologías de trabajo para obtener las muestras: Compuesto directo y Masterbatch. La primera hace referencia a la introducción de la nanopartícula en forma de polvo en la tolva de alimentación de la extrusora junto con la granza de polímero. La segunda hace referencia a la alimentación de las nanopartículas en forma de un masterbatch o concentrado. La diferencia entre ambas metodologías es el tiempo de residencia del material en la extrusora y, por lo tanto, el tiempo que el material está sometido a cizalla. En el compuesto directo las nanopartículas sufren un proceso de extrusión (1 etapa) y en el masterbatch se someten a dos procesados (2 etapas).

El masterbatch se produjo con las siguientes condiciones de procesado:

- $15 \%$ de GMC o NTC: los masterbatch comerciales de nanopartículas suelen contener entre un 15 ó $20 \%$ en peso de nanopartícula. Normalmente se diluyen a bajos porcentajes por que se obtener un masterbatch con un contenido mayor daría lugar a factores de dilución muy altos. Por otro lado, la baja 
densidad aparente de las nanopartículas dificulta el obtener concentrados de mayor porcentaje.

- Configuración de husillo de alta cizalla (Figura 15)

- $600 \mathrm{rpm}$

- Perfil de temperaturas: $230^{\circ} \mathrm{C} / 220^{\circ} \mathrm{C} / 220^{\circ} \mathrm{C} / 210^{\circ} \mathrm{C} / 200^{\circ} \mathrm{C} / 190^{\circ} \mathrm{C}$

- Producción: 6 kg/h

Las condiciones de procesado del masterbatch se seleccionaron aplicando una configuración de husillo de alta cizalla y una velocidad de extrusión media-alta. Se consideraron unas condiciones de cizalla intermedia ya que antes de la preparación de las muestras no se conocían las condiciones de procesado óptimas.

Tabla 9: Compuestos obtenidos para el estudio de la dispersión del grafeno multicapa

\begin{tabular}{|c|c|c|c|c|}
\hline BLOQUE & conf_husillo & $\mathbf{r p m}$ & metodología & CÓ́DIGO MUESTRA \\
\hline 1 & alta cizalla & 100 & compound directo & B1-AC100-CD-G \\
\hline 2 & alta cizalla & 300 & compound directo & B2-AC300-CD-G \\
\hline 3 & alta cizalla & 600 & compound directo & B3-AC600-CD-G \\
\hline 4 & alta cizalla & 800 & compound directo & B4-AC800-CD-G \\
\hline 5 & alta cizalla & 100 & masterbatch & B5-AC100-MB-G \\
\hline 6 & alta cizalla & 300 & masterbatch & B6-AC300-MB-G \\
\hline 7 & alta cizalla & 600 & masterbatch & B7-AC600-MB-G \\
\hline 8 & alta cizalla & 800 & masterbatch & B8-AC800-MB-G \\
\hline 9 & baja cizalla & 100 & compound directo & B9-BC100-CD-G \\
\hline 10 & baja cizalla & 300 & compound directo & B10-BC300-CD-G \\
\hline 11 & baja cizalla & 600 & compound directo & B11-BC600-CD-G \\
\hline 12 & baja cizalla & 800 & compound directo & B12-BC800-CD-G \\
\hline 13 & baja cizalla & 100 & masterbatch & B13-BC100-MB-G \\
\hline 14 & baja cizalla & 300 & masterbatch & B14-BC300-MB-G \\
\hline 15 & baja cizalla & 600 & masterbatch & B15-BC600-MB-G \\
\hline 16 & baja cizalla & 800 & masterbatch & B16-BC800-MB-G \\
\hline
\end{tabular}


Tabla 10: Compuestos obtenidos para el estudio de la dispersión de los nanotubos de carbono

\begin{tabular}{|c|c|c|c|c|}
\hline BLOQUE & conf_husillo & rpm & metodología & CÓDIGO MUESTRA \\
\hline 17 & alta cizalla & 100 & compound directo & B17-AC100-CD-NT \\
\hline 18 & alta cizalla & 300 & compound directo & B18-AC300-CD-NT \\
\hline 19 & alta cizalla & 600 & compound directo & B19-AC600-CD-NT \\
\hline 20 & alta cizalla & 800 & compound directo & B20-AC800-CD-NT \\
\hline 21 & alta cizalla & 100 & masterbatch & B21-AC100-MB-NT \\
\hline 22 & alta cizalla & 300 & masterbatch & B22-AC300-MB-NT \\
\hline 23 & alta cizalla & 600 & masterbatch & B23-AC600-MB-NT \\
\hline 24 & alta cizalla & 800 & masterbatch & B24-AC800-MB-NT \\
\hline 25 & baja cizalla & 100 & compound directo & B25-BC100-CD-NT \\
\hline 26 & baja cizalla & 300 & compound directo & B26-BC300-CD-NT \\
\hline 27 & baja cizalla & 600 & compound directo & B27-BC600-CD-NT \\
\hline 28 & baja cizalla & 800 & compound directo & B28-BC800-CD-NT \\
\hline 29 & baja cizalla & 100 & masterbatch & B29-BC100-MB-NT \\
\hline 30 & baja cizalla & 300 & masterbatch & B30-BC300-MB-NT \\
\hline 31 & baja cizalla & 600 & masterbatch & B31-BC600-MB-NT \\
\hline 32 & baja cizalla & 800 & masterbatch & B32-BC800-MB-NT \\
\hline
\end{tabular}

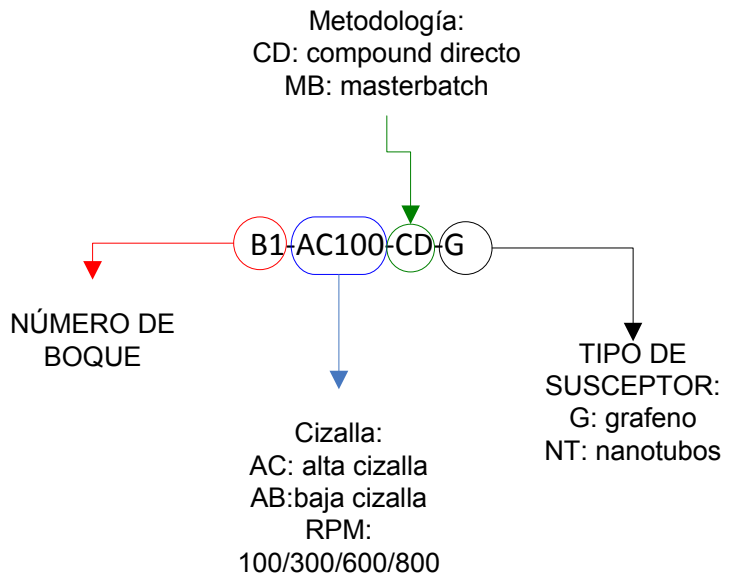

Figura 18. Descripción de la codificación de las muestras 


\subsubsection{Técnicas de caracterización}

\subsubsection{Microscopía óptica}

\section{A) Introducción teórica}

La imagen en un microscopio se forma por la transmisión de los rayos provenientes de una fuente luminosa a través del objeto. El microscopio óptico está formado por un sistema de lentes convergentes que cumplen la función de aumentar la imagen de un objeto. El poder de aumento de una lente está determinado por el grado de curvatura de su superficie y la distancia focal. Se disponen de dos juegos de lentes: el primer juego de lentes, cercano al objeto en estudio, se denomina objetivo y el segundo juego, cercano al ojo del observador, se denomina ocular ${ }^{152}$. El poder de aumento de un sistema óptico tiene sus límites y el aumentar las imágenes acarrea pérdida de información o detalles del objeto estudiado. Esto puede ser resuelto mediante la resolución.

La resolución es la capacidad que tiene un microscopio óptico de aislar dos puntos que se encuentran muy próximos entre sí, de manera que se puedan ver individualizados uno del otro ${ }^{153}$. La riqueza de detalles que puede ser observada al microscopio depende de la habilidad de este para hacer que los puntos del objeto que están muy cercanos aparezcan en la imagen como puntos separados. La distancia entre esos dos puntos se conoce como límite de resolución, el cual es también referido como el poder de resolución y puede ser utilizado como un indicador del rendimiento del microscopio.

Al observar pequeños objetos al microscopio, la luz incidente proveniente de ellos es desviada de su trayectoria inicial y mientras más pequeños sean, mayor será la desviación. Las lentes del objetivo deben recolectar como sea posible la mayor cantidad de rayos desviados para formar una imagen nítida; a más rayos capturados, mayor resolución. De aquí se obtiene la definición de apertura numérica, que se define por la siguiente ecuación:

$$
A N=n \operatorname{sen} \alpha
$$

(Ecuación 4)

Donde AN es la apertura numérica, $n$ es el índice de refracción del medio que se encuentra entre el objeto y el objetivo (Para el aire $n=1$ y para el vidrio $o$ aceite $n=1.51$ ) y $\alpha$ es la mitad del ángulo de apertura del objetivo. 
Otra manera de incrementar la resolución es creando, del lado de la fuente luminosa, un cono amplio con un ángulo mayor. Para ello se emplea otro juego de lentes denominado condensador el cual posee la misma apertura numérica que el objetivo.

El poder de resolución de un microscopio compuesto de campo claro puede ser calculado mediante la fórmula:

$$
d=\frac{\lambda}{2 A N}
$$

Donde $\mathrm{d}$ es el poder de resolución expresado en micrómetros y $\lambda$ es la longitud de onda de la luz incidente.

Por lo tanto, la resolución de un microscopio óptico depende:

- Apertura numérica del objetivo y condensador: La relación apertura/resolución es directamente proporcional; a mayor apertura, mayor resolución.

- Longitud de onda de la radiación electromagnética utilizada: La relación longitud de onda/resolución es inversamente proporcional; a menor longitud de onda, mayor resolución.

\section{B) Metodología}

El análisis de la dispersión de las nanocargas en la matriz polimérica se realizó mediante un microscopio óptico LEICA modelo Leitz DMRX equipado con dos tipos de software:

- Leica Application Suite V3, empleado para la captura y el tratamiento de las imágenes.

- Leica Mw, para el análisis del tamaño y distribución de partículas.

El microscopio óptico nos permite analizar las muestras a aumentos moderados -permitiendo resoluciones de hasta 1 micra, analizando la morfología de los nanocompuestos de una forma global.

Preparación de las muestras: Las muestras fueron obtenidas mediante moldeo por compresión con una prensa de platos calientes modelo SPEAC 2 toneladas. En primer lugar se aplica temperatura para fundir el material (en 
este caso $210^{\circ} \mathrm{C}$ para ambos sistemas NT y GMC). A continuación se aplican dos toneladas de presión obteniendo discos de un espesor de 25 micras. De esta forma se obtiene un disco translúcido que nos permite observar los aglomerados de nanopartículas en el microscopio.

Con el software de conteo de partículas se obtienen el tamaño medio de los aglomerados, el tamaño máximo y el mínimo, al igual que la densidad de los mismos. Para realizar este análisis se capturaron 10 campos distintos de cada una de las muestras con el fin de realizar un análisis estadístico más preciso. La densidad de aglomeración porcentual fue calculada de la siguiente forma ${ }^{154}$ :

$$
\text { densidad aglomerados }(\%)=\frac{\text { Area total }}{\text { Area de la muestra }} \cdot 100
$$

(Ecuación 6)

\subsubsection{Microscopio electrónico de barrido (SEM)}

\section{A) Introducción teórica}

Con el microscopio óptico es posible alcanzar un aumento máximo de 1000x. Esta limitación se resuelve a través de la microscopía electrónica, ya que emplea un haz de electrones en lugar de un rayo de luz visible.

En el microscopio electrónico de barrido (SEM) se hace incidir un delgado haz de electrones acelerados, con energías desde unos cientos de eV hasta unas decenas de $\mathrm{keV}(50 \mathrm{keV})$, sobre una muestra gruesa, opaca a los electrones. Este haz se focaliza sobre la superficie de la muestra de forma que realiza un barrido de la misma siguiendo una trayectoria de líneas paralelas. Se producen imágenes tridimensionales gracias a una mayor profundidad de campo. Se escanea la superficie del espécimen con un haz de electrones (primarios) y los electrones que rebotan (secundarios) son recogidos por un detector cuya señal se observa en un monitor. Los átomos de la muestra producen rayos $X$ que también son detectados pudiéndose analizar la composición de la muestra. 


\section{B) Metodología}

Para el presente estudio se empleó un microscopio electrónico de barrido de escritorio de la marca Phenom Pro X. El microscopio trabaja a voltaje de múltiple aceleración $(5,10,15 \mathrm{keV})$, llegando a una resolución de aproximadamente $12 \mathrm{~nm}$.

Preparación de las muestras: Las muestras se prepararon por fractura criogénica de probetas de tamaño $(80 \times 10 \times 40) \mathrm{mm}$ obtenidas por moldeo por compresión según las condiciones detalladas en el apartado "3.2.1.1. Equipamiento". La superficie de fractura se recubrió con oro por la técnica de recubrimiento por pulverización catódica o "sputter coating" antes de su observación por SEM.

\subsubsection{Microscopio electrónico de transmisión (TEM)}

\section{A) Introducción teórica}

La microscopía electrónica de transmisión (TEM) es la herramienta de caracterización más ampliamente utilizada para determinar la forma y el tamaño de las nanopartículas. Los microscopios electrónicos más sencillos constan de dos lentes formadoras de la imagen de manera muy parecida a los microscopios ópticos convencionales. La iluminación proviene de un cañón de electrones emitidos por un filamento de wolframio (W) o boruro de lantano $\left(\mathrm{LaB}_{6}\right)$. Los electrones son acelerados al aplicar un potencial negativo (100 kV - $1000 \mathrm{kV})$ y focalizados mediante dos lentes condensadoras sobre una muestra delgada, transparente a los electrones. Después de pasar a través de la muestra los electrones son recogidos y focalizados por la lente objetivo dentro de una imagen intermedia ampliada. La imagen es ampliada aún más gracias a las lentes proyectoras y finalmente se proyecta sobre una pantalla fluorescente o una película fotográfica. Un TEM de dos lentes puede llegar a aumentar la imagen alrededor de 1000 veces. Los microscopios de gran resolución (tres lentes generadoras de imagen) son capaces de ampliar la imagen hasta 500.000 veces y tienen poderes de resolución de unas fracciones de $\mathrm{nm}$. Normalmente poseen aumentos de entre $1000-200.000$ ó de $2500-500.000$. 
Las diferencias entre el SEM y el TEM es que el SEM explora la superficie de la imagen punto por punto, al contrario que el TEM, que examina una gran parte de la muestra cada vez, produciendo una imagen plana pero de extraordinaria resolución.

\section{B) Metodología}

Para el análisis de la morfología de las nanopartículas en el nanocompuesto se empleó un microscopio de transmisión de electrones de gran resolución marca JEOL JEM-1010, equipado con el software de análisis de imagen MegaView III. Las muestras se analizaron con un voltaje de $100 \mathrm{kV}$ y $79 \mathrm{~mA}$.

Preparación de las muestras: Las probetas obtenidas por moldeo por compresión (similares a las probetas empleadas en el análisis SEM) fueron cortadas con un ultramicrotomo Reichert \& Jung FC4E (Reichert Microscope Services, USA) para obtener una fina película de aproximadamente $100 \mathrm{~nm}$ de espesor. Para el análisis la muestra fue colocada sobre una rejilla de cobre de 200 mallas.

\subsubsection{Reómetro rotacional}

\section{A) Introducción teórica}

Los viscosímetros rotacionales constan básicamente de dos partes que se encuentran separadas por el material a estudiar. Dichas partes pueden ser dos cilindros, dos superficies paralelas, una superficie y un cono de pequeño ángulo, un rotor en el interior de un cilindro, etc. El movimiento de una de estas partes provoca la aparición de un gradiente de velocidades a lo largo del fluido. Para determinar la viscosidad del fluido se mide el esfuerzo necesario para producir una determinada velocidad angular.

La reología rotacional es muy utilizada para la caracterización de nanocompuestos, ya que es capaz de describir indirectamente la dispersión de las nanopartículas y los cambios microestructurales ${ }^{155,156,157,158}$. Los principales efectos se observan a bajas frecuencias $(0.1-1 \mathrm{rad} / \mathrm{s})$, pues en esta región es posible detectar mínimas interacciones energéticas en la propia red de nanopartículas: 
- La viscosidad aumenta con el contenido de nanopartículas, sobre todo la viscosidad dinámica relacionada con el módulo de almacenamiento. Estos efectos apenas se observan en el módulo de pérdidas ${ }^{159}$.

- El aumento de la viscosidad está relacionado con el aumento de la relación de aspecto de las nanopartículas, pudiendo comparar así los efectos de diferentes condiciones de procesado de los nanocompuestos ${ }^{168}$.

- El módulo de almacenamiento puede ser empleado en el análisis de la formación de la red de nanopartículas que indican que se han interconectado. Al representar el módulo de almacenamiento versus la frecuencia angular se llega a observar un "plateau" a bajas frecuencias, indicando que la red se ha formado ${ }^{160}$.

- Las curvas obtenidas al representar el módulo de almacenamiento versus el módulo de pérdidas se emplean para estudiar cambios en la microestructura en homopolímeros, copolímeros y mezclas de los mismos a diferentes temperaturas ${ }^{161,162}$. Aplicado a los nanocompuestos, cambios en las curvas con diferentes porcentajes de nanopartículas indican cambios en la estructura para una misma temperatura.

A elevadas frecuencias la viscosidad presenta pocos cambios independientemente del porcentaje de nanopartículas. Esto indica que, en la práctica, estos nanocompuestos serían procesados en condiciones similares a los polímeros vírgenes ya que los procesos de transformación de polímeros más comunes trabajan en estas condiciones.

\section{B) Metodología}

En este caso se empleó un reómetro rotacional de la marca TA Instruments modelo AR-G2, con sistema de medida plato-plato de $25 \mathrm{~mm}$ de diámetro y separación de $1000 \mu \mathrm{m}$. La viscosidad dinámica ( $\left.\eta^{\prime}\right)$, el módulo de almacenamiento (G') y el módulo de pérdidas (G") se midieron a unas frecuencias entre $200-0.01 \mathrm{rad} / \mathrm{s}$ y a una temperatura de $200^{\circ} \mathrm{C}$. 


\subsubsection{Termogravimetría}

\section{A) Introducción teórica}

La termogravimetría consiste en una técnica que determina la evolución del peso de una muestra frente al tiempo o a la temperatura bajo una atmósfera determinada -oxidante o inerte normalmente-. Es decir, permite el estudio de la estabilidad térmica de los nanocompuestos. En este ensayo el calentamiento se realiza a una velocidad controlada. Todas las muestras deben compararse a la misma velocidad de calentamiento, ya que también varía la rapidez de la pérdida de masa.

En el análisis termogravimétrico el material se calienta en una atmósfera determinada con una rampa de temperatura controlada. La curva obtenida representa la variación de la masa respecto de la temperatura o del tiempo suministrando información acerca de la estabilidad térmica y de la composición de los intermedios (que puedan formarse durante el proceso de descomposición de las substancias orgánicas) y del residuo final. En la investigación de nanocompuestos es muy interesante conocer la variabilidad de la estabilidad térmica existente entre los polímeros vírgenes y los que contienen refuerzo inorgánico, pues proporciona información acerca de la capacidad del material de mantener sus propiedades, interconectando dos variables: la temperatura y la adicción de nanopartículas, siempre y cuando el análisis se lleve a cabo en idénticas condiciones ${ }^{163}$.

\section{B) Metodología}

Para los ensayos se empleó un equipo de análisis temogravimétrico de la marca TA Instruments modelo TGA Q5000. Los ensayos se realizaron con las siguientes condiciones: $20 \mathrm{mg}$ de muestra se calentó en atmósfera de nitrógeno desde $50^{\circ} \mathrm{C}$ a $600^{\circ} \mathrm{C}$ con una velocidad de calentamiento de $10^{\circ} \mathrm{C} /$ min y en aire de $600^{\circ} \mathrm{C}$ a $800^{\circ} \mathrm{C}$ a la misma velocidad de calentamiento. Cada muestra se ensayó con tres réplicas. 


\subsubsection{Espectroscopia de impedancia electroquímica}

\section{A) Introducción teórica}

Las propiedades dieléctricas de los nanocompuestos se midieron por espectroscopia de impedancia electroquímica. Esta técnica determina las propiedades dieléctricas de los materiales a diferentes frecuencias y temperaturas. Permite el estudio de la dinámica molecular y de los procesos de transporte de cargas, en particular en materiales aislantes. Durante el ensayo se aplica un voltaje a una frecuencia dada, causando una corriente con la misma frecuencia. La impedancia se calculará dividiendo el voltaje aplicado por la intensidad de corriente generada en el ensayo. Con estos datos se podrán calcular las propiedades dieléctricas de los nanocompuestos.

Las propiedades objeto de estudio fueron:

- Permitividad $\varepsilon^{*}=\varepsilon^{\prime}-\mathrm{j} \varepsilon^{\prime \prime}$

- Tangente de pérdidas (o pérdida dieléctrica) tan $\delta=\varepsilon " / \varepsilon$ '

La parte real de la permitividad, $\varepsilon^{\prime}$, llamada constante dieléctrica, determina qué cantidad de la energía incidente que penetra en el material. La parte imaginaria de la permitividad compleja, $\varepsilon$ " 0 factor de pérdidas, hace referencia a la capacidad del material de almacenar energía. La propiedad más importante es la tangente de pérdidas, ya que predice la habilidad de un material para convertir la energía incidente en calor.

\section{B) Metodología}

En este caso se empleó un espectrómetro dieléctrico Novocontrol (Hundsangen, Alemania) con un amplificador SR830 y un interfaz dieléctrico Alpha. Se realizaron medidas a $30^{\circ} \mathrm{C}, 40^{\circ} \mathrm{C}, 50^{\circ} \mathrm{C}$ and $60^{\circ} \mathrm{C}$ y un rango de frecuencias de $10^{-1}<\mathrm{f}<3 \times 10^{6} \mathrm{~Hz}$ con una amplitud de $0.1 \mathrm{~V}$. Las medidas se realizaron en sólido, recubriendo las mismas por dos electrodos de oro. El recubrimiento se realizó en atmósfera de nitrógeno. 


\subsubsection{Medida de las propiedades eléctricas}

\section{A) Introducción teórica}

El procedimiento para la medida de la conductividad eléctrica se basó en la norma UNE-EN ISO 3915, método aplicable a materiales con resistencia menor a $120 \mathrm{M} \Omega$. Se realizaron dos tipos de medida:

- Resistividad volumétrica: se calculó por el método de los 4 puntos en el que la probeta se conecta al multímetro por 4 electrodos. Se aplica un voltaje de $10 \mathrm{~V}$ y se obtiene la resistencia del material. El equipo aplica el voltaje a la intensidad de corriente mínima para que el material conduzca la corriente. La conductividad se calcula según las siguientes fórmulas:

$$
\begin{gathered}
\rho=\frac{b * d}{l} * R(\text { Ohm.cm }) \\
\sigma=\frac{1}{\rho}(\mathrm{S} / \mathrm{cm})
\end{gathered}
$$

Donde:

$\mathrm{b} \equiv$ anchura $(\mathrm{cm})$

$\mathrm{d} \equiv$ espesor $(\mathrm{cm})$

I $\equiv$ longitud $(\mathrm{cm})$

$\mathrm{R} \equiv$ resistencia $(\mathrm{Ohm})$

- Resistividad superficial: La resistividad superficial sigue la misma metodología que la volumétrica pero sólo se aplica el voltaje en dos puntos superficiales de la probeta. La conductividad superficial se calcula según las siguientes fórmulas:

$$
\begin{gathered}
\rho=\frac{b}{l} * R(\text { Ohm.sq) } \\
\sigma=\frac{1}{\rho}(S / s q)
\end{gathered}
$$


Donde:

$\mathrm{b} \equiv$ anchura $(\mathrm{cm})$

I $\equiv$ distancia entre electrodos $(\mathrm{cm})$

\section{B) Metodología}

La medida de la conductividad eléctrica se realizó mediante un multímetro Keithley 2000. Las medidas se realizaron sobre probetas de dimensiones (10 x 80 x 4) mm y se empleó plata conductora (Electrodag 1415M de Acheson) para mejorar el contacto con los electrodos.

\subsubsection{Ensayos dinámico-mecánicos (DMA)}

\section{A) Introducción teórica}

Las propiedades viscoelásticas de los materiales compuestos pueden ser estudiadas por análisis térmico dinámico mecánico (DMA) ${ }^{164}$.EI DMA es un equipo que estudia el comportamiento de un material cuando es sometido a una fuerza oscilante sinusoidal mientras se varía la temperatura. La deformación resultante $(\varepsilon)$ también es sinusoidal y de la misma frecuencia, pero con un desfase, que se expresa como ángulo de fase $\delta$. En los materiales poliméricos la respuesta a la deformación ante un esfuerzo aplicado es intermedia entre la de un sólido elástico y la de un fluido viscoso; donde las propiedades mecánicas resultan dependientes del tiempo o frecuencia de análisis, así como de la temperatura.

Mediante el DMA se determina el módulo del material, que es la relación entre el esfuerzo y la deformación, en función de la temperatura hasta temperaturas ligeramente por debajo de la temperatura de fusión. Para un material viscoelástico, el módulo es una cantidad compleja: $E^{*}=E^{\prime}+i E^{\prime \prime}$ donde $E^{\prime}$ es el módulo de almacenamiento (o componente en fase) y E" es el módulo de pérdida (o componente fuera de fase). La relación E"/E' es igual a la tangente del ángulo de fase, tan $\delta$, que alcanza un pico a la temperatura de transición 
vítrea $(\mathrm{Tg})$. La tangente delta (tan $\delta$ ) es una medida de la movilidad molecular. Un valor alto de tan $\delta$ indica una alta movilidad molecular en el material.

\section{B) Metodología}

Para estos ensayos se empleó el equipo de la casa TA Instruments modelo DMA2980, en modo flexión biempotrado. Se aplicó un rango de temperaturas de $-50^{\circ} \mathrm{C}-200^{\circ} \mathrm{C}$ en probetas de compresión. Se fijó la frecuencia a $1 \mathrm{~Hz}$ y la amplitud a $10 \mu \mathrm{m}$.

\subsubsection{Espectroscopia infrarroja con transformada de Fourier (FT-IR)}

\section{A) Introducción teórica}

Las moléculas son flexibles, de forma que los átomos están continuamente oscilando en torno a su posición de equilibrio. Durante esta vibración tanto las distancias entre los átomos como los ángulos de los enlaces cambian constantemente respecto de su posición nominal debido a la agitación térmica. Cuando estas moléculas son expuestas a la radiación infrarroja absorben en determinadas longitudes de onda (o frecuencias). Este hecho se debe a que la molécula absorbe exclusivamente cuando la vibración de los átomos genera un campo eléctrico (cambio en su momento dipolar) con la misma frecuencia que la onda IR incidente. Por tanto, una molécula absorberá exclusivamente a unas determinadas frecuencias del espectro infrarrojo, que serán función de los enlaces y grupos funcionales propios de esta molécula. El conjunto de frecuencias a las que absorbe una molécula (bandas de absorción) son específicas para esta molécula, lo que permitirá diferenciarla de cualquier otra.

En función de las distancias entre átomos y los movimientos que tiene lugar en cada uno de los enlaces entre los mismos, una molécula presentará una serie de bandas propias asociadas a sus enlaces, permitiendo la detección de los grupos funcionales presentes en la misma. Esto hace la espectroscopia infrarroja una herramienta muy útil para el análisis cualitativo (identificación) de compuestos orgánicos. En este caso, será útil para determinar la 
presencia de posibles grupos carbonilo como indicadores de la termooxidación del polipropileno.

\section{B) Metodología}

Los ensayos se llevaron a cabo en un espectrofotómetro de Infrarrojos por Transformada de Fourier NICOLET 6700 con las siguientes características:

- Método de medida: Reflexión en Smart Orbit con cristal de Diamante

- No de barridos: 10

- Resolución $\left(\mathrm{cm}^{-1}\right): 4$

- Rango de barrido $\left(\mathrm{cm}^{-1}\right): 4000-400$

\subsubsection{Espectroscopia RAMAN}

\section{A) Introducción teórica}

Es una técnica fotónica de alta resolución que proporciona en pocos segundos información química y estructural de cualquier material o compuesto orgánico y/o inorgánico. Se basa en el examen de la luz dispersada por el material al incidir un haz de luz monocromático (láser). Se trata de una técnica rápida y no destructiva.

El efecto RAMAN estudia que una muy pequeña parte de esa luz dispersada tiene diferente energía (frecuencia). Ese fenómeno está asociado a la vibración y rotación de determinados enlaces químicos. Como el efecto es muy débil se necesitan fuentes de luz intensas (láser) para obtener suficiente señal.

La Espectroscopia RAMAN da información muy detallada sobre enlaces de tipo carbono, con lo que es muy útil para estudiar la morfología de nanopartículas carbonosas, como los NTC y el GMC. Los espectros RAMAN de estas partículas ofrecen amplia información sobre su morfología: número de capas en GMC o pared simple o múltiple en NTC, defectos, oxidaciones, tratamientos, etc. 
En la Figura 19 y la Figura 20 se resume los picos más importantes para la interpretación del espectro Raman de los NTC y del GMC, respectivamente.

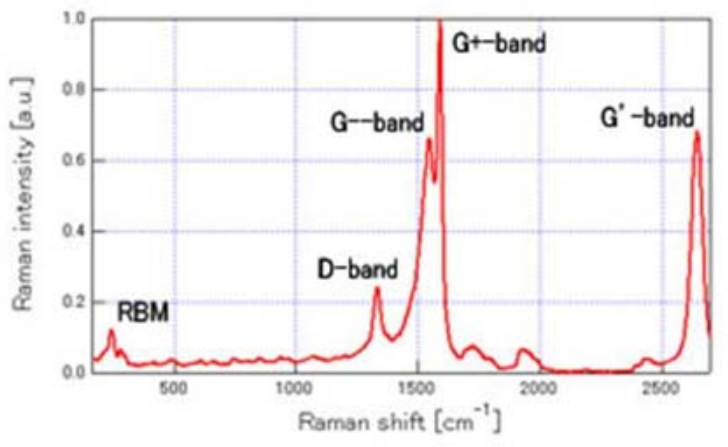

Banda D: Modo inducido por el desorden.

Banda G+: vibración en el eje del nanotubo.

Banda G-: carácter metálico.

Banda RBM: vibración radial. Depende del diámetro del tubo.

ID/IG: funcionalización del CNT

Figura 19. Interpretación espectrómetro Raman de los NTC ${ }^{165}$

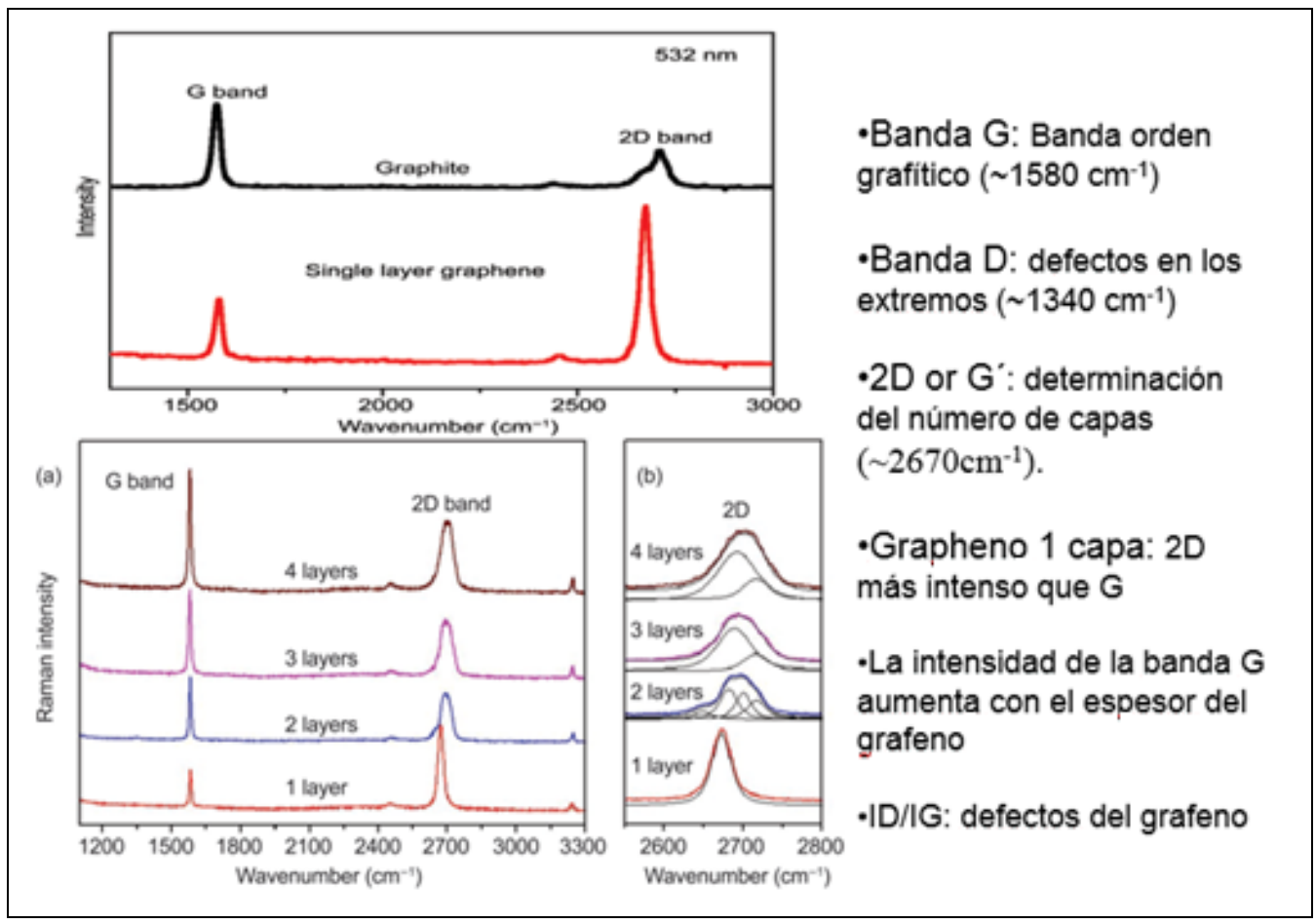

Figura 20. Interpretación espectro Raman GMC ${ }^{166}$ 


\section{B) Metodología}

Los ensayos de espectroscopia Raman se realizaron en un equipo Horiba XploRA dotado con un microscopio confocal BX41, una fuente láser LCS-S11 y un detector CCD refrigerado por aire. Para las mediciones se empleó un láser de longitud de onda $532 \mathrm{~nm}$.

La preparación de las muestras se realizó formando una disolución del GMC y los NTC en etanol. Las disoluciones se dispersaron por ultrasonidos durante 15 min. Posteriormente se depositaron sobre un vidrio y se evaporaron. 


\subsubsection{Calentamiento por microondas}

\subsubsection{Equipamiento}

Se empleó un microondas de laboratorio de frecuencia $5,8 \mathrm{GHz}$ de la empresa alemana Fricke \& Mallah. El mismo se muestra en la Figura 21.

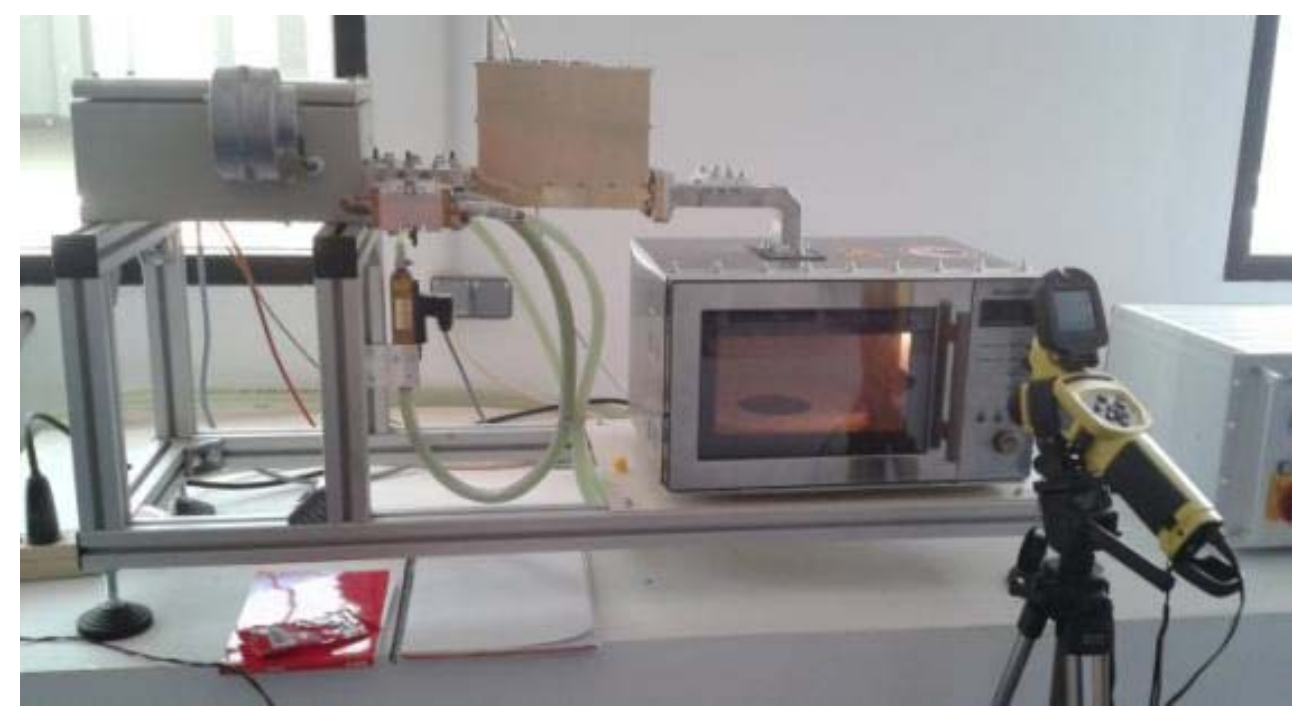

Figura 21. Microondas multimodo de laboratorio de frecuencia $5.8 \mathrm{GHz}$ y disposición de la cámara termográfica

Se fabricó un molde circular de teflón con un rebaje en el centro con el fin de contener los pellets en la parte central y obtener un calentamiento homogéneo evitando los "hot spots" o puntos calientes frecuentes en los microondas de sistema multimodo. En la Figura 22 se muestra el molde fabricado y cómo se situaron los pellets de los compuestos a la hora de realizar el experimental. 


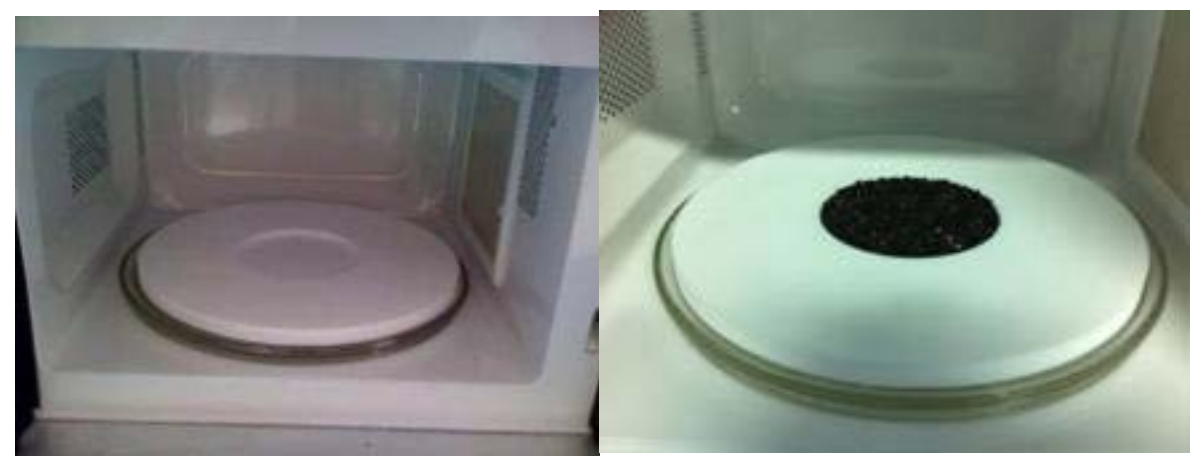

Figura 22. Molde de teflón para contener los pellets en la cavidad del microondas

\subsubsection{Medida de la temperatura}

La medida de la temperatura alcanzada por los diferentes compuestos fue realizada empleando una cámara de infrarrojos modelo TROPEC IC120LV, con una resolución geométrica de $1.1 \mathrm{mrad}$. La cámara se situó sobre un trípode y la medida se realizó abriendo la puerta del microondas tras el tiempo de calentamiento. Ésta se consideró la mejor forma de medir la temperatura de la muestra tras probar diferentes métodos de medida: pirómetro y fibra óptica. El pirómetro no es adecuado para los rangos de temperatura que había que medir en el experimental. La fibra óptica tenía como desventaja que necesita el contacto con la muestra y, si el compuesto se fundía, había que desechar la fibra. Además con la fibra óptica se determina una temperatura puntual sin tener ninguna información sobre la homogeneidad del calentamiento ni la representatividad de dicha medida 


\section{CAPÍTULO 4: ESTUDIO DE LA DISPERSIÓN DE LOS NANOCOMPUESTOS}

\subsection{Análisis morfológico}

Las técnicas y metodologías empleadas para caracterizar la dispersión obtenida en cada muestra fueron las siguientes.
A. Estudio micrográfico: microscopia óptica, SEM y TEM.
B. Densidad de aglomerados: es un cálculo de la proporción de superficie de aglomerados respecto a la superficie total de la muestra.
C. Tamaño medio de partícula: está correlacionado con el tamaño general de los aglomerados en la muestra.
D. Histogramas: mediante el conteo de partículas y análisis estadístico de las frecuencias de repetición para cada tamaño de partícula.
E. Índice de dispersión.

\subsubsection{Estudio micrográfico}

\subsubsection{Microscopía óptica}

\section{A) Sistema PP/NTC:}

La dispersión alcanzada de los NTC en la matriz de PP fue analizada, como primera aproximación, mediante microscopía óptica. Se realizaron micrografías con alto contraste de todos los nanocompuestos obtenidos, con la finalidad de lograr una buena identificación de la geometría del aglomerado frente al fondo de la imagen. La Figura 23 muestra las micrografías de los compuestos obtenidos con diferentes rangos de cizalla y tiempos de residencia. En lugar de mostrar todas las micrografías se han representado los extremos para ayudar a obtener conclusiones (ver Figura 18 con la descripción de la codificación de las muestras):

- Baja cizalla y bajo tiempo de residencia se representa con la muestra obtenida con la configuración de baja cizalla, a baja velocidad de extrusión e introduciendo las nanocargas en polvo. (muestra B25) 
- Alta cizalla y alto tiempo de residencia se representa con la muestra obtenida con la configuración de alta cizalla, a alta velocidad de extrusión e introduciendo las nanocargas en forma de masterbatch. (muestra B24)

- Baja cizalla y alto tiempo de residencia se representa con la muestra obtenida con la configuración de baja cizalla, a baja velocidad de extrusión e introduciendo las nanocargas en forma de masterbatch. (muestra B29)

- Alta cizalla y bajo tiempo de residencia se representa con la muestra obtenida con la configuración de alta cizalla, a alta velocidad de extrusión e introduciendo las nanocargas en polvo. (muestra B20)

Se observa que introduciendo los NTC en forma de masterbatch se mejora la dispersión de los NTC incluso trabajando con una configuración de husillo de baja cizalla y baja velocidad de extrusión. Grandes aglomerados de NTC con tamaños superiores a las $500 \mu \mathrm{m}$ se observan en los compuestos procesados a bajas cizallas y con la incorporación directa de las nanopartículas en polvo (Figura 23a). En esas condiciones, si se aumenta la velocidad de extrusión y se emplea una configuración de alta cizalla se obtiene una mejora en la dispersión (Figura 23c).

La influencia de la configuración de husillo y de la velocidad de la extrusora es más acusada cuando se trabaja en compound directo. Incorporando los NTC en forma de masterbatch se provoca que el proceso sea menos dependiente del resto de parámetros de procesado. Mediante el procesado con masterbatch los NTC están sometidos a dos procesos de extrusión (2 etapas). Es decir, están sometidos a esfuerzos de cizalla durante más tiempo. Se puede concluir que el tiempo de residencia de los NTC en la extrusora es el factor determinante para obtener una buena dispersión y que puede ser optimizada aplicando además alta cizalla mediante la configuración de husillo y la velocidad de extrusión. 


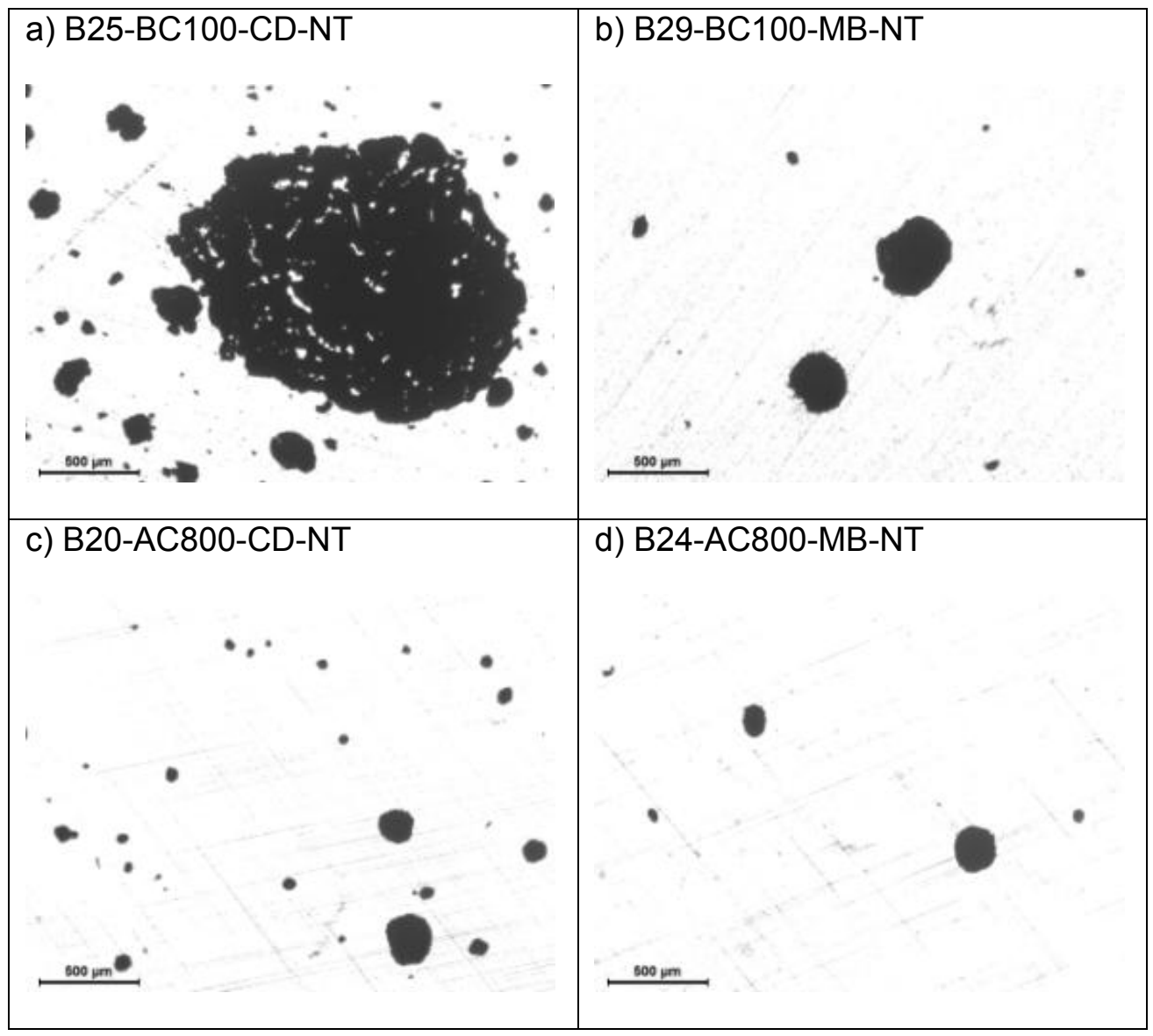

Figura 23. Imágenes de microscopía óptica x25: a) B25-BC100-CD-NT; b) B29BC100-MB-NT; c) B20-AC800-CD-NT; d) B24-AC800-MB-NT

La Figura 24 compara dos compuestos producidos vía masterbatch, uno con una configuración de husillo de baja cizalla (Figura 24a) y el otro a alta cizalla (Figura 24b). Se observa que el grado de cizalla impartido durante el procesado no resulta en diferencias destacables en la morfología del nanocompuesto. Es decir, resultados similares son obtenidos con configuraciones de husillo más o menos agresivas.

A nivel industrial sería de gran utilidad obtener una buena dispersión sin tener que modificar el husillo de la extrusora y este análisis demuestra que es 
factible si se trabaja con masterbatch y se aumentan la velocidad de extrusión. De esta manera se compensa la falta de cizalla que otorgan los elementos de husillo con el aumento de la velocidad de extrusión y el aumento del tiempo de residencia.

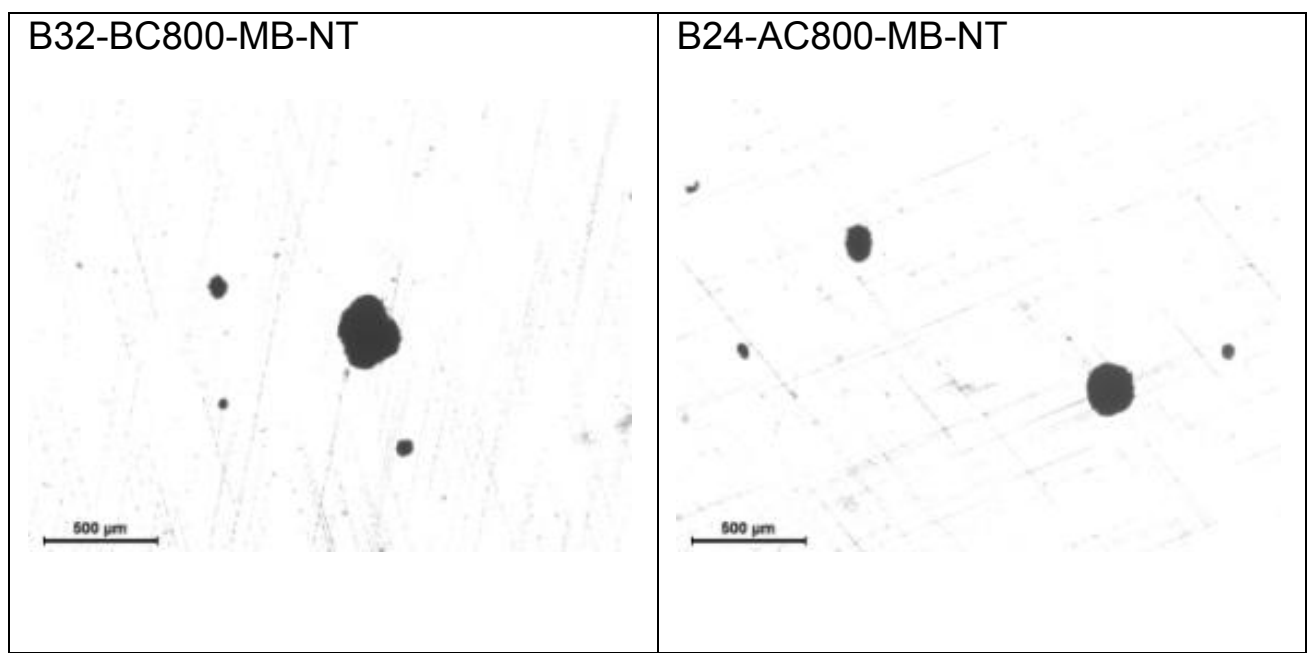

Figura 24. Imágenes de microscopía óptica x25: a) B32-BC800-MB-NT; b) B24AC800-MB-NT

\section{B) Sistema PP/GMC:}

La dispersión de los GMC en la matriz de PP fue analizada mediante microscopía óptica de forma análoga a la que fue llevada a cabo en los nanocompuestos de NTC. Se realizaron micrografías de todos los nanocompuestos obtenidos, aunque para un adecuado análisis aquí se recopilan solamente las más significativas.

La Figura 25 muestra las micrografías de los compuestos producidos a diferentes grados de cizalla y tiempos de residencia. En primer lugar cabe destacar que la diferencia en morfología entre las distintas muestras es mucho menor que la observada en los nanocompuestos de NTC. Siguen apareciendo aglomerados de GMC pero de mucho menor tamaño que los observados en los nanocompuestos de NTC. Las nanopartículas de NTC 
tienen mayor tendencia a aglomerarse formando grandes agregados de NTC enmarañados los cuales se dispersan con mayor dificultad que el GMC. Alta cizalla y alto tiempo de residencia siguen siendo los parámetros más favorables de procesado (Figura 25d). Sin embargo, las diferencias obtenidas empleando configuraciones de husillo de baja cizalla y bajo tiempo de residencia no son tan significativas.

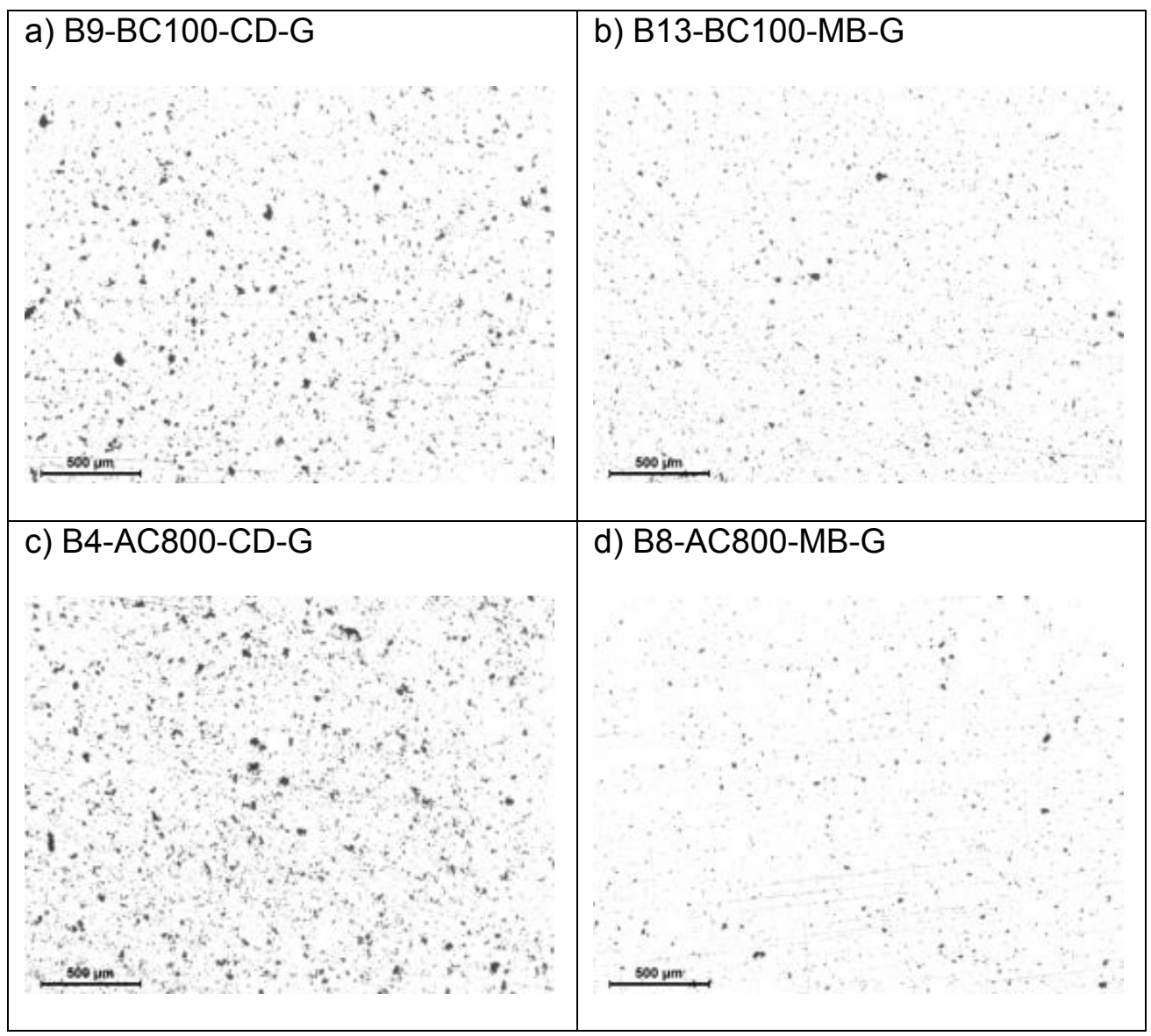

Figura 25. Imágenes de microscopía óptica x25: a) B9-BC100-CD-G; b) B13BC100-MB-G; c) B4-AC800-CD-G; d) B8-AC800-MB-G 
Incorporando el GMC vía masterbatch se mantiene la misma tendencia que se observa en los nanocompuestos de NTC, donde la configuración de husillo tenía poca influencia si se trabajaba a altas velocidades de extrusión (ver Figura 26).

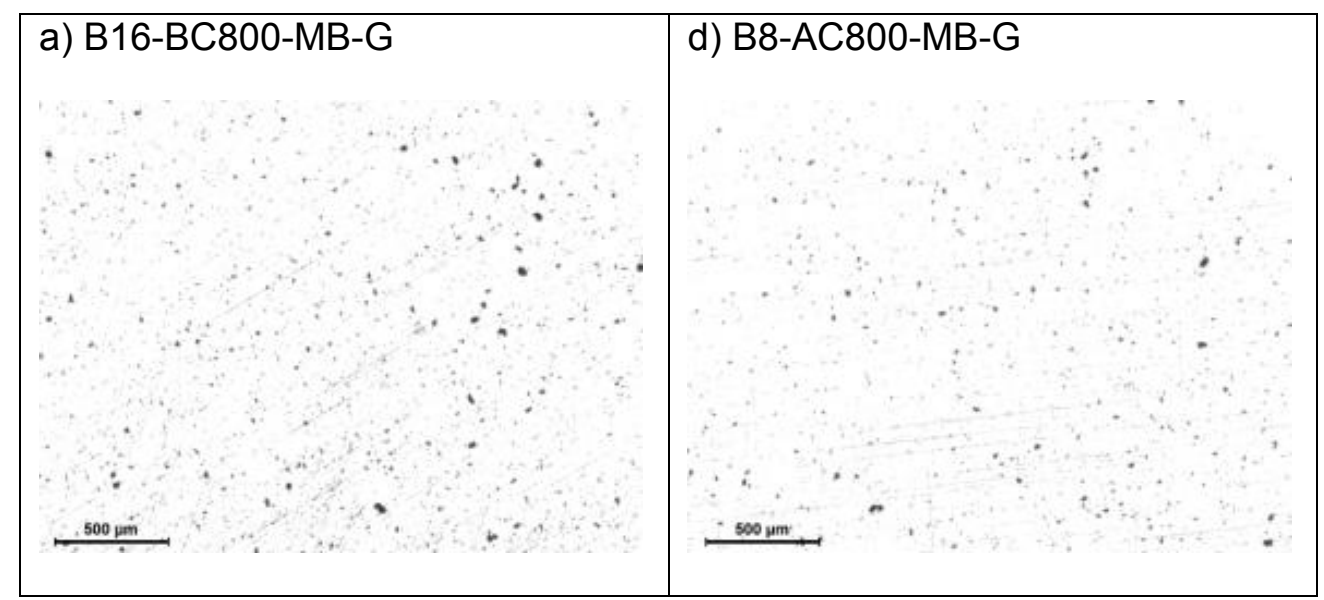

Figura 26. Imágenes de microscopía óptica x25: a) B16-BC800-MB-G; b) B8AC800-MB-G

\subsubsection{Microscopía electrónica de barrido (SEM)}

\section{A) Sistema PP/NTC:}

Se realizó microscopía electrónica de barrido para estudiar en profundidad la morfología de los nanocompuestos producidos y las imágenes confirman los resultados obtenidos por microscopia óptica. Se seleccionaron las siguientes muestras para el análisis:

- B25-BC100-CD-NT, representando la cizalla y tiempo de residencia más bajos. (ver Figura 27 y Figura 28)

- B24-AC800-MB-NT, representando la cizalla y tiempo de residencia más altos. (ver Figura 29 y Figura 30) 
La Figura 27 y la Figura 28 muestran las micrografías de los compuestos de NTC producidos a baja cizalla y bajo tiempo de residencia (1 etapa o compound directo), obtenidas las imágenes a bajos y altos aumentos, respectivamente. La Figura 28 muestra la imagen de un aglomerado de nanotubos de carbono. Un aglomerado está conformado por NTC enmarañados, los cuales son muy difícilmente dispersados o separados por la alta afinidad de los NTC entre sí y su baja afinidad por el polímero matriz. La presencia de grandes aglomerados reduce la efectividad de los NTC ya que actúan como micropartículas y pueden ser un punto caliente o "hot spot" cuando se someta a radiación microondas.

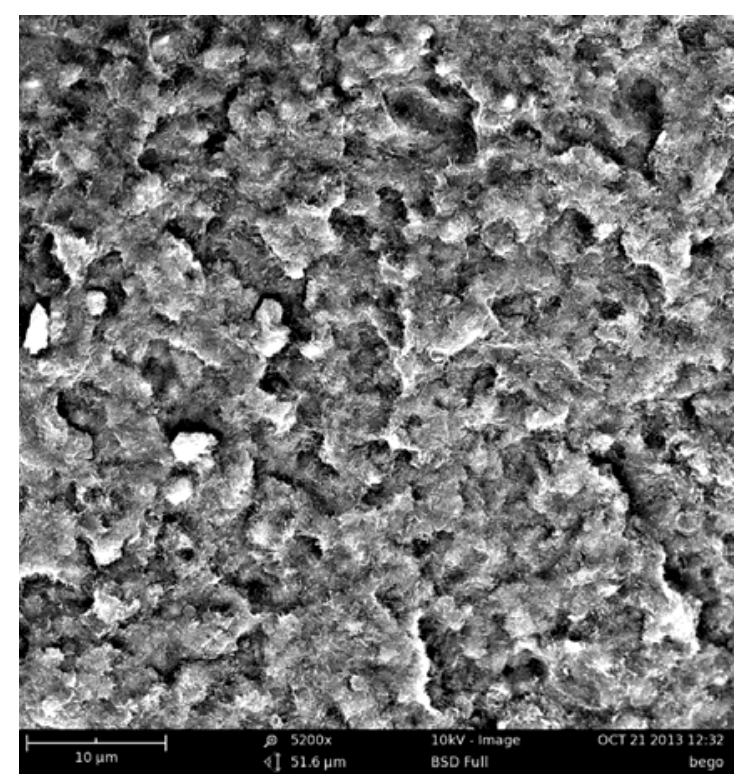

Figura 27. Imagen SEM del compuesto B25-BC100-CD-NT_5200x 


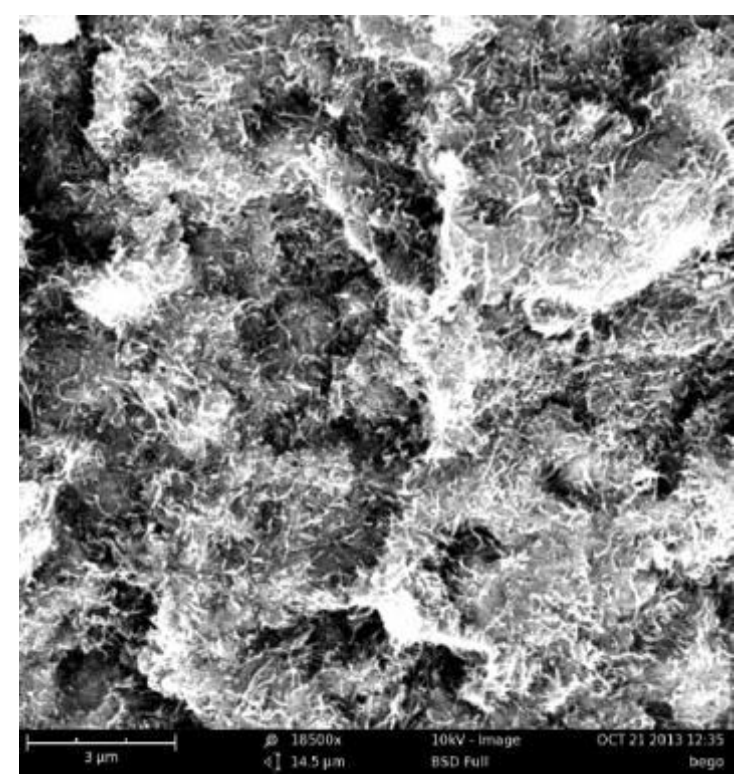

Figura 28. Imagen SEM del compuesto B25-BC100-CD-NT_18500x

El aumento del tiempo de residencia tiene un efecto positivo en la reducción del tamaño de los aglomerados de NTC. La Figura 29 y la Figura 30 son imágenes a diferentes aumentos del nanocompuesto de NTC obtenido con masterbatch, alta velocidad de husillo y configuración de husillo agresiva. Ambas figuras muestran una morfología mucho más homogénea con los NTC mejor dispersos y distribuidos en la matriz de PP, aunque todavía se observan pequeños aglomerados. El hecho de realizar el proceso en dos etapas corrobora la mejora en la dispersión y distribución de los nanotubos.

EI SEM corrobora los resultados observados en el microscopio óptico, concluyendo que para obtener una buena dispersión de los NTC es necesario un alto tiempo de residencia y alta cizalla. Así pues, un menor número de aglomerados y de menor tamaño se observan en los nanocompuestos obtenidos con dichas condiciones de procesado, tanto en microscopía óptica como electrónica.

Otro factor a evaluar es la interfase entre los NTC y el polipropileno matriz. En las imágenes obtenidas a mayores aumentos, sobretodo en la Figura 30 en la que los NTC están mejor dispersados, se puede evaluar la afinidad química entre los NTC y el PP. Se observa que los NTC están unidos al 
polipropileno de forma que no queda un hueco entre ambos, lo cual indicaría una buena compatibilidad entre ambos.

La alta energía mecánica aplicada durante la extrusión del nanocompuesto podría implicar la rotura de los NTC. La longitud de los NTC no pudo ser evaluada mediante SEM, por lo que se seleccionó la microscopía electrónica de transmisión como técnica más idónea.

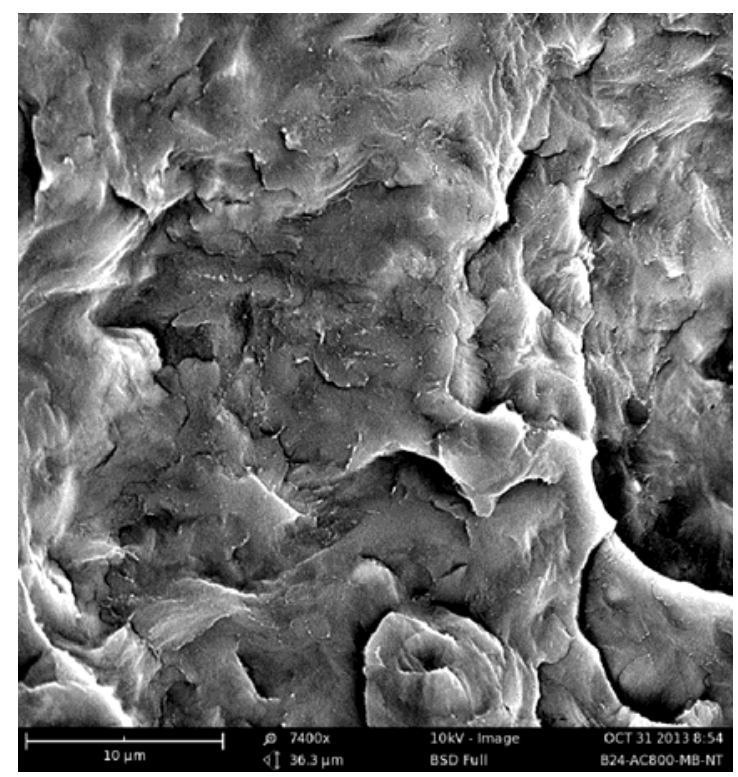

Figura 29. Imagen SEM del compuesto B24-AC800-MB-NT_7400x 


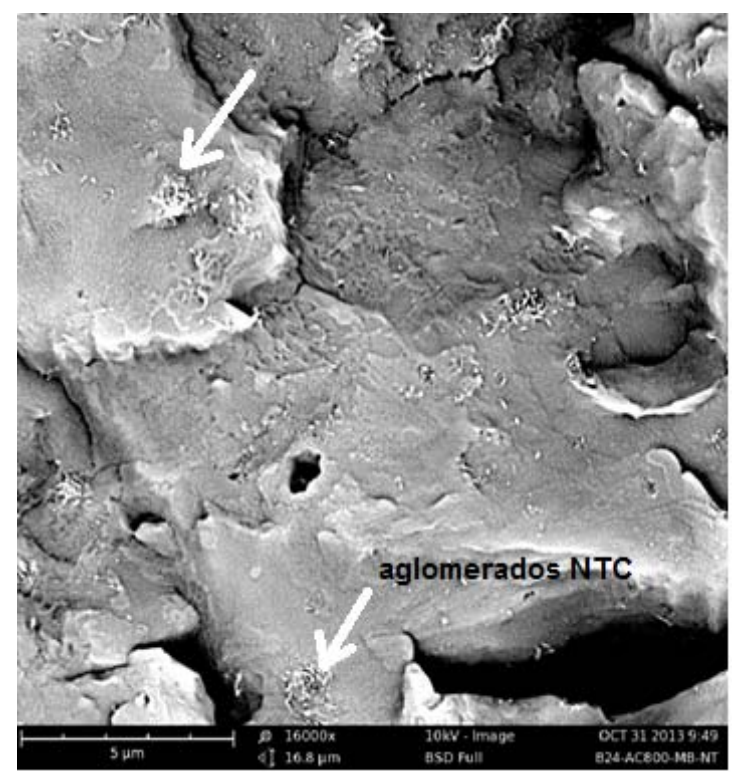

Figura 30. Imagen SEM del compuesto B24-AC800-MB-NT_16000x

\section{B) Sistema PP/GMC:}

Se realizó microscopía electrónica de barrido para estudiar en profundidad la morfología de los nanocompuestos con grafeno multicapa (GMC).

En la Figura 31 se muestran dos imágenes SEM del nanocompuesto obtenido a baja cizalla y bajo tiempo de residencia (B9-BC100-CD-G) (compound directo / 1 etapa). Ambas imágenes fueron tomadas a grandes aumentos con el fin de analizar la morfología general del nanocompuesto. En las imágenes se pueden ver láminas de GMC distribuidas por la matriz de PP, marcadas con flechas en las imágenes. Se encuentran láminas de gran tamaño como la destacada en la figura. Del análisis de estas figuras se puede concluir que las partículas de grafeno no están en contacto unas con otras, estando mucho más aisladas que los NTC. Se observan partículas de diferentes tamaños, encontrando láminas de GMC de plano x-y de gran tamaño. No se aprecia la orientación de las partículas en una dirección destacada. 

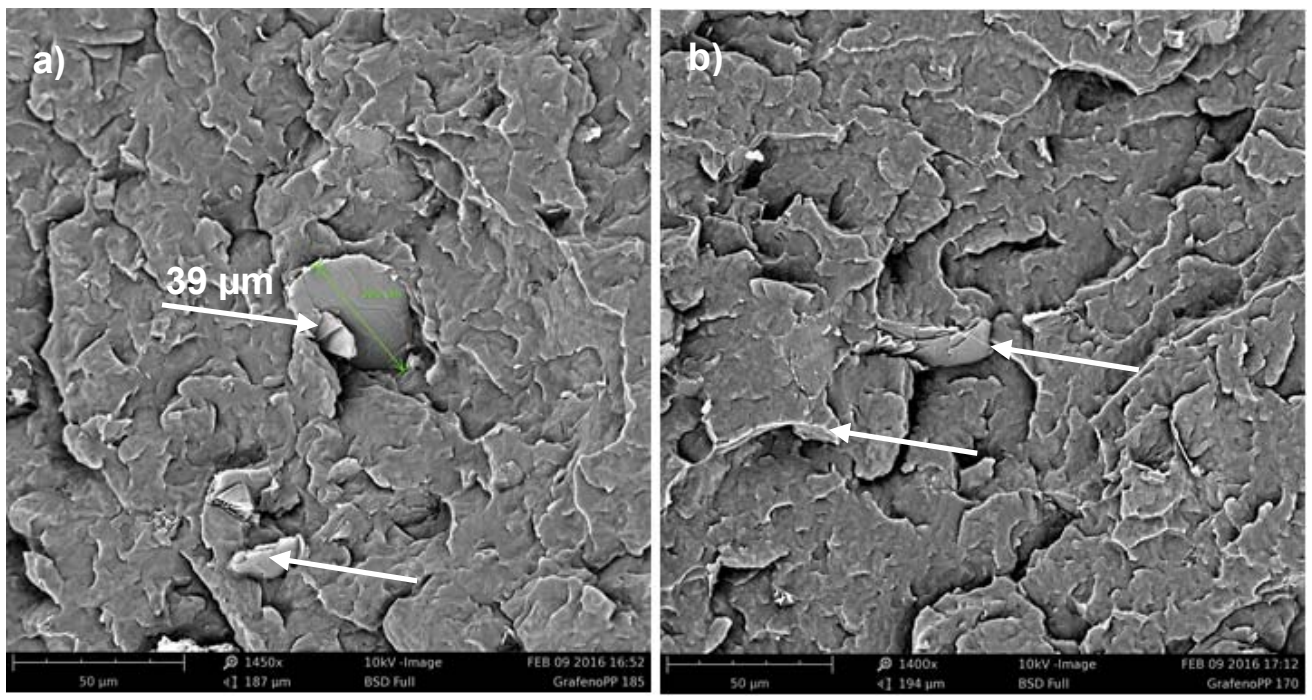

Figura 31. Imágenes SEM del compuesto B9-BC100-CD-G_1400x

Observando este mismo nanocompuesto (B9-BC100-CD-G) a mayores aumentos (ver Figura 32), se observa que predomina la morfología agregada compuestas por un gran número de capas de grafeno, a pesar de que es posible detectar algunas de estas láminas de grafeno de forma aislada en la matriz. Tal y como confirmó el espectro Raman de las partículas de GMC, el número de láminas que conforman la partícula es muy elevado. Las partículas observadas en el SEM harían referencia a partículas originales y no a aglomerados de las mismas. En el análisis de las imágenes de microscopia óptica se observaron partículas de gran tamaño para los compuestos procesados por compuesto directo. El análisis SEM confirma el gran tamaño del GMC, tanto en diámetro (plano x-y), como en espesor.

En relación a la compatibilidad química del grafeno con el PP, el carácter apolar de la matriz respecto a la nanocarga mucho más polar, da lugar a una baja interacción en la interfase. Aunque a priori la partícula puede quedar embebida en la matriz, en aquellas regiones donde se transfieren los esfuerzos mecánicos, se pueden apreciar zonas en las que no hay cohesión entre fases, pudiendo afectar negativamente en la transferencia de carga, (ver Figura 32b). Las muestras observadas en el SEM fueron obtenidas por criofractura, de forma que la rotura de la probeta se produce a través de las zonas o planos de debilidad, y en este caso, las partículas de grafeno actúan como concentradores de tensiones 
Esta baja adhesión podría mejorarse si la superficie de las partículas fuera sometida a tratamientos de modificación superficial que incorporasen grupos funcionales capaces de interaccionar con la matriz de polipropileno. Sin embargo, como es sabido, esos tratamientos afectan de forma negativa a la conductividad eléctrica a través de su superficie ${ }^{167}$.
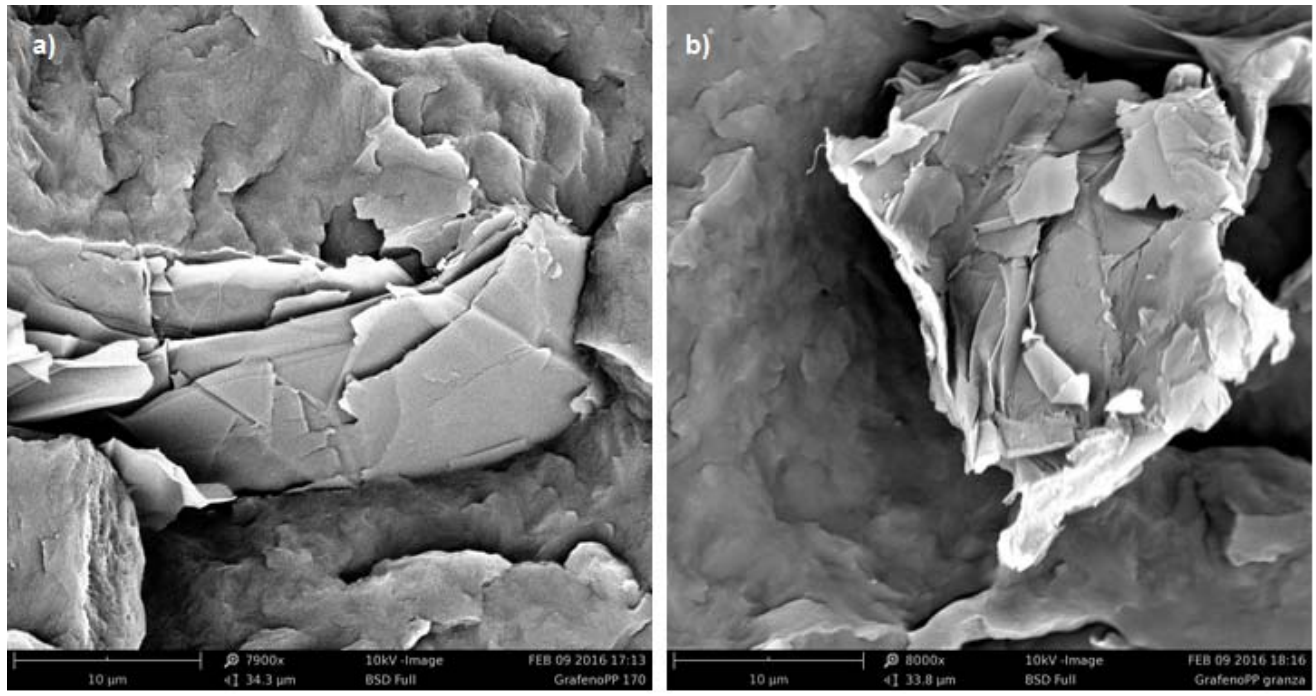

Figura 32. Imagen SEM del compuesto B9-BC100-CD-G_a) 7900x y b) 8000x

En la Figura 33 se muestran las imágenes SEM del nanocompuesto de GMC obtenido a alta cizalla y alto tiempo de residencia (B8-AC800-MB-G). Haciendo un análisis de la morfología general del nanocompuesto se observa que las partículas de GMC se encuentran en forma laminar distribuidas por la matriz y su espesor parece menor que el detectado con los compuestos obtenidos a baja cizalla. Algunas de las partículas medidas son de menor tamaño que las encontradas en los compuestos de baja cizalla. Si se comparan estos resultados con las imágenes de microscopía óptica, se observa misma tendencia obteniendo tamaños de partícula menores para los compuestos procesados a alta cizalla. En general, la relación de aspecto del GMC obtenido a alta cizalla es superior al encontrado en los compuestos obtenidos a baja cizalla y bajo tiempo de residencia teniendo en cuenta el menor número de capas observado en cada caso. 
En la Figura 34 se observa una partícula aislada a mayores aumentos. El número de capas del GMC es menor que el observado en la Figura 32. Por lo tanto, a pesar de que las partículas de grafeno puedan ser menores en diámetro, la reducción de espesor (número de capas) es mucho menor, aumentando la relación de aspecto y, en consecuencia, la eficacia del GMC. Se observa que el GMC se rompe en su plano x-y debido a la alta cizalla pero también se observan partículas de menor espesor (número de capas).

En la Figura 34 también se puede analizar la interfase PP/GMC. Nuevamente, se observa falta de unión entre el plano del GMC y la matriz de PP. Esta mala adhesión refleja la baja compatibilidad química de ambos materiales.
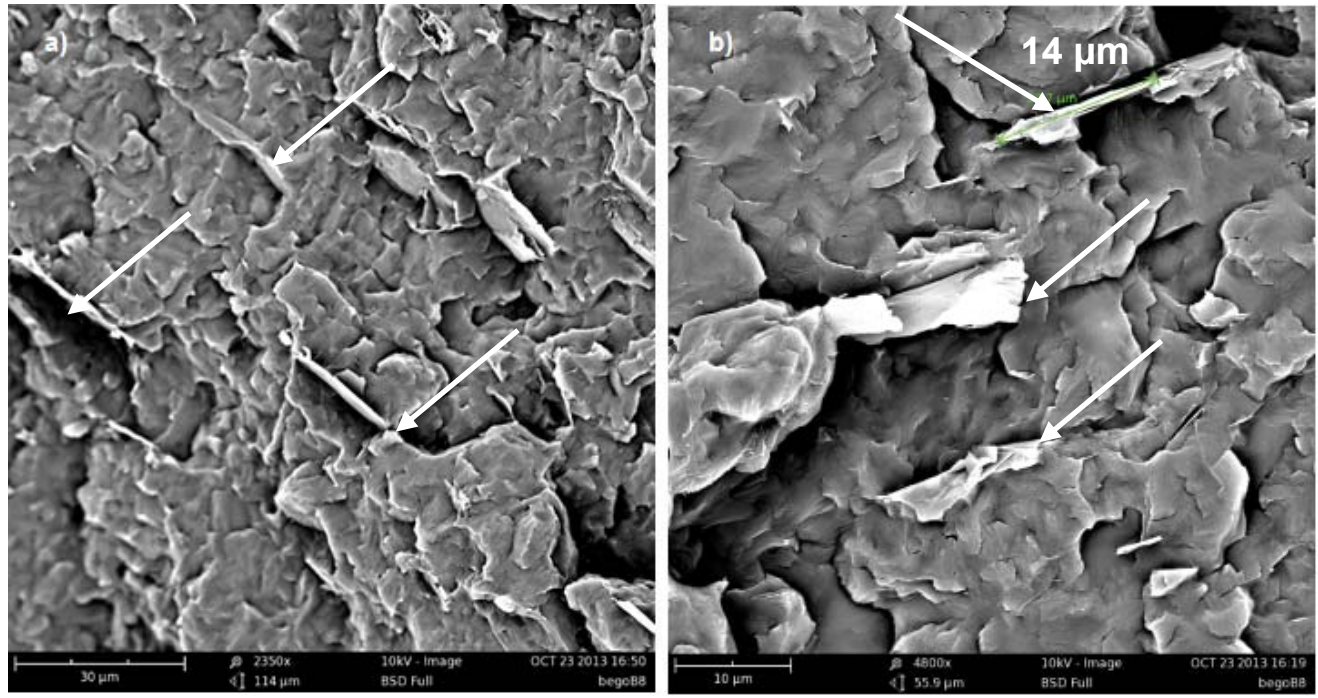

Figura 33. Imágenes SEM del compuesto B8-AC800-MB-G_a) 2350x, b) 4800x 


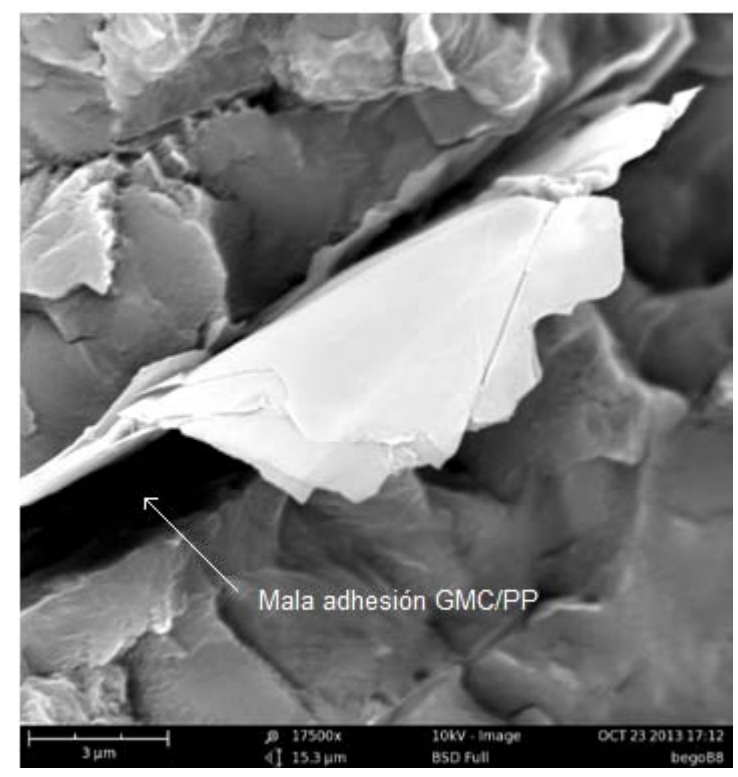

Figura 34. Imagen SEM del compuesto B8-AC800-MB-G_17500 


\subsubsection{Microscopía electrónica de transmisión (TEM)}

\section{A) Sistema PP/NTC:}

Se realizó microscopía electrónica de transmisión (TEM) para estudiar la estructura de los NTC en la matriz polimérica, ya que es una técnica de alta resolución que permite la evaluación del tamaño de los NTC y su disposición en la matriz polimérica. Se analizaron las siguientes muestras:

- B20-AC800-CD-NT, representando alta cizalla y tiempo de residencia bajos. (ver Figura 35a y Figura 35b)

- B24-AC800-MB-NT, representando alta cizalla y tiempo de residencia más altos. (ver Figura 35c y Figura 35d)

Analizando las imágenes TEM de ambos compuestos, se observa que las muestras obtenidas vía masterbatch (ver Figura 46c y Figura 35d) tienen menor número de aglomerados que las obtenidas por compound directo (ver Figura 35c y Figura 35d). Esto se debe a que con el masterbatch se aumenta el tiempo de residencia del compuesto en la extrusora, se somete a esfuerzos de cizalla durante más tiempo y se rompen los aglomerados en mayor medida que incorporando los NTC en forma de polvo. En algunas de las imágenes se observan NTC de mejor longitud pero no son concluyentes ya que se encontraron en ambos compuestos.

La ruptura de los NTC reduce su relación de aspecto, lo cual influye de manera directa en la efectividad de la nanocarga. La incorporación de NTC de poca longitud tiene muy poca influencia en las propiedades del polímero ${ }^{109}$. Por lo tanto el objetivo es dispersar adecuadamente los NTC en la matriz de polipropileno sin que los esfuerzos de cizalla aplicados provoquen la ruptura de los mismos. Se debe alcanzar un compromiso entre la dispersión y la relación de aspecto de los NTC en el nanocompuesto.

En todas las muestras analizadas se observaron NTC de menor tamaño dispersos de forma aislada. Por lo tanto, no se puede concluir que determinadas condiciones de extrusión provoquen una mayor ruptura de los NTC. Sin embargo, sí se observó una disminución de los aglomerados en las muestras obtenidas a partir de masterbatch o concentrados (ver Figura 35c y Figura 35d). La presencia de aglomerados es otro de los factores que reducen 
la efectividad de los NTC, tal y como se observó tras la revisión del estado del arte ${ }^{103}$. Así pues, la microscopía electrónica de transmisión concluye que altos tiempos de residencia son necesarios para obtener una buena dispersión de los NTC, siendo las muestras obtenidas a alta cizalla y alto tiempo de residencia las que presentan menor número de aglomerados de NTC.

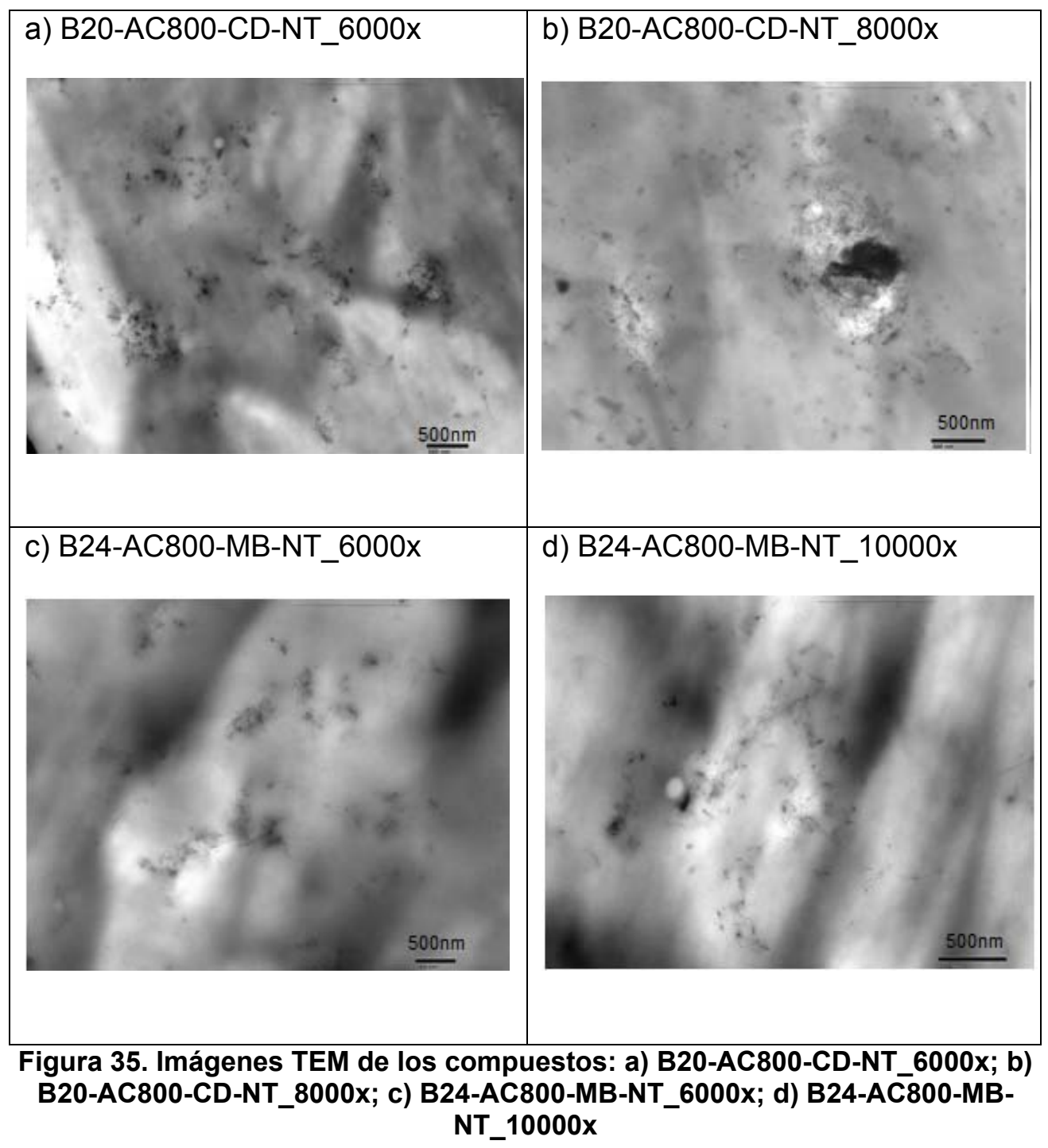




\section{B) Sistema PP/GMC:}

Se realizó microscopía electrónica de transmisión (TEM) para estudiar la estructura de los GMC en la matriz polimérica.

El análisis de los nanocompuestos de GMC por microscopía electrónica de transmisión fue difícil debido a la dificultad en la preparación de las muestras. La estructura laminar de la partículas de GMC y su gran tamaño en comparación con los NTC (en las imágenes SEM se observa que el plano el gran tamaño del plano $x-y$ del $G M C)$ ), provoca que las finas láminas se rompan al realizar el corte con el ultramicrotomo. Aun así, pudieron obtenerse imágenes tales como las mostradas en la Figura 36. Es difícil obtener una conclusión sobre la estructura del GMC en la matriz visualizando las imágenes TEM. En este caso las imágenes SEM fueron mucho más útiles en la caracterización de las mismas. Se observan láminas de grafeno en las imágenes obtenidas pero no son del todo representativas ya que las partículas con mayor número de capas producían agujeros al realizar el corte de la muestra y no pudieron ser analizadas. 


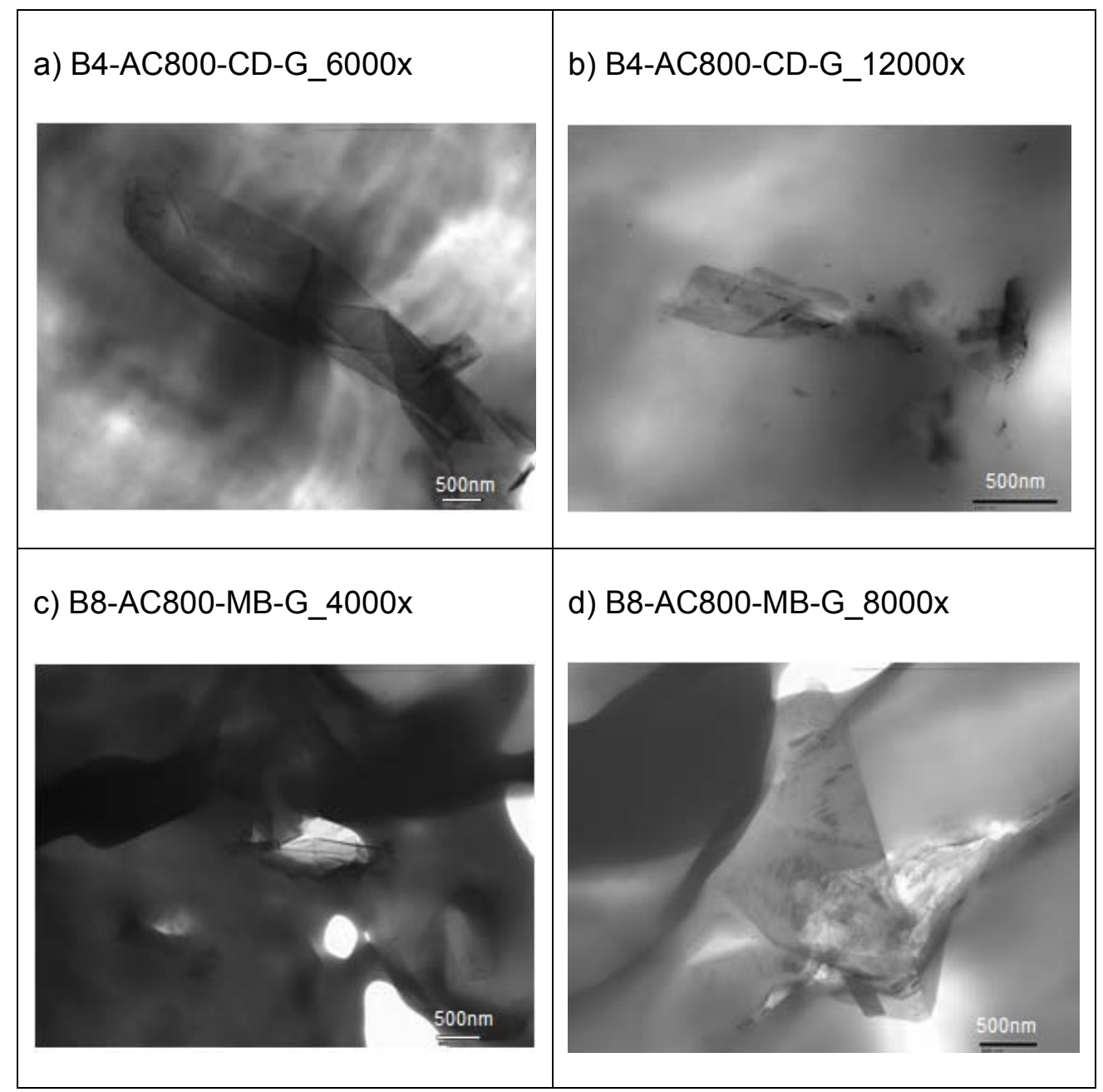

Figura 36. Imágenes TEM de los compuestos: a) B4-AC800-CD-G_6000x; b) B4-AC800-CD-G_12000x; c) B8-AC800-MB-G_4000x; d) B8-AC800-MB-G_8000x 


\subsubsection{Densidad de aglomerados}

Se analizó la densidad de aglomerados y el tamaño medio de las partículas para cuantificar la dispersión de ambas nanopartículas en cada uno de los nanocompuestos. Para ello se empleó un software de conteo de partículas sobre las imágenes de microscopía óptica. El método detallado se explica en el capítulo 3 de la presente memoria.

\section{A) Sistema PP/NTC:}

En la Figura 37 se representan gráficamente las densidades de aglomerados obtenidas para los nanocompuestos de nanotubos de carbono. El cálculo de las densidades de aglomerados se realizó según la Ecuación 6 del presente documento (capítulo 3). Se representa la densidad de aglomerados en función de la velocidad de extrusión para las diferentes configuraciones de husillo y metodologías de incorporación de las nanopartículas.

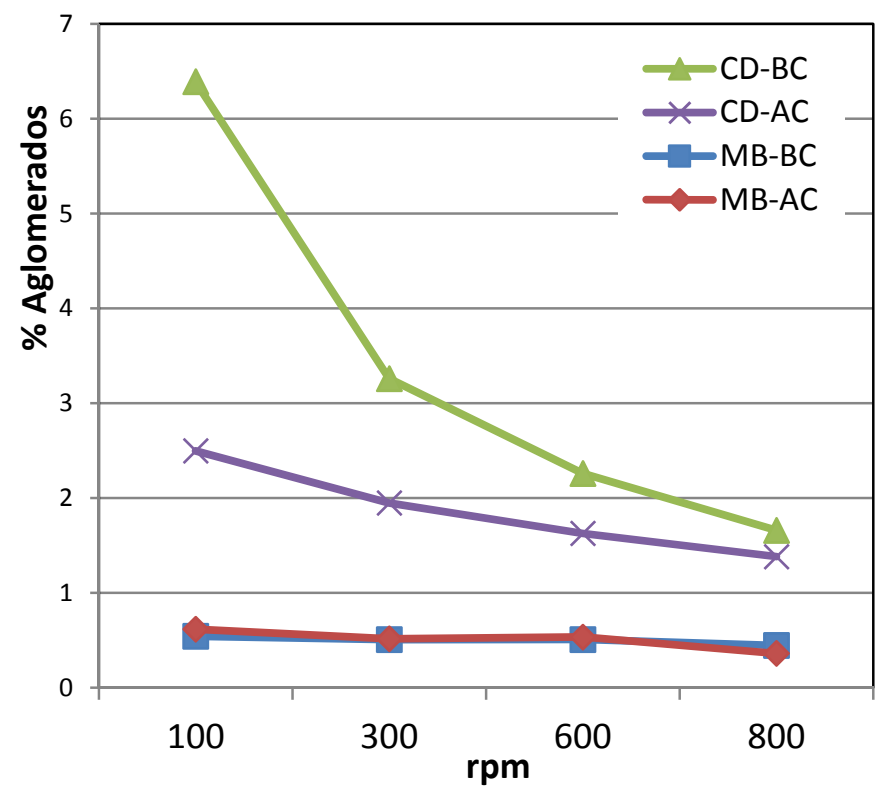

Figura 37. Proporción de aglomerados obtenidos en compuestos de PP $+1 \%$ MWCNT, en función de las velocidades de husillo empleadas. CD-BC (Compound directo-Husillo baja cizalla), CD-AC (Compound directo-Husillo alta cizalla), MB-BC (Masterbatch-Husillo baja cizalla), MB-AC (MasterbatchHusillo alta cizalla) 
Se observa que las muestras obtenidas a partir de compound directo son muy sensibles a la velocidad de extrusión. La densidad de aglomerados baja drásticamente al aumentar la velocidad del husillo. Este efecto se observa para todos los compuestos obtenidos a partir de la nanopartícula en polvo (CD- compound directo), tanto si se aplica un husillo de baja cizalla como si el husillo es menos agresivo. En consecuencia, siempre que se introduzcan los NTC en forma de polvo se debería extruir a altas velocidades husillo (800 rpm), ya que en este caso es el factor determinante para la obtención de una buena dispersión.

Sin embargo, en los compuestos obtenidos a partir de masterbatch la densidad de aglomerados es menos dependiente de la velocidad y de la configuración de husillo aplicada. Esto supone que al procesar dos veces el compuesto se asegura una mayor dispersión de partículas, alcanzando una densidad de aglomerados mínima del orden del 0,5\%. Estos resultados concuerdan con el análisis de dispersión basado en las micrografías estudiadas anteriormente, en las que se observaba una dispersión óptima de los NTC en condiciones de procesado de alta cizalla y alto tiempo de residencia (masterbatch).

Por otro lado, cabe destacar que, comparando los compuestos obtenidos a partir de masterbatch con aquellos obtenidos a partir de polvo, se observa una notable disminución de la densidad de aglomerados independientemente del resto de condiciones de procesado. Por ello, se puede predecir que la metodología de introducción de las nanopartículas será el factor más influyente para obtener una óptima dispersión.

Los valores de densidad de aglomerados obtenidos fueron introducidos como variable respuesta del diseño de experimentos detallado en el Capítulo 3, punto 3.2.1.2. Los factores a analiza son: metodología (compuesto directo o masterbatch), velocidad de husillo y configuración de husillo.

Se realizó el análisis de varianza ANOVA multifactorial llevado a cabo mediante el software Statgraphics. Los resultados del mismo se muestran en la Tabla 11. Los factores con un efecto significativo en la densidad de aglomerados son aquellos cuyo valor $\mathrm{P}$ es inferior al 0.05 . Es decir, se puede afirmar con un nivel de confianza del $95 \%$ que esos factores influyen en el 
valor de la densidad de aglomerados de la muestra. Por lo tanto, la velocidad de extrusión $(P=0.0418)$ y la metodología de introducción de los NTC $(P=0.0009)$ son los factores que influyen en la obtención de una densidad de aglomerados baja, destacando la metodología como factor más influyente.

Tabla 11: Análisis de Varianza para densidad de aglomerados. PP + 1\% NTC.

\begin{tabular}{|l|l|l|l|l|l|}
\hline Fuente & $\begin{array}{l}\text { Suma de } \\
\text { Cuadrados }\end{array}$ & Gl & Cuadrado Medio & $\begin{array}{l}\text { Razón- } \\
F\end{array}$ & Valor-P \\
\hline A:conf_husillo & 2,3141 & 1 & 2,3141 & 2,43 & 0,1452 \\
\hline B:rpm & 4,94882 & 1 & 4,94882 & 5,19 & 0,0418 \\
\hline C:metodología & 18,0589 & 1 & 18,0589 & 18,94 & 0,0009 \\
\hline Error total & 11,4419 & 12 & 0,953495 & & \\
\hline Total (corr.) & 36,7638 & 15 & & & \\
\hline
\end{tabular}

En la Figura 38 se representa el diagrama de Pareto para cada uno de los factores. Gracias a este diagrama se puede evaluar la magnitud e importancia de cada uno de los factores. El efecto de cada uno de los factores sobre la densidad de aglomerados se representa en forma de barra. El diagrama muestra el valor absoluto de los efectos y traza una línea de referencia en la gráfica. Cualquier efecto que se extienda más allá de esta línea de referencia es un factor influyente.

De todos los factores estudiados se confirma de nuevo la metodología de introducción de las nanopartículas como factor más influyente. Es decir, el empleo de masterbatch es la forma más eficaz de trabajar con NTC y obtener una dispersión óptima de los mismos. La incorporación de los NTC en forma de masterbatch implica un mayor tiempo de residencia de las nanopartículas en la extrusora. Por lo tanto, el material está sometido a esfuerzos de cizalla durante mayor tiempo, mejorando la dispersión de los mismos en la matriz de polipropileno. 


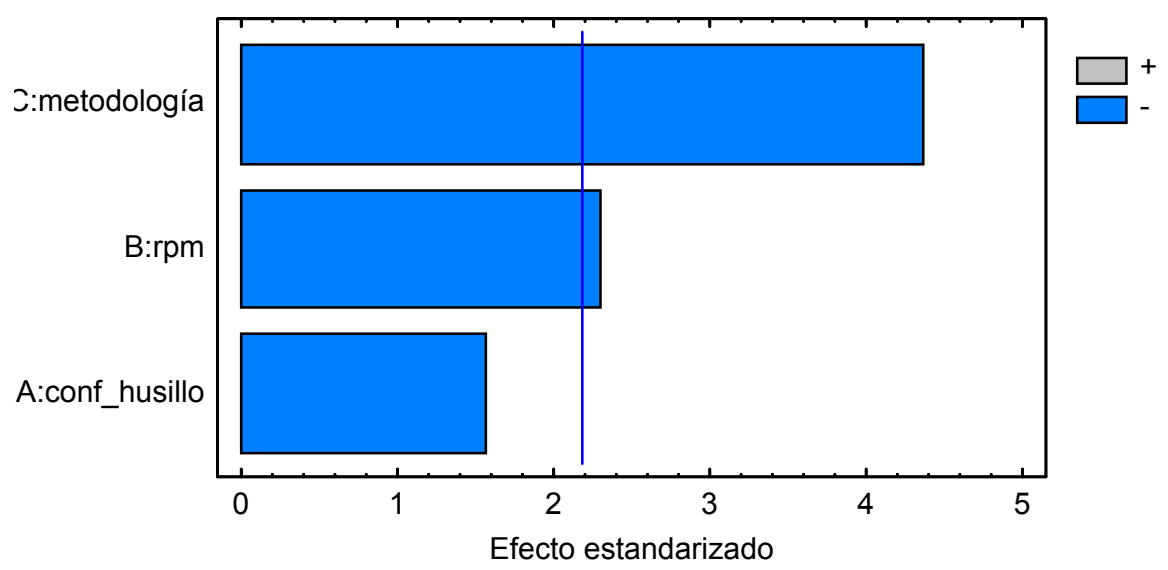

Figura 38. Diagrama de Pareto estandarizada para densidad de aglomerados. PP + 1\% MWCNT

El siguiente objetivo del análisis consiste en estudiar cómo influye la variación cada uno de los factores sobre la densidad de aglomerados con el fin de poder optimizar la dispersión al máximo. La

Figura 39 muestra cómo varía la densidad de aglomerados con cada uno de los factores estudiados. En el eje de abscisas se representan los diferentes niveles ensayados para cada uno de los factores.

Los resultados más positivos se alcanzaron empleando una configuración de husillo de alta cizalla, una alta velocidad de husillo e introduciendo los NTC en forma de masterbatch. 


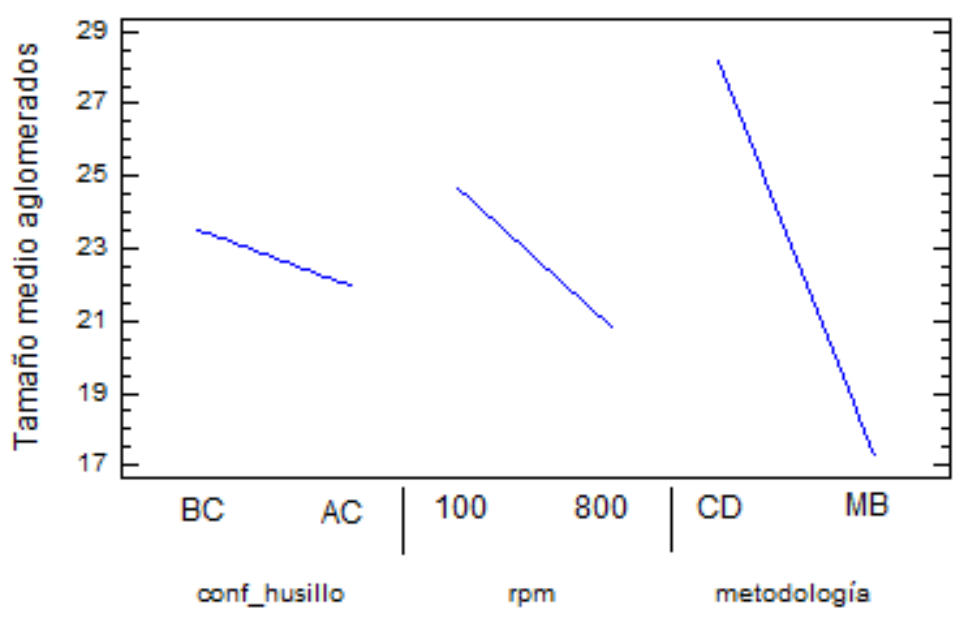

Figura 39. Gráfica de efectos principales para densidad de aglomerados. PP + $1 \%$ NTC.

\section{B) Sistema PP/GMC:}

La Figura 40 representa gráficamente las densidades de aglomerados obtenidas para los nanocompuestos de GMC. Se observa que las muestras obtenidas por compound directo disminuyen gradualmente la densidad de aglomerados al aumentar la velocidad del husillo, pero no tan drásticamente como en el caso de los compuestos de NTC. Al igual que para los NTC, las muestras obtenidas a partir del masterbatch no experimentan una variación considerable de la densidad de aglomerados al aumentar la velocidad del husillo, manteniendo la densidad de aglomerados con valores constantes alrededor del $3 \%$ en todas las condiciones de extrusión. 


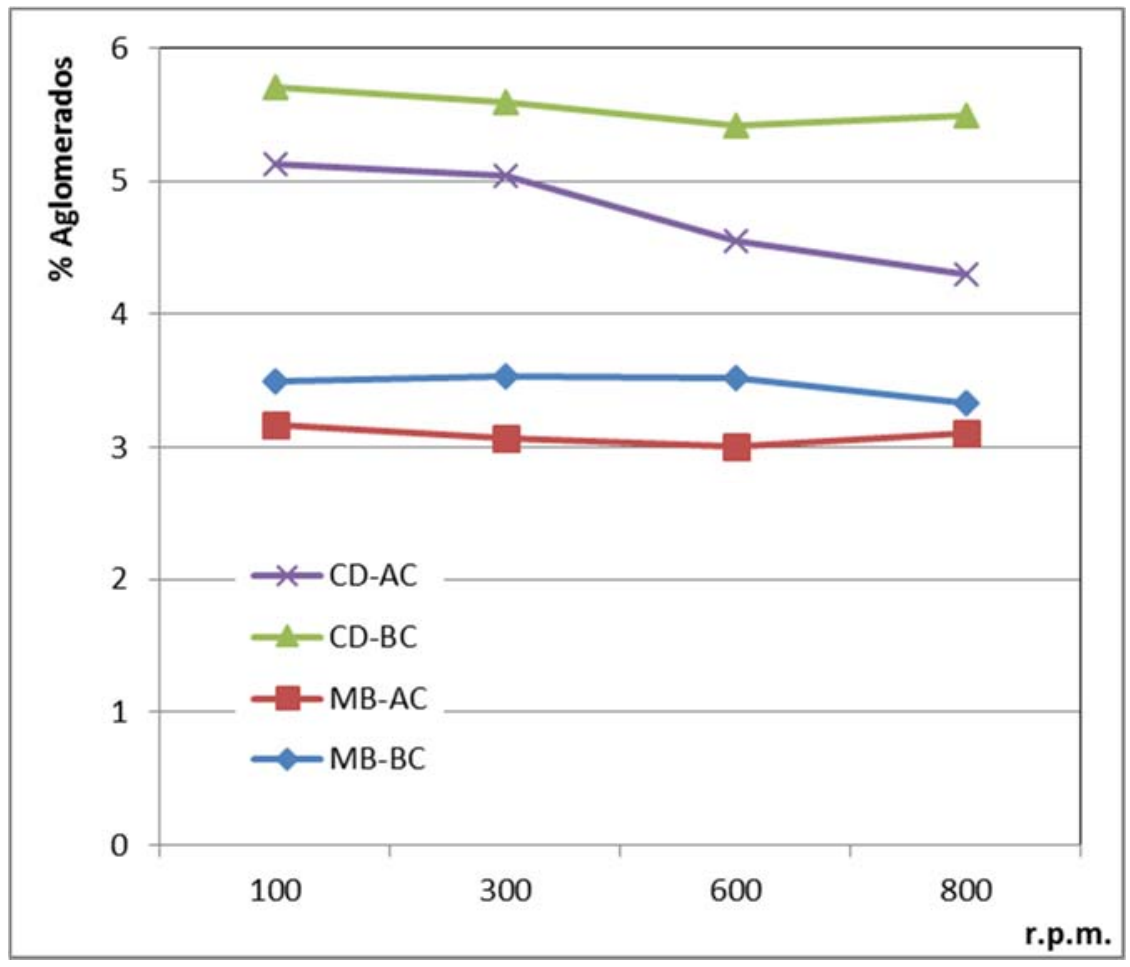

Figura 40. Proporción de aglomerados obtenidos en compuestos de PP $+1 \%$ GMC, en función de las velocidades de husillo empleadas. (CD-BC, Compound directo-Husillo baja cizalla. CD-AC, Compound directo-Husillo alta cizalla. MBBC, Masterbatch-Husillo baja cizalla. MB-AC, Masterbatch-Husillo alta cizalla.)

La Tabla 12 recopila los resultados del análisis de varianza ANOVA multifactorial para los nanocompuestos de GMC. Como se comentó en el análisis de los sistemas con NTC, se buscan aquellos factores cuyo valor $\mathrm{P}$ sea inferior al 0.05. La metodología de introducción del GMC destaca como factor de mayor influencia en la obtención de una baja densidad de aglomerados. Sin embargo, la velocidad de husillo no tiene una influencia destacable como en los nanocompuestos de NTC. 
Tabla 12: Análisis de Varianza para densidad de aglomerados. PP + 1\% GMC.

\begin{tabular}{|l|l|l|l|l|l|}
\hline Fuente & $\begin{array}{l}\text { Suma de } \\
\text { Cuadrados }\end{array}$ & Gl & Cuadrado Medio & $\begin{array}{l}\text { Razón- } \\
\text { F }\end{array}$ & Valor-P \\
\hline A:conf_husillo & 0,171086 & 1 & 0,171086 & 1,22 & 0,2916 \\
\hline B:rpm & 0,25718 & 1 & 0,25718 & 1,83 & 0,2011 \\
\hline C:metodología & 14,0201 & 1 & 14,0201 & 99,74 & 0,0000 \\
\hline Error total & 1,68675 & 12 & 0,140563 & & \\
\hline Total (corr.) & 16,1351 & 15 & & & \\
\hline
\end{tabular}

El diagrama de Pareto mostrando la influencia de cada uno de los factores se representa en la Figura 41. Se observa que sólo la metodología de introducción del GMC es un factor influyente en la densidad de aglomerados. Por lo tanto, tal y como ocurre con los nanocompuestos de NTC, el empleo de masterbatch de GMC es de gran importancia para maximizar la dispersión de las nanopartículas.

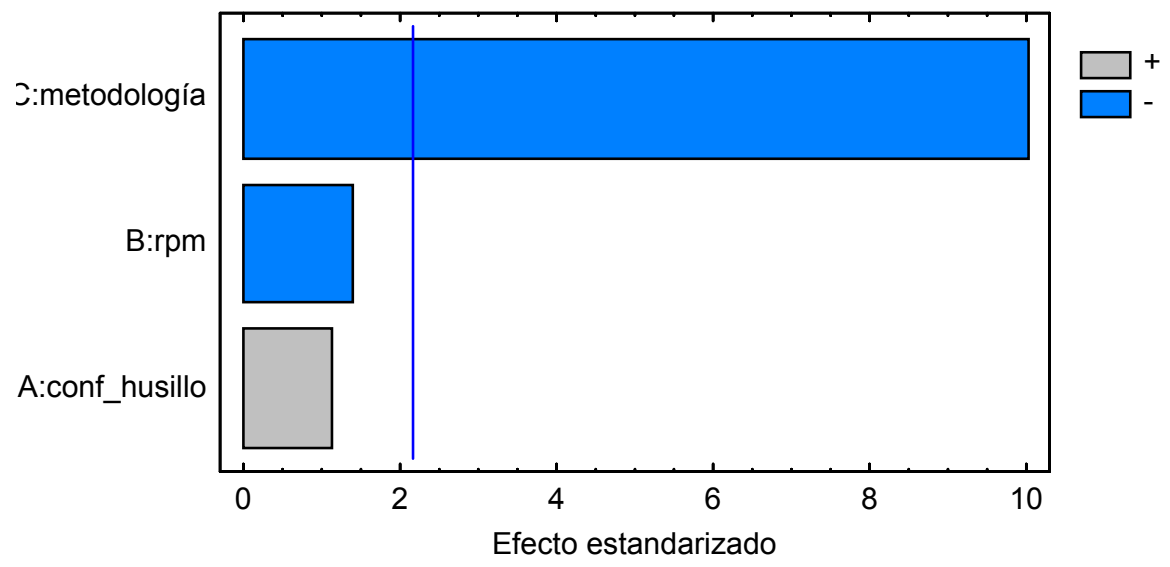

Figura 41. Diagrama de Pareto estandarizada para densidad de aglomerados. PP $+1 \%$ grafeno multicapa.

La influencia de cada uno de los parámetros de procesado estudiados se recoge en la Figura 42. Se confirma que el factor que mayor influencia tiene en la densidad de aglomerados del GMC es la metodología de trabajo, al igual que ocurría con los nanocompuestos de NTC. Sin embargo, en el caso del grafeno, la velocidad de husillo y la configuración del mismo no presentan tanta influencia. Por lo tanto, el tiempo de residencia del GMC en la extrusora se muestra nuevamente como un parámetro más influyente para obtener una buena dispersión del grafeno. Estos resultados coinciden con el análisis de 
las micrografías de los nanocompuestos en los que se observó una mejora de la dispersión trabajando con masterbatch, que ya se predijo como el factor de mayor importancia.

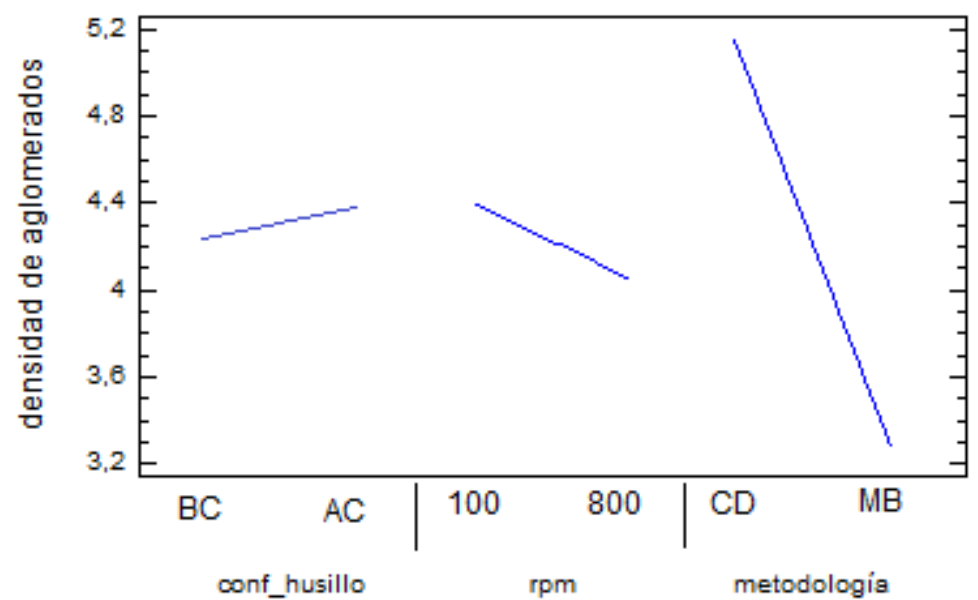

Figura 42. Gráfica de efectos principales para tamaño medio aglomerados. PP $+1 \%$ GMC 


\subsubsection{Tamaño medio de partícula}

\section{A) Sistema PP/NTC:}

El tamaño medio de partícula de los diferentes nanocompuestos se representa en la Figura 43, donde se muestran los valores obtenidos para cada velocidad de husillo y metodología de trabajo. Se observa la fuerte influencia del procesado en el tamaño medio de partícula, siendo de nuevo la metodología de introducción de los NTC el factor más influyente.

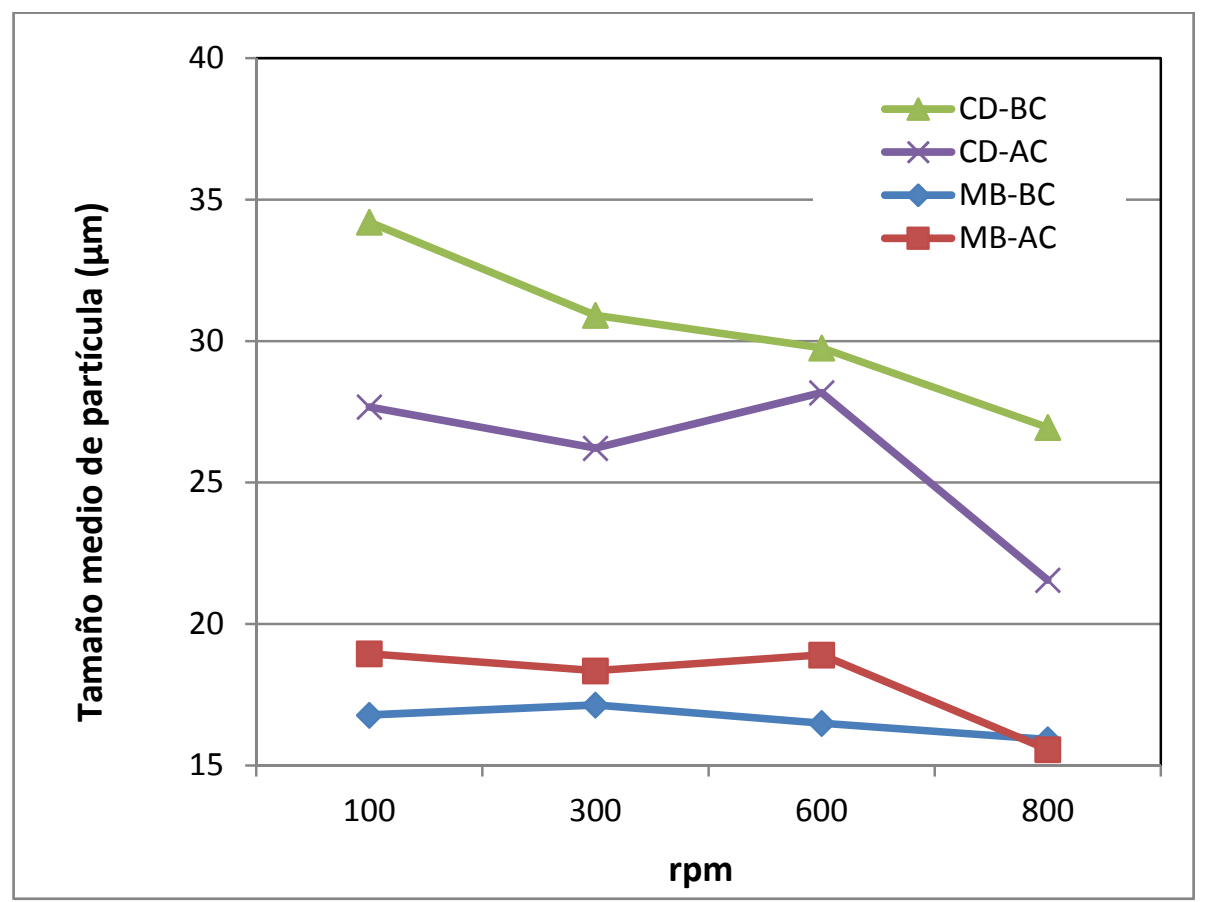

Figura 43. Tamaños de partículas obtenidos en compuestos de PP $+1 \%$ NTC (CD-BC, Compound directo-Husillo baja cizalla. CD-AC, Compound directoHusillo alta cizalla. MB-BC, Masterbatch-Husillo baja cizalla. MB-AC, Masterbatch-Husillo alta cizalla).

De nuevo se realizó el análisis de varianza ANOVA multifactorial pero introduciendo como variable respuesta el tamaño de aglomerados. Como resultado se confirmó la metodología de introducción de los NTC como factor más influyente, obteniendo un valor $P=0.0000$. En la Figura 44 se representa el diagrama de Pareto. No se muestran más detalles de los resultados del 
análisis por ser prácticamente similares a los obtenidos con la densidad de aglomerados. EL tamaño medio de partícula y la densidad de aglomerados están directamente relacionados. Se están analizando partículas a nivel microscópico. Tratándose de NTC, lo que se observa son aglomerados y los NTC individuales sólo serán vistos con microscopía SEM o TEM, tal y como se determinó en el estudio de la morfología. Cuanto más pequeño sea el tamaño de los aglomerados, significará que más cantidad de NTC están dispersos en la matriz y, en consecuencia, no serán visibles con microscopio óptico. Aplicando la fórmula para el cálculo de la densidad de aglomerados, a mayor área de muestra con aglomerados, menor dispersión de los nanotubos en la matriz. Por lo tanto, una menor densidad de aglomerados y un menor tamaño medio de los mismos indican que los NTC están mejor dispersos en la matriz de polipropileno.

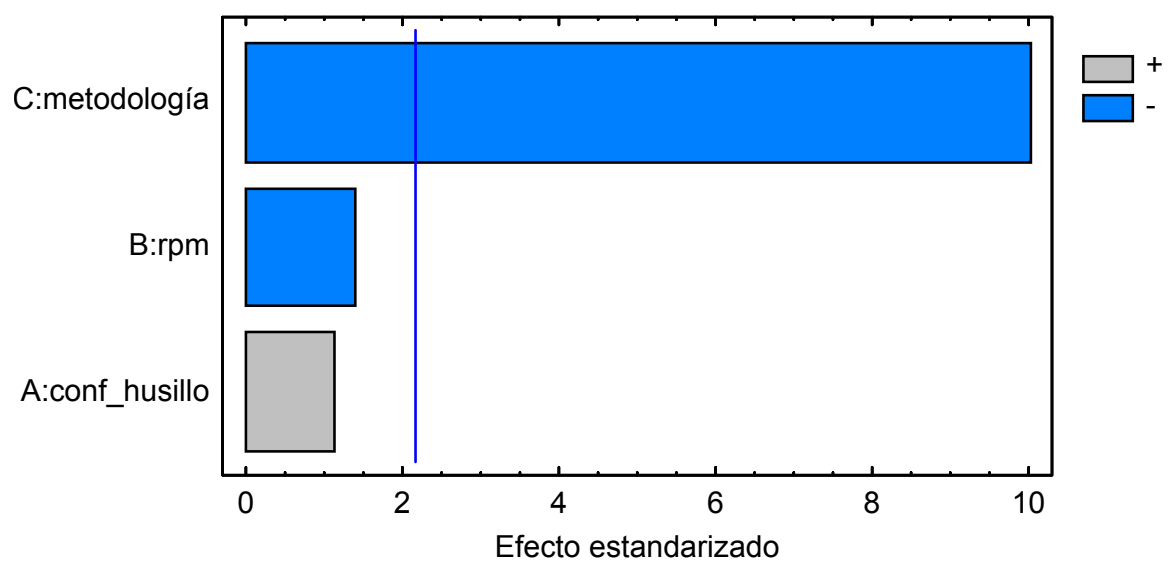

Figura 44. Diagrama de Pareto estandarizada para tamaño medio de aglomerados. PP $+1 \%$ NTC.

\section{B) Sistema PP/GMC:}

La Figura 45 representa la variación del tamaño medio de partícula con la velocidad de extrusión para nanocompuestos de GMC obtenidos con diferentes condiciones de procesado. En esta gráfica se observa la misma tendencia que para la densidad de aglomerados. A mayor cizalla y tiempo de residencia, se obtiene un menor tamaño medio de partícula. Pero también es de gran interés la comparación con los resultados obtenidos con los NTC. 
El estudio del tamaño medio de partícula apoyado de las micrografías ofrece una clara diferencia entre el grado de dispersión de los compuestos de grafeno y los de NTC. Como se puede observar en la Figura 45, y comparando con la Figura 43, los tamaños medios de partícula obtenidos en los compuestos de NTC son prácticamente el doble en tamaño que los obtenidos en los compuestos de GMC. Sin embargo, como se ha comprobado anteriormente, la densidad de aglomerados es mayor para los compuestos de grafeno.

Es difícil comparar partículas de diferente morfología. Un NTC dispersado en la matriz de PP no puede ser observado mediante microscopía óptica, a no ser que esté enrollado sobre sí mismo. Pero, aun así, teniendo una longitud de $1,5 \mu \mathrm{m}$, el tamaño de partícula visible al microscopio será muy pequeño. El caso de una partícula de GMC es diferente. Tiene una estructura laminar, que sólo es nanométrica en el plano z (o espesor) y micrométrica en el plano $\mathrm{x}-\mathrm{y}$ (o diámetro). Si se observa un nanocompuesto de GMC en el microscopio óptico sólo no serán visibles aquellas partículas con posición perpendicular al plano de observación. Las láminas con el resto de disposiciones serán visibles por el microscopio ya que el diámetro es de $5 \mu \mathrm{m}$. En consecuencia, un mayor número de partículas serán captadas por el microscopio y el área cubierta por partículas en la muestra será mayor, dando valores mayores de densidad de aglomerados aunque el tamaño medio de partícula sea inferior a los NTC. 


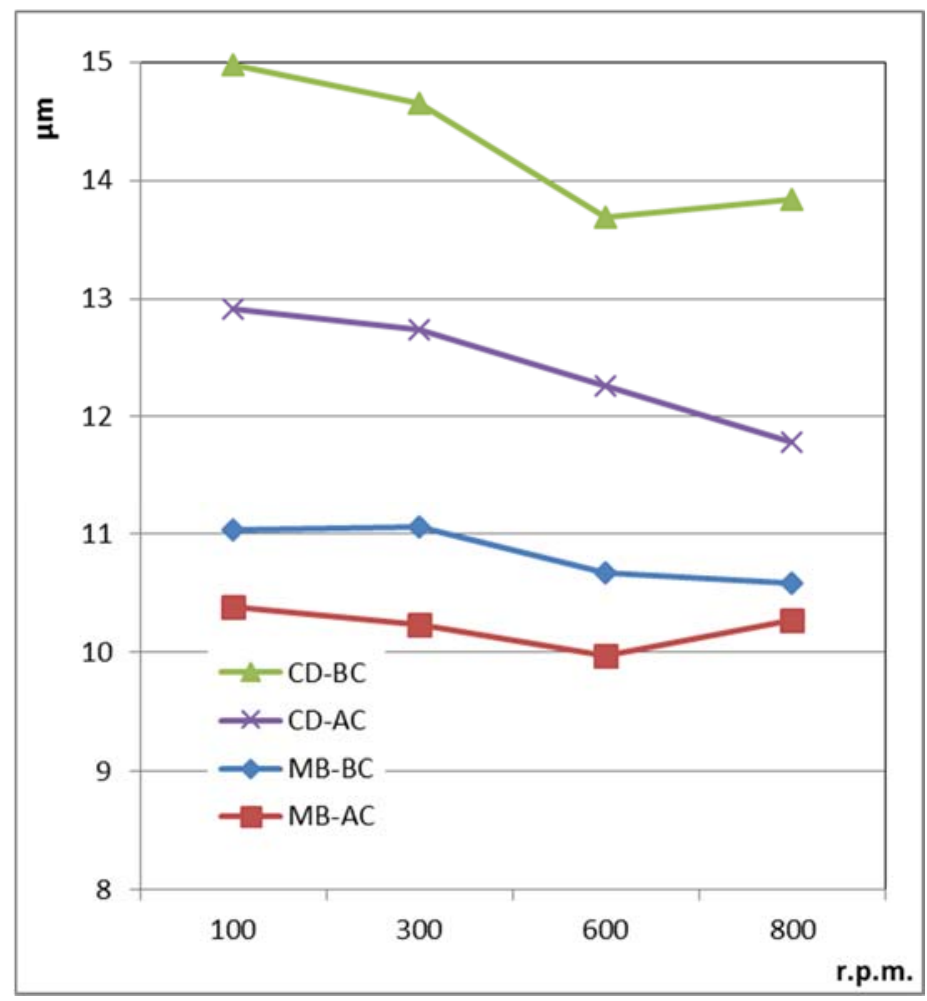

Figura 45. Tamaños medios de partículas obtenidos en compuestos de PP + $1 \%$ GMC. (CD-BC, Compound directo-Husillo baja cizalla. CD-AC, Compound directo-Husillo alta cizalla. MB-BC, Masterbatch-Husillo baja cizalla. MB-AC, Masterbatch-Husillo alta cizalla.)

El análisis de varianza ANOVA multifactorial para los nanocompuesto de GMC confirmó de nuevo que la metodología de introducción del GMC es como factor más influyente, obteniendo un valor $P=0.0000$. La Figura 46 muestra el diagrama de Pareto con la influencia de cada uno de los factores con respecto al tamaño medio de partículas de GMC. 


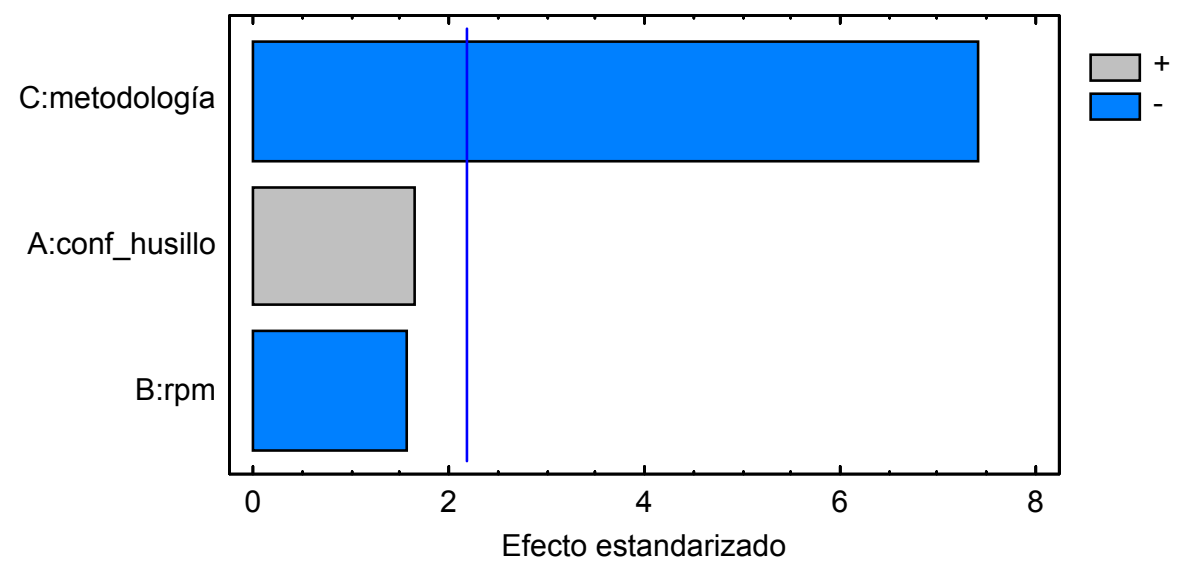

Figura 46. Diagrama de Pareto estandarizada para tamaño medio de aglomerados. PP + $1 \%$ GMC. 


\subsubsection{Histogramas}

Mediante histogramas se pretende comparar los resultados obtenidos, estudiando la frecuencia de repetición de los diferentes tamaños de partícula en las diferentes muestras.

\section{A) Sistema PP/NTC:}

A continuación se comparan los histogramas extraídos de las muestras de NTC obtenidas bajo las configuraciones más extremas de trabajo, es decir, la cizalla más baja y menor tiempo de residencia (Compound Directo-Baja Cizalla a $100 \mathrm{rpm}$-B25-BC100-CD-NT) versus la cizalla más alta y mayor tiempo de residencia (Masterbatch-Alta Cizalla a 800 rpm - B24-AC800-MBNT).

En el caso de los compuestos de NTC (Figura 47), los histogramas reflejan un incremento de la dispersión en los compuestos producidos mediante masterbatch, alta cizalla y alta velocidad. La distribución de tamaños de partícula es más homogénea en los compuestos producidos a alta cizalla por lo que se obtiene una mejor distribución de los NTC en la matriz de PP que se deberá reflejar en un calentamiento por microondas mucho más homogéneo. 


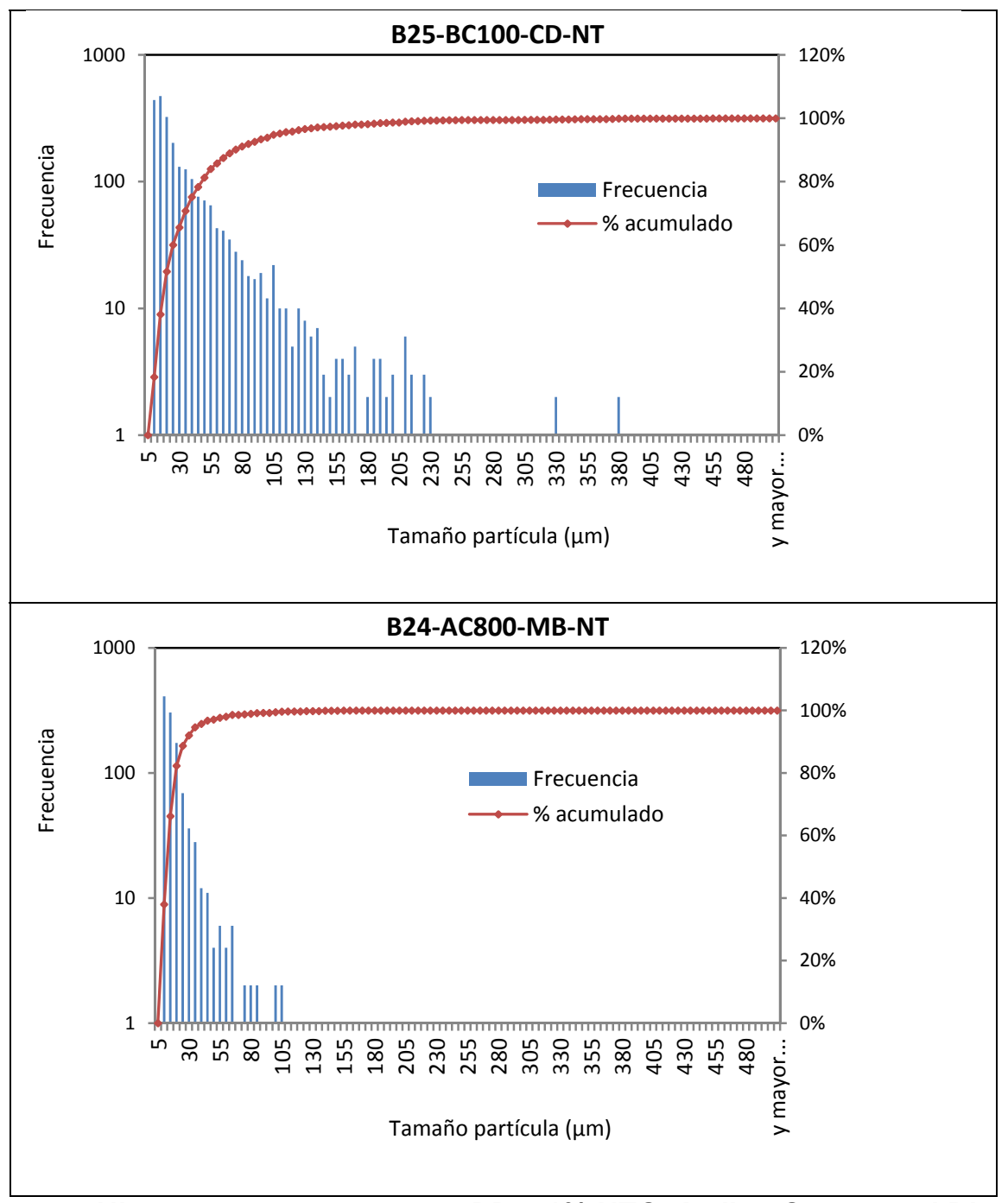

Figura 47. Histogramas compuestos PP + 1\% NTC. Arriba, Compound DirectoBaja Cizalla a 100rpm (B25-BC100-CD-NT). Abajo, Masterbatch-Alta Cizalla a 800rpm (B24-AC800-MB-NT)

\section{B) Sistema PP/GMC:}

A continuación se comparan los histogramas extraídos de las muestras de GMC obtenidas bajo las configuraciones más extremas de trabajo, es decir, la cizalla más baja y menor tiempo de residencia (Compound Directo-Baja Cizalla a $100 \mathrm{rpm}$ - B9-BC100-CD) versus la cizalla más alta y mayor tiempo 
de residencia (Masterbatch-Alta Cizalla a 800 rpm - B8-AC800-MB-G), ver Figura 48.

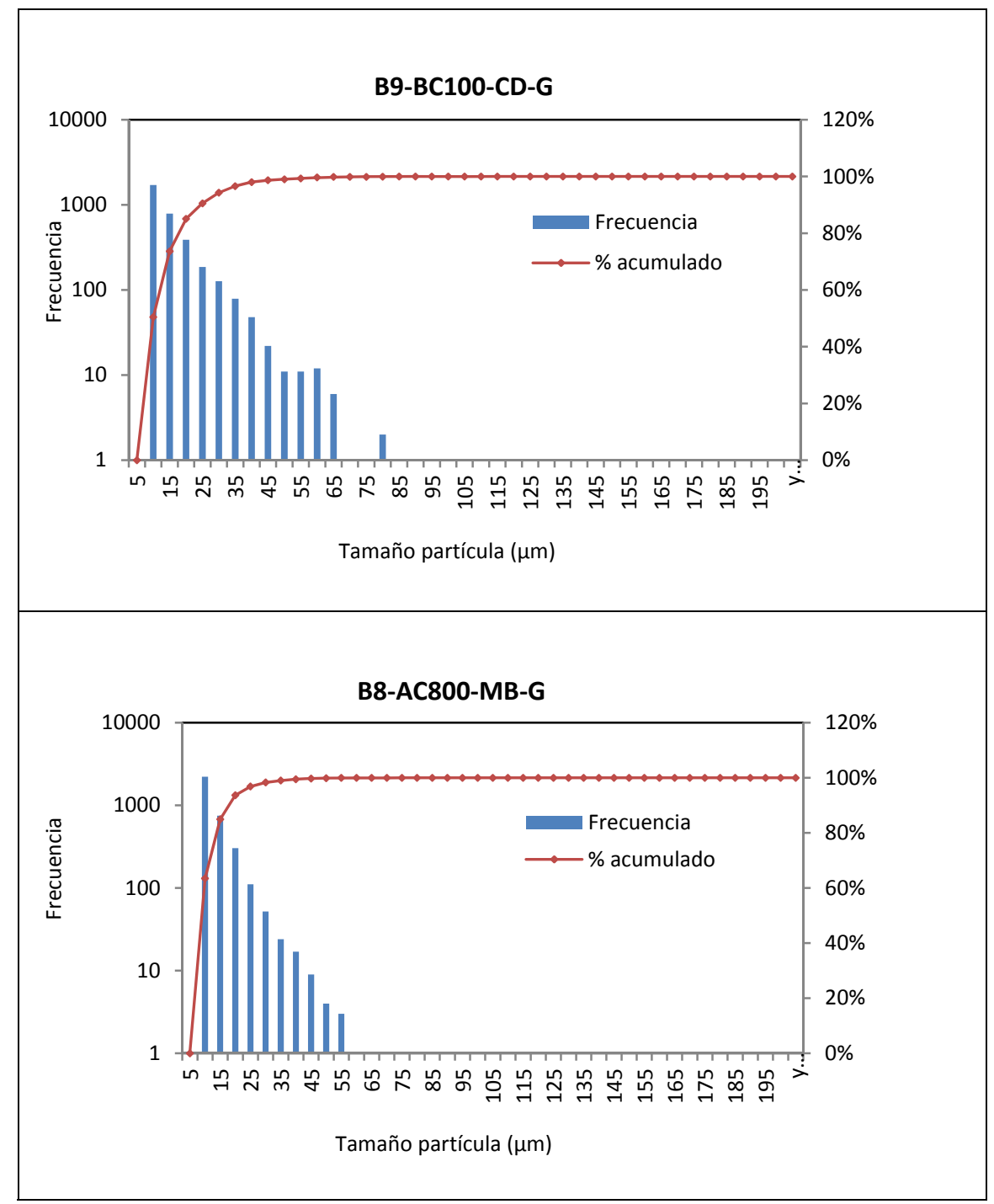

Figura 48. Histogramas compuesto PP + 1\% GMC. Izquierda, Compound Directo-Baja Cizalla a 100rpm (B9-BC100-CD-G). Derecha, Masterbatch-Alta Cizalla a 800rpm (B8-AC800-MB-G). 
En los histogramas de los compuestos de grafeno se observa que la distribución de tamaños de partícula se hace más estrecha a alta cizalla, resultando en un compuesto más homogéneo. Las diferencias entre los compuestos de GMC producidos a alta y baja cizalla no son tan grandes como los apreciados en los compuestos de NTC (Figura 47). Por lo tanto, se observa una mayor sensibilidad a las condiciones de procesado por parte de los nanocompuestos de NTC.

\subsection{5. Î́ndice de dispersión}

Se calculó el factor de dispersión para cada muestra con la fórmula que se muestra a continuación (Ecuación $7^{168}$ ). Este factor muestra el porcentaje total de carga que ha quedado correctamente disperso en la matriz polimérica. Como se observa en la fórmula, el factor de dispersión es otra forma de hacer referencia a la densidad de aglomerados, pero teniendo en cuenta la fracción volumétrica de las nanopartículas en el nanocompuesto. Este método para cuantificar la dispersión de los NTC es una adaptación de la norma "ASTM test method D2663" para el cálculo de la dispersión de negro de humo en caucho.

$$
D=\left(1-\rho \frac{\frac{A}{A 0}}{\phi v o l}\right) 100 \quad \text { Ecuación } 7
$$

Donde $A / A_{0}$ es la densidad de aglomerados, $\rho$ es el factor efectivo de los NTC que no están aglomerados (se considera 0.25 para los NTC ${ }^{166}$ ) y $\Phi_{\text {vol }}$ es la fracción volumétrica de NTC tomando la densidad de los NTC como 1.75 $\mathrm{g} / \mathrm{cm}^{3}$.

El factor de dispersión es de gran utilidad para comparar diferentes grados de dispersión en muestras con diferente contenido de nanopartículas. En este caso el contenido de nanopartícula es constante por lo que el valor obtenido es comparable a la densidad de aglomerados de la muestra.

\section{A) Sistema PP/NTC}

En el caso de los nanocompuestos de NTC, debido a que todas las muestras eran semiconductoras se pudo obtener la relación entre factor de dispersión 
(D), energía mecánica específica (SME) y conductividad eléctrica ( $\sigma$ ). Más adelante se estudiarán las propiedades eléctricas de los nanocompuestos pero se incluyen en este apartado para correlacionar los resultados con el índice de dispersión y la energía mecánica específica.

Antes de analizar los resultados obtenidos se debe introducir el término de energía mecánica específica de un proceso de mezclado en fundido en extrusora co-rotativa doble husillo. La energía mecánica específica (SME) de un proceso hace referencia a la energía mecánica que la extrusora aplica a un material durante el procesado del mismo. Es una herramienta muy útil a la hora de comparar o escalar procesos. Compuestos obtenidos con diferentes husillos, temperatura o velocidad de extrusión pueden obtener materiales con propiedades similares, siempre y cuando la SME de dos procesos sea similar. La fórmula que define la energía mecánica específica se detalla en la Ecuación 8.

$S M E\left[\frac{\mathrm{kw}}{\mathrm{kg} / \mathrm{h}}\right]=\frac{K W_{\text {motor }} \times T(\%) \times \frac{v_{\text {proceso }}(r p m)}{v_{\text {max. }}(r p m)} \times \varepsilon(\%)}{Q(\mathrm{~kg} / \mathrm{h})}$

Ecuación 8

KWmotor= potencia de la máquina

$\% \mathrm{~T}=$ par motor aplacado del proceso (\%)

Vproceso $=$ velocidad de los husillos durante

el proceso (rpm)

Vmax $=$ velocidad máxima de la máquina $(\mathrm{rpm})$

$\varepsilon=$ eficiencia del motor $(0.97)$

$\mathrm{Q}=$ producción $(\mathrm{kg} / \mathrm{h})$ 
Por tanto, la forma adecuada de referirse a la cizalla en un proceso de compounding es indicando la energía mecánica específica ya que tiene en cuenta todos los parámetros que intervienen en el proceso de producción.

Una vez calculada la SME y la conductividad eléctrica de los compuestos (metodología detallada en el capítulo 3), se compararon con los índices de dispersión de cada nanocompuesto para relacionar las condiciones óptimas de procesado, con la dispersión y conductividad alcanzada en los compuestos. Los datos obtenidos se muestran en la Tabla 13.

Tabla 13. Factor de dispersión, SME y conductividad de los nanocompuestos de NTC

\begin{tabular}{|c|c|c|c|}
\hline Muestra & $\begin{array}{c}\text { Factor de } \\
\text { dispersión (D) }\end{array}$ & SME $(\mathrm{kWh} / \mathrm{kg})$ & $\begin{array}{c}\text { Conductividad } \\
(\mathrm{S} / \mathrm{sq})\end{array}$ \\
\hline B17-AC100-CD-NT & 95,84 & 0,099 & $5,7 \mathrm{E}-04$ \\
\hline B18-AC300-CD-NT & 96,76 & 0,207 & $5,8 \mathrm{E}-04$ \\
\hline B19-AC600-CD-NT & 96,59 & 0,397 & $4,3 \mathrm{E}-04$ \\
\hline B20-AC800-CD-NT & 97,11 & 0,481 & $1,1 \mathrm{E}-03$ \\
\hline B21-AC100-MB-NT & 98,71 & 0,093 & $2,2 \mathrm{E}-03$ \\
\hline B22-AC300-MB-NT & 98,92 & 0,225 & $3,7 \mathrm{E}-03$ \\
\hline B23-AC600-MB-NT & 98,88 & 0,397 & $3,0 \mathrm{E}-03$ \\
\hline B24-AC800-MB-NT & 99,24 & 0,481 & $3,2 \mathrm{E}-03$ \\
\hline B25-BC100-CD-NT & 86,64 & 0,135 & $1,0 \mathrm{E}-07$ \\
\hline B26-BC300-CD-NT & 93,18 & 0,26 & $1,0 \mathrm{E}-07$ \\
\hline B27-BC600-CD-NT & 95,27 & 0,45 & $8,7 \mathrm{E}-05$ \\
\hline B28-BC800-CD-NT & 96,53 & 0,55 & $9,1 \mathrm{E}-04$ \\
\hline B29-BC100-MB-NT & 98,86 & 0,144 & $1,0 \mathrm{E}-07$ \\
\hline B30-BC300-MB-NT & 98,94 & 0,27 & $6,9 \mathrm{E}-04$ \\
\hline B31-BC600-MB-NT & 98,93 & 0,486 & $5,2 \mathrm{E}-03$ \\
\hline B32-BC800-MB-NT & 99,07 & 0,577 & $8,1 \mathrm{E}-03$ \\
\hline
\end{tabular}

Para analizar los resultados de forma más visual se obtuvo una gráfica tridimensional, ver Figura 49. De este gráfico se obtiene como conclusión que la conductividad eléctrica está altamente relacionada con el grado de dispersión de los NTC. Mejores valores de conductividad de obtuvieron con altos factores de dispersión (superiores al 99\%), los cuales pudieron ser obtenidos con unas condiciones de procesado que aseguraran una energía mecánica específica alrededor de $0.5 \mathrm{kWh} / \mathrm{kg}$ (área de color rojo en el gráfico). 
Los mejores resultados de dispersión y conductividad de obtuvieron para la muestra B24-AC800-MB-NT. Por este motivo, se seleccionarán estas condiciones para preparar compuestos con diferentes porcentajes de NTC y que serán analizados en el siguiente Capítulo.

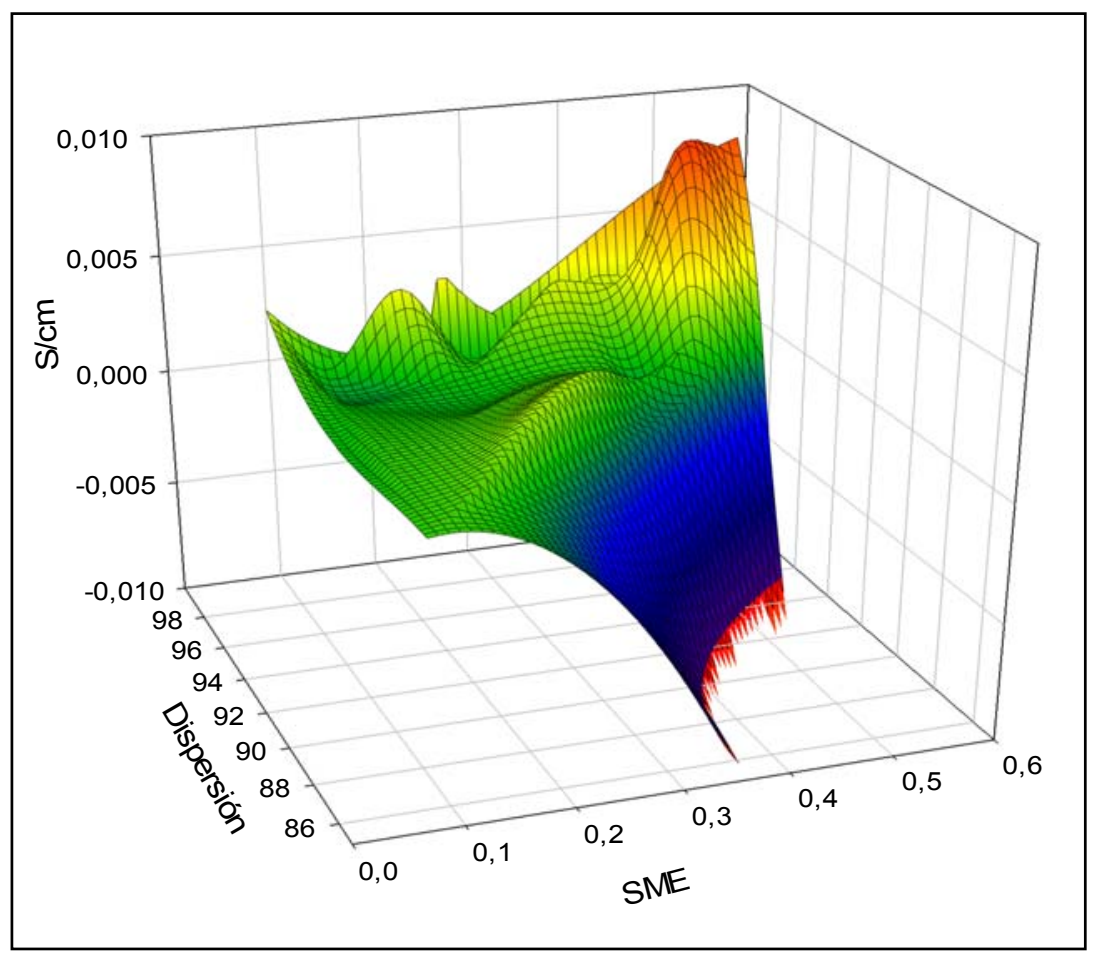

Figura 49. Gráfico 3D: Dispersión vs SME vs conductividad 


\section{B) Sistema PP/GMC:}

El factor de dispersión también se calculó para los nanocompuestos de GMC según la Ecuación 7. Como factor efectivo de las partículas GMC que no están aglomerados se tomó el mismo valor que para los NTC $(\rho=0.25)$ y la fracción volumétrica se calculó tomando la densidad del GMC como $2 \mathrm{~g} / \mathrm{cm}^{3}$ (obtenido de XGScience). Los resultados se recopilan en la Tabla 14.

Tabla 14. Factor de dispersión de los compuestos de GMC

\begin{tabular}{|c|c|c|}
\hline Muestra & $\begin{array}{c}\text { Factor de } \\
\text { dispersión } \\
(\%)\end{array}$ & SME $(\mathrm{kWh} / \mathrm{kg})$ \\
\hline B1-AC100-CD-G & 88,06 & 0,091 \\
\hline B2-AC300-CD-G & 88,30 & 0,170 \\
\hline B3-AC600-CD-G & 88,68 & 0,257 \\
\hline B4-AC800-CD-G & 88,53 & 0,397 \\
\hline B5-AC100-MB-G & 93,36 & 0,089 \\
\hline B6-AC300-MB-G & 93,59 & 0,184 \\
\hline B7-AC600-MB-G & 93,40 & 0,298 \\
\hline B8-AC800-MB-G & 93,79 & 0,394 \\
\hline B9-BC100-CD-G & 89,28 & 0,103 \\
\hline B10-BC300-CD-G & 89,46 & 0,193 \\
\hline B11-BC600-CD-G & 90,47 & 0,364 \\
\hline B12-BC800-CD-G & 91,01 & 0,481 \\
\hline B13-BC100-MB-G & 92,70 & 0,010 \\
\hline B14-BC300-MB-G & 92,60 & 0,189 \\
\hline B15-BC600-MB-G & 92,63 & 0,367 \\
\hline B16-BC800-MB-G & 93,02 & 0,405 \\
\hline
\end{tabular}

A diferencia de los sistemas con NTC, en este caso no se pudo relacionar la conductividad eléctrica con el factor de dispersión ya que ninguna de las muestras era semiconductora (conductividad $>10^{-6} \mathrm{~S} / \mathrm{cm}$ ) con un $1 \%$ de GMC.

En concordancia con los resultados obtenidos para los nanocompuestos de NTC, se observa que en este caso la muestra B8-AC800-MB-G presenta una mejor dispersión $(93,79 \%)$, presentando también valores máximos de energía mecánica específica (SME). Sin embargo, llama la atención que la energía mecánica específica es menor que la obtenida para los NTC. Esto quiere decir que la extrusora necesita menos energía para mezclar el GMC en 
comparación con los NTC. Con el fin de analizar en más detalle este efecto se estudiaron las propiedades reológicas de ambos sistemas. 


\subsection{Propiedades reológicas}

Se estudiaron las propiedades reológicas de los nanocompuestos procesados en condiciones extremas, tal y como se hizo en el análisis morfológico, con el fin de obtener conclusiones más claras y determinantes de la influencia del procesado en las propiedades reológicas del nanocompuesto.

\section{A) Sistema PP/NTC}

En la Figura 50 se representa la viscosidad dinámica versus frecuencia con el objetivo de analizar los cambios de viscosidad a bajas frecuencias como indicativo del grado de dispersión y de la relación de aspecto de los mismos en la matriz de PP.

A bajas frecuencias las muestras procesadas a alta cizalla o vía masterbatch muestran un aumento de la viscosidad respecto el PP virgen. El aumento de la viscosidad es indicativo de una mejora en la dispersión de las nanopartículas. Por ese motivo, la muestra B25, obtenida a baja cizalla y compound directo (CD), no aumenta la viscosidad en gran medida en el rango de bajas frecuencias. Estos resultados coinciden con lo observado durante el estudio micrográfico, donde se obtuvo una dispersión de los NTC en la matriz muy deficiente.

El aumento de la viscosidad a bajas frecuencias también está relacionado con el aumento de la relación de aspecto de los NTC, por lo que se podría concluir que a alta cizalla y alto tiempo de residencia se desenmarañan los aglomerados de NTC, obteniendo mayor número nanotubos individuales. Estos mismos resultados concuerdan con el análisis morfológico previo en el que se observaba menor número de aglomerados con dichas condiciones de procesado, factor que tiene una influencia directa en la efectividad de los NTC $y$, por lo tanto, en las propiedades finales del nanocompuesto.

A altas frecuencias las muestras procesadas con una configuración de husillo de alta cizalla y alta velocidad de extrusión muestran una reducción en la viscosidad. Esto podría indicar que la matriz se está degradando debido a la rotura de cadenas de PP con dichas condiciones de procesado. Esta posible 
degradación será estudiada por espectroscopia de infrarrojo (FTIR) más adelante.

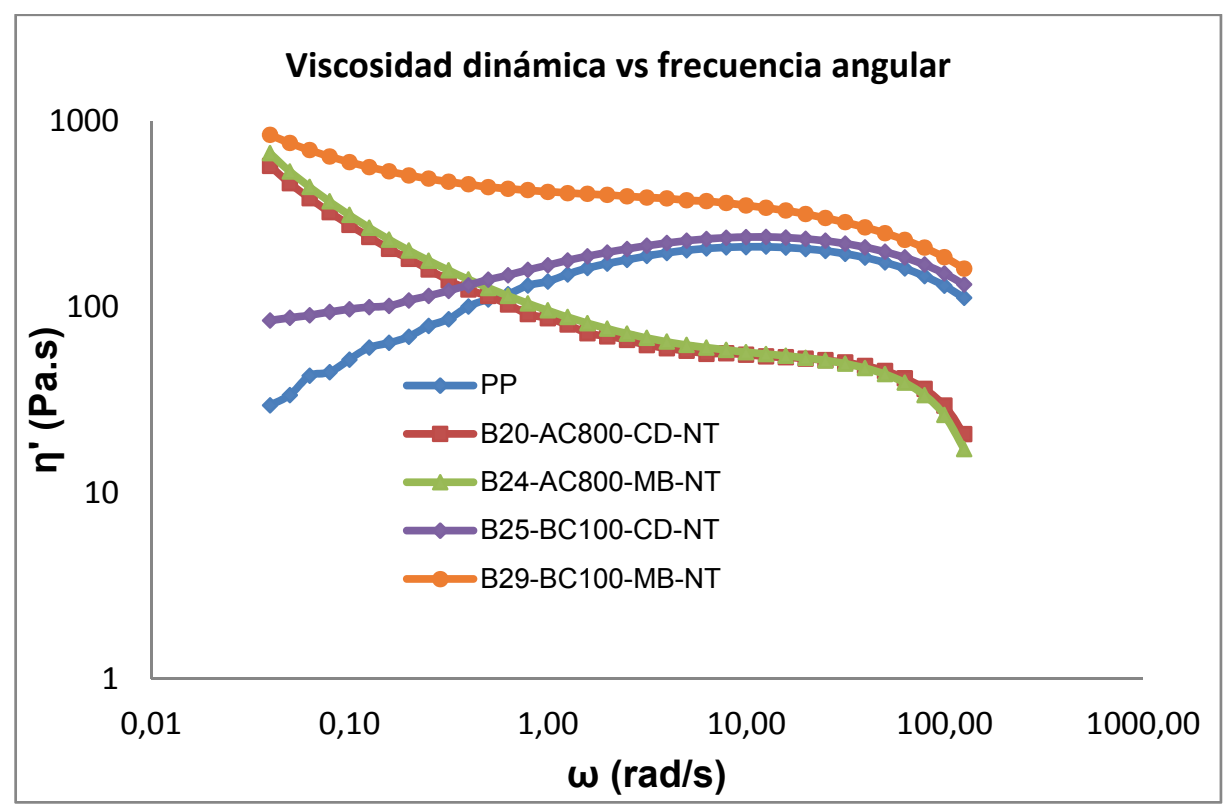

Figura 50. Viscosidad dinámica vs frecuencia angular para los nanocompuestos de NTC

La Figura 51 muestra la variación del módulo de almacenamiento con la frecuencia. Esta gráfica se emplea para estudiar la microestructura de los nanocompuestos, ya que aparece un "plateau" en la curva a bajas frecuencias como indicativo de la interconexión de las nanopartículas. Por lo tanto, cuando las curvas muestran una pendiente muy poco acusada a bajas frecuencias ("plateau") es indicativo de la interconexión y formación de la red de NTC. Las muestras B20 y B24, obtenidas a alta cizalla y alta velocidad de husillo, muestran esta zona "plateau" a bajas frecuencias (marcada en la gráfica). Por este motivo, cabe esperar que estos nanocompuestos muestren mejores propiedades eléctricas que aquellos obtenidos con condiciones de procesado poco agresivas. Sin embargo, en los nanocompuestos obtenidos con baja cizalla y baja velocidad no se observa dicho "plateau". Al estudiar las propiedades eléctricas se deberán observar unos valores menores para estas muestras. 


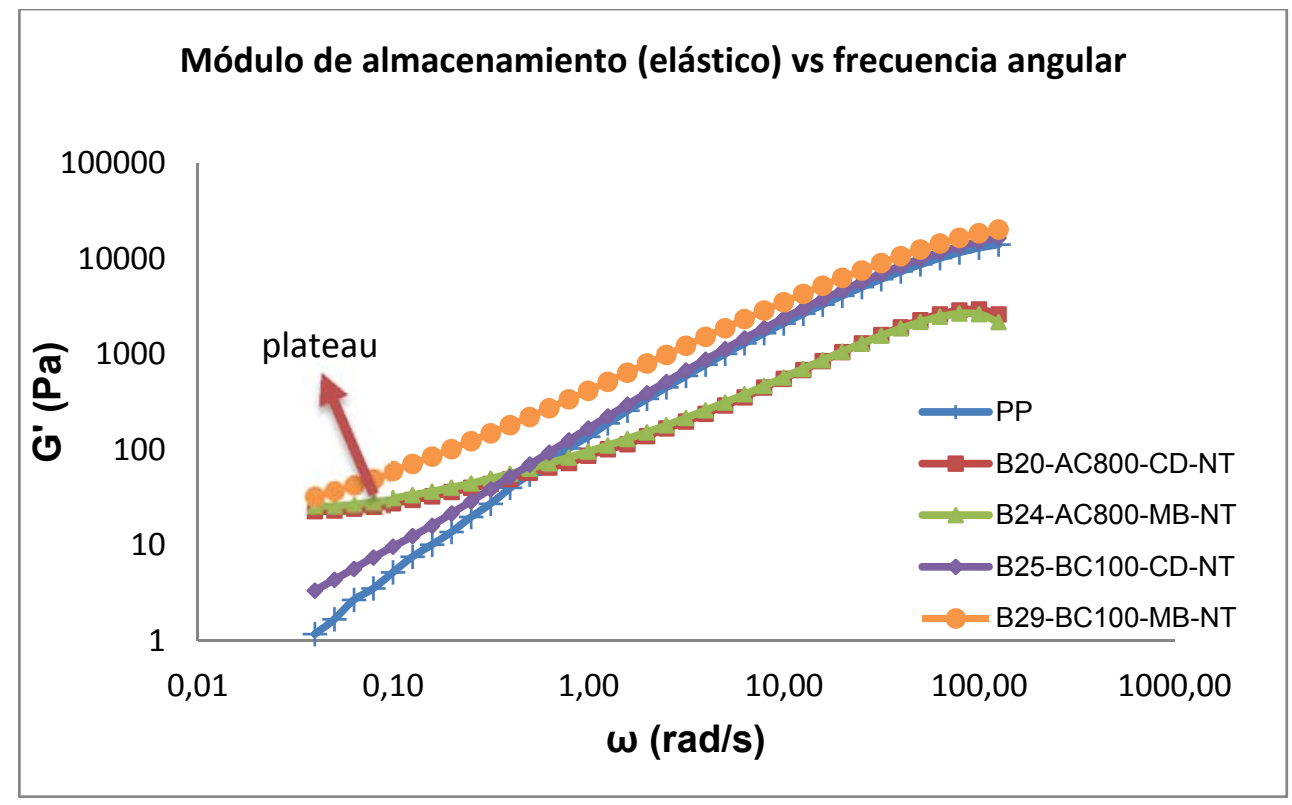

Figura 51. Módulo de almacenamiento versus frecuencia angular de los nanocompuestos de NTC

\section{B) Sistema PP/GMC}

Se realizó la misma caracterización reológica que la llevada a cabo con los nanocompuestos de NTC.

La Figura 52 representa la viscosidad dinámica versus frecuencia. Se puede observar que los compuestos producidos a baja cizalla tienen un comportamiento similar al PP virgen, aunque la viscosidad baja ligeramente (muestras B9 y B13). Sin embargo, en las muestras producidas a alta cizalla la viscosidad baja drásticamente, siendo mayor la bajada cuando el compuesto se produce vía masterbatch. Esta bajada puede ser debida a la disminución de la relación de aspecto de las láminas de grafeno por la rotura de las partículas o a la degradación del polímero. Pero esta pérdida tan acusada también puede deberse a un efecto lubricante de las partículas laminares. Es bien conocido el efecto lubricante del grafito ${ }^{169,170}$. En este caso las láminas de grafeno apiladas, aun siendo un número mucho menor que en las partículas de grafito, tienen un efecto lubricante similar sobre el PP. 
Los resultados obtenidos para la viscosidad de los compuestos de GMC son muy distintos de los obtenidos con los NTC. En este caso ninguna de las muestras presenta un aumento de la viscosidad a bajas o altas frecuencias con respecto al PP virgen. Este efecto sobre la viscosidad ya se observó al calcular la energía mecánica específica del procesado de ambos sistemas, siendo mucho menor la energía necesaria para mezclar el GMC que los NTC.

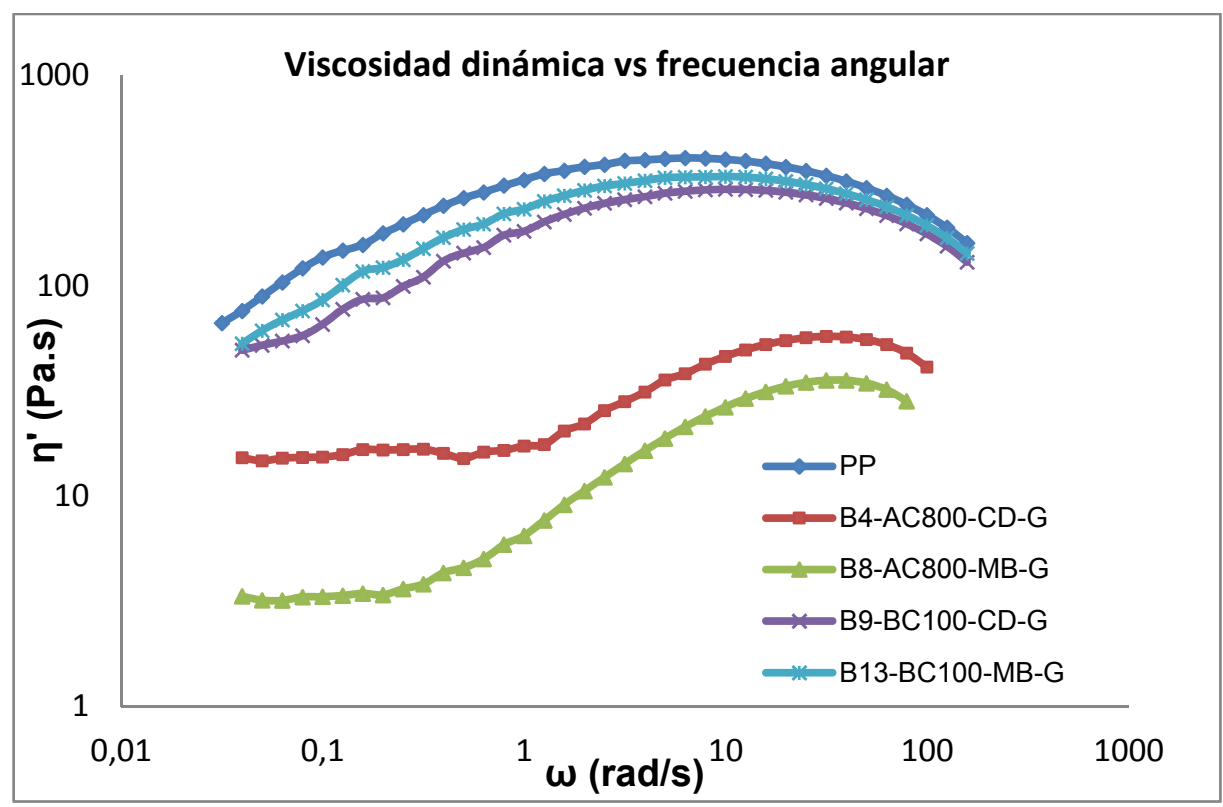

Figura 52. Viscosidad dinámica versus frecuencia angular para los compuestos de GMC

La Figura 53 muestra el módulo de almacenamiento versus frecuencia. Analizando la Figura 53, se observa que a bajas frecuencias ninguna curva alcanza una zona de "plateau". Es decir, las nanopartículas no están interconectadas entre sí, no se crea una red, tal y como se observó en las imágenes SEM donde las partículas de GMC se encontraron aisladas en unas de otras en la matriz de PP. 


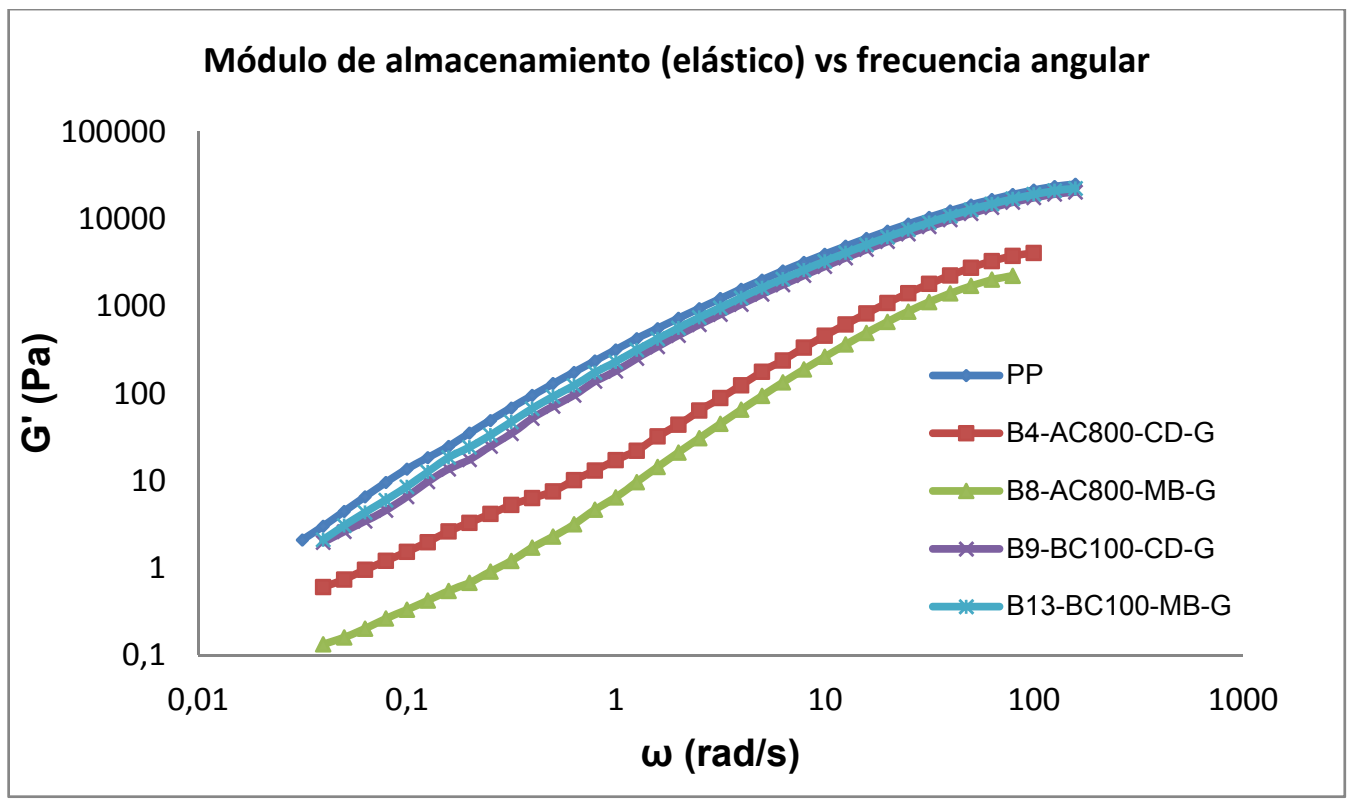

Figura 53. Módulo de almacenamiento versus frecuencia para los compuestos de GMC 


\subsection{Propiedades eléctricas}

\section{A) Sistema PP/NTC}

La bibliografía revisada concluyó que las propiedades eléctricas de los nanocompuestos de NTC estaban influenciadas en gran medida por la dispersión de los NTC en la matriz polimérica. Munson-McGee et al. ${ }^{111}$ demostraron que el límite de percolación de un nanocompuesto podía variar del $1 \%$ al $15 \%$ de contenido de NTC dependiendo de las condiciones de procesado y, en consecuencia, del grado de dispersión de los NTC.

En la Figura 54 se han representado las conductividades superficiales de los compuestos obtenidos por compound directo y vía masterbatch. Se observa que los valores obtenidos para muchos de los nanocompuestos estarían dentro del rango de polímeros conductores la que la conductividad superficial es superior a $10^{-06} \mathrm{~S} / \mathrm{sq}$.

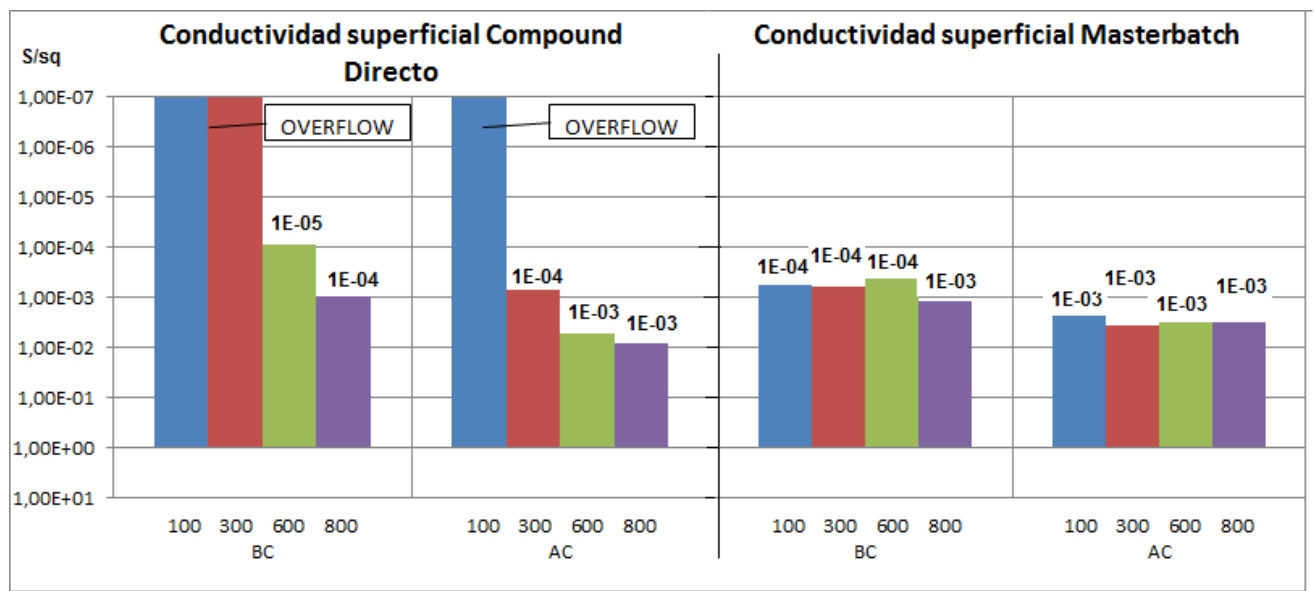

Figura 54. Conductividad superficial de los nanocompuestos PP+1\% NTC a diferentes condiciones de procesado

Comparando las condiciones de procesado con la conductividad alcanzada se obtienen las siguientes conclusiones:

- La introducción de lo NTC en forma de masterbatch (2 etapas) hace que la conductividad eléctrica del compuesto sea menos dependiente de las condiciones de procesado. Aun así, se observa una tendencia 
clara: a mayor velocidad de extrusión, mayor es la conductividad eléctrica. Si se emplea un husillo de alta cizalla, este efecto es mucho menor ya que se compensa la cizalla otorgada por la velocidad del husillo con la introducción de elementos amasadores de alta mezcla dispersiva.

- Si los NTC se incorporan en la extrusora en forma de polvo, la dependencia de las propiedades eléctricas con las condiciones de procesado es muy acusada. Se puede pasar de un compuesto con propiedades antiestáticas [10-09-10-12 $\mathrm{S} / \mathrm{sq}]$ o disipativas [10-05-10-08 $\mathrm{S} / \mathrm{sq}$ ] a un compuesto semiconductor variando las condiciones de extrusión, sin aumentar la cantidad de NTC en el nanocompuesto. Las muestras poco conductoras se marcan como "overflow" porque están fuera del rango del multímetro empleado. La tendencia es similar a la detectada con el masterbatch pero mucho más acusada. Las mejores conductividades se obtienen de nuevo a altas velocidades de husillo y configuración de alta cizalla.

- Si se comparan las metodologías de introducción de los NTC, es decir, la influencia del tiempo de residencia, se puede afirmar que en condiciones de alta cizalla y alta velocidad se consiguen propiedades eléctricas similares. Puede parecer que son algo mejores en los compuestos obtenidos con polvo pero, tratándose de conductividad eléctrica, se hace referencia a rangos y no tanto a valores concretos.

A la hora de seleccionar las condiciones óptimas de procesado para el calentamiento por microondas se tiene en cuenta las propiedades eléctricas y el grado de dispersión de las nanopartículas. Se pretende conseguir un calentamiento efectivo y homogéneo con nanocompuestos con las siguientes propiedades:

- Alta conductividad eléctrica: en este caso se podría seleccionar las condiciones de procesado de alta cizalla, alta velocidad y compound directo. Ofrecen buenas propiedades eléctricas y no son condiciones tan agresivas con el compuesto. Sin embargo, hay que tener en cuenta la dispersión.

- Dispersión óptima de las partículas susceptoras para que el calentamiento sea lo más homogéneo posible: aquí se deben 
descartar los compuestos obtenidos por compound directo ya que con masterbatch se alcanzaban mejores dispersiones de los NTC.

La Tabla 15 recopila los resultados obtenidos para los compuestos obtenidos con materbatch y por compound directo. Se compara la dispersión con las propiedades eléctricas. Con ambas metodologías se obtienen conductividades eléctricas dentro del mismo rango, pero la dispersión es superior introduciendo los NTC en forma de masterbatch y, por lo tanto, esta metodología y condiciones de procesado serán las empleadas para el resto del experimental.

Tabla 15: Comparación de propiedades entre las metodologías masterbatch y compound directo para condiciones de procesado de alta cizalla

\begin{tabular}{|l|c|c|c|}
\cline { 2 - 4 } \multicolumn{1}{c|}{} & $\begin{array}{c}\text { Índice de } \\
\text { dispersión }\end{array}$ & $\begin{array}{c}\text { Conductividad } \\
\mathbf{( S / s q )}\end{array}$ & $\begin{array}{c}\text { Tamaño medio de } \\
\text { aglomerados }(\boldsymbol{\mu m})\end{array}$ \\
\hline MB-AC-800 & $99.07 \%$ & $1.1 \mathrm{E}^{-03}$ & 10.6 \\
\hline CD-AC-800 & $97.11 \%$ & $8.1 \mathrm{E}^{-03}$ & 14.0 \\
\hline
\end{tabular}

Las propiedades eléctricas de los nanocompuestos de NTC también concuerdan con las propiedades reológicas. La Figura 55 muestra como con la misma cantidad de NTC se obtiene una diferencia de cuatro órdenes de magnitud en la conductividad eléctrica al variar las condiciones de procesado. Este efecto puede ser relacionado con la obtención de una zona plateau en la gráfica viscosidad vs frecuencia. Esta zona indica que existe una interconexión entre los NTC que forman la red conductora y permiten la circulación de los electrones a través del nanocompuesto. 


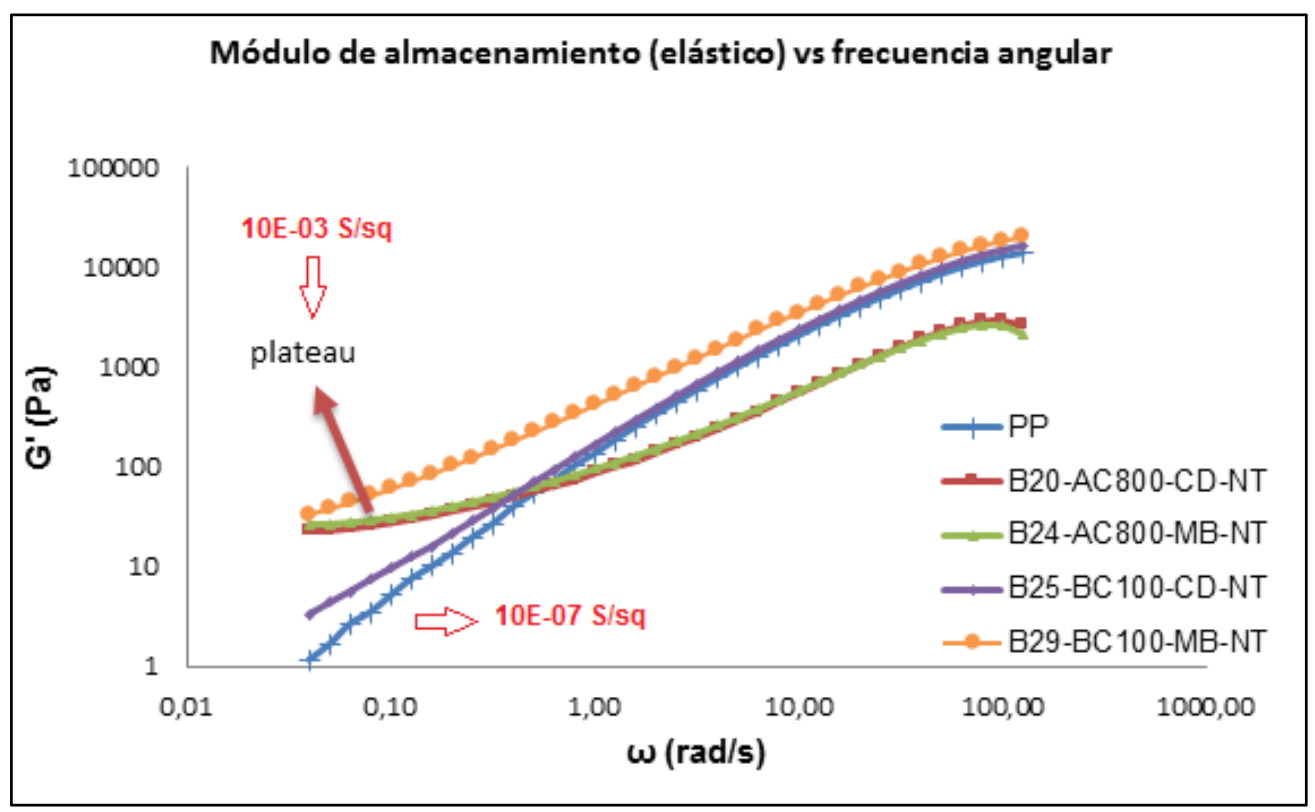

Figura 55. Relación entre las propiedades reológicas y eléctricas de los nanocompuestos PP + $1 \%$ NTC

\section{B) Sistema PP/GMC}

El sistema PP/GMC muestra un comportamiento aislante con un porcentaje de GMC del 1\%, independientemente del grado de dispersión del compuesto. 


\subsection{Estudio de la degradación}

Se empleó espectroscopia infrarroja con transformada de Fourier (FT-IR) para analizar la posible termo-oxidación del PP matriz como consecuencia de la elevada energía mecánica impartida al material en aquellas condiciones de procesado que implican valores más altos de cizalla. La oxidación del polipropileno da lugar a grupos carbonilo que se detentan a $1716 \mathrm{~cm}^{-1} \mathrm{en}$ el espectro FTIR ${ }^{171}$. La Figura 56 muestra el espectro infrarrojo de los nanocompuestos de GMC y NTC procesados a baja cizalla (B8 y B24, respectivamente) y a alta cizalla (B9 y B25), e incluso en dos etapas de procesado (Masterbatch). En ninguno de los casos se aprecia la presencia del grupo carbonilo, por lo que se puede concluir que no ha habido degradación del PP por termo-oxidación.

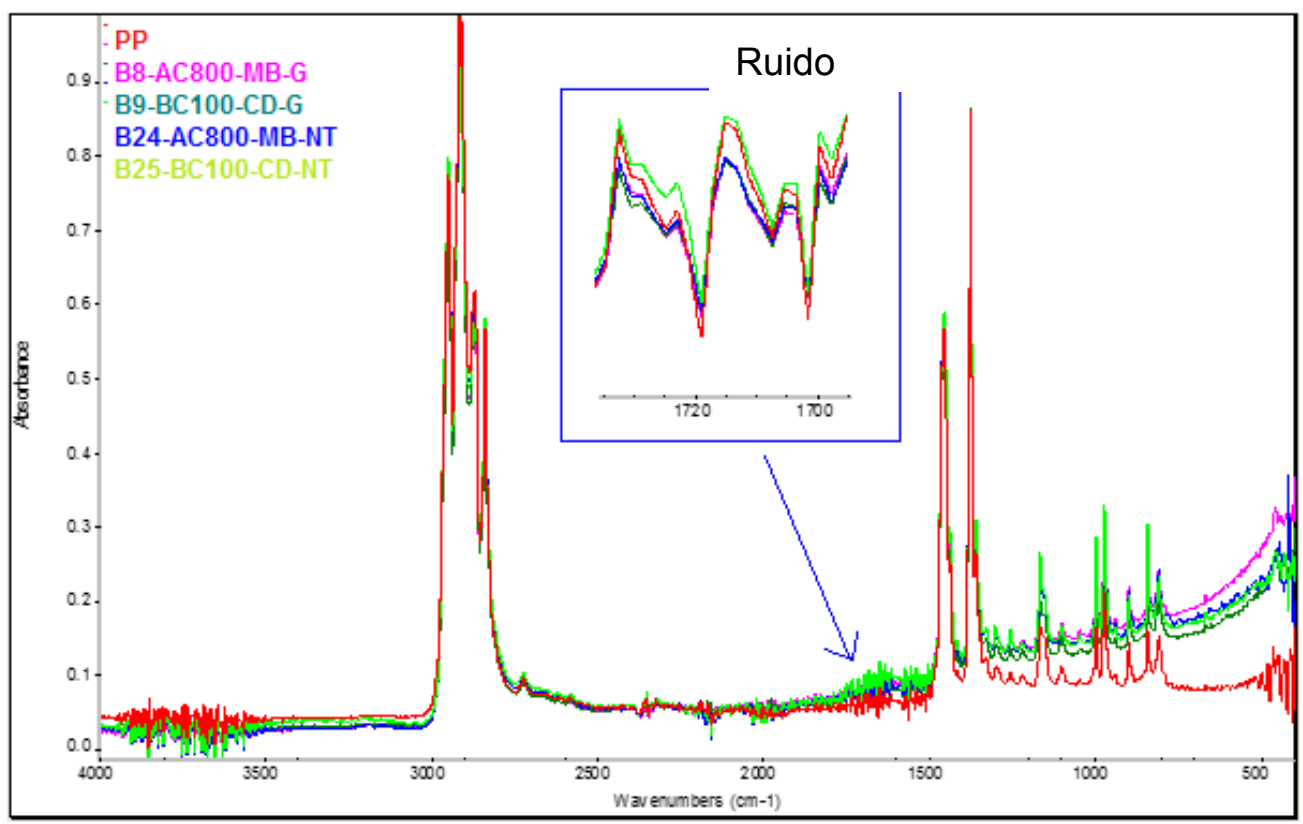

Figura 56. FT-IR de los nanocompuestos de GMC y NTC a diferentes condiciones de procesado 


\subsection{Conclusiones preliminares}

El tiempo de residencia de los NTC y del GMC en la extrusora es un factor determinante para obtener una buena dispersión, siendo la forma óptima de incorporación de las nanopartículas en la extrusora en forma de masterbatch, donde el material es sometido a dos etapas de procesado.

Condiciones de procesado de alta cizalla influyen de manera positiva en la dispersión de los NTC y el GMC (configuraciones de husillo agresivas y alta velocidad de extrusión).

Así pues, las condiciones de extrusión óptimas coinciden para ambos sistemas, siendo las más favorables:

Alimentación de las nanopartículas en forma de "masterbatch" o concentrado.

Procesado de los nanocompuestos a altas velocidades de extrusión que aseguren la aplicación de alta cizalla: $800 \mathrm{rpm}$ como valor óptimo.

\section{Configuración de husillo: Alta cizalla}

Las condiciones de procesado óptimas son similares para ambos sistemas nanocompuestos, aunque influyen de manera menos significativa en la dispersión de GMC. Asimismo, se verificó que la matriz de polipropileno no sufre degradación térmica bajo las condiciones de procesado seleccionadas.

Bajo las condiciones de procesado óptimas y mediante observación micrográfica (SEM y MO) los nanocompuestos basados en NTC muestran menor tamaño de aglomerados y el GMC menor número de capas de grafeno.

Un índice de dispersión del $99 \%$ se alcanzó con una SME de $0.5 \mathrm{kWh} / \mathrm{kg}$ para los nanocompuestos de NTC mientras que para los nanocompuestos de GMC se obtuvo un índice de dispersión del 93\% empleando una SME de 0.4 $\mathrm{kWh} / \mathrm{kg}$. Esta reducción en la energía mecánica específica con las mismas condiciones de procesado y el mismo contenido de nanopartícula denotan el carácter lubricante del GMC. 
Con un contenido en peso del $1 \%$ de NTC se obtiene un nanocompuesto semiconductor eléctrico. Las condiciones de procesado pueden variar la conductividad eléctrica obtenida en 4 órdenes de magnitud.

Los nanocompuestos con $1 \%$ en peso de GMC son aislantes eléctricos independientemente de las condiciones de extrusión aplicadas. 


\section{CAPÍTULO 5: INFLUENCIA DEL PORCENTAJE DE \begin{tabular}{llllll}
\hline CARGA & EN LAS & PROPIEDADES & DE & LOS \\
\hline
\end{tabular} NANOCOMPUESTOS}

El objetivo del presente capítulo consiste en estudiar cómo afecta el contenido de nanotubos de carbono y grafeno multicapa en las propiedades de los nanocompuestos. Para ello, se prepararon compuestos PP/NTC y PP/GMC con diferentes concentraciones de NTC $(0,5 \%, 1 \%, 3 \%, 5 \%)$ y GMC $(0,5 \%$, $1 \%, 3 \%, 5 \%$ y $10 \%$ ) empleando las condiciones de procesado seleccionadas como más adecuadas en el capítulo anterior.

La Tabla 16 recopila las muestras obtenidas para cada sistema. En el capítulo anterior se observó que el nanocompuesto con $1 \%$ de GMC obtenido para el estudio del efecto de la dispersión, no mostraba cambios en las propiedades eléctricas, a diferencia del compuesto con $1 \%$ de NTC. Por ello, se decidió incorporar una muestra con un contenido en peso más elevado de grafeno multicapa (del 10\%)

Así mismo, el método seleccionado para la dosificación de la nanocarga fue mediante dilución de un masterbatch o concentrado al 15\% de nanocarga. Las condiciones de procesado del masterbatch se seleccionaron aplicando una configuración de husillo de alta cizalla y una velocidad de extrusión media-alta. Se consideraron unas condiciones de cizalla intermedia ya que antes de la preparación de las muestras no se conocían las condiciones de procesado óptimas. 
Tabla 16: Compuestos obtenidos para la percolación de los NT y GMC

\begin{tabular}{|c|c|c|}
\hline Nanopartícula & Porcentaje & Código de muestra \\
\hline \multirow{4}{*}{ NT } & $15 \%$ & Masterbatch \\
\cline { 2 - 3 } & 0.5 & 0.5_NT \\
\cline { 2 - 3 } & 1 & 1_NT \\
\cline { 2 - 3 } & 3 & 3_NT \\
\cline { 2 - 3 } & 5 & 5_NT \\
\hline \multirow{5}{*}{ GMC } & $15 \%$ & Masterbatch \\
\cline { 2 - 3 } & 0.5 & 0.5_GMC \\
\cline { 2 - 3 } & 1 & 1_GMC \\
\cline { 2 - 3 } & 3 & 3_GMC \\
\cline { 2 - 3 } & 5 & 5_GMC \\
\cline { 2 - 3 } & 10 & 10_GMC \\
\hline
\end{tabular}




\subsection{Propiedades reológicas}

En una primera caracterización se realizaron ensayos reológicos de los compuestos obtenidos con diferentes porcentajes de NTC y GMC.

\section{A) Sistema PP/NTC}

La Figura 57 muestra la viscosidad dinámica respecto a la frecuencia angular para los compuestos basados en NTC. Se observa que a bajas frecuencias $(0.1$ - $1 \mathrm{rad} / \mathrm{s})$ los compuestos con $1 \%, 3 \%$ y $5 \%$ de NTC incrementan la viscosidad. El efecto de los NTC es mucho más acusado a bajas frecuencias. El aumento de la viscosidad con el porcentaje de NTC se debe al incremento de la rigidez del nanocompuesto, tal y como puede observarse en la Figura 58 , donde el módulo de almacenamiento se incrementa a bajas frecuencias con el contenido de NTC. Este comportamiento es el esperado y similar al encontrado en la bibliografía revisada ${ }^{155-158}$. La formación de la red de NTC interconectados es la responsable de este aumento de la viscosidad a bajas frecuencias ${ }^{172}$. A altas frecuencias la viscosidad disminuye, siendo más parecida al comportamiento del polímero virgen. Esto se debe al comportamiento pseudoplástico de los sistemas nanocompuestos ("shear thinning"), los cuales muestran una disminución de la viscosidad con el aumento de la cizalla. El incremento de la movilidad de las cadenas poliméricas debido a la cizalla contrarresta el impedimento ejercido por la red de los NTC ${ }^{158}$. 


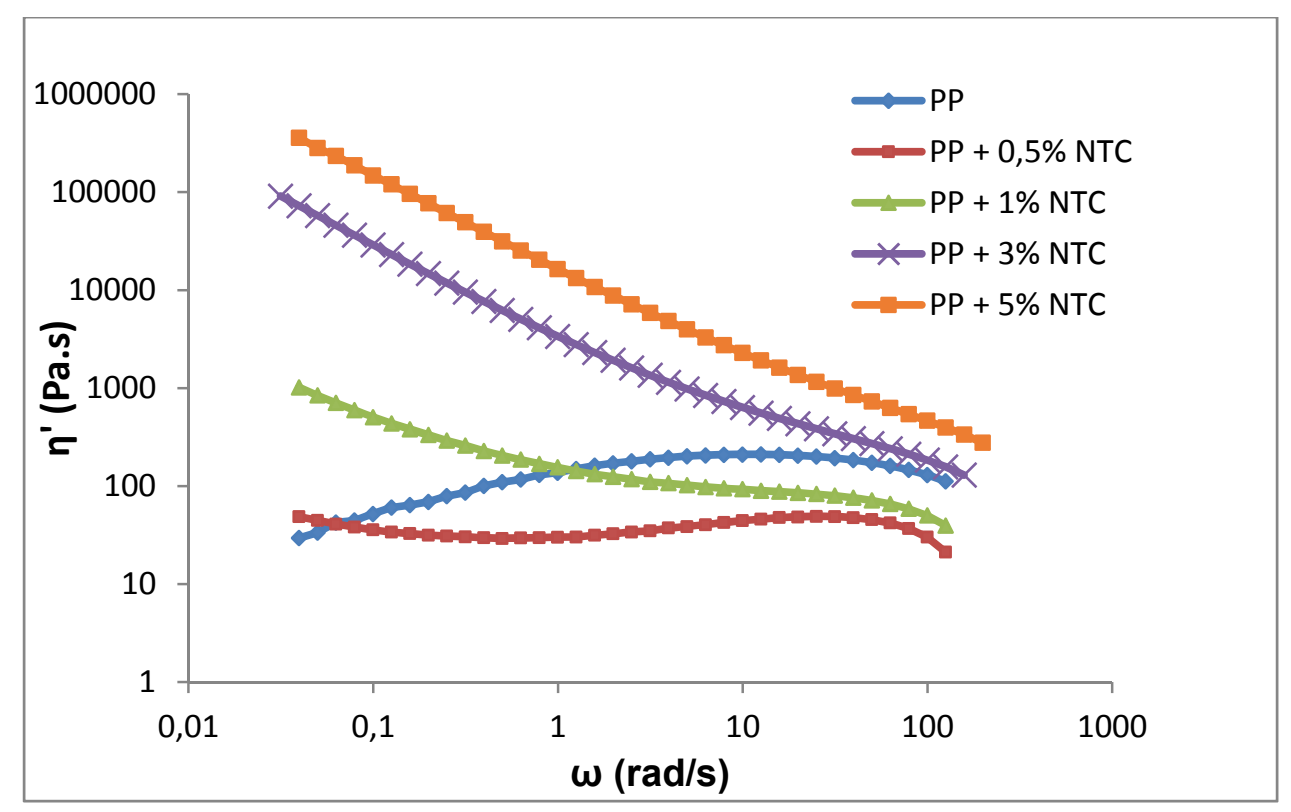

Figura 57. Viscosidad dinámica versus frecuencia angular para compuestos con diferente contenido de NTC

La Figura 58 representa el módulo de almacenamiento respecto a la frecuencia. Esta gráfica es de gran utilidad para calcular el límite de percolación de los NTC en la matriz de PP. Cuando en la gráfica que se observa una zona "plateau" a bajas frecuencias, se puede afirmar que se ha obtenido una red de NTC interconectados ${ }^{159}$. Si se observa la gráfica, con un contenido de NTC del $0.5 \%$ la curva no muestra esta zona "plateau". Sin embargo, con $1 \%$ de NTC el "plateau" se observa a bajas frecuencias, ya que la pendiente de la curva es muy poco pronunciada. Se puede afirmar que la percolación para los compuestos desarrollados estaría alrededor $1 \%$ de NTC (a falta de haber desarrollado compuestos a concentraciones intermedias). El aumento de la viscosidad de los nanocompuestos indica un aumento en la rigidez del material. 


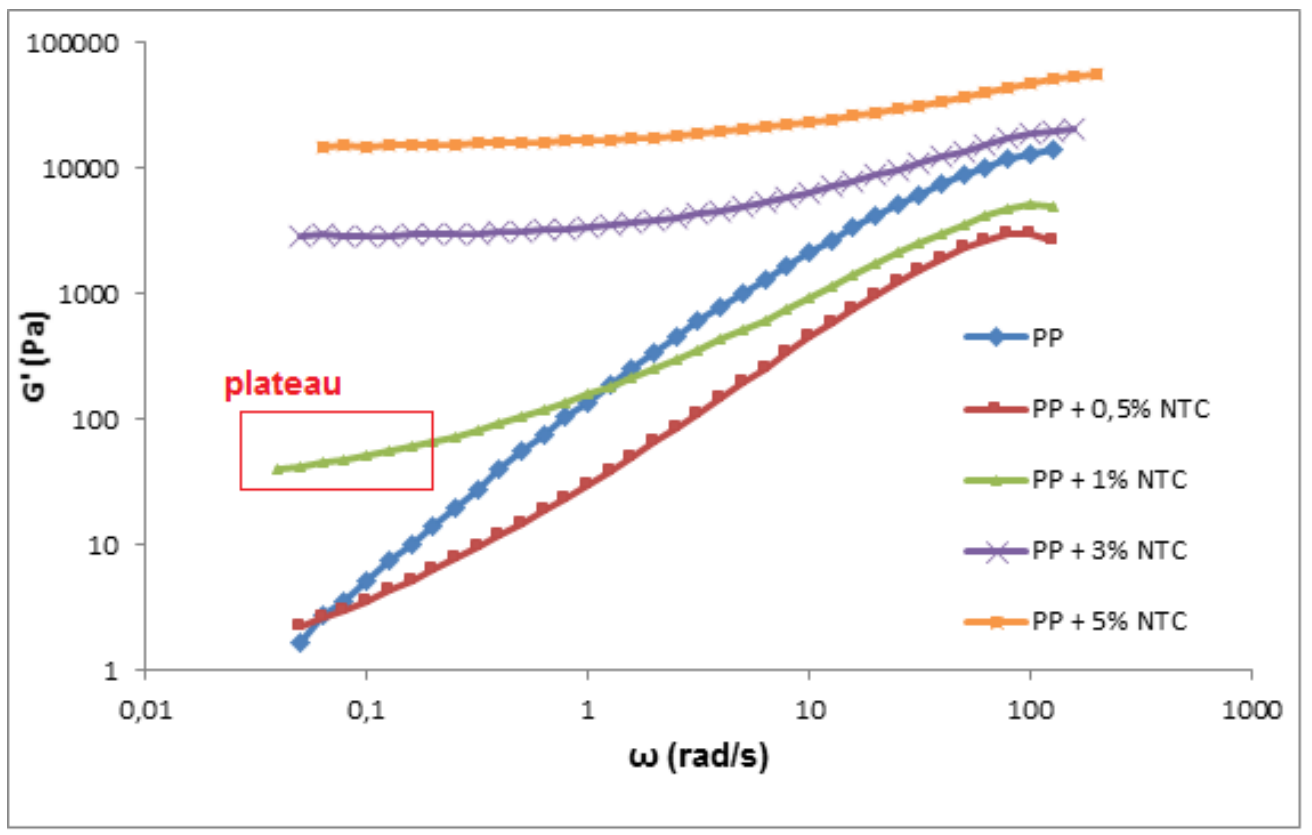

Figura 58. Módulo de almacenamiento versus frecuencia angular para compuestos con diferente contenido de NTC

La Figura 59 representa el módulo de almacenamiento respecto al módulo de pérdidas. Este tipo de gráficas se emplean para observar cambios en la estructura de un polímero al introducir una carga a una temperatura fija ${ }^{173,174}$. A medida que se incrementa el contenido de NTC, aumentan las curvas de módulo de almacenamiento respecto al módulo de pérdidas. Es decir, cuanto mayor es el contenido de NTC mayor son los cambios microestructurales en el polipropileno.

Estas curvas se emplean para estudiar cambios en la microestructura en homopolímeros, copolímeros y mezclas de los mismos a diferentes temperaturas. Aplicado a los nanocompuestos, cambios en las curvas con diferentes porcentajes de nanopartículas indican cambios en la estructura para una misma temperatura. Por sí misma esta gráfica no aporta mucha información pero será de gran utilidad para comparar entre los NTC y el GMC en la estructura del polímero. 


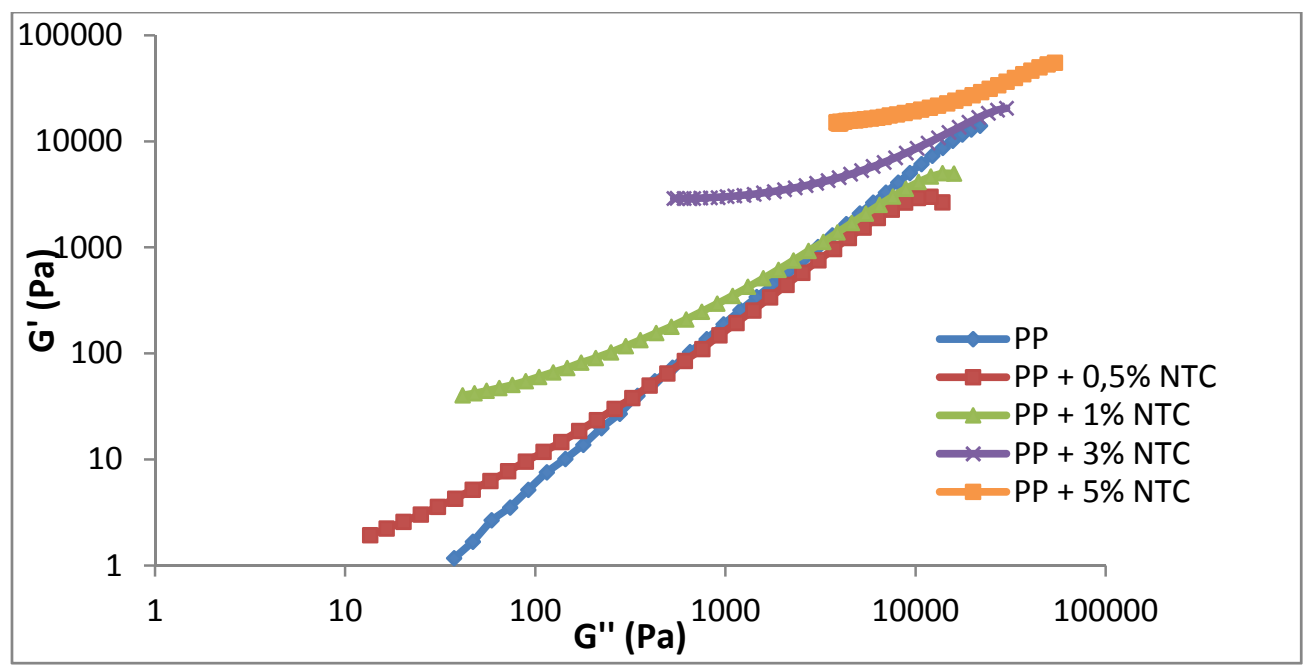

Figura 59. Módulo de almacenamiento versus módulo de pérdidas para compuestos con diferente contenido de NT

\section{B) Sistema PP/GMC}

En la Figura 60 representa la viscosidad dinámica versus la frecuencia para los nanocompuestos de GMC. En un primer análisis se observa un comportamiento diferente al obtenido con los nanotubos de carbono. Tan solo los compuestos con un $5 \%$ y $10 \%$ de GMC aumentan su viscosidad dinámica a bajas frecuencias con respecto al PP virgen, indicando que la red de nanopartículas interconectadas se obtendría alrededor del 5\% de GMC. De nuevo se observa que para pequeños porcentajes de GMC la viscosidad dinámica es inferior a la del polímero virgen en todo el rango de frecuencias. Esto puede deberse a un efecto lubricante de carga similar al comportamiento del grafito ${ }^{175}$. En este sentido, las laminillas de grafeno que componen las capas de una partícula de grafito están unidas entre sí por enlaces secundarios de tipo puentes de hidrógeno. Bajo esfuerzos de cizalla, dichas interacciones se rompen con facilidad permitiendo que las laminillas puedan deslizar unas sobre otras dando como consecuencia un comportamiento "lubricante". Este efecto es más visible a menores frecuencias dado que los procesos de movimiento e interacción de los grupos de cadena con las partículas de grafeno multicapa ocurren con más lentitud. 
A partir de un $5 \%$ de GMC prevalece el comportamiento reforzante de la nanocarga respecto al deslizamiento de las laminillas de grafeno dando lugar a un aumento de la rigidez del nanocompuesto. En la Figura 61, que representa el módulo de almacenamiento frente a la frecuencia, se comprueba que para los compuestos con un 5\% y $10 \%$ aumenta el módulo de almacenamiento a bajas frecuencias, justificando el aumento de la rigidez de ambos nanocompuestos.

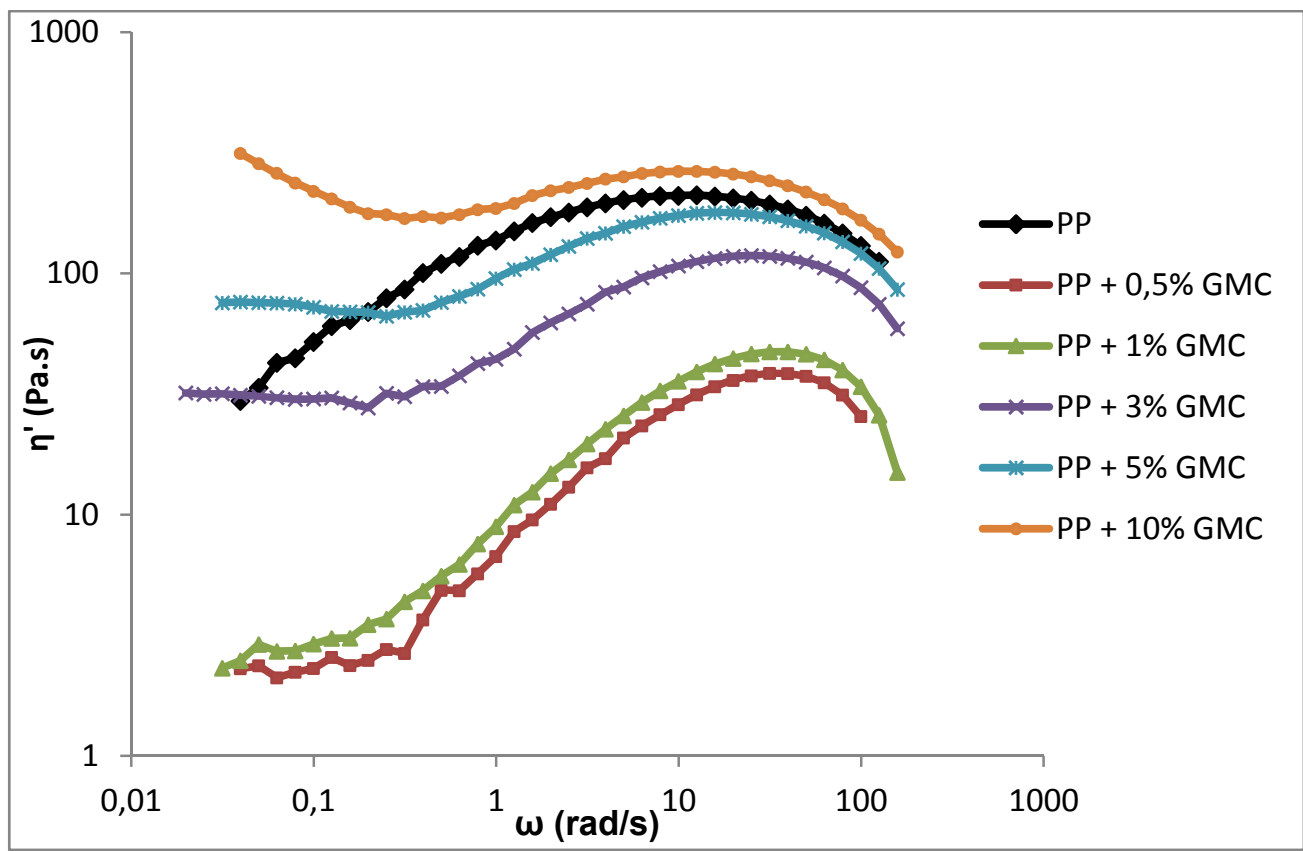

Figura 60. Viscosidad dinámica versus frecuencia angular para los nanocompuestos de GMC

La Figura 61 muestra la variación del módulo de almacenamiento con la frecuencia para los diferentes porcentajes de GMC. Al analizar esta gráfica se observa que no hay una zona "plateau" para los compuestos con bajos porcentajes de grafeno. Todas las curvas muestran una pendiente pronunciada a bajas frecuencias. Esta zona sólo se muestra ligeramente en el compuesto con un $10 \%$ de GMC, donde la pendiente de la curva es menos acusada. El aumento de la rigidez también es más significativo para el nanocompuesto con un $10 \%$ de GMC por lo que se podría afirmar que la red de GMC interconectados se obtiene con dicho porcentaje. 


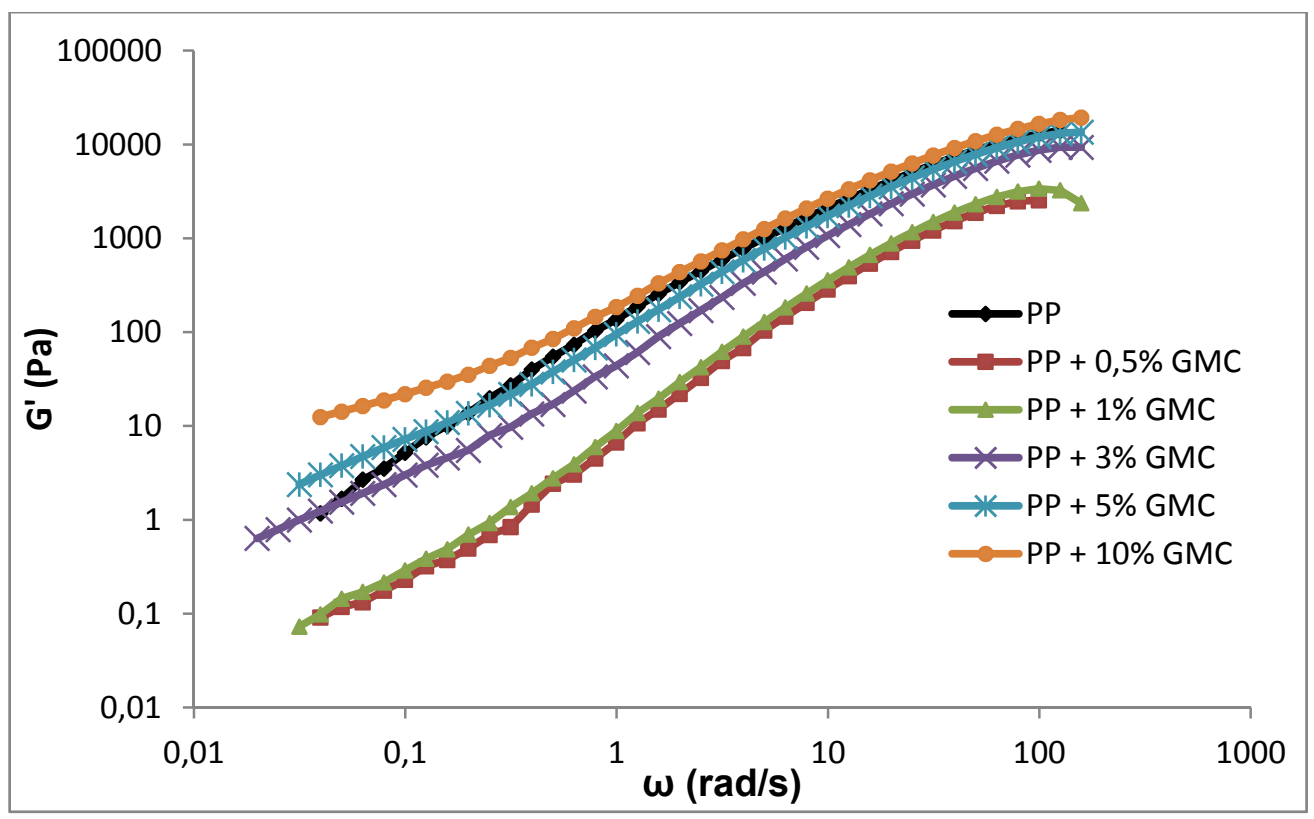

Figura 61. Módulo de almacenamiento versus frecuencia angular para los nanocompuestos de GMC

La Figura 62 representa el módulo de almacenamiento respecto el módulo de pérdidas. Los nanocompuestos basados en GMC muestran comportamiento muy diferente al encontrado en los nanocompuestos de NTC. Se observan diferencias en las curvas con respecto al PP virgen pero esas diferencias son mínimas si se compara con los NTC. Por lo tanto, se puede afirmar que los cambios estructurales de PP son menos acusados empleando GMC en comparación con los NTC. 


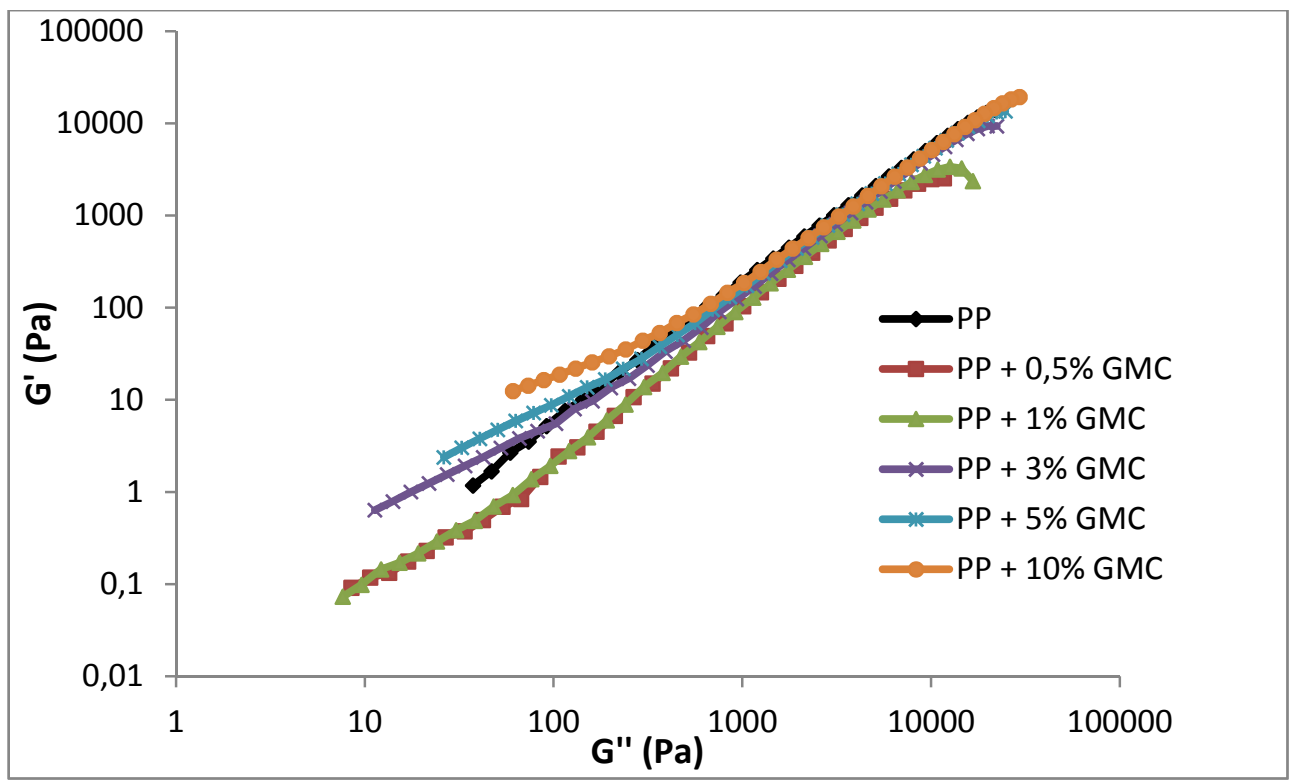

Figura 62. Módulo de almacenamiento versus módulo de pérdidas versus frecuencia angular para los nanocompuestos de GMC 


\subsection{Propiedades eléctricas}

Se analizaron las propiedades eléctricas de los nanocompuestos sobre probetas obtenidas por moldeo por compresión. La Figura 63 compara la conductividad volumétrica de los nanocompuestos con diferentes porcentajes de NTC.

En el caso de los nanocompuestos basados en NTC la conductividad eléctrica aumenta con el porcentaje de nanotubos de forma exponencial. Todos los nanocompuestos de NTC muestran un comportamiento semiconductor aunque en diferentes valores de conductividad. Cabe destacar el gran salto de propiedades eléctricas entre el $0.5 \%$ y el $1 \%$ de NTC, aumentando la conductividad en tres órdenes de magnitud. Estos resultados se ven respaldados por las propiedades reológicas estudiadas con anterioridad, en las que se observaba que la red de interconexión de los NTC se formaba alrededor del $1 \%$ de contenido de NTC.

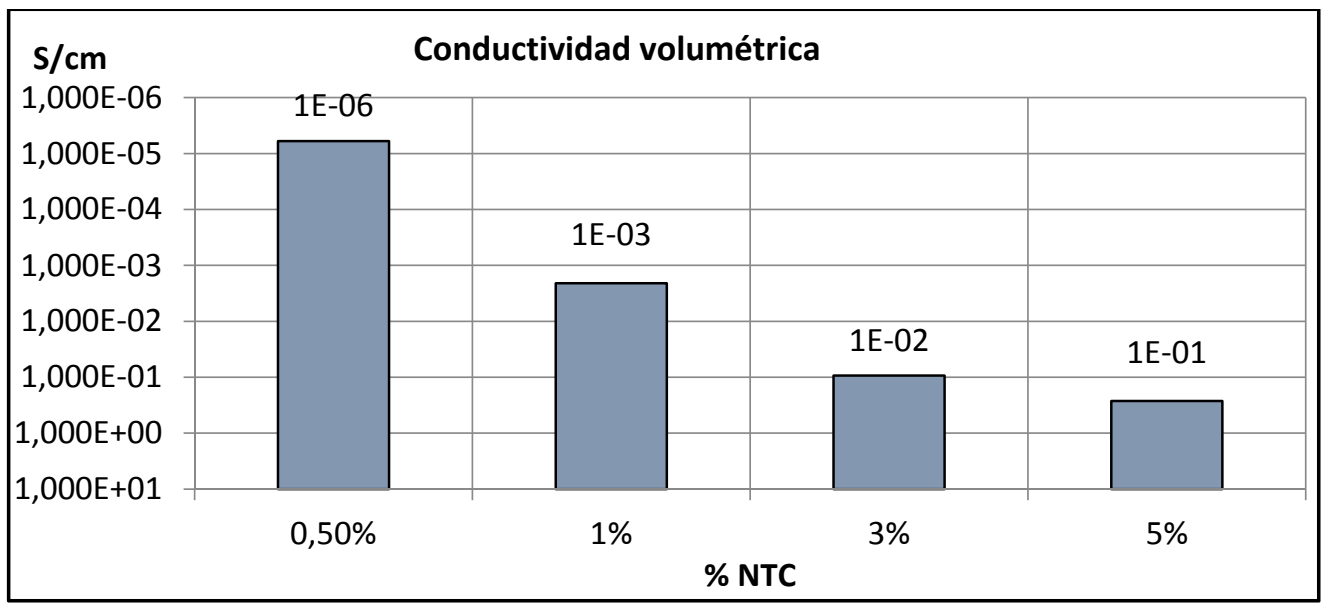

Figura 63. Conductividad volumétrica para los nanocompuestos con diferente porcentaje de NTC

La Figura 64 muestra los valores de conductividad volumétrica de los nanocompuestos de GMC. Los nanocompuestos empiezan a mostrar un comportamiento semiconductor a partir de una concentración del $10 \%$ de GMC. A más bajas concentraciones la conductividad está fuera del rango del multímetro empleado, es decir, mayor a $10^{-7} \mathrm{~S} / \mathrm{cm}$. Las propiedades eléctricas de los nanocompuestos de GMC también coinciden con los ensayos 
reológicos en los que se observó que a partir del 10\% de GMC se formaba la red o se interconectaban las partículas entre sí.

Según la literatura reportada, este no es un resultado típico de una nanopartícula ya que, debido a su gran relación de aspecto, deberían alcanzarse percolaciones con bajos porcentajes de carga. Pero, tal y como analizamos por espectroscopia Raman y tras el estudio morfológico, el grafeno multicapa estudiado tiene un gran número de capas. Al aumentar el espesor reduce la relación de aspecto y necesitando mayor contenido en el nanocompuesto para alcanzar la formación de la red conductora.

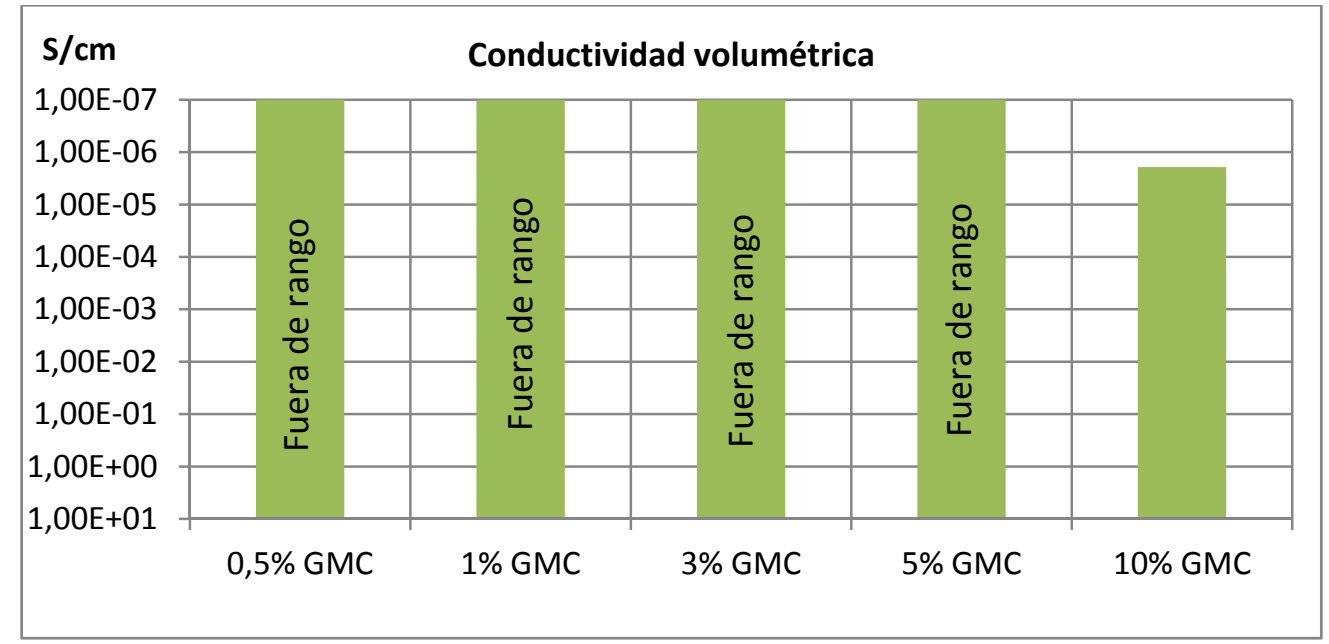

Figura 64. Conductividad volumétrica de los nanocompuestos con diferente contenido de GMC 


\subsection{Propiedades dieléctricas}

Se analizaron las propiedades dieléctricas de los nanocompuestos de NTC y GMC mediante espectroscopia de impedancia electroquímica. Se determinó la constante dieléctrica, el factor de pérdidas y la tangente de pérdidas para cada uno de los compuestos.

La Figura 65 muestra la variación de la contante dieléctrica para los nanocompuestos de NTC y el efecto de la temperatura en dicha propiedad. La constante dieléctrica aumenta con el porcentaje de NTC para todas las temperaturas evaluadas. La contante dieléctrica (parte real de la permitividad) indica qué cantidad de la energía incidente es capaz de penetrar en el material, por lo que interesa que el nanocompuesto muestre una constante dieléctrica elevada. Otro dato importante es que la contante dieléctrica de los nanocompuestos con $0.5 \%$ y $1 \%$ de NTC se mantiene casi constante con la temperatura. Sin embargo, si se aumenta el porcentaje de NTC su valor aumenta con la temperatura. Esto es muy importante a la hora de controlar el calentamiento del nanocompuesto por microondas. Al aumentar la constante dieléctrica con el aumento de la temperatura, el nanocompuesto incrementa su capacidad de absorber radiación durante el calentamiento haciendo que éste sea exponencial. El material podría calentarse tan rápidamente que imposibilite el control de la temperatura alcanzada durante el procesado microondas.

Con altos porcentajes de NTC el calentamiento se acelerará cuando el material aumenta la temperatura, haciendo el proceso difícilmente controlable. La contante dieléctrica sin la tangente de pérdidas no proporciona suficiente información. El factor de pérdidas es determinante, ya que proporciona información sobre la capacidad de un material de convertir la energía en calor. Por lo tanto, será un parámetro muy importante a la hora de seleccionar el mejor sistema nanocompuesto para ser calentado por microondas ${ }^{176}$. 


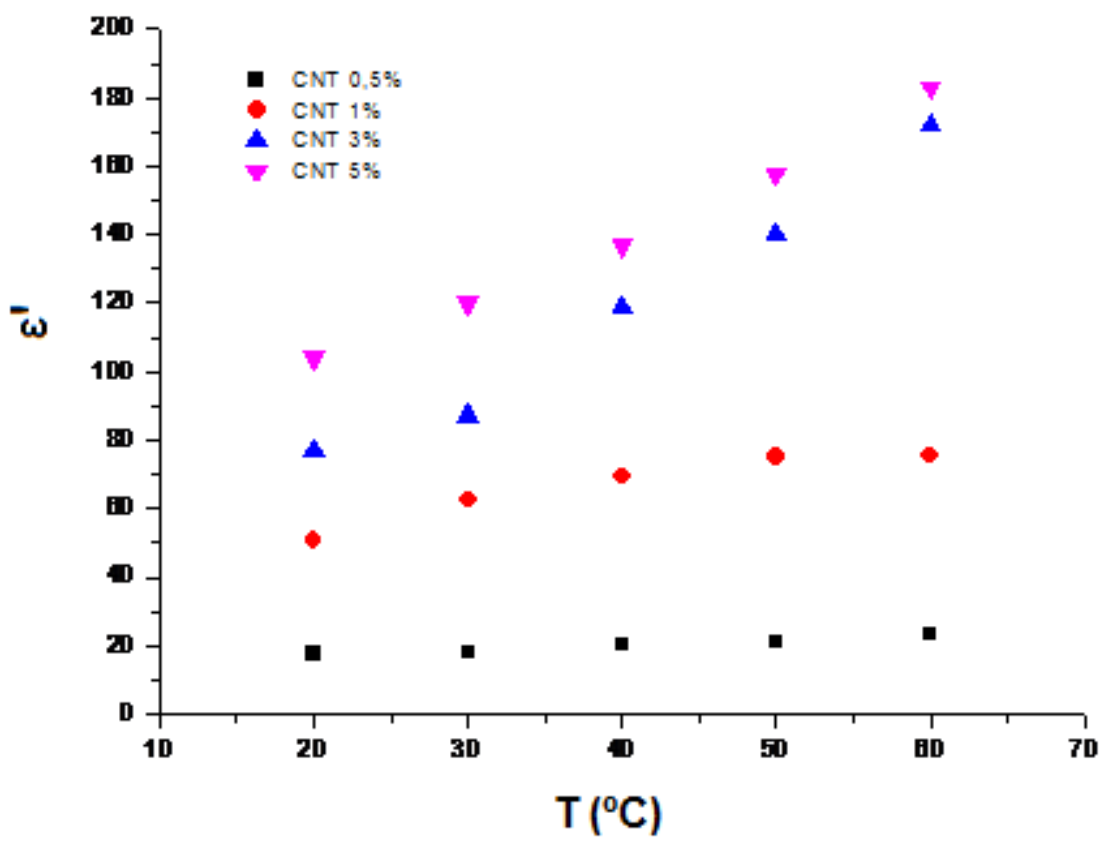

Figura 65. Constante dieléctrica versus temperatura para diferentes concentraciones de NTC

La parte imaginaria de la permitividad, el factor de pérdidas se muestra en la Figura 66 para cada uno de los nanocompuestos a diferentes frecuencias. En la gráfica se representa su variación con la frecuencia para cada compuesto. La tendencia es la misma para cada uno de ellos. A medida que aumenta la frecuencia, el factor de pérdidas disminuye. Para el calentamiento por microondas interesa un factor de pérdidas lo más alto posible, ya que el material tendrá mayor capacidad de transformar la energía incidente en calor. Debido a limitaciones del equipo de medida no se alcanzaron las frecuencias correspondientes a las regiones habituales del microondas. De todas formas, estos resultados son de utilidad para estudiar claramente la tendencia del factor de pérdidas. 


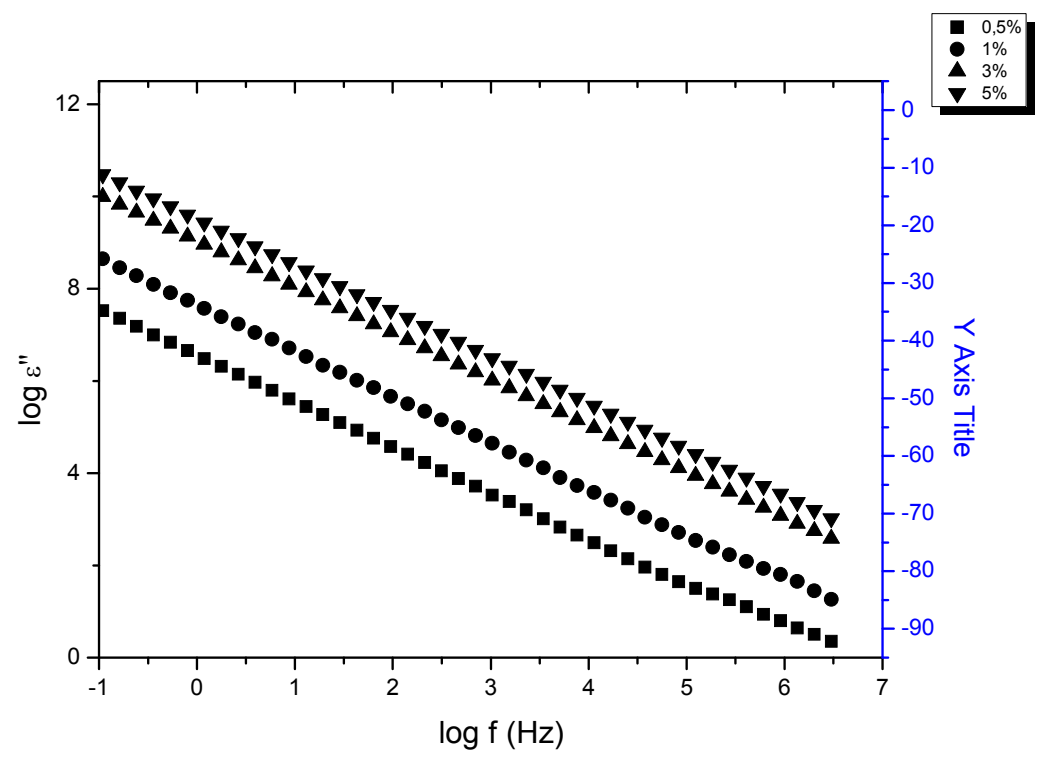

Figura 66. Factor de pérdidas ( $\left.\mathcal{E}^{\prime \prime}\right)$ a diferentes frecuencias para los nanocompuestos PP con diferentes contenidos de NTC a $50^{\circ} \mathrm{C}$

La Figura 67 representa la tangente de pérdidas respecto al porcentaje de NTC. La tangente de pérdidas indica la capacidad del material para absorber energía y transformarla en calor. En ella se representa la variación de la tangente de pérdidas para cada nanocompuesto a diferentes temperaturas. Para todas las temperaturas se observa un aumento de la tangente de pérdidas con el porcentaje de NTC. Esta gráfica aporta información relevante ya que permitirá hacer una selección y predecir el comportamiento de los compuestos una vez introducidos en el microondas Por lo tanto, el calentamiento por microondas será mayor cuanto mayor sea el porcentaje de nanotubos. Asimismo, en la gráfica también se observa que a medida que aumenta el contenido de NTC se produce un mayor aumento de la tangente de pérdidas con la temperatura. Este resultado podría indicar que el proceso de calentamiento se hace incontrolable. Es decir, que el material se calienta tan rápidamente que no permite controlar el proceso de producción y puede que el material se degrade antes de obtener un producto final. Sin embargo, las muestras con $0.5 \%$ y $1 \%$ de NTC muestran un comportamiento más 
estable, de forma que la tangente de pérdidas varía poco con el aumento de la temperatura.

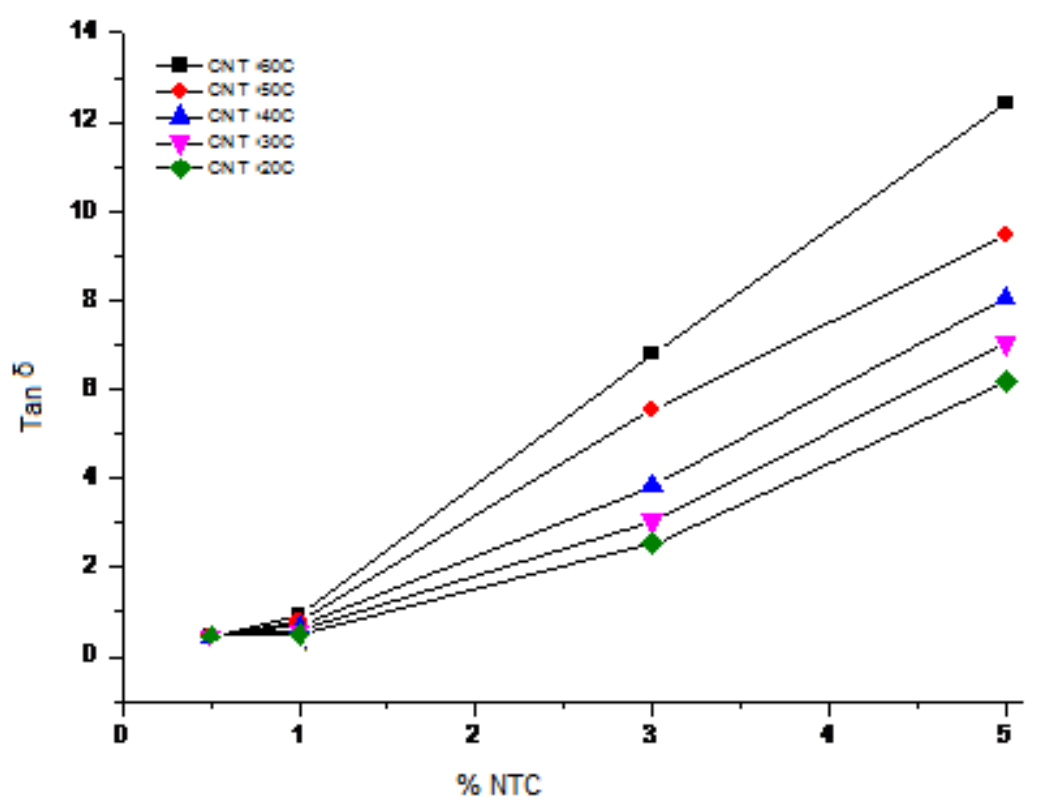

Figura 67. Tangente de pérdidas respecto la concentración de NTC

Así mismo, se analizaron las propiedades dieléctricas de los nanocompuestos de GMC, obteniendo resultados totalmente diferentes a los obtenidos con los nanocompuestos de NTC. En las gráficas se representan los resultados de ambos sistemas nanocompuestos con el fin de comparar el comportamiento del GMC con los NTC (Figura 68 y Figura 69).

La Figura 68 muestra la gráfica de la constante dieléctrica respecto a la temperatura para los nanocompuestos con diferentes porcentajes de NTC y GMC. La constante dieléctrica de los nanocompuestos basados en GMC prácticamente no varía con la composición ni con la temperatura. Además, los valores obtenidos con GMC son mucho inferiores incluso que los 
alcanzados con un $0.5 \%$ de NTC. Este hecho significa que la interacción de los nanocompuestos de GMC con la radiación microondas se prevé muy baja ya que no muestra capacidad de absorber la energía incidente y transformarla en calor.

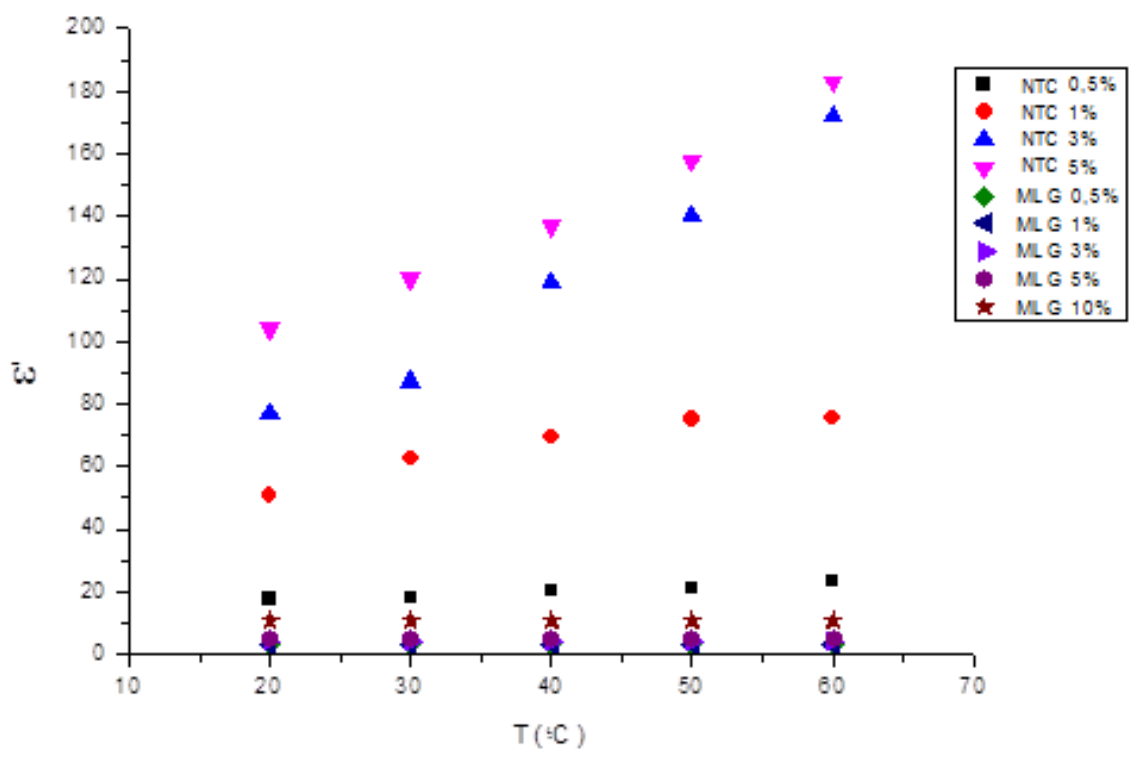

Figura 68. Variación de la constante dieléctrica con la temperatura para los nanocompuestos de NTC y GMC

El mismo comportamiento se muestra en la Figura 69, donde se representa la tangente de pérdidas en función del contenido de nanocarga (grafeno multicapa y NTC). La tangente de pérdidas para los nanocompuestos de GMC es prácticamente nula para todas las temperaturas y porcentajes de GMC. Es decir, absorberán poca energía y la generación de calor será baja. La eficiencia de calentamiento se estima muy baja, incluso mucho menor que para los compuestos con bajo porcentaje de NTC. 


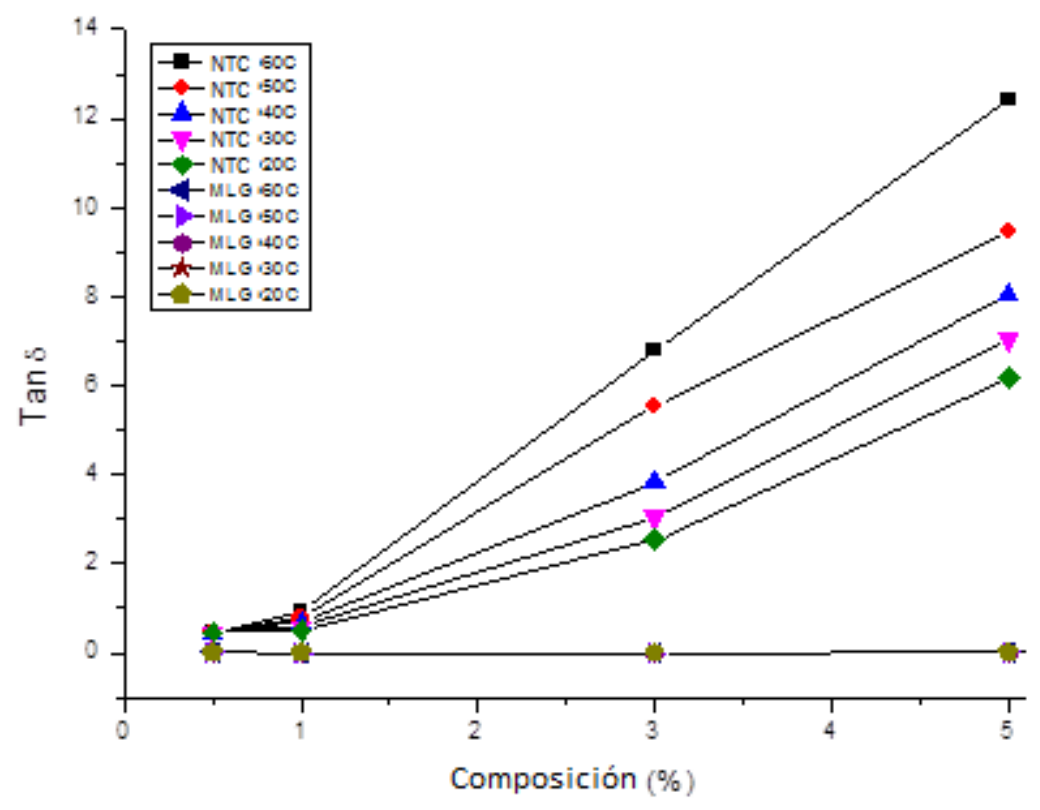

Figura 69. Tangente de pérdidas para los nanocompuestos de NTC y GMC a diferente temperatura 


\subsection{Propiedades mecánicas}

Las propiedades mecánicas de los nanocompuestos se evaluaron mediante el ensayos dinámico-mecánicos. El polipropileno (PP) típicamente muestra tres procesos de relajación debidos a movimientos moleculares activados por la energía térmica o calor al que se somete el polímero durante el ensayo. El primero de ellos ocurre a temperaturas alrededor de los $-50^{\circ} \mathrm{C}$ y recibe el nombre de relajación- $\mathrm{y}$. Este proceso se debe a movimientos de corto rango como la rotación de los grupos metílicos en los extremos de las cadenas poliméricas. La relajación- $\beta$ es la dominante, tiene lugar cerca de los $0^{\circ} \mathrm{C}$ y hace referencia a la transición vítrea. A temperatura cercana a los $100^{\circ} \mathrm{C}$ se da la relajación- a la cual está influenciada por la orientación de las cadenas poliméricas ${ }^{177}$.

La Figura 70 y la Figura 71 representan la variación del módulo de almacenamiento con respecto a la temperatura para ambos sistemas. El comportamiento dinámico-mecánico para ambos sistemas PP/NTC y PP/GMC mostró un aumento de la rigidez con el contenido de nanocarga. En los dos casos se observa un aumento del módulo de almacenamiento al aumentar el porcentaje de nanocarga en todo el rango de temperaturas. Se obtuvo un aumento del módulo de almacenamiento del 125\% para ambos sistemas con un porcentaje de aditivación en peso del 1\%. Este aumento de la rigidez puede estar asociado al hecho de que las nanopartículas limitan el movimiento de las cadenas poliméricas de PP, tal y como ha sido reportado por otros autores ${ }^{178}$. Resultados similares fueron publicados por Kim et al. ${ }^{179}$ donde analizaron la influencia de la incorporación de nanografito en matrices de polipropileno, obteniendo un módulo de almacenamiento de $2500 \mathrm{MPa}$ para un $7 \%$ de contenido en peso de nanografito en LLDPE a bajas temperaturas en comparación a los $1000 \mathrm{MPa}$ obtenidos con el LLDPE virgen.

Comparando el comportamiento como refuerzo mecánico de los NTC con el GMC se puede afirmar que tienen un efecto similar sobre las propiedades mecánicas, ya que con el mismo porcentaje de adición el módulo de almacenamiento aumenta en la misma medida. 


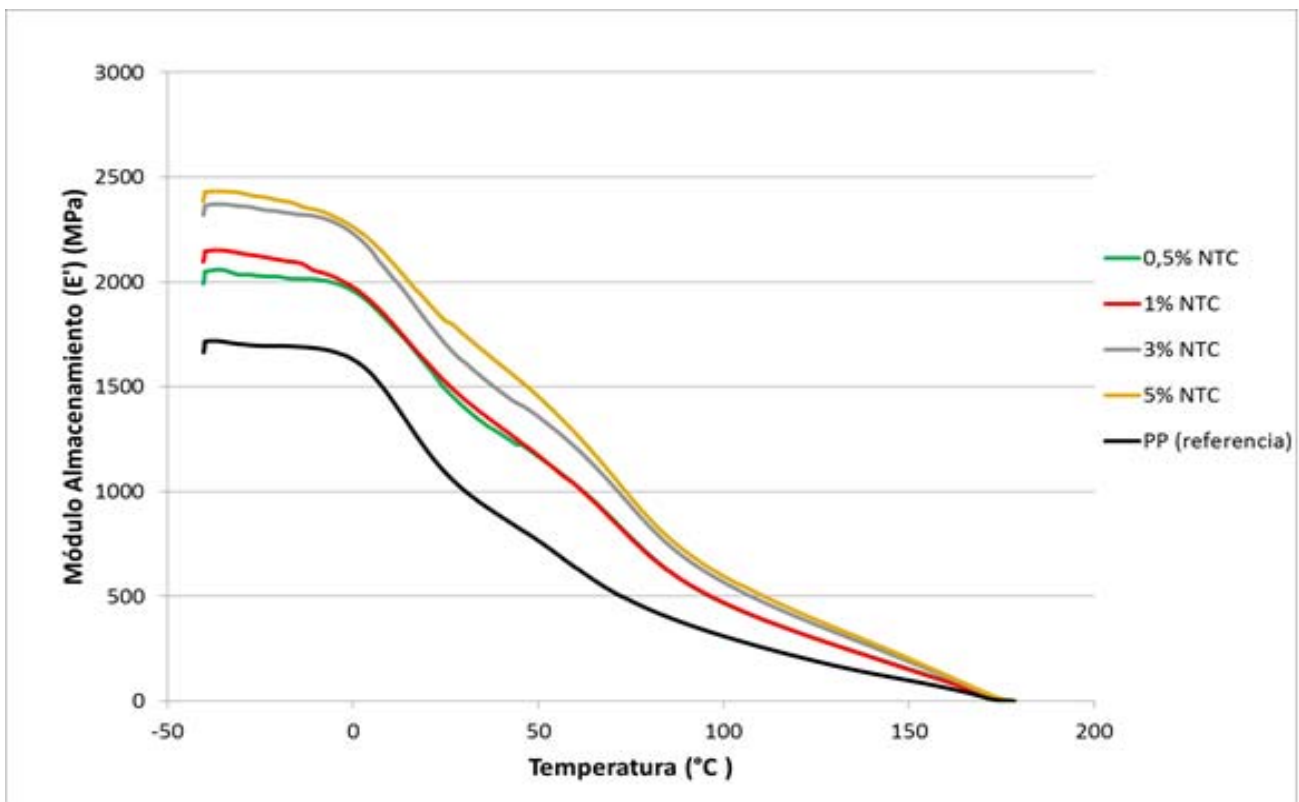

Figura 70. Módulo de almacenamiento versus temperatura para los nanocompuestos con diferentes porcentajes de NTC

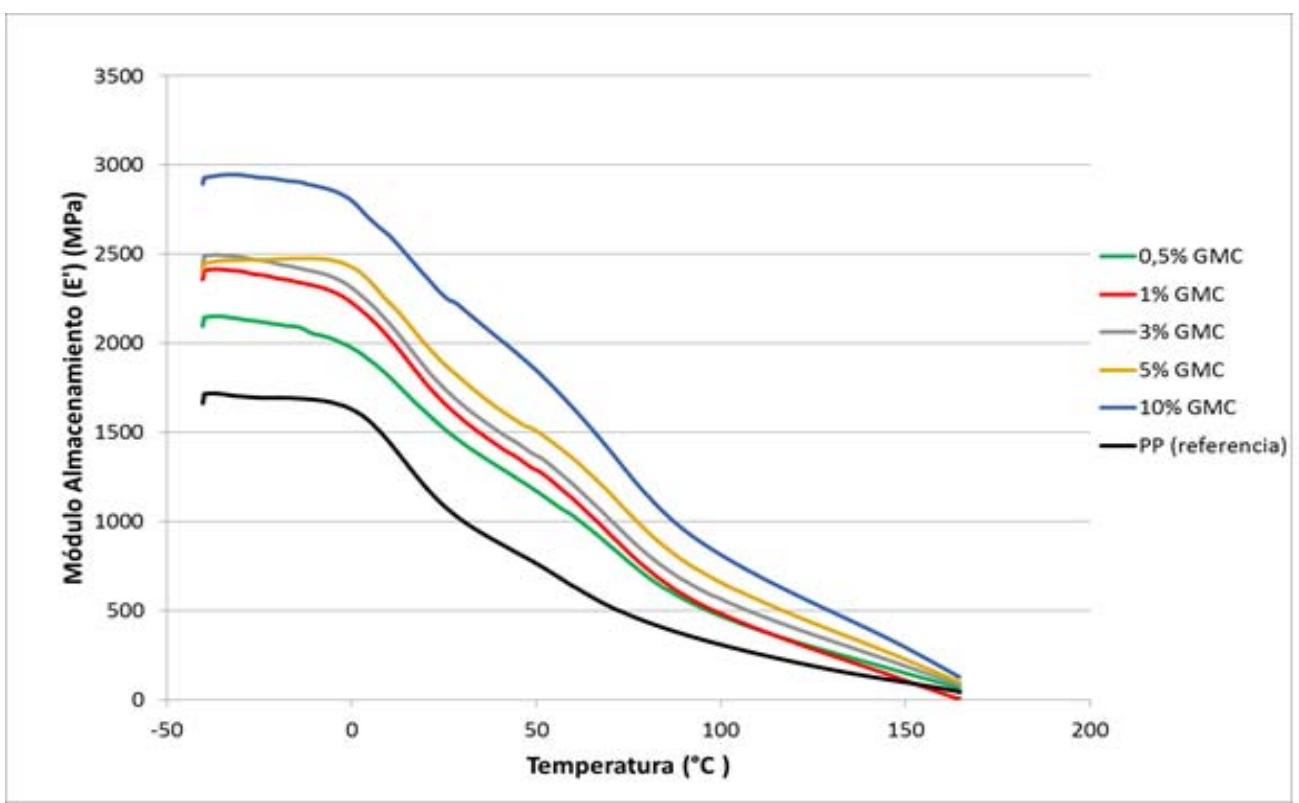

Figura 71. Módulo de almacenamiento versus temperatura para los nanocompuestos con diferentes porcentajes de GMC 
La Figura 72 y la Figura 73 representan la variación de la tangente de delta con la temperatura para ambos sistemas nanocompuestos. Ambas figuras muestran muy poca variación en los procesos de relajación- $\beta$ y relajación- $\alpha$. Se observa una disminución del pico pero no un desplazamiento del mismo. Por tanto, no se puede afirmar que haya un efecto en la cristalinidad del PP.

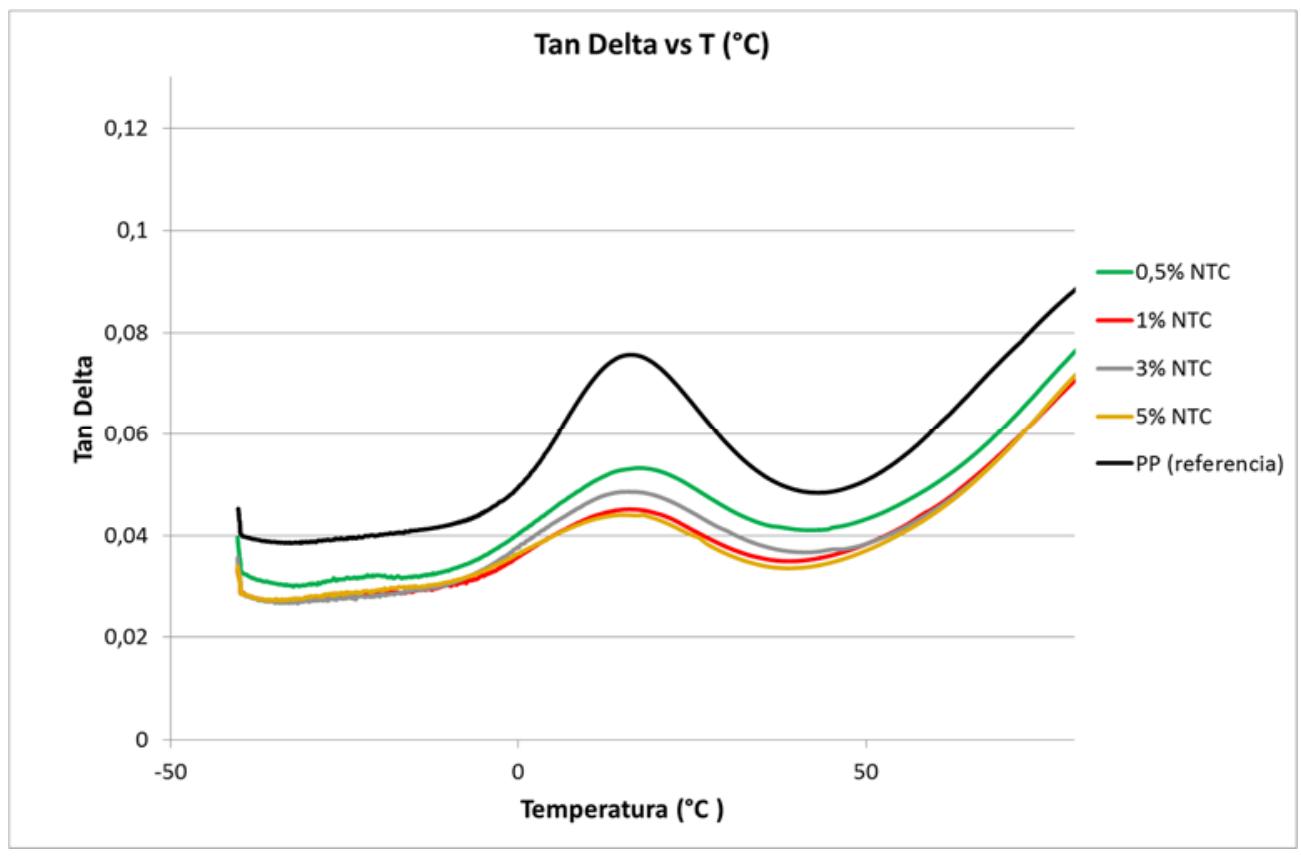

Figura 72. Tangente de Delta versus temperatura para los nanocompuestos con diferentes porcentajes de NTC 


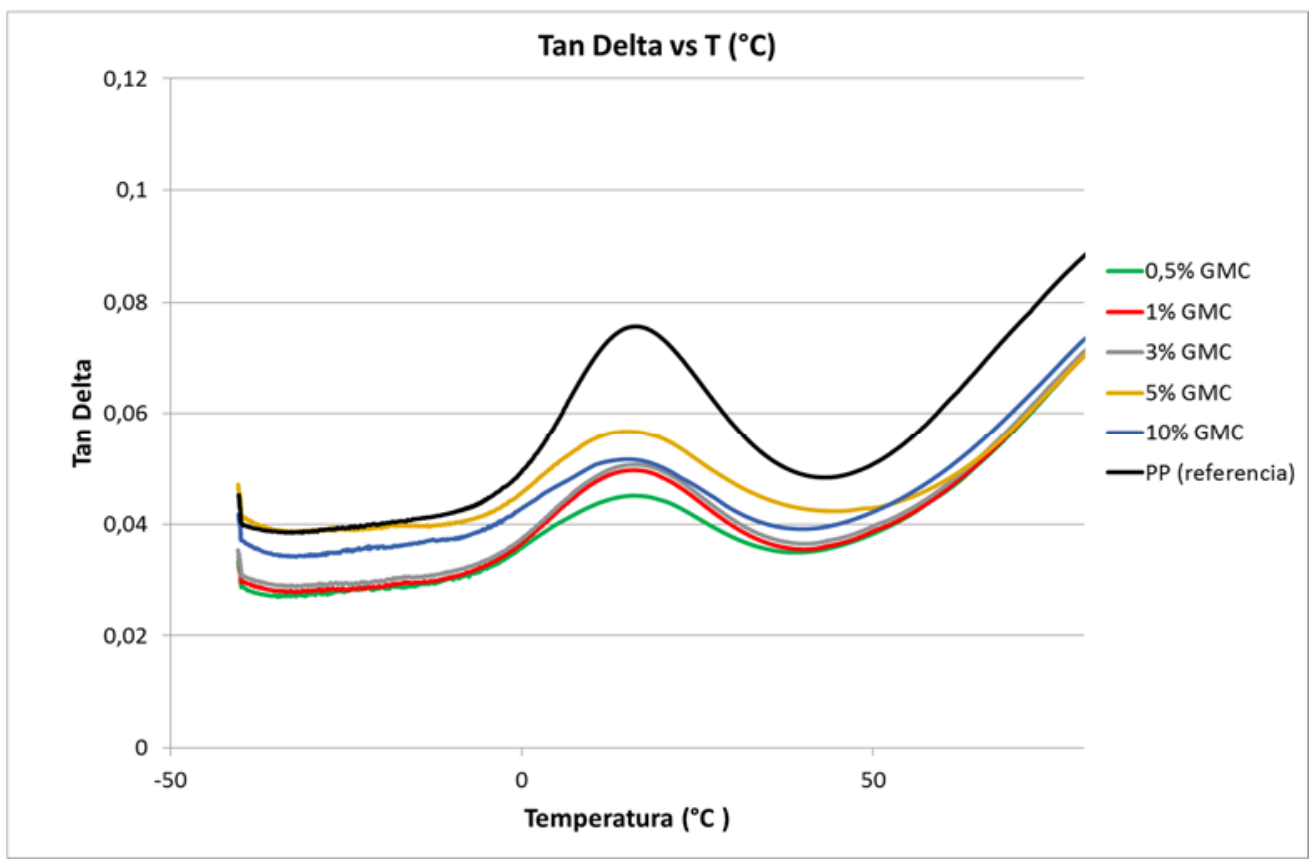

Figura 73. Tangente de Delta versus temperatura para los nanocompuestos con diferentes porcentajes de NTC 


\subsection{Propiedades térmicas}

La estabilidad térmica de los nanocompuesto de NTC y GMC fue evaluadas mediante análisis termogravimétrico (TGA). La Figura 74 y la Figura 75 muestran los valores de pérdida de masa con respecto al tiempo para los nanocompuesto basados en NTC y GMC respectivamente. Ambas figuras son una ampliación de la curva cuando comienza la pérdida de peso del material. Tomando el valor de la temperatura de descomposición (medido en el onset), tal y como se recopila en la Tabla 17, se puede apreciar un aumento de la estabilidad térmica en ambos sistemas nanocompuestos. Este efecto es muy similar para ambos sistemas, consiguiendo un aumento de la temperatura de descomposición de $16-17^{\circ} \mathrm{C}$ para contenidos de $5 \%$ de GMC y NTC. T. Kashiwagi et al. ${ }^{180}$ y D. Bikiaris et al ${ }^{181}$ demostraron que los NTC reducen la degradación termo-oxidativa del polipropileno. Este efecto esta ocasionado por aumento de la interacción interfacial entre los nanotubos y el polipropileno que conlleva un aumento de la energía de activación de la degradación ${ }^{182}$.

En referencia a los nanocompuestos basados en GMC también se observó un aumento de la estabilidad térmica del polipropileno. Este mismo efecto ha sido demostrado por varios autores. P. Song et al ${ }^{183}$ atribuyeron el aumento de la temperatura de degradación del polipropileno a la barrera física que produce el grafeno debido a su estructura laminar que impide la difusión del oxígeno, disminuyendo la degradación térmica del polipropileno. 


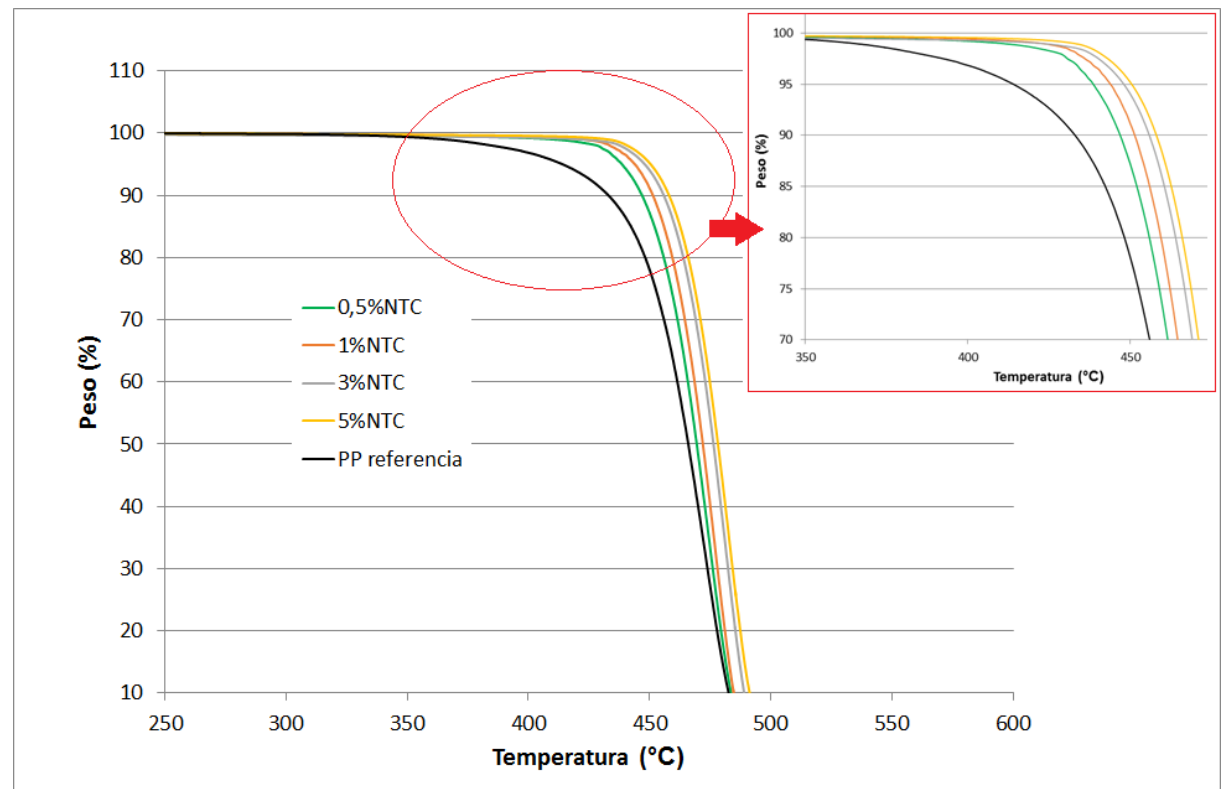

Figura 74. Análisis termogravimétrico de los nanocompuestos basados en NTC

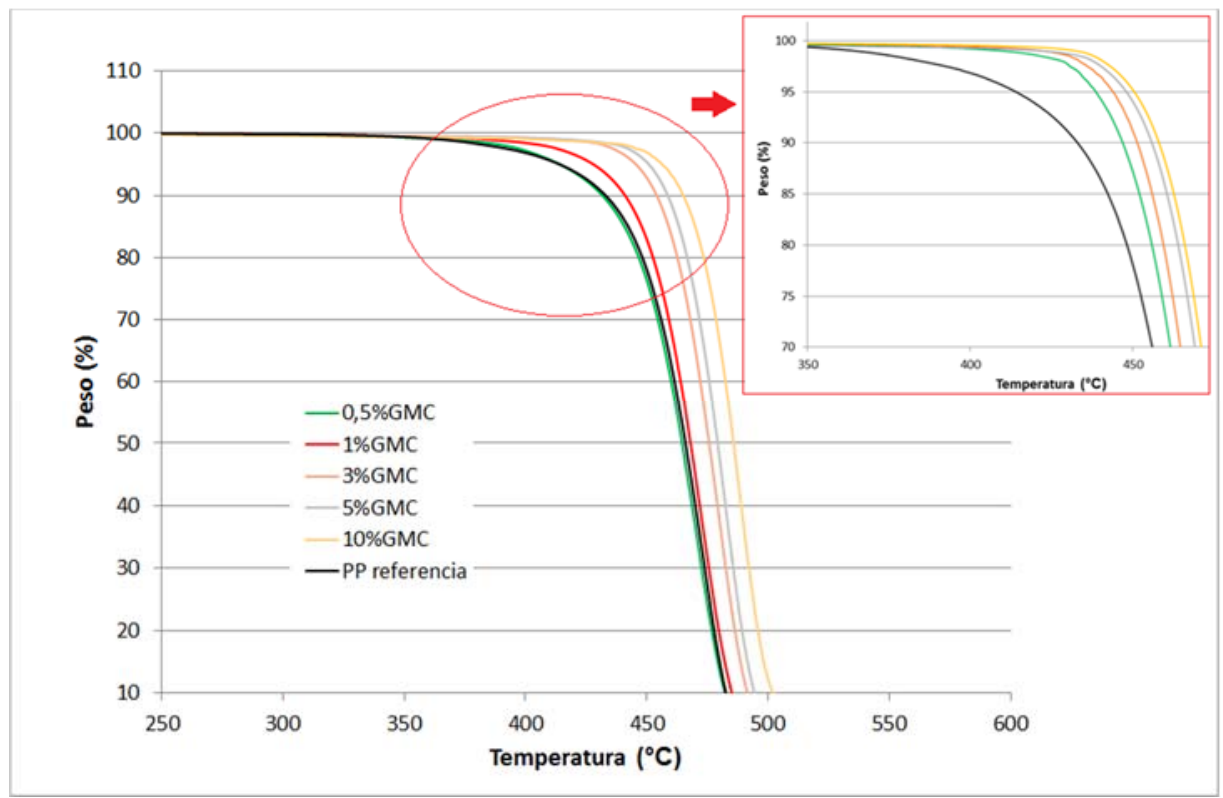

Figura 75. Análisis termogravimétrico de los nanocompuestos basados en GMC 
Tabla 17: Temperatura de degradación para los sistemas PP/NTC y PP/GMC

\begin{tabular}{|c|c|}
\hline Muestra & Temperatura Degradación $\left({ }^{\circ} \mathrm{C}\right)$ \\
\hline PP Referencia & $447,4^{\circ} \mathrm{C}$ \\
\hline $0,5 \%$ NTC & $453,2^{\circ} \mathrm{C}$ \\
\hline $1 \%$ NTC & $457,3^{\circ} \mathrm{C}$ \\
\hline $3 \%$ NTC & $461,7^{\circ} \mathrm{C}$ \\
\hline $5 \%$ NTC & $463,3^{\circ} \mathrm{C}$ \\
\hline $0,5 \%$ GMC & $444,8^{\circ} \mathrm{C}$ \\
\hline $1 \%$ GMC & $449,5^{\circ} \mathrm{C}$ \\
\hline $3 \%$ GMC & $458,7^{\circ} \mathrm{C}$ \\
\hline $5 \%$ GMC & $464,4^{\circ} \mathrm{C}$ \\
\hline $10 \%$ GMC & $470,2^{\circ} \mathrm{C}$ \\
\hline
\end{tabular}




\subsection{Conclusiones preliminares}

Del estudio reológico se concluye que un aumento del contenido de NTC incrementa la viscosidad del nanocompuesto a bajas frecuencias para todo el rango de composiciones estudiadas. Sin embargo, para los sistemas PP/GMC, solamente es visible un aumento de la viscosidad a contenidos superiores al $5 \%$. Para contenidos inferiores se observa un efecto lubricante similar al grafito.

Todos los nanocompuestos PP/NTC mostraron un comportamiento semiconductor, obteniéndose valores de conductividad volumétrica en el rango de $\left[10^{-1}-10^{-6}\right] \mathrm{S} / \mathrm{cm}$ según el contenido de NTC. Asimismo, el límite de percolación eléctrica para los nanocompuestos de NTC se sitúa alrededor del $1 \%$ de NTC, mientras que para los nanocompuestos con GMC este límite se encuentra alrededor del $10 \%$ de GMC, con un valor de conductividad eléctrica de $10^{-6} \mathrm{~S} / \mathrm{cm}$.

La constante dieléctrica y el factor de pérdidas de los nanocompuestos de NTC aumentaron gradualmente con el incremento del contenido en NTC. Por lo tanto, muestran capacidad para absorber radiación microondas y convertir esta energía en calor.

Las propiedades dieléctricas de los nanocompuestos de GMC fueron muy bajas en comparación con los NTC y apenas variaron aumentando el contenido de GMC. La capacidad para almacenar energía y transformarla en calor será muy limitada debido a sus bajas propiedades dieléctricas.

Del análisis dinámico-mecánico se concluye que la adición de nanocarga a la matriz de polipropileno da lugar a un aumento en el módulo de almacenamiento, indicando un incremento en la rigidez mecánica de los nanocompuestos. Se obtuvo un aumento del módulo de almacenamiento del $125 \%$ para ambos sistemas con un porcentaje de aditivación en peso del $1 \%$.

Ambos sistemas nanocompuestos PP/NTC y PP/GMC presentan un aumento de la estabilidad térmica con el incremento del contenido de nanocarga respecto al PP virgen. Esta mejora es ligeramente más alta en el caso de los nanotubos de carbono, debido a la mayor interacción en la interfase matriz/NTC. 


\section{CAPÍTULO 6: CALENTAMIENTO POR MICROONDAS DE LOS NANOCOMPUESTOS}

\subsection{Influencia de la dispersión en la eficacia de calentamiento}

Los nanocompuestos de PP/NCT y PP GMC obtenidos con diferentes condiciones de procesado y $1 \%$ de nanocarga (capítulo 4 ), fueron sometidos a radiación microondas durante 60 s a una potencia de $700 \mathrm{~W}$ con la finalidad de evaluar la influencia del grado de dispersión de las nanopartículas en el calentamiento alcanzado por el material. Los ensayos de calentamiento se realizaron a la potencia máxima del equipo microondas que se incluye en el rango de los magnetrones más habituales en la industria. El tiempo de calentamiento se fijó como máximo en 60 s con el fin de ser menor a los ciclos de calentamiento convencional de polímeros. Los compuestos fueron calentados en formato granza siguiendo el procedimiento especificado en el capítulo 3, apartado 3.2.3. La temperatura alcanzada por la muestra se determinó mediante una cámara termográfica. Se tomaron los valores de temperatura de diez puntos de la muestra y cada ensayo se repitió tres veces, con el fin de tener mayor reproducibilidad de las medidas.

La Figura 76 muestra la temperatura alcanzada por cada nanocompuesto PP/NTC, representada en un diagrama de cajas (Box-Plot). Los valores de temperatura media, los percentiles ( $q 1=25 \%$ y $q 3=75 \%$ ) y los valores máximos y mínimos se calcularon para realizar un análisis más completo del comportamiento del material ante la radiación microondas. Este gráfico es de utilidad para valorar la dispersión de medidas de temperatura alcanzada por cada nanocompuesto. Se puede analizar si el calentamiento es homogéneo (poca diferencia entre los valores mínimo, medio y máximo) o si, por el contrario, se observan muchos puntos calientes o "hot spots" (gran diferencia entre los valores mínimos, medios y máximos). En el gráfico se observan que con nanocompuestos obtenidos vía masterbatch (MB) se alcanza un valor de temperatura media muy similar independientemente de la velocidad de husillo aplicada. Sin embargo, en los nanocompuestos obtenidos por compound directo (CD) se observa un aumento de la temperatura al aumentar la velocidad de extrusión. La temperatura máxima más alta alcanzada se obtuvo en los nanocompuestos obtenidos a baja cizalla y por compound directo. Esto 
se debe a la baja dispersión de los NTC en la matriz, ya que la presencia de aglomerados produce puntos calientes que alcanzan temperaturas muy altas pero de forma heterogénea, registrándose en las zonas adyacentes temperaturas mucho más bajas. Por ello, aunque la temperatura media es elevada, la dispersión de resultados es muy grande, lo cual significa que el calentamiento no es homogéneo. Este motivo se justifica la necesidad de representar las desviaciones de temperatura mediante un diagrama de cajas y no la temperatura media.

A partir de estos resultados se puede concluir que los compuestos con $1 \%$ de NTC producidos vía masterbatch ofrecen un calentamiento más homogéneo para todas las condiciones de procesado empleadas que aquellos obtenidos por compound directo. Tal y como ocurrió en los estudios de dispersión, el comportamiento frente a la radiación de microondas presenta mayor independencia de las condiciones de procesado si los compuestos son obtenidos vía masterbatch. En el estudio de la dispersión se observó el mismo comportamiento en referencia al tamaño medio de partículas y la densidad de aglomerados obtenida. Al igual que la dispersión se mejoraba con la cizalla para los compuestos obtenidos por compound directo, se produce un aumento de las temperaturas alcanzadas al aumentar la velocidad de extrusión. 


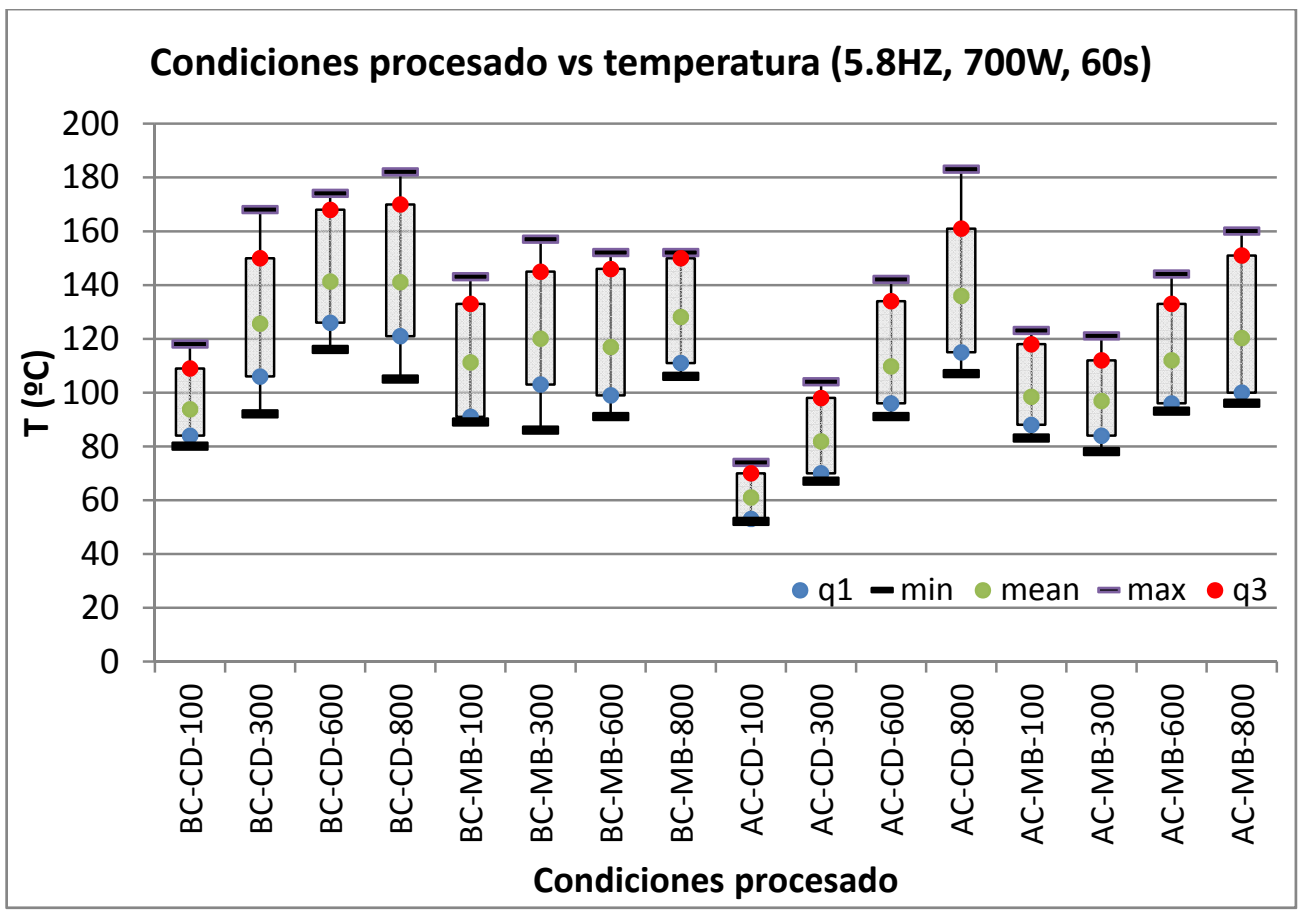

Figura 76. Temperatura alcanzada por los nanocompuesto tras $60 \mathrm{~s}$ de exposición a la radiación microondas $(700 \mathrm{~W}, 5.8 \mathrm{GHz})$

La Figura 77 recopila los resultados del mismo experimental pero esta vez para los nanocompuesto de PP $+1 \%$ GMC obtenidos con diferentes condiciones de procesado. Se representa la temperatura alcanzada para cada uno de ellos. Todos los nanocompuestos muestran un calentamiento muy pobre. En la gráfica se observa que todas las muestras alcanzan una temperatura alrededor de $25-30^{\circ} \mathrm{C}$. Es decir, no superan la temperatura ambiente, por lo que son totalmente transparentes a la radiación microondas al $1 \%$ en peso de GMC. Estos resultados se obtuvieron en las mismas condiciones que el sistema PP/CNT, con el fin de poder comparar entre ambos. Para forzar el comportamiento susceptor de los GMC se realizó un experimento en el que las muestras fueron calentadas durante cinco minutos a 700W y no se obtuvieron mejoras en el calentamiento.

Asimismo, se realizó también un experimento en el que las muestras fueron calentadas durante tiempos más largos (5 minutos) a 700W, sin observar ninguna mejora en el calentamiento. 
Atendiendo a los resultados de conductividad eléctrica obtenidos en el capítulo 4 para los nanocompuestos con $1 \%$ de GMC, en el que se observó un carácter totalmente aislante $\mathrm{y}$ donde las propiedades dieléctricas mostraban poca variación con respecto al PP virgen. Con todo ello, se predecía un bajo calentamiento por microondas que se confirma en este experimental.

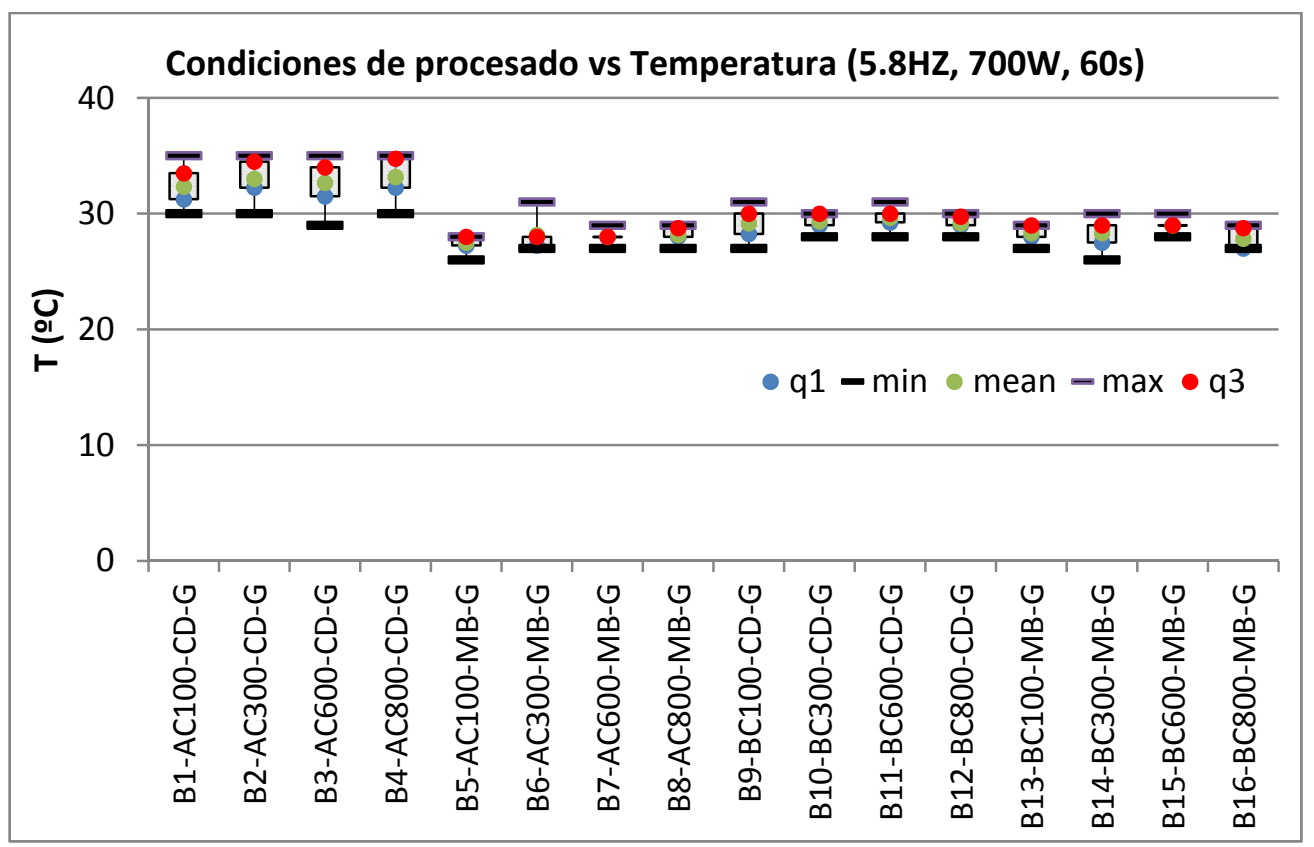

Figura 77. Temperatura alcanzada por los nanocompuesto tras $60 \mathrm{~s}$ de exposición a la radiación microondas $(700 \mathrm{~W}, 5.8 \mathrm{GHz})$ 
A) Influencia del tamaño medio de partícula y la densidad de aglomerados en la temperatura alcanzada por radiación microondas

Figura 78 y la Figura 79 muestran la relación entre el tamaño medio de partícula y la densidad de aglomerados para diferentes condiciones de procesado, respectivamente. El objetivo consiste en evaluar la influencia de la dispersión de los NTC en el calentamiento por microondas.

La temperatura alcanzada por microondas aumenta al reducirse el tamaño medio de partícula y la densidad de aglomerados. Por lo tanto, una mejora de la dispersión de los NTC en la matriz de PP aumenta la temperatura media alcanzada en el microondas. Cabe destacar que con condiciones de procesado de alta cizalla (configuración de husillo de alta cizalla) y alto tiempo de residencia (NTC incorporados vía masterbatch), se obtiene una menor dependencia de la temperatura alcanzada en el microondas con la velocidad de extrusión de los nanocompuestos. Esto se observa en la Figura 79d, en la que la temperatura media alcanzada es muy similar a $100 \mathrm{rpm}$ o a $800 \mathrm{rpm}$. Por el contrario, a baja cizalla se observa un gran salto en la temperatura alcanzada si se compara entre los compuestos producidos a $100 \mathrm{rpm}$ y los obtenidos a 800 rpm (ver Figura 79b). 


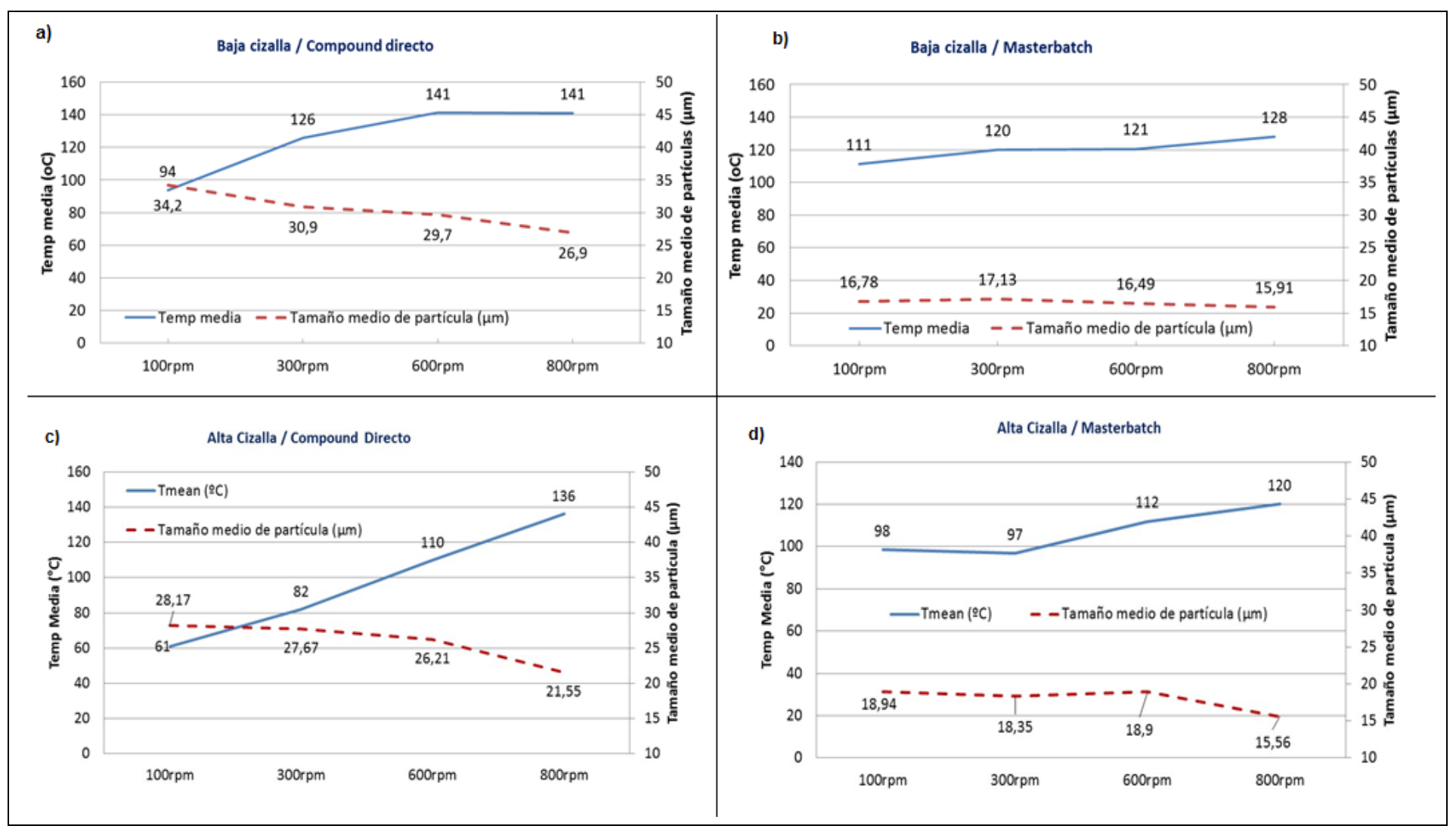

Figura 78. Temperatura media alcanzada vs tamaño medio de partícula para los compuestos producidos en diferentes condiciones de procesado: a) baja cizalla / compound directo, b) baja cizalla / masterbatch, c) alta cizalla / compound directo, d) alta cizalla / masterbatch 


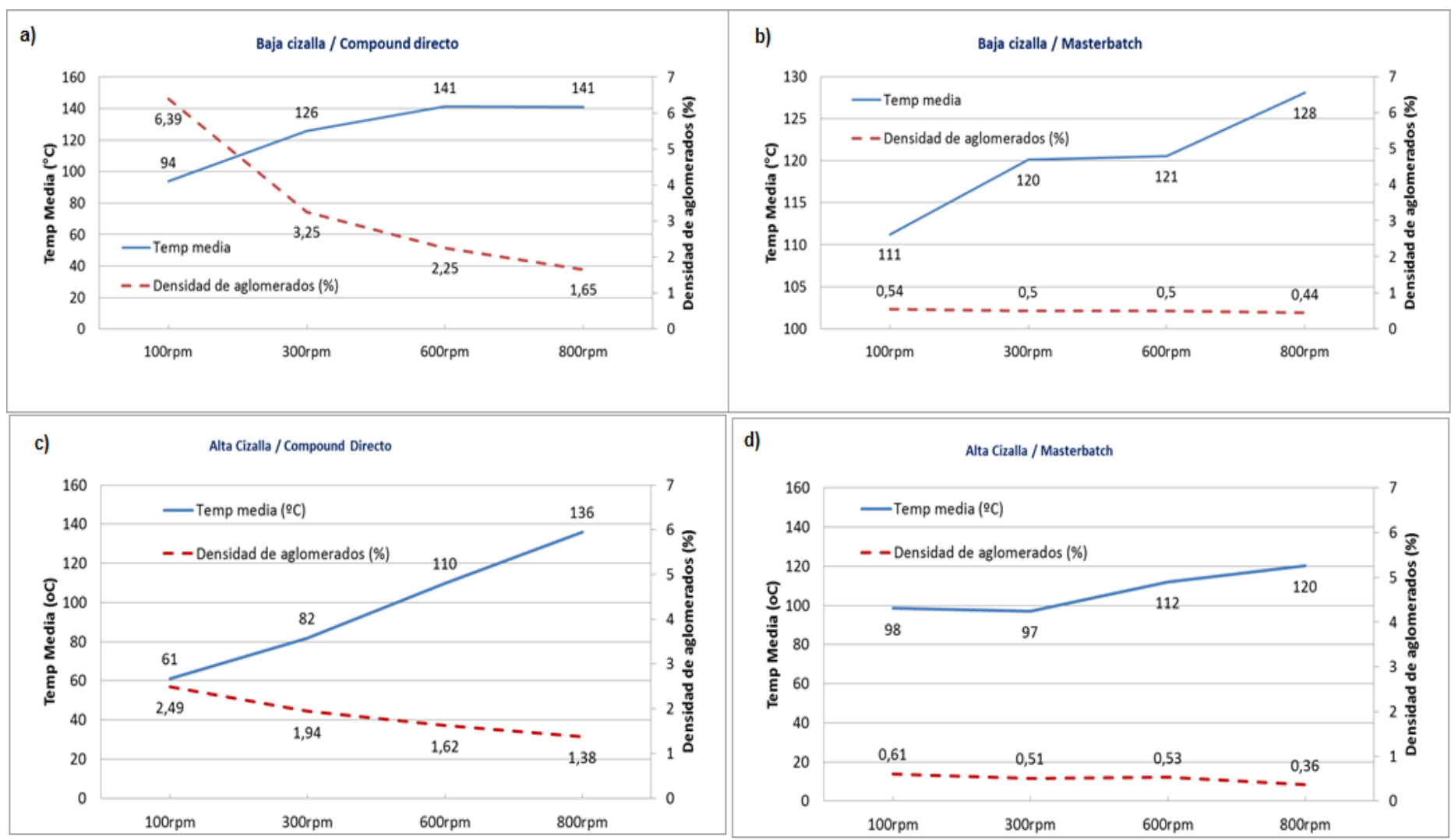

Figura 79. Temperatura media alcanzada vs densidad de aglomerados para los compuestos producidos en diferentes condiciones de procesado: a) baja cizalla / compound directo, b) baja cizalla / masterbatch, c) alta cizalla / compound directo, d) alta cizalla / masterbatch 
B) Influencia factor de conductividad eléctrica en la temperatura alcanzada por radiación microondas

Tal y como se determinó en el apartado 4.3, los sistemas basados en nanotubos de carbono presentan propiedades eléctricas superiores a los sistemas de grafeno multicapa. La Figura 80 muestra la relación entre la conductividad eléctrica superficial de los sistemas de NTC para nanocompuestos obtenidos con diferentes condiciones de procesado.

La conductividad eléctrica de los nanocompuestos puede correlacionarse con la efectividad de los NTC como susceptor de microondas. La Figura 80 muestra esta correlación para nanocompuestos obtenidos con diferentes condiciones de procesado con la temperatura media alcanzada en el microondas y con la conductividad superficial. En todas las gráficas se observa la misma tendencia. La temperatura media alcanzada se incrementa con la conductividad eléctrica del material. Los nanocompuestos mejoran sus propiedades eléctricas cuando se procesan a alta cizalla (configuración de husillo agresiva y alta velocidad de extrusión) y altos tiempo de residencia (Ios NTC se introducen vía masterbatch). Por tanto, las gráficas confirman que la efectividad de calentamiento de los nanocompuestos aumenta a medida que aumenta la conductividad eléctrica.

Comparando las gráficas entre sí, se observa que los valores más altos de temperatura se obtienen para los compuestos obtenidos por compound directo. En el capítulo 4 se analizó la dispersión de los NTC, obteniendo un grado de dispersión menor para los compuestos obtenidos por compound directo. Al estar representando la temperatura media, ésta puede incrementarse debido a la aparición de puntos calientes o "hot spots" causados por la mayor presencia de aglomerados, con la consecuente heterogeneidad de la muestra. También se obtienen mayores diferencias entre el procesado a $100 \mathrm{rpm}$ y $800 \mathrm{rpm}$ alcanzando temperaturas más bajas que con los compuestos obtenidos vía masterbatch.

Coincidiendo con las medidas de dispersión, los compuestos obtenidos a partir de masterbatch son aquellos que muestran mayor homogeneidad entre las muestras obtenidas con independencia de las condiciones de cizalla (rpm y configuración de husillo). 
Al aumentar la conductividad se produce un aumento en la temperatura alcanzada por el nanocompuesto, manteniendo la concentración de NTC pero variando las condiciones de procesado. El aumento de la cizalla y del tiempo de residencia causa un efecto positivo en la conductividad eléctrica como se vio en el capítulo 4 y esto se refleja en un aumento de la temperatura alcanzada en el microondas.

Por lo tanto, se puede concluir que una mejora en la dispersión de los NTC aumenta la conductividad eléctrica de los nanocompuestos y, a su vez, su efectividad como susceptor de microondas. 


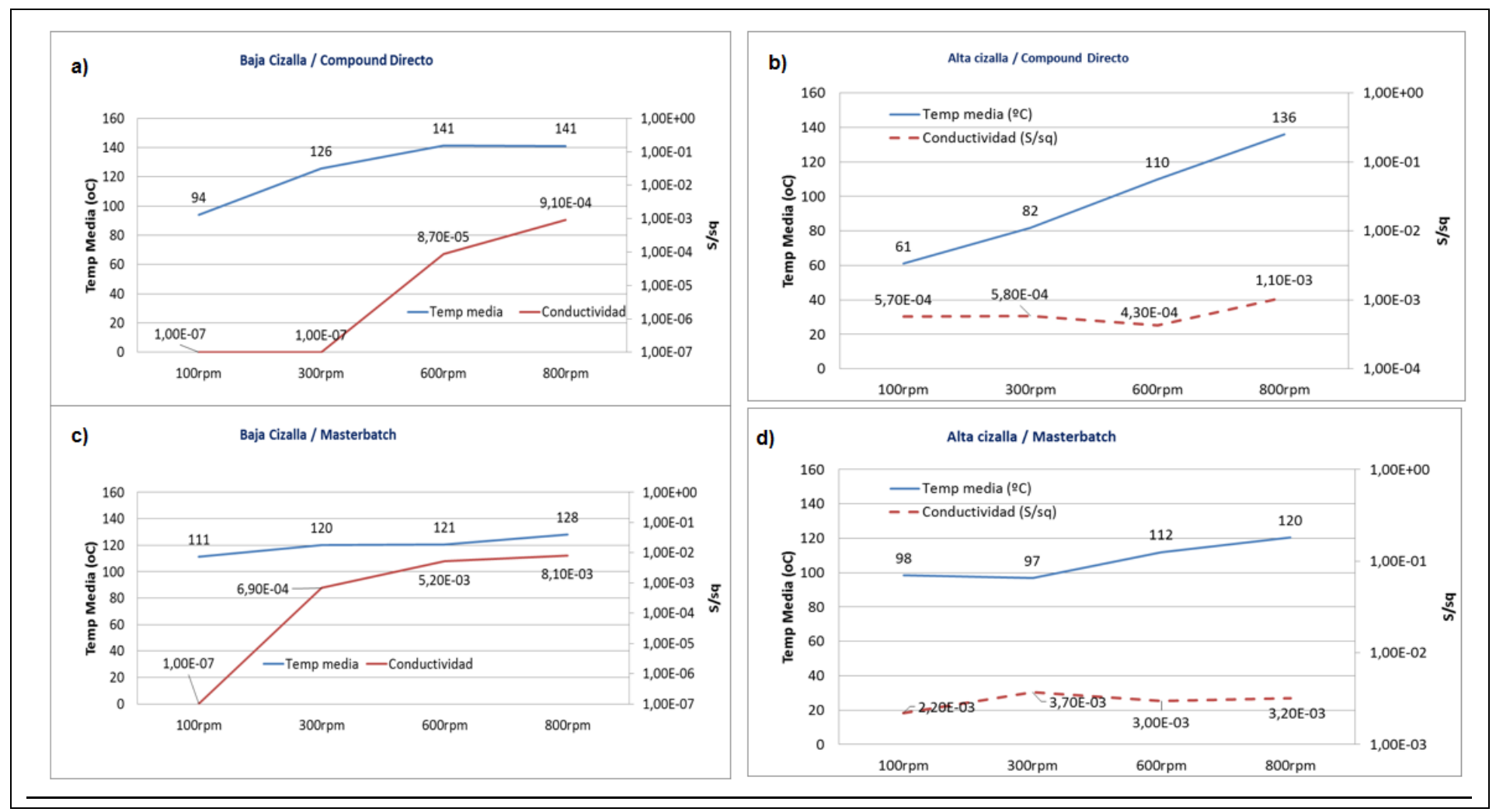

Figura 80. Temperatura media alcanzada vs conductividad superficial para los compuestos producidos en diferentes condiciones de procesado: a) baja cizalla / compound directo, b) baja cizalla / masterbatch, c) alta cizalla / compound directo, d) alta cizalla / masterbatch 


\subsection{Eficiencia de calentamiento}

Los nanocompuestos con diferentes porcentajes de NTC y GMC fueron sometidos a radiación microondas con una potencia de $700 \mathrm{~W}$ a durante diferentes tiempos de calentamiento (20s, 40s y 60s). Cada experimento se repitió 10 veces, tomando 5 valores de temperatura para calcular la temperatura media. Las muestras se introdujeron en formato de granza según el procedimiento detallado en el capítulo 3, apartado 3.2.3.

La Figura 81 representa las temperaturas medias alcanzadas por los nanocompuestos respecto al porcentaje de NTC a diferentes tiempos de exposición a la radiación microondas. Se observa que la temperatura aumenta gradualmente con el porcentaje de NTC. Incluso a bajos porcentajes de NTC se consigue aumentar la temperatura de la muestra. Con un contenido del $0.5 \%$ de NTC ya se muestra una absorción de radiación microondas. No se muestran las barras de error para poder analizar mejor las gráficas, ya que la disparidad de los valores conseguidos para cada uno de los nanocompuestos se valorará en el apartado 6.3. Homogeneidad de calentamiento.

El calentamiento de polímeros por microondas tiene como objetivo reducir la energía necesaria para fundir y procesar los polímeros. Por lo tanto, el susceptor de microondas debe ser capaz de sobrepasar la temperatura de fusión del polímero en el mínimo periodo de tiempo posible, similar o inferior al tiempo que se necesita actualmente para fundir el polímero en inyección o extrusión $(50-90 \mathrm{~s})$. 


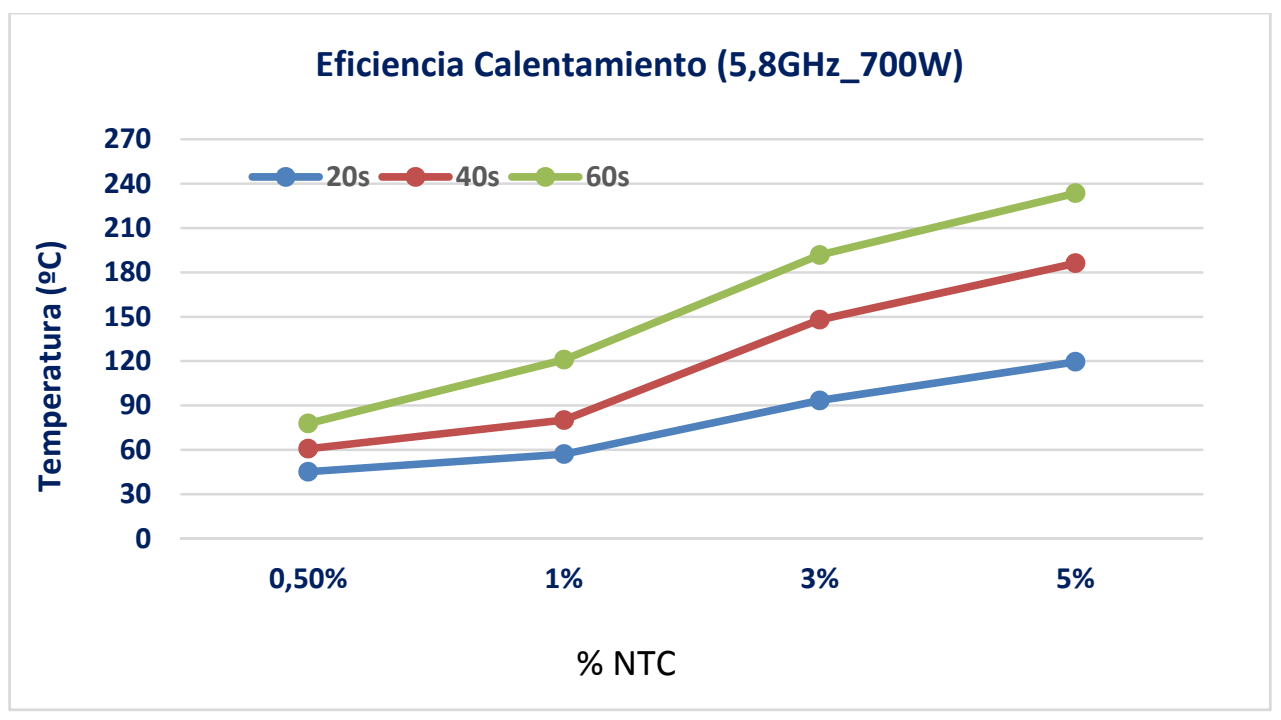

Figura 81. Eficiencia de calentamiento para los nanocompuestos de NTC

Los resultados obtenidos para la eficiencia de calentamiento en los nancompuestos PP/GMC a diferentes tiempos de calentamiento (20s, 40s y 60 s) se recopilan en la Figura 82 . En ella se observa que a partir del $5 \%$ de GMC se produce una absorción mínima de radiación microondas. Las muestras con menor contenido de GMC son transparentes a la radiación microondas y, por tanto, en la gráfica no se observa ningún aumento de la temperatura. Estos resultados coinciden con las propiedades eléctricas y dieléctricas analizadas con anterioridad. En el caso de los nanocompuestos de GMC un $10 \%$ sería el porcentaje más idóneo pero, aun así, no podría ser válido para la transformación de polímeros ya que la temperatura alcanzada es menor en comparación con los NTC y demasiado baja para el fundido de la mayoría de matrices poliméricas de gran consumo. 


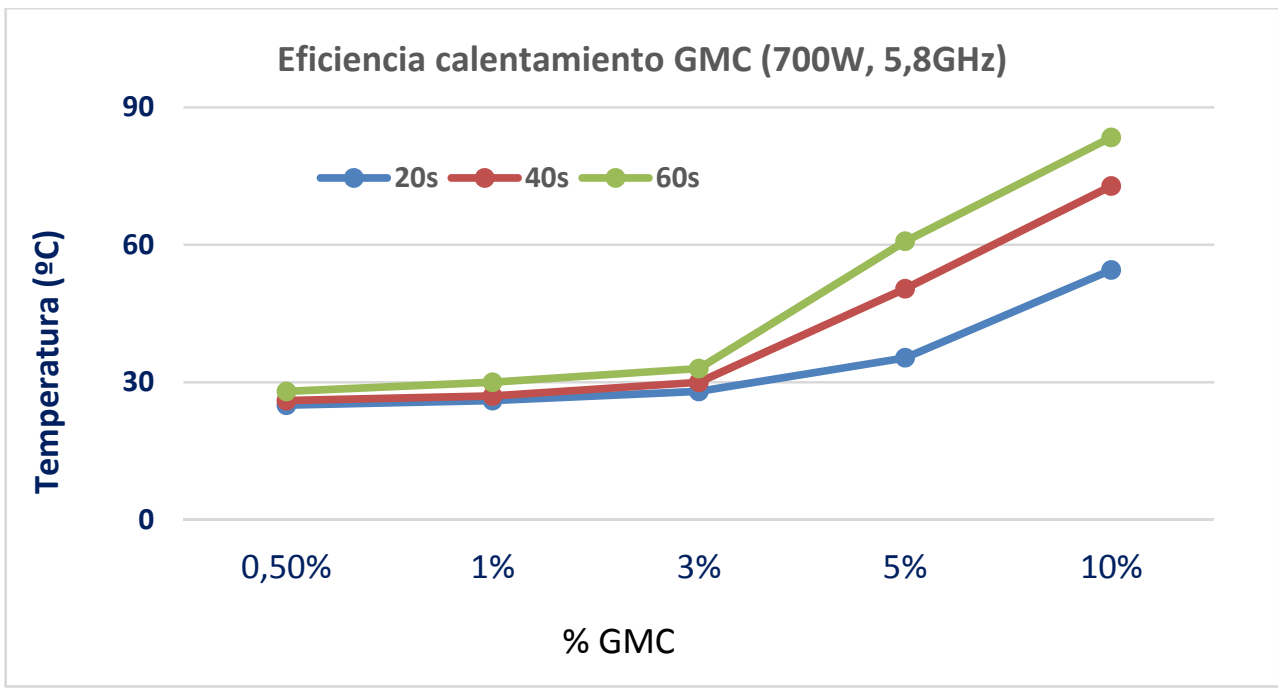

Figura 82. Eficiencia de calentamiento para los nanocompuestos de GMC

Harper et al $^{184}$ definieron la eficiencia de calentamiento como la pendiente de las curvas de temperatura respecto al porcentaje de carga susceptora, a partir de un trabajo llevado a cabo en matrices de polietileno aditivadas con negro de humo. En el presente experimental se calculó del mismo modo la eficiencia de calentamiento para los compuestos de NTC y GMC, obteniendo como unidades de la eficiencia ${ }^{\circ} \mathrm{C} / \%$. Mediante este parámetro se calcula el aumento de temperatura que se obtendrá en cada sistema para un tiempo de calentamiento dado. Los valores obtenidos para cada velocidad de calentamiento y cada sistema se recopilan en la Tabla 18. En ella se observa que los valores de temperatura por contenido de susceptor son mucho mayores en el caso de los nanocompuestos PP/NTC. Los valores en los sistemas $\mathrm{PP} / \mathrm{GMC}$ son muy bajos, con una eficiencia máxima de $5^{\circ} \mathrm{C} / \%$ para un minuto de calentamiento frente a los $34.6^{\circ} \mathrm{C} / \%$ obtenidos con los NTC.

Los resultados obtenidos concuerdan con la conductividad eléctrica y las propiedades dieléctricas de los nanocompuestos. Una alta movilidad de los electrones y una rotación de los dipolos se reflejan en los ensayos microondas absorbiendo más radiación electromagnética y, por lo tanto, aumentando en mayor medida la temperatura del nanocompuesto. 
Tabla 18: Valores de eficiencia de calentamiento de los nanocompuestos de carbono a diferentes tiempos de calentamiento

\begin{tabular}{|c|c|c|}
\hline $\begin{array}{c}\text { Tiempo } \\
\text { calentamiento }\end{array}$ & $\begin{array}{c}\text { Eficiencia calentamiento } \\
\left(\mathbf{}{ }^{\circ} \mathbf{C} / \%\right)\end{array}$ & $\begin{array}{c}\text { Eficiencia calentamiento } \\
\left({ }^{\circ} \mathrm{C} / \%\right)\end{array}$ \\
\cline { 2 - 3 } & NTC & GMC \\
\hline 20 & 16.6 & 3.1 \\
\hline 40 & 27.7 & 4.9 \\
\hline 60 & 34.6 & 5.7 \\
\hline
\end{tabular}




\subsection{Homogeneidad de calentamiento}

Además de la eficiencia de calentamiento es de gran importancia analizar si el calentamiento de la muestra es homogéneo o la temperatura media alcanzada es tan alta debido a la aparición de puntos calientes. La mejor forma de comparar la forma en la que se calienta la muestra es representando diagramas de cajas, que representan las temperaturas máximas y mínimas, la temperatura media y los percentiles. Cuanto más estrecha sea la caja y las desviaciones, más homogéneo será el calentamiento.

La Figura 83 muestra los valores de temperatura alcanzados cuando se aplican $20 \mathrm{~s}$ de calentamiento para los nanocomposites con distinto porcentaje de NTC. Con un $5 \%$ de NTC se alcanzan unas temperaturas máximas de $180^{\circ} \mathrm{C}$ por lo que se podría pensar que con un ciclo de calentamiento tan corto la muestra sería procesable, es decir, estaría toda la masa fundida. Sin embargo, fijándose con más detalle en los valores, se observa que la temperatura mínima es de unos $80^{\circ} \mathrm{C}$ y que el $75 \%$ de los valores de temperatura tomados están por debajo de $130^{\circ} \mathrm{C}$, por lo que este valor de $180^{\circ} \mathrm{C}$ se asociaría a la aparición de puntos calientes. Esto puede ocurrir al estar muy por encima del límite de percolación de los NTC. El umbral de percolación a partir del cual se da la formación de una red interconectada de nanotubos, se vio en el capítulo 3 que aparecía alrededor del $1 \%$ de carga. A medida que el contenido de NTC se incrementa, aunque la dispersión sea buena, los NTC tienden a aglomerarse ya que no hay volumen físico suficiente para su correcta dispersión y, por ende, aparecerán más puntos calientes. Así mismo, se observa que con un 3\% el diagrama de cajas también es ancho pero en menor medida que al $5 \%$. Sin embargo, con un contenido de NTC del $1 \%$ el calentamiento es más homogéneo. La diferencia entre la temperatura máxima y mínima es muchísimo menor que para porcentajes mayores.

A continuación se va a proceder a estudiar el sistema ( $1 \%$ de NTC) aplicando diferentes tiempos de calentamiento con el objetivo de analizar si el calentamiento sigue siendo homogéneo. 


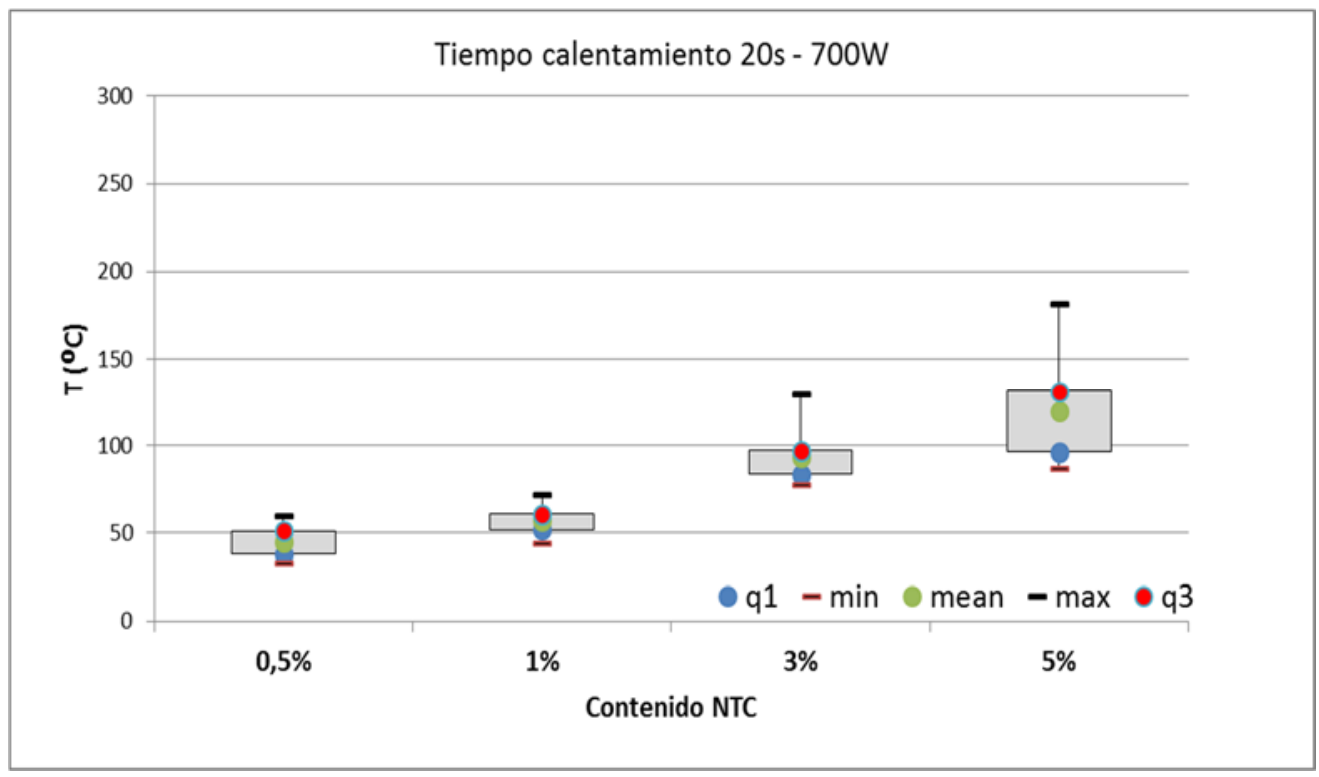

Figura 83. Temperatura versus contenido de NTC para 20s de calentamiento a 700W

El calentamiento de los nanocompuestos durante 40s se muestra en la Figura 84. La tendencia sigue siendo la misma que para calentamientos de 20s: altos porcentajes de NTC producen un calentamiento no uniforme de la muestra. Contenidos del $0.5 \%$ y del $1 \%$ muestran un calentamiento más homogéneo, siendo algo más efectivo el empleo de un $1 \%$ de NTC como susceptor. 


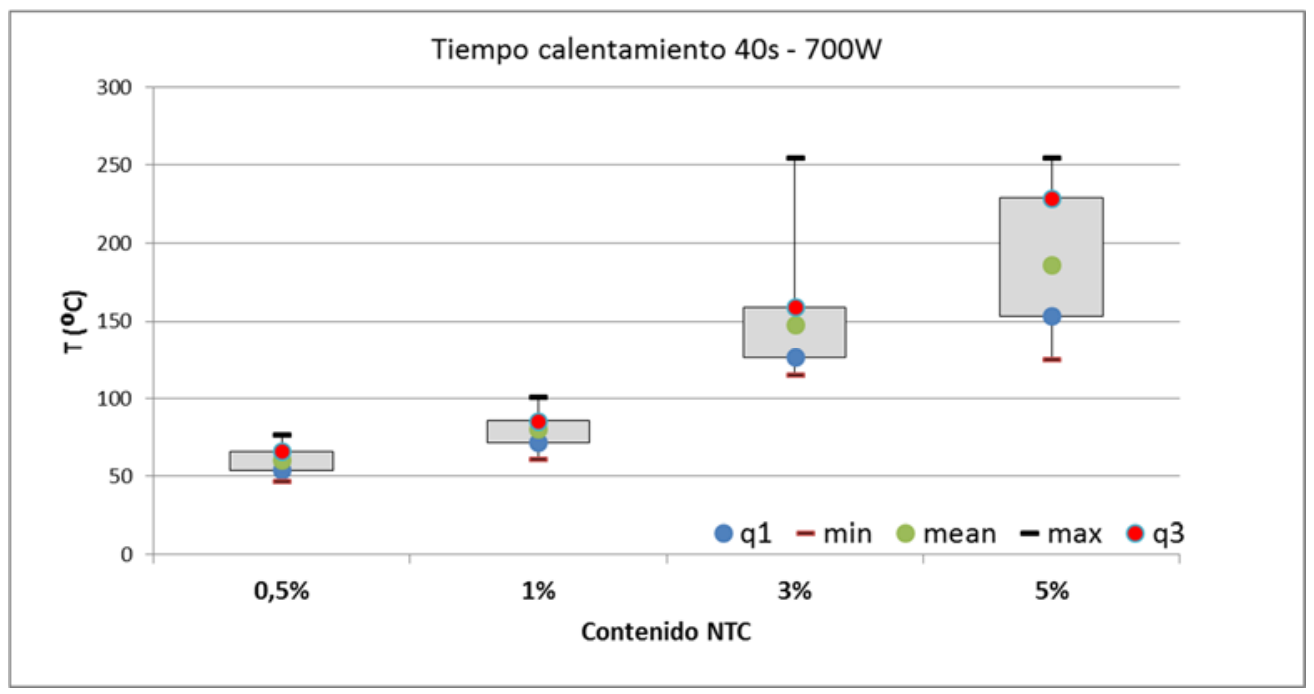

Figura 84. Temperatura versus contenido de NTC para 40s de calentamiento a 700W

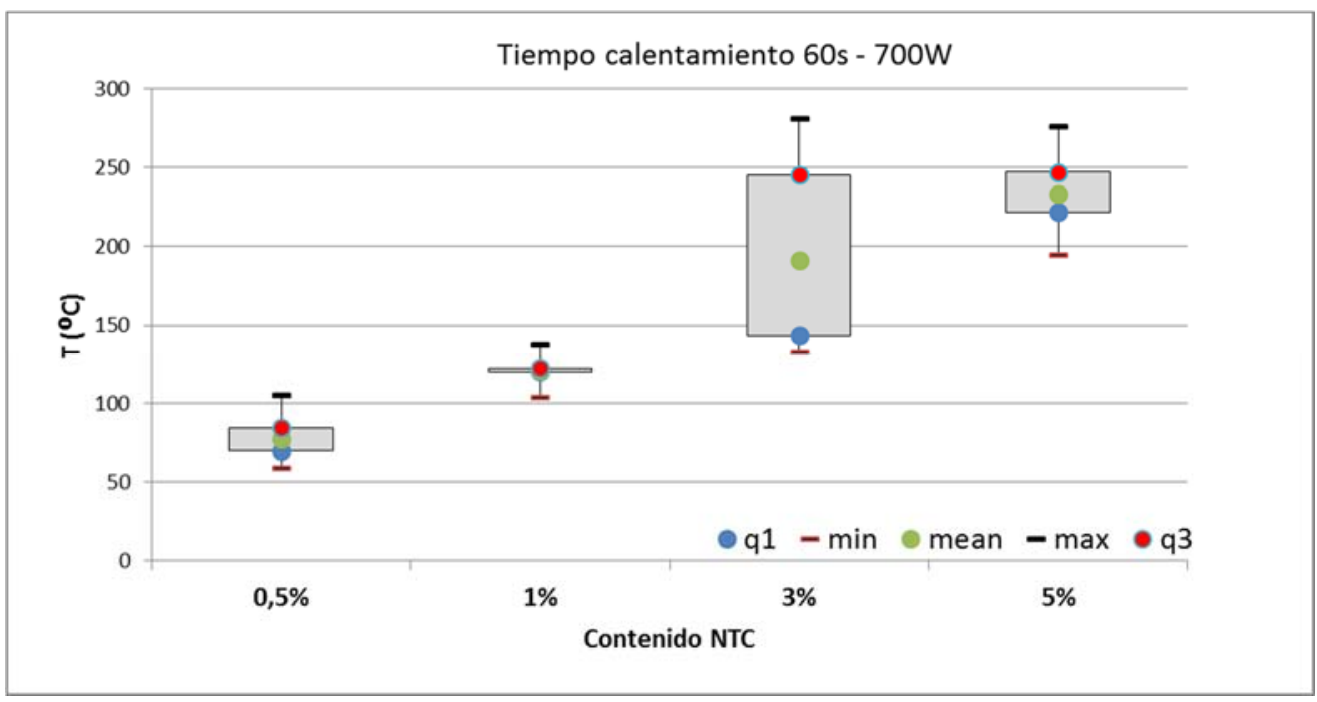

Figura 85. Temperatura versus contenido de NTC para 60 s de calentamiento a 700W

Con calentamientos de un minuto todavía hay más diferencias entre porcentajes de NTC. Altos porcentajes muestran una gran disparidad entre los valores de temperatura recopilados (ver Figura 85). 
Con calentamientos de un minuto todavía hay más diferencias entre porcentajes de NTC. Altos porcentajes muestran una gran disparidad entre los valores de temperatura recopilados (ver Figura 85).

Por todo lo expuesto anteriormente, el $1 \%$ de NTC es definitivamente seleccionado para la validación del sistema y la producción de un prototipo a escala planta piloto.

La Figura 86 recopila las diferentes fotos tomadas con la cámara termográfica tras 60 s de calentamiento microondas. Las fotos se muestran con el fin de analizar la homogeneidad de calentamiento. Hay que tener en cuenta que la cámara adapta los colores según los rangos de temperatura. Es decir, el mismo color entre fotografías no implica la misma temperatura. Se puede obtener el mismo rango de colores para una muestra que alcanza $30^{\circ} \mathrm{C}$ que para otra que alcanza $100^{\circ} \mathrm{C}$. Aun así, estas fotografías son de utilidad para analizar la homogeneidad del calentamiento. Pocos cambios en el color de la muestra indicarán mayor homogeneidad.

Analizando los valores y las fotografías se deduce cuál es el nanocompuesto que presenta un calentamiento más uniforme. $1 \%$ de NTC se postula como el contenido idóneo de susceptor de microondas para alcanzar una temperatura homogénea en un tiempo aceptable. Tiempos de calentamiento muy cortos también dificultaría el control del proceso por lo que el rango de 60 - 90 s corresponde a tiempos aceptables. 


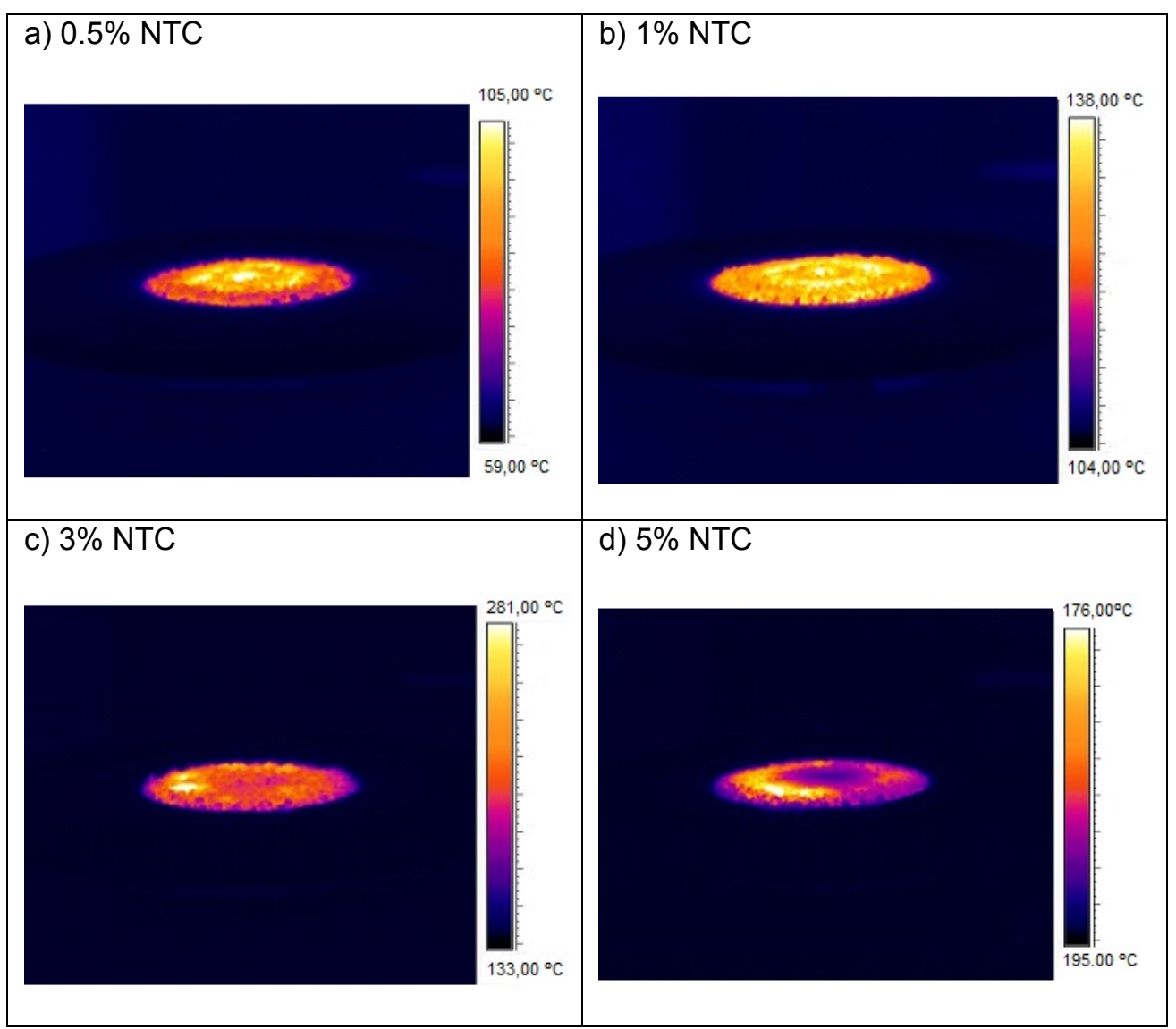

Figura 86. Fotos cámara termográfica tras $60 \mathrm{~s}$ de calentamiento: a) $0.5 \% \mathrm{NTC}$,

b) $1 \%$ NTC, c) $3 \%$ NTC, d) $5 \%$ NTC

La Figura 87, Figura 88 y Figura 89 representan las temperaturas alcanzadas por los nanocompuestos con diferentes porcentajes de GMC y diferentes tiempos de calentamiento mediante diagramas de cajas. Independientemente del tiempo de calentamiento se observa la misma tendencia. El calentamiento con altos porcentajes de GMC $(5 \%$ y $10 \%)$ es mucho más homogéneo que con altos porcentajes de NTC (3\% y $5 \%$ ). Esto puede deberse a que el GMC no alcanza valores de conductividad eléctrica tan buenos como los de los NTC, por lo que no se generan tantos puntos calientes. Sin embargo, aunque el calentamiento sea homogéneo, los valores de temperatura alcanzados son muy bajos, haciendo que estos nanocompuestos no sean susceptibles de ser procesados por microondas. 


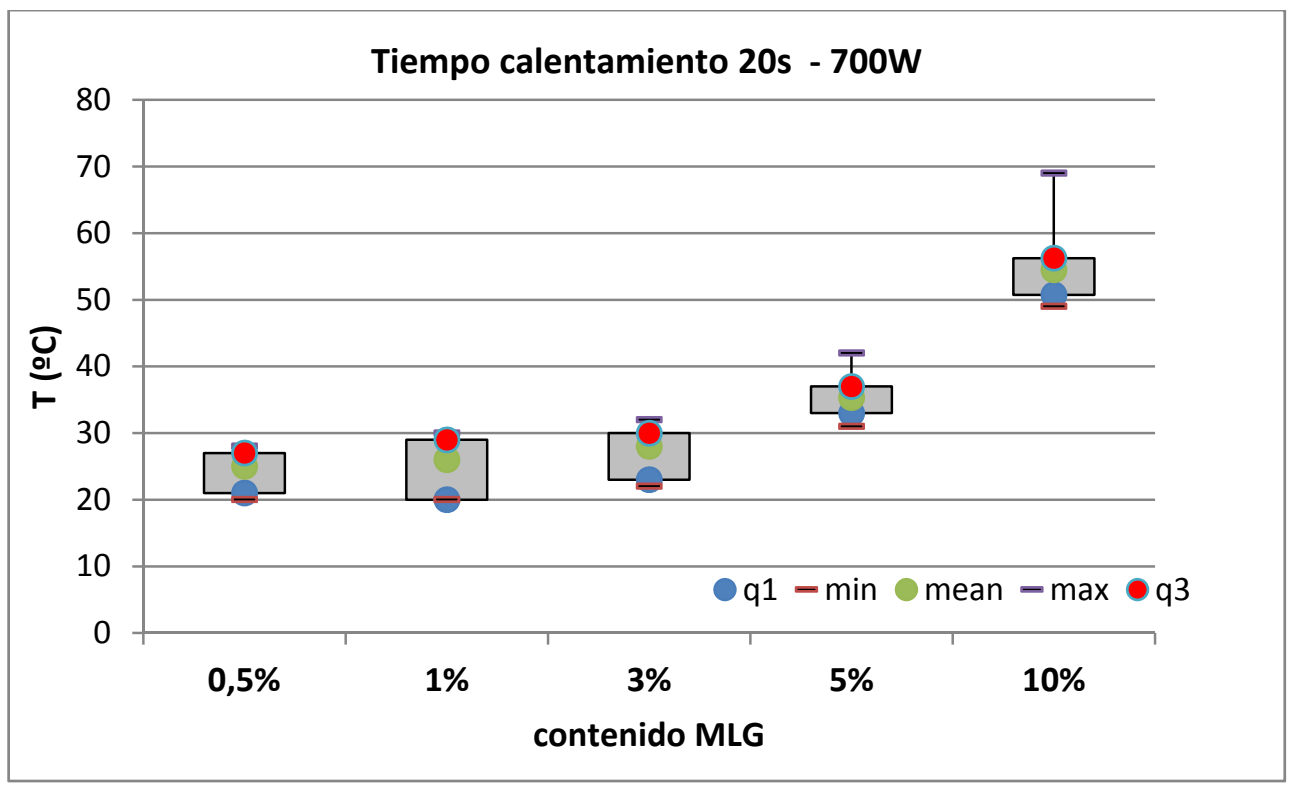

Figura 87. Temperatura versus contenido de GMC para 20 s de calentamiento a 700W

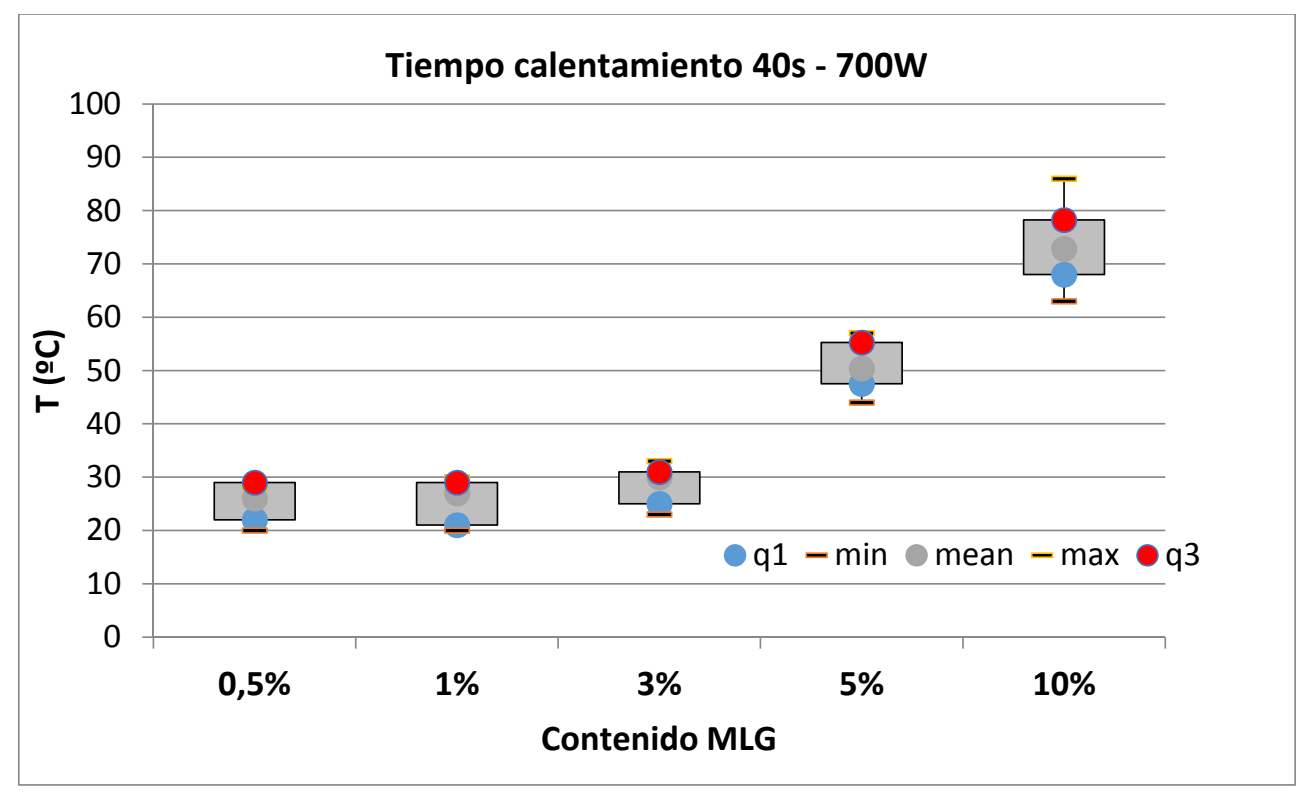

Figura 88. Temperatura versus contenido de GMC para 40 s de calentamiento a $700 \mathrm{~W}$ 


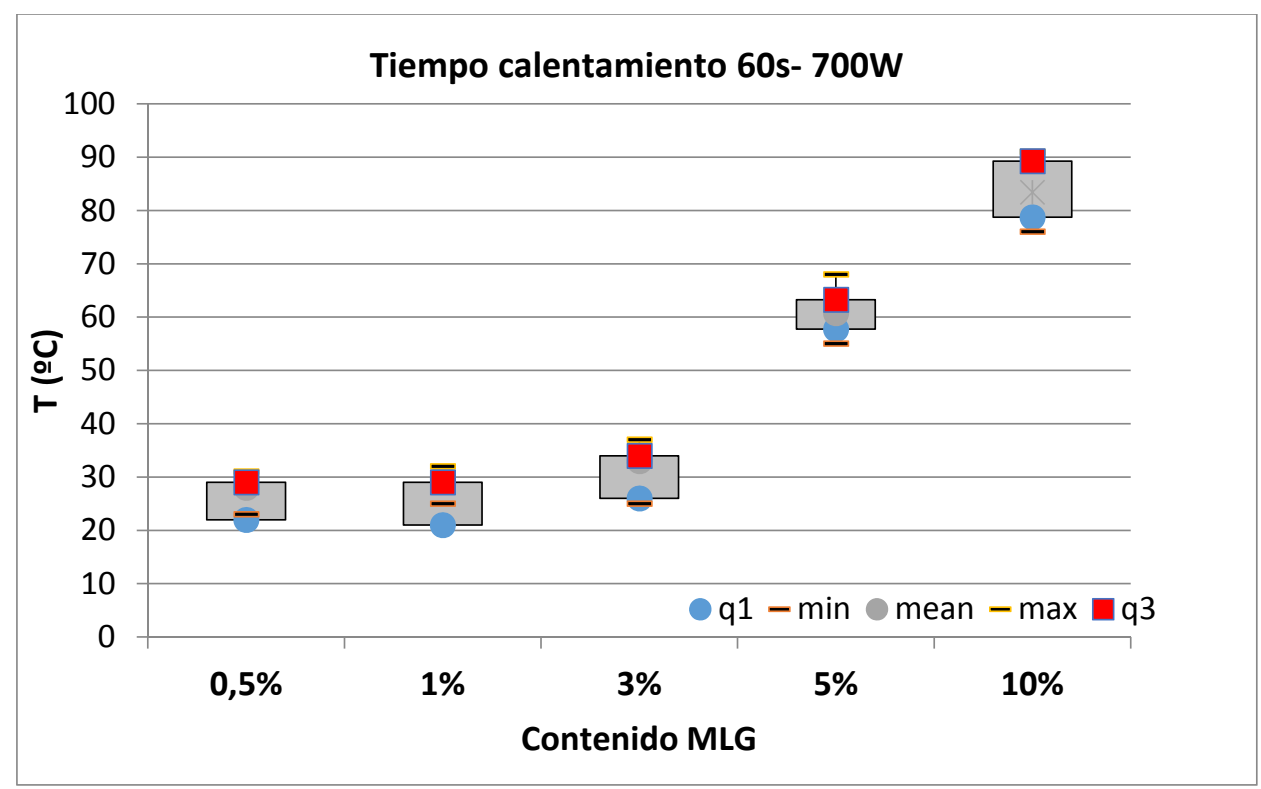

Figura 89. Temperatura versus contenido de GMC para 60 s de calentamiento a 700W 


\subsection{Conclusiones y selección del mejor sistema susceptor}

El grado de dispersión de los NTC en la matriz de PP es un factor de alta importancia para aumentar la eficacia de los NTC como susceptores de microondas, aumentando su eficacia a medida que se reduce el tamaño medio de partícula y la densidad de aglomerados de los nanocomposites.

Una mejora en la dispersión de los NTC aumenta la conductividad eléctrica de los nanocompuestos y a su vez su efectividad como susceptor de microondas.

Nanocompuestos con un 1\% de GMC son completamente transparentes a la radiación microondas incluso tras 5 minutos de calentamiento a máxima potencia.

A partir del 5\% de GMC se empieza a ver una absorción de radiación microondas, aunque los valores de temperatura alcanzados no hacen a estos nanocompuestos susceptibles de ser procesados por microondas, incluso con contenidos de $10 \%$ de GMC.

Altos porcentajes de NTC muestran una gran disparidad entre los valores de temperatura recopilados, mientras que los nanocompuestos con $1 \%$ de NTC muestran un calentamiento muy homogéneo y con pocos puntos calientes que podrían causar problemas en el procesado por degradación del polipropileno matriz.

El $1 \%$ de NTC se seleccionó para la validación del sistema y la producción de un prototipo a escala planta piloto. 


\section{CAPÍTULO 7: DESARROLLO DE PROTOTIPO}

La validación del sistema PP/NTC como susceptor de microondas se llevó a cabo en el marco del proyecto europeo ESPRIT. En este proyecto se abordó el desarrollo de polímeros auto-reforzados con propiedades óptimas. Con los procesos de transformación convencionales es muy difícil obtener un producto formado por una matriz polimérica reforzada con fibras de la misma naturaleza polimérica. Esto se debe a los largos ciclos de calentamiento que conllevan la fusión parcial o total de las fibras, perdiendo así sus propiedades como refuerzo.

Se propuso como solución el empleo de la radiación microondas para el calentamiento selectivo y rápido de la matriz, quedando el refuerzo sin fundir, dando lugar a un compuesto termoplástico de propiedades mecánicas elevadas. La Figura 90 muestra de forma esquemática el proceso por el cual se obtienen polímeros auto-reforzados empleando el calentamiento selectivo por radiación microondas.

Uno de los prototipos desarrollados consistió en una espinillera empleada en el equipamiento de jugadores de futbol.

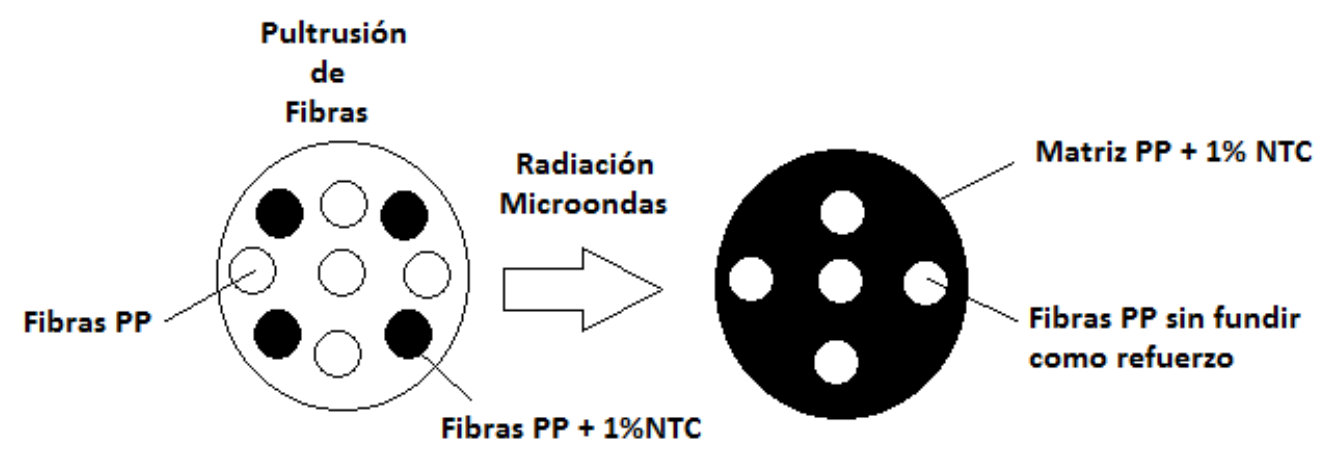

Figura 90. Concepto de material auto-reforzado empleando NTC como susceptor de radiación microondas 
La fabricación del prototipo implicó las siguientes etapas o procesos:

1) Obtención de compuestos en extrusora doble husillo: Se obtuvieron $50 \mathrm{~kg}$ del compuesto desarrollado en el presente trabajo empleando las mejores condiciones de procesado. Material: PP DUCOR 1101S + $1 \%$ NTC Nanocyl NC7000.

2) Extrusión de fibra a partir del compuesto desarrollado

3) Pultrusión de la fibra para la obtención de pellets de fibra larga (ver Figura 92), combinando fibra de polipropileno con NTC y fibra de polipropileno sin susceptor de radiación microondas (ver Figura 91).

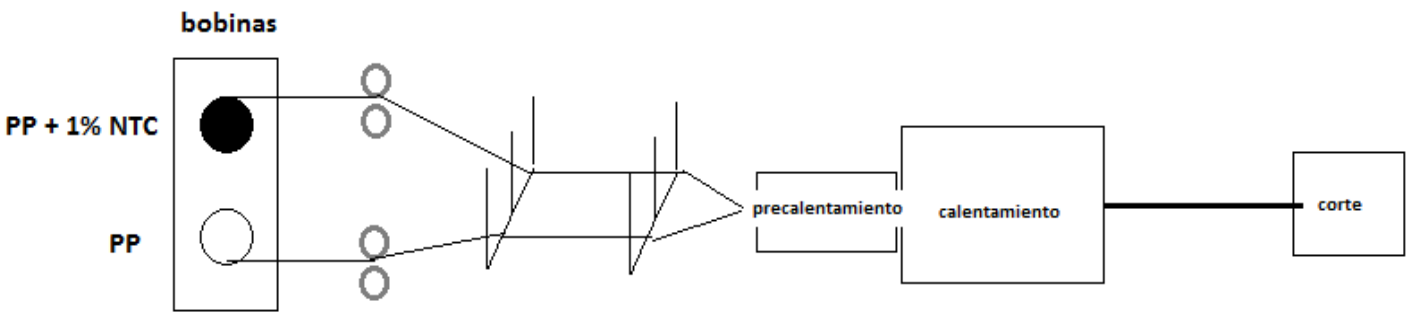

Figura 91. Esquema del proceso de pultrusión

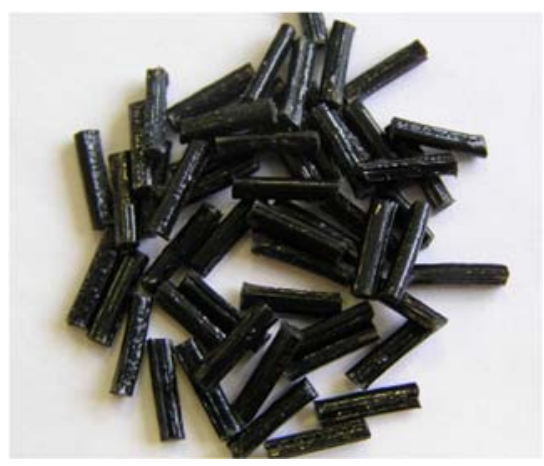

Figura 92. Pellets de fibra larga combinando PP virgen con PP $+1 \%$ NTC

4) Calentamiento de los pellets de fibra larga en horno microondas multimodo con el objetivo de fundir la fibra con NTC rápidamente sin fundir la fibra de PP de refuerzo (ver Figura 93) 


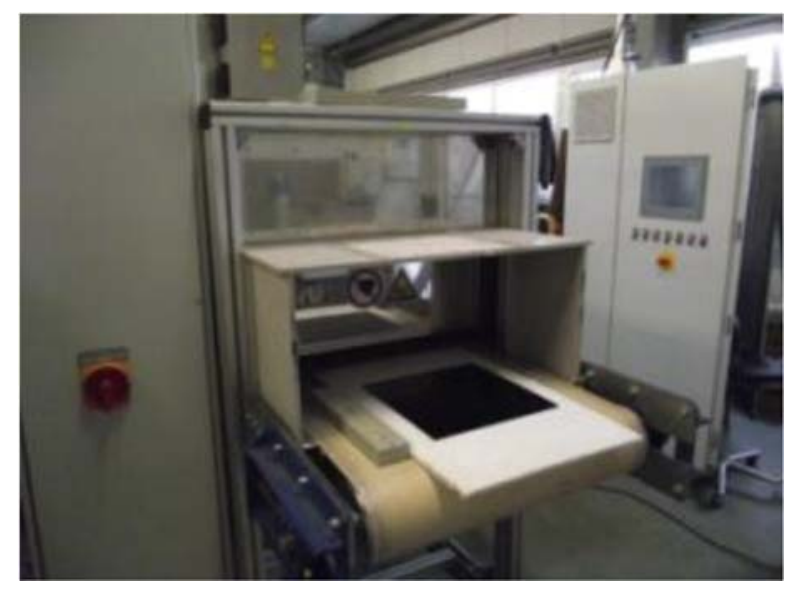

Figura 93. Horno microondas multimodo para el calentamiento de los pellets

5) Moldeo por compresión para la obtención de la pieza prototipo (Figura 94)
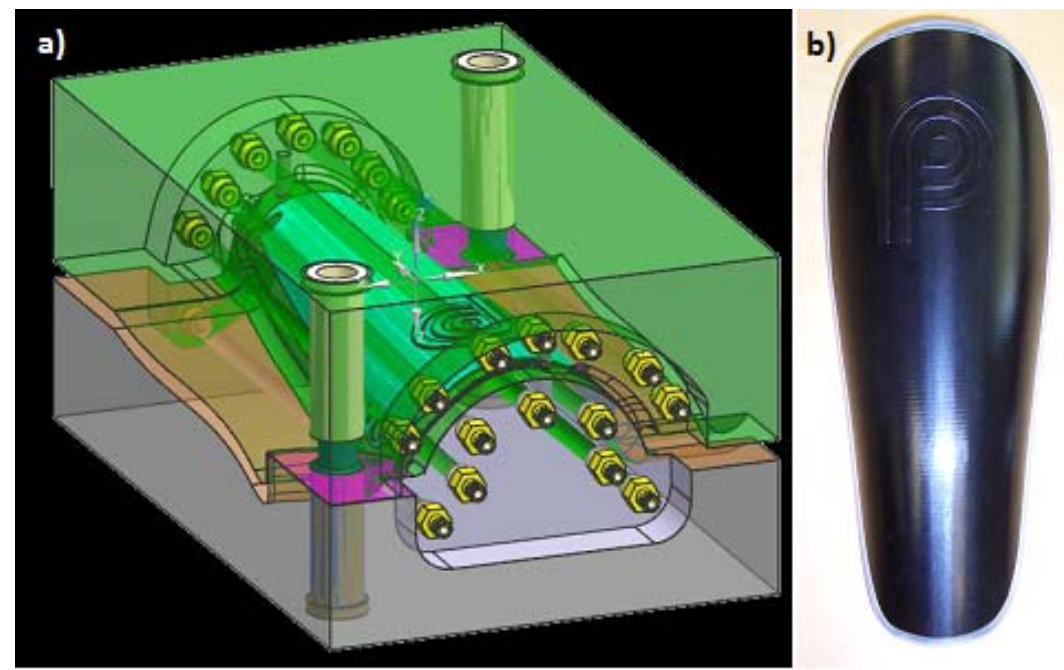

Figura 94. a) molde empleado para la fabricación de la espinillera; b) espinillera prototipo

La espinillera obtenida fue comparada con la comercial. Se obtuvo un aumento de la resistencia al impacto del $20 \%$ y un aumento del módulo elástico del $12 \%$. 


\section{CAPÍTULO 8: CONCLUSIONES}

La presente Tesis Doctoral se ha centrado en el desarrollo de sistemas nanocompuestos capaces de ser calentados por radiación microondas. Para ello, se prepararon nanocompuestos PP/NTC y PP/GMC mediante mezclado en fundido en extrusora co-rotativa de doble husillo de una matriz de polipropileno (PP) con nanotubos de carbono (NTC) y grafeno multicapa (GMC).

En una primera fase, el trabajo de tesis incluye un estudio de la influencia de las condiciones de procesado en la dispersión de las nanopartículas en la matriz de polipropileno (PP) para un porcentaje fijo de carga de $1 \%$. A partir de las condiciones de procesado seleccionadas, en una segunda etapa se prepararon nanocompuestos PP/NTC y PP/GMC con diferentes contenidos de carga y se llevó a cabo una caracterización extensa de las propiedades. En otra fase, se analizó la eficiencia de calentamiento en ambos sistemas mediante la aplicación de radiación por microondas. Finalmente, se evaluó la viabilidad del sistema seleccionado como susceptor de microondas mediante la fabricación y análisis de un prototipo.

De la investigación realizada se pueden derivar las siguientes conclusiones:

A) Influencia de las condiciones de procesado en el grado de dispersión del GMC y los NTC

- El tiempo de residencia de los NTC y del GMC en la extrusora se mostró como un factor determinante a la hora de obtener una buena dispersión, siendo la incorporación de las nanopartículas en la extrusora a través de la dilución de un masterbatch, (nanopartículas son sometidas a dos etapas de procesado) el método más adecuado Asimismo, condiciones de procesado de alta cizalla influyen de manera positiva en la dispersión de los NTC y el GMC (configuraciones de husillo agresivas y alta velocidad de extrusión).

- Se seleccionaron como condiciones de procesado más adecuadas para la fabricación de los sistemas PP/GMC y PP/NTC: la utilización del método de dilución de un masterbatch para la incorporación de las nanopartículas en la extrusora, el empleo de una configuración de 
husillo de alta cizalla y la aplicación de velocidades de extrusión altas (800 rpm).

- Bajo las condiciones de procesado óptimas y mediante observación micrográfica (SEM y MO), los nanocompuestos basados en NTC mostraron menor tamaño de aglomerados y el GMC menor número de capas de grafeno.

- Un índice de dispersión del 99\% se alcanzó con una SME de 0.5 $\mathrm{kWh} / \mathrm{kg}$ para los nanocompuestos PP/NTC, mientras que para los nanocompuestos PP/GMC se obtuvo un índice de dispersión del 93\% empleando una SME de $0.4 \mathrm{kWh} / \mathrm{kg}$. Esta reducción en la energía mecánica específica con las mismas condiciones de procesado y el mismo contenido de nanopartícula denotan el carácter lubricante del GMC.

- Con un contenido en peso del $1 \%$ de NTC se obtuvo un nanocompuesto semiconductor eléctrico. Sin embargo, los nanocompuestos con $1 \%$ en peso de GMC mostraron un comportamiento aislante independientemente de las condiciones de extrusión aplicadas.

- Se verificó que la matriz de polipropileno no sufrió degradación térmica bajo las condiciones de procesado seleccionadas.

B) Influencia de la dispersión en el calentamiento por radiación microondas

- El grado de dispersión de los NTC en la matriz de PP es un factor de alta importancia para aumentar la eficacia de los NTC como susceptores de microondas, aumentando su eficacia a medida que se reduce el tamaño medio de partícula y la densidad de aglomerados de los nanocomposites.

- Una mejora en la dispersión de los NTC aumenta la conductividad eléctrica de los nanocompuestos y a su vez su efectividad como susceptor de microondas.

- Nanocompuestos con un $1 \%$ de GMC son completamente transparentes a la radiación microondas incluso tras 5 minutos de calentamiento a máxima potencia. 


\section{C) Comparación entre las propiedades de nanocompuestos PP/NTC y PP/GMC preparados en las condiciones seleccionadas}

- La incorporación de NTC y de GMC aumenta la rigidez mecánica del polipropileno. Ambas nanopartículas muestran un comportamiento semejante en referencia a las propiedades mecánicas evaluadas. Se obtuvo un aumento del módulo de almacenamiento del $125 \%$ para ambos sistemas con un porcentaje de aditivación en peso del $1 \%$.

- El aumento del contenido de NTC incrementa la viscosidad del nanocompuesto hasta con bajos contenidos de NTC. Sin embargo, en el caso del GMC la viscosidad del nanocompuesto disminuye con respecto al polipropileno y tan solo se aprecia un ligero aumento a partir de un contenido del $5 \%$ en peso de GMC. Estos resultados concuerdan con la bajada de la energía mecánica específica obtenida durante la extrusión de los nanocompuestos, verificando el efecto lubricante del GMC. Por tanto, el GMC muestra un efecto lubricante similar a un grafito.

- El límite de percolación eléctrica para los nanocompuestos de NTC se encuentra alrededor del $1 \%$ de NTC, mientras que para el GMC este límite está alrededor del $10 \%$ de GMC. Todos los nanocompuestos de NTC mostraron un comportamiento semiconductor, obteniendo valores de conductividad volumétrica situados en un rango de [10-1 10-6] S/cm según el contenido de NTC. El GMC sólo mostró sólo mostró un valor de conductividad eléctrica en el rango de polímero semiconductor, obteniendo un valor de $10^{-6} \mathrm{~S} / \mathrm{cm}$ para un contenido del $10 \%$ de GMC.

- La constante dieléctrica y el factor de pérdidas de los nanocompuestos de NTC aumentaron gradualmente con el incremento del contenido en NTC. Las propiedades dieléctricas de los nanocompuestos de GMC fueron muy bajas en comparación con los NTC y apenas variaron aumentando el contenido de GMC.

- Ambos sistemas nanocompuestos aumentan la estabilidad térmica del polipropileno. 
D) Comparación entre la eficiencia de calentamiento de los nanocompuestos basados en NTC y GMC

Tras el estudio y comparación del comportamiento susceptor de radiación microondas de los sistemas nanocompuestos PP/NTC y PP/GMC se obtuvieron las siguientes conclusiones:

- Los NTC muestran un mejor comportamiento como aditivos susceptores de la radiación microondas en comparación con el GMC.

- Los NTC absorben mayor radiación microondas por los siguientes motivos:

o Mejores propiedades eléctricas: el límite de percolación al 1\% en contenido de NTC mientras que el GMC sitúa este límite en un $10 \%$ de nanocarga.

o Mejores propiedades dieléctricas: mayor constante dieléctrica y tangente de pérdidas.

- Nanocompuestos con bajos porcentajes de GMC son completamente transparentes a la radiación microondas incluso tras 5 minutos de calentamiento a máxima potencia. A partir del $5 \%$ de GMC se empieza a ver una absorción de radiación microondas, aunque los valores de temperatura alcanzados no hacen a estos nanocompuestos susceptibles de ser procesados por microondas, incluso con contenidos de $10 \%$ de GMC.

- Todos los compuestos basados en NTC son capaces de absorber radiación microondas y aumentar su temperatura incluso con porcentajes del $0.5 \%$ de NTC. Altos porcentajes de NTC muestran una gran disparidad entre los valores de temperatura recopilados. Esto se debe a la aparición de mayor número de aglomerados que actúan como "hot spots" o puntos calientes. Sin embargo, los nanocompuestos con $1 \%$ de NTC muestran un calentamiento mucho más homogéneo

- El nanocompuesto PP + $1 \%$ de NTC se seleccionó para la validación del sistema y la producción de un prototipo a escala planta piloto por la homogeneidad de calentamiento obtenida. 


\section{E) Evaluación de un prototipo}

- La tecnología de calentamiento por microondas se validó a nivel planta piloto mediante la producción de una espinillera en la que el material matriz se compone de PP aditivado con $1 \%$ de NTC y como material de refuerzo se emplean fibras de PP. El calentamiento selectivo y rápido de la matriz permite conformar la pieza final sin fundir las fibras de PP quedando en la pieza final como refuerzo. La principal ventaja del empleo de materiales auto-reforzados es el reciclado tras la vida útil del producto. 


\section{REFERENCIAS}

${ }^{1}$ www.plasticseurope.org

2 http://www.amtmicrowave.com/loss_mechanisms.htm

3 H.S.Ku, F.Siu, E.Siores, J.A.R.Ball, "Variable frequency microwave (VFM) processing facilities and application in processing thermoplastic matrix composites", Journal of Materials Processing Technology, vol. 139, pp. 291-295, (2003)

${ }^{4}$ http://physics.tutorvista.com/waves/electromagnetic-waves.html

5 A. Singh, S. Verma, "Fundamentals of microwave engineering: principles, waveguides, microwave amplifiers and applications", Ed. Asoke K. Ghosh, ISBN-97881-203-37-16-9, New Delhi, (2009)

6 Thuery, J., "Microwaves: Industrial, Scientific and Medical Applications", Artech House, Inc. pp. 159 - 486, (1992)

7 Siligardi C, Leonelli C, Fang Y, Agrawal D, "Microwave processing of materials", Mater. Res. Soc. Symp. Vol 430, (1996).

8 Smith R.B. (ed), "Industrial Applications of Microwave Energy", IMPI-Europe, London, (1974)

${ }^{9}$ Fang Y., Roy D. M., Cheng J, Roy R, Agrawal D.K., Ceramic Transactions, Editors D.E. Clark et al , Westerville,Ohio, Vol 36, pp. 397, (1993).

10 Mandal S., Seal A., Dalui S., Dey A., Ghatak S, Mukhopadhay A K, "Mechanical characteristics of microwave sintered silicon carbide", Bull. Mater. Sci, Vol24, pp 121124, (2001).

${ }^{11}$ Lee K Y and Case E D, "Microwave Sintering of Alumina Matrix Zirconia Composites using a Single-mode Microwave Cavity", Journal of Materials Science Letters, Vol 18, Issue 3, pp 201-203, (1999)

12 DasS., Mukhopadhyay A, Datta S, Basu D, "Prospects of microwave processing: An overview", Bull. Mater. Sci. Vol 32, pp. 1-13, (2009).

13 A. C. Metaxas,Roger J. Meredith, "Industrial Microwave Heating", IEE Power Engineering Series 4, Editors: A.T. Johns, C. Ratcliff, J.R. Platts.

14 Dr. Rudolf Emmerich, Fraunhofer Institute for Chemical Technology, Polymer Engineering,

http://www.ict.fraunhofer.de/en/comp/pe/mp/heating_plastics_microwaves.html

15 David E., Clark, Diane C., Folz, Jon K.West, "Processing materials with microwave energy", Materials Science and Engineering, pp. 153-158, (2000)

16 Morteza Oghbaei, Omid Mirzaee, "Microwave versus conventional sintering: A review of fundamentals, advantages and applications", Journal of Alloys and Compounds, Vol. 494, pp. 175 - 189, (2000)

17 Clark D.E., Ahmad I., Dalton R.C., "Microwave ignition and combustion synthesis of composites", Materials Science and Engineering, vol. 144, pp. 91 - 97, (1991)

${ }^{18}$ Metaxas A.C., Meredith R.J., "Industrial Microwave Heating", Ed. Peter Peregrinus, ISBN 0-906048-89-3, London, (1983)

${ }^{19}$ National Research Centre (NRC), Microwave Processing of Materials, National Materials Advisory Board, Commision onm Engineering and Technical Systems, National Academy Press, USA, (1994) 
$20 \mathrm{http} / / /$ www.amtmicrowave.com/loss_mechanisms.htm

${ }^{21}$ N.H. Williams. J., Microwave Power 2, 123, (1967)

22 Zulkifli Ahmad (2012). Polymer Dielectric Materials, Dielectric Material, Dr. Marius Alexandru Silaghi (Ed.), ISBN: 978-953-51-0764-4, InTech, DOI: 10.5772/50638. Available from: http://www.intechopen.com/books/dielectric-material/polymerdielectric-materials

$23 \mathrm{Ku}$, Harry S. and Siores, Elias and Ball, James A. R.,"Review - microwave processing of materials: part I". Transactions, Hong Kong Institution of Engineers, 8 (3). pp. 31-37. ISSN 1023-697X, (2001)

${ }^{24}$ Kitagawa K, Kanuma Y, (1986), "The reliability of magnetrons for microwave ovens", Journal of Microwave Power, vol 21, pp. 149-158, (1989)

${ }^{25}$ E.T. Thostenson, T., -W. Chou, "Microwave processing: fundamentals and applications", Composites : Part A, Vol. 30, pp. 1055 - 1071, (1999)

${ }^{26}$ Gerling J.E., "Microwave power: a technical review", Journal of Microwave Power, Vol. 22, pp. $149-158,(1987)$

${ }^{27}$ Lauf RJ, Bible DW, Johnson AC, Everliegh CA, "2-18 GHz broadband microwave heating systems", Microwave Journal, Vol. 36, pp. 24-27, (1999)

${ }^{28}$ Collin RE., "Foundations for microwave engineering", Ed. McGraw-Hill, New York, (1966)

${ }^{29}$ Veley VV., " Modern Microwave Technology", Englewood Cliffs, NJ:Prentice-Hall, (1987)

${ }^{30}$ C.O. Kappe, A. Stadler, " Microwaves in Organic and Medicinal Chemistry", Ed. Wiley-VCH, Weinheim, (2005)

${ }^{31}$ C.Antonio, R.T.Deam., "Comparison of linear and non-linear sweep rate regimes in variable frequency microwave technique for uniform heating in materials processing". Journal of Materials Processing Technology, Vol.169, 234-241, (2005)

32 H.S.Ku,M.MacRobert,E.Siores,J.A.R.Ball., "Application of Variable Frequency Microwave (VFM) to Adhesives. Plastics, Rubber, and Composites", Vol.29, No.6, 278-284, (2006)

${ }^{33}$ H.S.Ku, F.Siu, E.Siores, J.A.R.Ball. Applications of Fixed and Variable Frequency Microwave (VFM) Facilities in Polymeric Materials Processing and Joining. 2nd World Engineering Congress, 22-25, Kuching, Malaysia, (2002)

${ }^{34}$ Institution of Electrical Engineers, "Microwave anntena theory and design", Ed. Peter Peregrinus Ltd., ISBN 0-86341-017-0, United Kingdom, (1988)

${ }^{35}$ G.Horeis, S.Pichler,A.Stadler,W.Gössler, C.O.Kappe, $5^{\text {th }}$ International Electronic Conference on Synthetic Organic Chemistry.(September 2001)

36 FOLGUERAS, Luiza de Castro; NOHARA, Evandro Luis; FAEZ, Roselena and REZENDE, Mirabel Cerqueira. Dielectric microwave absorbing material processed by impregnation of carbon fiber fabric with polyaniline. Mat. Res. [online]. 2007, vol.10, n.1 [cited 2010-12-29], pp. 95-99 Available from: $<$ http://www.scielo.br/scielo.php?script=sci_arttext\&pid=S1516-

14392007000100020\&lng=en\&nrm=iso>. ISSN 1516-1439. doi: 10.1590/S151614392007000100020.

${ }^{37}$ Masaru Chino, Kazuo Kikuchi, and Taro Hasegawa, "Design of Two-Layered Absorber Using Dielectrics", J. Inst. Telev. Eng. Jpn., vol. 31, no. 7, pp. 565-571. ,(1977) 
${ }^{38}$ Alayli, Y. , Djouaher, R., " Influence of the Sorbed Atmospheric Humidity on the Microwave Conductivity of a Composite Material: Potential Applications in EMI Shielding and Absorbers", Measurement Science and Technology, vol. 8, no. 9, pp. 793-797, (1997)

39 Donald R. Askeland, "Ciencia e Ingeniería de los materiales". Ed. Paraninfo Thompon Learning., (2001)

40 Jow J., Hawley M.C., "Dielectric analysis of Epoxy/Amine resins using microwave cavity technique", Polymer Engineering and Science, Vol. 28, pp. 1450-1454, (1988). ${ }^{41}$ Chem M, McGranth E., "Microwave radiation calorimetry of thermoplastics", Proceedings of the American Chemical Sociaty, Division of Polymeric Materials: Science and Engineering, Vol. 60, pp. 443-447, (1989).

42 DeNeuse M.T., "Microwave heating of PEEK", Proceedings of the American Chemical Sociaty, Division of Polymeric Materials: Science and Engineering, Vol. 66, pp. 428-429, (1992).

${ }^{43}$ D. Bogdal, P. Penczek, J. Pielichowski, A. Prociak, "Microwave assisted synthesis, crosslinking, and processing of polymeric materials", Advanced Polymer Science, vol. 163, pp. 193-263, (2003).

${ }^{44}$ Largarov A. N., Matitsin S. M., "Microwave properties of polymer materials containing conducting inclusions", Proceedings of the American Chemical Sociaty, Division of Polymeric Materials: Science and Engineering, Vol. 63, pp. 426-427, (1992).

${ }^{45}$ Agrawal R.J., Drzal L.T., "Effects of microwave Processing on fiber-matrix adhesion in composites", Journal of Adhesion, Vel. 29, pp. 63-79, (1989).

${ }^{46} \mathrm{~J}$. Yang, Y. Wu, "Relation between dielectric property and desulphurization of coal by microwaves", Fuel 66, pp. 1745-1747, (1987).

47 S. Marland, A. Merchant, "Dielectric properties of coal", Fuel 80, pp. 1893-1849, (2001).

${ }^{48} \mathrm{~K}$. Wu, T. Ting, "Synthesis and microwave electromagnetic characteristics of bamboo charcoal/polyaniline composites in $2-40 \mathrm{G} \mathrm{Hz}$ ", Synthetic metals 158, pp.688694, (2008).

49 S.Challa, W. Little, "Measurement of dielectric properties of char at $2.45 \mathrm{GHz}$ ", Energy 29, pp. 131-137, (1994).

50 J.E. Atwater, R.R. Wheeler, "Temperature dependent complex permittivity of graphitized carbon blacks at microwave frequencies between 0.2 and $26 \mathrm{GHz}$, Material Science 39, pp. 151-157, (2004).

51 J. Ma, M. Fang, "Microwave-assisted catalytic combustion of diesel soot", Applied Catalysis 159, pp. 211-228, (1997).

52 J.E. Atwater, R.R. Wheeler, "Microwave permittivity and dielectric relaxation of a high surface area activated carbon", Applied Physics A 159, pp. 125-129, (2004).

${ }^{53} \mathrm{H}$. Lin, H. Zhu, "Microwave absorbing properties of co-filled carbon nanotubes", Materials Research Bulletin 43, pp. 2697-2702, (2008).

${ }^{54}$ L. Zhang, H. Zhu, "Dielectric, magnetic and microwave absorbing properties of multi-walled carbon nanotubes filled with $\mathrm{Sm}_{2} \mathrm{O}_{3}$ nanoparticles", Materials Letters 63, pp. 272-274, (2009).

$55 \mathrm{~J}$. A. Menéndez, A. Arenillas, "Microwave heating processes involving carbón materials", Fuel Processing Technology 91, pp. 1-8, (2010). 
56 J. Harper, D. Price, "Use of fillers to enable the microwave processing of polypropylene", Microwave Power \& Electromagnetic Energy 40, pp. 219-227, (2007). 57 F. Liu, X. Qian, X. Wu, "The response of carbon black filled high-density polyethylene to microwave processing", Journal of Materials Processing Technologies 210, pp. 1991-1996, (2010).

58 Xiangxuan Liu, Zeyang Zhang, Youpeng Wu, "Absorption properties of carbon black/silicon carbide microwave absorbers", Composites: Part B 42, pp. 326-329, (2011).

${ }^{59}$ C. Brosseau, F. Boulic, P. Queffelec, "Dieléctric and microstructure properties of carbon black composites", Journal of Applied Physics 81, pp. 882-891, (1996).

${ }^{60}$ K.H. Wu, T.H. Ting, G.P. Wang, "Effect of carbon content on electrical and microwave absorbing properties of polyaniline/carbon black nanocomposites", Polymer Degradation and Stability 93, pp. 483-488, (2008).

61 A.A. Al-Ghamdi, Farid El-Tantawy, "New electromagnetic wave shielding effectiveness at microwave frequency of polyvinyl chloride reinforced graphite/copper nanoparticles", Composites: Part A, vol 41, pp. 1693-1701, (2010)

${ }^{62}$ Yuzun Fan, Haibin Yang, Minghui Li, Guangtian Zou, "Evaluation of the microwave absorption property of flake graphite", Materials Chemistry and Physics, Vol. 115, pp. 696-698, (2009).

${ }^{63}$ Mohammed H. Al-Saleh, Uttandaraman Sundararaj, "Electromagnetic interference shielding mechanisms of CNT/polymer composites", Carbon 47, pp. 1738-1746, (2009).

${ }^{64}$ Zunfeng Liu, Gang Bai, Yi Huang, "Reflection and absorption contributions to the electromagnetic interference shielding of single-walled carbon nanotube/polyurethane composites", Carbon 45, pp. 821-827, (2007).

65 A.A. Al-Ghamdi, Farid El-Tantawy, "New electromagnetic wave shielding effectiveness at microwave frequency of polyvinyl chloride reinforced graphite/copper nanoparticles", Composites: Part A 41, pp. 1693-1701, (2010).

${ }^{66}$ Marina Koledintseva, Poorna Chander, James Drewniak, "Engineering of ferritegraphite composite media for microwave shields", Electromagnetic compatibility 2006, EMC 2006. 2006 IEEE, International Symposium, vol.3, no., pp.598-602, 14-18 Aug. 2006. doi: 10.1109/ISEMC.2006.1706381, (2006).

${ }^{67}$ F. Nanni, P. Travaglia, M. Valentini, "Effect of carbón nanofibres dispersion on the microwave absorbing properties of CNF/epoxy composites", Composites Science and Technology 69, pp. 485-490, (2009).

${ }^{68} \mathrm{R}$. Benitez, A. Fuentes, K. Lozano, "Effects of microwave assisted heating of carbon nanofiber reinforced high density polyethylene", Journal of Materials Processing Technology 190, pp. 324-331, (2007).

69 Peng Zhihua, Peng Jingcui, Peng Yanfeng, "Complex permittivity and microwave absorption properties of carbon nanotubes/polymer composite: A numerical study", Physics Letters A372, pp. 3714-3718, (2008).

70 Zhuangjun Fan, Guohua Luo, Zengfy Zhang, "Electromagnetic and microwave absorbing properties of multi-walled carbon nanotubes/polymer composites", Material Science and Engineering B 132, pp. 85-89, (2006). 
${ }^{71}$ Xiaodong Chen, Guiqin Wang, Yuping Duan, "Microwave absorption properties of barium titanate/epoxide resin composites" Journal of Applied D: Applied Physics 40, pp. 1827-1830, (2007).

72 V.I. Dubkova, A. P. Dostanko, "Investigation of the effect of a microwave field on the curing process and properties of epoxy compositions", Journal of Engineering Physics and Thermophysics 6, pp. 977-982, (1997).

73 J. Robertson, D.A. Hall, "Nonlinear dielectric properties of particulate barium titanate-polymer composites", Journal of Applied Physics 41, pp. 1-8, (2008).

${ }^{74}$ H.C. Pant, M.K. Patra, Aditya Verma, "Study of the dielectric properties of barium titanate-polymer composites", Acta Materialia 54, pp. 3163-3169, (2006).

${ }^{75}$ Qijia He, Aimin Zhang, "Effect of microwave irradiation on crystalline structure and dielectric property of PVDF/PZT composite", Journal of Material Science 43, pp. 820823, (2008).

${ }^{76}$ Frederic G. Jones, Thomas R. Shourt, Sei-Joo Jang, Applications of Ferroelectrics, IEEE 7th International Symposium on , vol., no., pp.455-458, 6-8 Jun 1990. doi: 10.1109/ISAF.1990.200287, (1990).

${ }^{77}$ R.S. Meena, S. Bhattachrya, "Complex permittivity, permeability and microwave absorbing properties of $\left(\mathrm{Mn}_{2-x} \mathrm{Zn} \mathrm{n}_{\mathrm{x}}\right)$ U-type hexaferrite", Journal of Magnetism and Magnetic Materials 322, pp. 2908-2914, (2010).

${ }^{78}$ Cheng-Hsiung Peng, Hong-Wen Wang, "Microwave absorbing materials using AgNiZn ferrite core-shell nanoporders as fillers", Journal of Magnetism and Magnetic Materials 284, pp. 113-119, (2004).

${ }^{79}$ S.M. Abbas, A.K. Dixit, "Complex permittivity, complex permeability and microwave absorption properties of ferrite-polymer composites", Journal of Magnetism and Magnetic Materials 309, pp. 20-24, (2007).

${ }^{80}$ A. Verma, A.K. Saxena, "Microwave permittivity and permeability of ferrite-polymer thick films", Journal of Magnetism and Magnetic Materials 263, pp. 228-234, (2003). 81. lijima, S.: Helical microtubules of graphitic carbon. Nature 354, 56-58 (1991).

${ }^{82}$ M Scarselli, P Castrucci and M De Crescenzi, "Electronic and optoelectronic nanodevices based on carbon nanotubes", Journal of Physics: Condensed Matter, Volume 24, Number 31, (2012).

${ }^{83}$ Catherine Journet, Matthieu Picher, Vincent Jourdain, "Carbon nanotube synthesis: from large-scale production to atom-by-atom growth", IOP Publishing Ltd Nanotechnology, Volume 23, Number 14, (2012).

84 J. Njuguna (ed.), Structural Nanocomposites, Engineering Materials, DOI: 10.1007/978-3-642-40322-4_2, Springer-Verlag Berlin Heidelberg (2013)

${ }^{85}$ Yan Huang and Eugene $\bar{M}$. Terentjev, "Dispersion of Carbon Nanotubes: Mixing, Sonication, Stabilization, and Composite Properties", Polymers, Vol. 4, pp. 275-295, (2012).

${ }^{86}$ McEuen, P.L., Fuhrer, M.S., Park, H.: Single-walled carbon nanotube electronics. IEEE Trans. Nanotechnol. 1, 78-85 (2002).

${ }^{87}$ Gao, B., Chen, Y.F., Fuhrer, M.S., Glattli, D.C., Bachtold, A.: Four-point resistance of individual single-wall carbon nanotubes. Phys. Rev. Lett. 95, 196802 (2005).

${ }^{88}$ Ebbesen, T.W., Lezec, H.J., Hiura, H., Bennett, J.W., Ghaemi, H.F., Thio, T.: Electrical conductivity of individual carbon nanotubes. Nature 382, 54-56 (1996). 
89 Dresselhaus, M.S., Dresselhaus, G., Charlier, J.C., Hernández, E.: Electronic, thermal and mechanical properties of carbon nanotubes. Philos. Trans. R. Soc. Lond. A. 362, 2065-2098 (2004)

90 Hone, J., Llaguno, M.C., Biercuk, M.J., Johnson, A.T., Batlogg, B., Benes, Z., Fischer, J.E.: Thermal properties of carbon nanotubes and nanotube-based materials. Appl. Phys. A 74, 339-343 (2002).

91 Berber, S., Kwon, Y.K., Tománek, D.: Unusually high thermal conductivity of carbon nanotubes. Phys. Rev. Lett. 84, 4613-4616 (2000).

92 Jou, W.S., Cheng, H.Z., Hsu, C.F.: A carbon nanotube polymer-based composite with high electromagnetic shielding. J. Electron. Mater. 35, 462-470 (2006).

93 Treacy, M.M.J., Ebbesen, T.W., Gibson, J.M.: Exceptionally high Young's modulus observed for individual carbon nanotubes. Nature 381, 678-680 (1996).

94 Yao, N., Lordi, V.: Young's modulus of single-walled carbon nanotubes. J. Appl. Phys. 84, 1939 (1998).

95 Demczyk, B.G., Wang, Y.M., Cumings, J., Hetman, M., Han, W., Zettl, A., Ritchie, R.O.: Direct mechanical measurement of the tensile strength and elastic modulus of multiwalled carbon nanotubes. Mater. Sci. Eng., A 334, 173-178 (2002).

96 Hone, J., Llaguno, M.C., Biercuk, M.J., Johnson, A.T., Batlogg, B., Benes, Z., Fischer, J.E.: Thermal properties of carbon nanotubes and nanotube-based materials. Appl. Phys. A 74, 339-343 (2002).

97 Hoang, A.S.: Electrical conductivity and electromagnetic interference shielding characteristics of multiwalled carbon nanotube filled polyurethane composite films. Adv. Nat. Sci. Nanosci. Nanotechnol. 2, 025007 (2011).

98 Lee, S., Müller, A.M., Al-Kaysi, R., Bardeen, C.J.: Using perylene-doped polymer nanotubes as fluorescence sensors. Nano Lett. 6, 1420-1424 (2006)

99 . Dervishi, E., Li, Z., Saini, V., Sharma, R., Xu, Y., Mazumder, M.K., Biris, A.S., Trigwell, S., Biris, A.R., Saini, D., Lupu, D.: Multifunctional coatings with carbon nanotubes for electrostatic charge mitigation. IEEE Trans. Ind. Appl. 45, 1547-1552 (2009).

100 Fu, X., Zhang, C., Liu, T., Liang, R., Wang, B.: Carbon nanotube buckypaper to improve fire retardancy of high-temperature/high performance polymer composites. Nanotechnology 21, 235701 (2010).

101 Zhao, Y., Wei, J., Vajtai, R., Ajayan, P.M., Barrera, E.V.: lodine doped carbon nanotube cables exceeding specific electrical conductivity of metals. Sci. Rep. 1, 1 (2011).

102 Mack, C., Sathyanarayana, S., Weiss, P., Mikonsaari, I., Hübner, C., Henning, F., Elsner, P.: Twin-screw extrusion of multi walled carbon nanotubes reinforced polycarbonate composites: Investigation of electrical and mechanical properties. IOP Conf. Ser. Mat. Sci. Eng. 40, 012020 (2012).

103 Coleman, J.N., Cadek, M., Blake, R., Nicolosi, V., Ryan, K.P., Belton, C., Fonseca, A., Nagy, J.B., Gun'ko, Y.K., Blau, W.J.: High-performance nanotube-reinforced plastics: Understanding the mechanism of strength increase. Adv. Funct. Mater. 14, 791-798 (2004).

104 Krause, B., Pötschke, P., Häußler, L.: Influence of small scale melt mixing conditions on electrical resistivity of carbon nanotube-polyamide composites. Compos. Sci. Technol. 69, 1505-1515 (2009). 
105 K. Prashantha, J. Soulestin, M. F. Lacrampe, M. Claes, G. Dupin, P. Krawczak, "Multi-walled carbon nanotube filled polypropylene nanocomposites based on masterbatch route: Improvement of dispersion and mechanical properties through PPg-MA addition", eXPRESS Polymer Letters Vol.2, No.10 (2008) 735-745. DOI: 10.3144/expresspolymlett.2008.87.

106 Castillo, F.Y., Socher, R., Krause, B., Headrick, R., Grady, B.P., Prada-Silvy, R., Pötschke, P.: Electrical, mechanical, and glass transition behavior of polycarbonatebased nanocomposites with different multi-walled carbon rnanotubes. Polymer 52, 3835-3845, (2011)

107 Coleman, J.N., Cadek, M., Blake, R., Nicolosi, V., Ryan, K.P., Belton, C., Fonseca, A., Nagy, J.B., Gun'ko, Y.K., Blau, W.J.: High-performance nanotube-reinforced plastics: Understanding the mechanism of strength increase. Adv. Funct. Mater. 14, 791-798 (2004).

108 Yuan, J.M., Fan, Z.F., Chen, X.H., Chen, X.H., Wu, Z.J., He, L.P.: Preparation of polystyrene-multiwalled carbon nanotube composites with individual-dispersed nanotubes and strong interfacial adhesion. Polymer 50, 3285-3291 (2009)

109 Schaefer, D.W., Justice, R.S.: How nano are nanocomposites? Macromolecules 40, 8501-8517 (2007).

110 Villmow, T., Pegel, S., Pötschke, P., Wagenknecht, U.: Influence of injection molding parameters on the electrical resistivity of polycarbonate filled with multiwalled carbon nanotubes. Compos. Sci. Technol. 68, 777-789, (2008).

111 Munson-McGee, S.H.: Estimation of the critical concentration in an anisotropic percolation network. Phys. Rev. B 43, 3331-3336, (1991).

112 Socher, R., Krause, B., Müller, M.T., Boldt, R., Pötschke, P.: The influence of matrix viscosity on MWCNT dispersion and electrical properties in different thermoplastic nanocomposites. Polymer 53, 495-504, (2012).

113 Sathyanarayana, S., Hübner, C., Diemert, J., Pötschke, P., Henning, F.: Influence of peroxide addition on the morphology and properties of polypropylene-multiwalled carbon nanotube composites. Compos. Sci. Technol. 84, 78-85, (2013).

114 Müller, M.T., Krause, B., Kretzschmar, B., Pötschke, P.: Influence of feeding conditions in twin-screw extrusion of PP/MWCNT composites on electrical and mechanical properties. Compos. Sci. Technol. 71, 1535-1542, (2011).

115 Krause, B., Villmow, T., Boldt, R., Mende, M., Petzold, G., Pötschke, P.: Influence of dry grinding in a ball mill on the length of multiwalled carbon nanotubes and their dispersion and percolation behaviour in melt mixed polycarbonate composites. Compos. Sci. Technol. 71, 1145-1153, (2011).

116 Wang, X., Bradford, P.D., Liu, W., Zhao, H., Inoue, Y., Maria, J.P., Li, Q., Yuan, F.G., Zhu, Y.: Mechanical and electrical property improvement in CNT/nylon composites through drawing and stretching. Compos. Sci. Technol. 71, 1677-1683, (2011).

117 Bauhofer, W., Kovacs, J.Z.: A review and analysis of electrical percolation in carbon nanotube polymer composites. Compos. Sci. Technol. 69, 1486-1498, (2009). 118 Krusic, P.J., Wassermann, E., Keizer, P.N., Morton, J.R., Preston, K.F.: Radical reactions of C60. Science 254, 1183-1185, (1991).

119 Ma, P.C., Tang, B.Z., Kim, J.K.: Effect of CNT decoration with silver nanoparticles on electrical conductivity of CNT-polymer composites. Carbon 46, 1497-1505, (2008). 
120 S. Peeterbroeck, F. Laoutid, J.-M. Taulemesse, F. Monteverde, J.-M. LopezCuesta, J. B. Nagy, M. Alexandre, P. Dubois, "Mechanical Properties and FlameRetardant Behavior of Ethylene Vinyl Acetate/High-Density Polyethylene Coated Carbon Nanotube Nanocomposites", Adv Funct Mater 17 2787-2791, (2007).

${ }^{121}$ B.H. Cipiriano, T. Kashiwagi, S.R. Raghavan, Y. Yang, E.A. Grulke, K. Yamamoto, J.R. Shields, J.F. Douglas, "Relation between the viscoelastic and flammability properties of polymer nanocomposites", Polym 49, pp. 4358-4368, (2008).

122 T. Kashiwagi, F. Du, K.I. Winey, K.M. Groth, J.R. Shields, S.P. Bellayer, H. Kim, J.F. Douglas, "Flammability Properties of Polymer Nanocomposites With SingleWalled Carbon Nanotubes: Effects of Nanotube Dispersion and Concentration", Polym 46, pp. 471-481, (2005).

123 B. Schartel, P. Pötschke, U. Knoll, M. Abdel-Goad, "Fire behavior of polyamide 6/multiwall carbon nanotube nanocomposites", Eur Polym J. 41, pp. 1061-1070, (2005).

124 S. Bocchini, A. Frache, G. Camino, M. Claes, "Influence of MWNT on Polypropylene and Polyethylene Photooxidation" Eur Polym J 43, pp.16-22, (2007).

125 T. Kashiwagi, E. Grulke, J. Hilding, K. Groth, R. Harris, K. Butler, J. Shields, S. Kharchenko, J. Douglas, "Thermal and flammability properties of polypropylene/carbon nanotube nanocomposites”, Polym, 45, pp. 4227-4233, (2004). 126 A. K. Geim, K. S. Novoselov, "The rise of grapheme", Nature Materials, vol. 6, pp. 183 - 191, (2007)

127 IUPAC. Compendium of Chemical Terminology, 2nd ed. (the "Gold Book"). Compiled by A. D. McNaught and A. Wilkinson. Blackwell Scientific Publications, Oxford (1997). XML on-line corrected version: http://goldbook.iupac.org (2006-) created by M. Nic, J. Jirat, B. Kosata; updates compiled by A. Jenkins. ISBN 09678550-9 8. doi:10.1351/goldbook.,Last update: 2014-02-24; version: 2.3.3.

128 Alberto Bianco, Hui-Ming Cheng, Toshiaki Enoki, Yury Gogotsi, Robert H. Hurt, Nikhil Koratkar, Takashi Kyotani, Marc Monthioux, Chong Rae Park, Juan M.D. Tascon, Jin Zhang, All in the graphene family - A recommended nomenclature for two-dimensional carbon materials, Carbon, Volume 65, Pages 1-6, (2013)

129 Jinseon Kim, Sanghyuk Kwon, Dae-Hyun Cho, Byunggil Kang, Hyukjoon Kwon, Youngchan Kim, Sung O. Park, Gwan Yeong Jung, Eunhye Shin, Wan-Gu Kim, Hyungdong Lee, Gyeong Hee Ryu, Minseok Choi, Tae Hyeong Kim, Junghoon Oh, Sungjin Park, Sang Kyu Kwak, Suk Wang Yoon, Doyoung Byun, Zonghoon Lee and Changgu Lee, "Direct exfoliation and dispersion of two-dimensional materials in pure water via temperature control", Nature Communications 6, Article number: 8294, (2015).

130 Dmitry V. Kosynkin, Amanda L. Higginbotham, Alexander Sinitskii, Jay R. Lomeda, Ayrat Dimiev, B. Katherine Price and James M. Tour, "Longitudinal unzipping of carbon nanotubes to form graphene nanoribbons", Nature, Vol. 458, pp. 872-876 (2009)

131 Liying Jiao, Li Zhang, Xinran Wang, Georgi Diankov \& Hongjie Dai, "Narrow graphene nanoribbons from carbon nanotubes", Nature, Vol. 458, pp. 877-880 (2009) 132 Sasha Stankovich, Dmitriy A. Dikin, Geoffrey H. B. Dommett, Kevin M. Kohlhaas, Eric J. Zimney, Eric A. Stach, Richard D. Piner, SonBinh T. Nguyen and Rodney S. Ruoff, "Graphene-based composite materials", Nature, Vol. 442, pp. 282-286, (2006) 
${ }^{133}$ I. Chasiotis, Q. Chen, G. M. Odegard, T. S. Gates, "Structure-property relationships in polymer al mechanics, Vol. 45, Issue 6, pp. 507-516, (2005).

134 Sanjib Biswas, Hiroyuki Fukushima, Lawrence T. Drzal, "Mechanical and electrical property enhancement in exfoliated grapheme nanoplatelet/liquid crystalline polymer nanocomposites", Composites: Part A 42, pp. 371-375, (2011)

135 B Galindo et al 2014 IOP Conf. Ser.: Mater. Sci. Eng. 64012008 doi:10.1088/1757$899 \times / 64 / 1 / 012008$

136 Steurer P, Wissert R. Thomann R. Muelhaupt, R. "Functionalized Graphenes and Thermoplastic Nanocomposites Based upon Expanded Graphite Oxide", Macromol. Rapid Commun. , Vol 30, pp. 316-327, (2009).

137 T. Ramanathan, A. A. Abdala, S. Stankovich, D. A. Dikin , M. Herrera-Alonso, R. D. Piner, D. H. Adamson, H. C. Schniepp, X. Chen, R. S. Ruoff, S. T. Nguyen, I. A. Aksay , R. K. Prud'Homme \& L. C. Brinson, "Functionalized graphene sheets for polymer Nanocomposites, Nature Nanotechnology 3, pp. 327-331, (2008).

138 H Kim, Christopher W. Macosko, "Processing-property relationships of polycarbonate/graphene composites" Polymer, Vol 50, pp.3797-3809, (2009).

139 Hyunwoo Kim, Yutaka Miura, and Christopher W. Macosko, "Graphene/Polyurethane Nanocomposites for Improved Gas Barrier and Electrical Conductivity”, Chem. Mater., Vol 22, pp. 3441-3450, (2010).

140 Das B., Prasad KE., Ramamurty U., Rao CNR, "Nano-indentation studies on polymer matrix composites reinforced by few-layer graphene", Nanotechnology, Vol 20, pp. 125705/1-125705/5, (2009).

141 Biercuk, M. J.; Llaguno, M. C.; Radosavljevic, M.; Hyun, J. K.; Johnson, A. T.; Fischer, J. E., "Carbon nanotube composites for thermal management", Appl. Phys. Lett., Vol. 80, pp. 2767-2769, (2002)

142 Leong, C.-K.; Chung, D. D. L., "Carbon black dispersions as thermal pastes that surpass solder in providing high thermal contact conductance" Carbon, Vol 41, pp. 2459-2469, (2003).

143 Liang, J.; Xu, Y.; Huang, Y.; Zhang, L.; Wang, Y.; Ma, Y.; Li, F.; Guo, T.; Chen, Y. J., "Phys. Chem. C, 113, 9921-9927, (2009)

144 G. L. Pollack, "Kapitza resistance," Rev. Mod. Phys., vol. 41, no. 1, pp. 48-81, (1969).

145 Kalaitzidou, K., H. Fukushima, and L.T. Drzal, "Multifunctional Polypropylene Composites Produced by Incorporation of Exfoliated Graphite Nanoplatelets", Carbon 45, pp. 1446-1452 (2007).

146 Fukushima, H, Drzal,L.T., Rook, B.P. \& Rich, M. J.. Thermal Conductivity of exfoliated graphite nanocomposites, J. Therm, Anal. Cal. 85, 235-238. (2006).

$147 \mathrm{Kim}, \mathrm{S}$. Do, Inhwan and Drzal, L. T., "Multifunctional Exfoliated Graphite Nanoplatelets-LLDPE Nanocomposites Fabricated By Solution Compounding Method And Various Screw Rotating Systems", Macromol. Mater. Eng, 294(3) 196-205 (2009).

${ }_{148}$ P. Steurer, R Wissert, R. Thomann, Rolf Mülhaupt, "Functionalized Graphenes and Thermoplastic Nanocomposites Based upon Expanded Graphite Oxide", Macromolecular Rapid Communications, Vol. 30, Issue 4-5, pp. 316-327, February 18, (2009) 
149 Kalaitzidou K, Fukushima H, "A new compounding method for expholiated graphite -polypropylene nanocomposites", Compos Part A, 38, pp. 1675-82, (2007)

150 K Wakabayashi, P.J. Brunner, J.Masuda, S. A. Hewlett, J.M. Torkelson, "Propylene-graphite nanocomposites made by solid-state shear pulverization: Effects of significantly exfoliated, unmodified graphite content on physical, mechanical and electrical properties" Polymer, Vol. 51, 5525-5531, (2010).

${ }^{151}$ M. Zdrojek, W. Gebicki, C. Jastrzebski, T. Melin, A. Huczko, "Studies of multiwall carbon nanotubes using Raman spectroscopy and atomic force microscopy", Solid State Phenomena, volume 99, pp.265, (2004).

152 Kapitza, H. G. Microscopy from the very begining. (2a ed.). Carl Zeiss Jena $\mathrm{GmbH}$ Frankfurt: Dipl.Bibl. Susanne Lichtenberg. (1997).

153 Davison, M., Abramowitz, M. Optical Microscopy. Olympus Microscopy Resource Center. Recuperado en Noviembre 28, 2007, de la World Wide Web:

http://www.olympusmicro.com

154 Gaurav R. Kasaliwal, Andreas Göldel, Petra Pötschke*, Gert Heinrich, "Influences of polymer matrix melt viscosity and molecular weight on MWCNT agglomerate dispersion", Polymer, Volume 52, Issue 4,1027-1036, (2011)

155 Tony Mc Nally, Petra Pötschke, Peter Halley, Michael Murphy, Darren Martin, "Polyethylene multiwalled carbon nanotube composites", Polymer, Vol 46, pp. 82228232, (2005).

${ }^{156}$ E. Ivanov. R. Kotsilkova, E. Krusteva, E. Logakis, A. Kyritsis, P. Pissis, C. Silvestre, D. Duraccio, M. Pezzuto, "Effects of processing conditions on rheological, thermal and electrical properties of multiwall carbon nanotube/ epoxy resin composites", Polymer Physics, Vol. 49, Issue 6, pp. 431-422, (2011).

157 Hao-Bin Zhang, Wen-Ge Zheng, Qing Yan, Zhi-Guo Jiang, Zhong-Zhen Yu, "The effect of surface chemistry of graphene on rheologicaland electrical properties of polymethylmethacrylate

Composites", Carbon, Vol., pp. 5117-5125, (2012).

158 M. El Achaby, A. Qaiss, "Processing and properties of polyethylene reinforced by graphene nanosheets and carbon nanotubes", Materials and Design, Vol 44, pp. 8189, (2013).

159 Petra Pötschke, TD Fornes, DR Paul, "Rheological behavior of multiwalled carbon nanotubes/polycarbonate composites”, Polymer, Vol. 43, pp. 3247-3255, (2002).

160 Shenoy AV, "Rheology of filled polymer systems", Dorchecht: Kluner Academic Publishers, (1999).

161 Han CD, Lem KW, Polym Engng Rev, Vol 2, pp. 135-165, (1983)

162 Utraki LA, "Rheology and processing of multiphase systems", In: Ottenbrite RM, Utracki LA, Inove S.editors. Current topics in polymers science, rheology and polymer processing/multiphase systems, Vol II, Munich: Hanser, (1997).

163 Sastre y Ferreira, 2003, Técnicas de análisis y caracterización de materiales. Capítulo 7: Análisis térmico. CSIC

164 R. Mesquita, D. Axmann, J. Geis-Gerstorfer, "Dynamic visco-elastic properties of dental composite resins; Dental Materials”, Vol 22, pp 258-267, (2006).

165 M.S. Dresselhausa, G. Dresselhausb, R. Saitoc, A. Joriod, "Raman spectroscopy of carbon nanotubes", Physics Report, Volume 409, Issue 2, Pages 47-99, (2005). 
166 Ying Wang, Zhen hua Ni, Ting Yu, Ze Xiang Shen, Hao min Wang, Yi hong Wu, Wei Chen and Andrew Thye Shen Wee, "Raman Studies of Monolayer Graphene: The Substrate Effect”, J. Phys. Chem. C, 112 (29), pp 10637-10640, (2008).

167 Manash Jyoti Deka, Upama Baruah, Devasish Chowdhury, "Insight into electrical conductivity of graphene and functionalized graphene: Role of lateral dimension of graphene sheet", Materials Chemistry and Physics, Vol.163, pp. 236-244, (2015).

${ }^{168}$ Beate Krause, Petra Pötschke, Liane Häußler, "Influence of small scale melt mixing conditions on electrical resistivity of carbon nanotube-polyamide composites", Composites Science and Technology, Vol. 69, pp. 1505-1515, (2009).

169 T. G. Gopakumar and D. J. Y. S. Page, "Polypropylene/Graphite Nanocomposites by Thermo-Kinetic Mixing", POLYMER ENGINEERING AND SCIENCE, Vol. 44, No. 6, (2004).

170 A. A. Katbab,A. N. Hrymak, K. Kasmadjian, "Preparation of Interfacially Compatibilized PP-EPDM Thermoplastic Vulcanizate/Graphite Nanocomposites: Effects of Graphite Microstructure upon Morphology, Electrical Conductivity, and Melt Rheology", Journal of Applied Polymer Science, Vol. 107, pp. 3425-3433 (2008)

171 Peng Hea, Yan Xiao, Puming Zhang, Chunhua Xing , Na Zhu, Xinyuan Zhua, Deyue Yana, "Thermal degradation of syndiotactic polypropylene and the influence of stereoregularity on the thermal degradation behaviour by in situ FTIR spectroscopy", Polymer Degradation and Stability 88, pp. 473-479, (2005).

172 A. Göldel, P. Pötschke, " Carbon nanotubes in multiphase polymer blends", In Polymer-Carbon nanotubes composites: Synthesys, Properties and Applications; Editors: T. McNally, P. Pöttchke, ISBN 1-84569-761-8, Woodhead Publishing, 2011, Champer 19.

173 Han CD, Lem KW, Polym Engng Rev, Vol 2, pp. 135-165, (1983)

174 Utraki LA, "Rheology and processing of multiphase systems", In: Ottenbrite RM, Utracki LA, Inove S.editors. Current topics in polymers science, rheology and polymer processing/multiphase systems, Vol II, Munich: Hanser, (1997).

175 Emilie Planes, Jannick Duchet, Abdherrahim Maazouz, Jean-Franc, ois Gerard, "Characterization of New Formulations for the Rotational Molding Based on EthylenePropylene Copolymer/Graphite Nanocomposites", POLYMER ENGINEERING AND SCIENCE, (2008), DOI 10.1002/pen-

176 J. Tang, M. Radosz, Y. Shen," Poly(ionic liquid)s as Optically Transparent Microwave-Absorbing Materials“, Macromolecules, Vol. 41, pp 493-496, (2008).

177 M. Pluta, Z. Bartczak, A. Galeski, "Changes in the morphology and orientation of bulk spheruliticpolypropylene due to plane-strain compression”, Polymer, Vol 41, pp. 2271-2288, (2000).

178 M.A. López Manchado , L. Valentini, J. Biagiotti, J.M. Kenny, "Thermal and mechanical properties of single-walled carbon nanotubes-polypropylene composites prepared by melt processing", Carbon, Vol.43, pp. 1499-1505, (2005).

179 Sumin Kim, Inhwan Do, Lawrence T. Drzal, "Thermal Stability and Dynamic Mechanical

Behavior of Exfoliated Graphite Nanoplatelets-LLDPE Nanocomposites", POLYMER COMPOSITES, (2010), DOI 10.1002/pc.20781 
180 T. Kashiwagi, E. Grulke, J. Hilding, R. Harris, W. Awad, J. Douglas, "Thermal and flammability properties of polypropylene/carbon nanotube nanocomposites", Polymer, Vol. 45, pp. 4227-4239, (2004).

181 D. Bikiaris, A. Vassiliou, K. Chrissafis, K.M. Paraskevopoulos, A. Jannakoudakis, A. Docoslis, "Effect of acid treated multi-walled carbon nanotubes on the mechanical, permeability, thermal properties and thermo-oxidative stability of isotactic polypropylene", Polymer Degradation and Stability, Vol. 93, pp. 952-967, (2008).

182 Marosföi B. B., Szabó A., Marosi Gy., Tabuani D., Camino G., Pagliari S., "Thermal and spectroscopic characterization of polypropylene-carbon nanotube composites", Journal of Thermal Analysis and Calorimetry, Vol 86, Issue 3, pp 669-673, (2006).

183 Pingan Song, Zhenhu Cao, Yuanzheng Cai, Liping Zhao, Zhengping Fang, Shenyuan Fu, "Fabrication of exfoliated graphene-based polypropylene nanocomposites with enhanced mechanical and thermal properties", Polymer, Vol 52, pp. 4001-4010, (2011).

${ }^{184}$ Harper J, Price D, Zhang J., "Use of fillers to enable the microwave processing of polyethylene", J Microw Power Electromagn Energy, 40(4):219-27, (2007). 